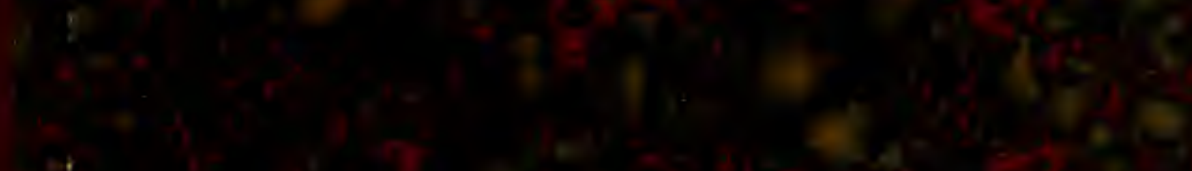

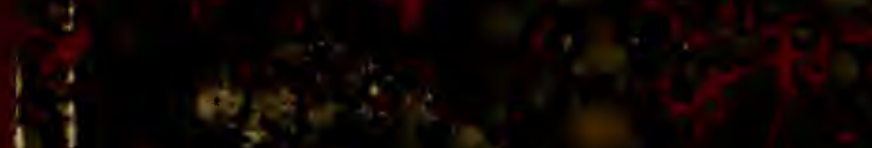

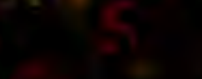

$$
x_{x}
$$

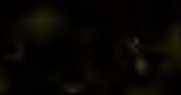

$+n$
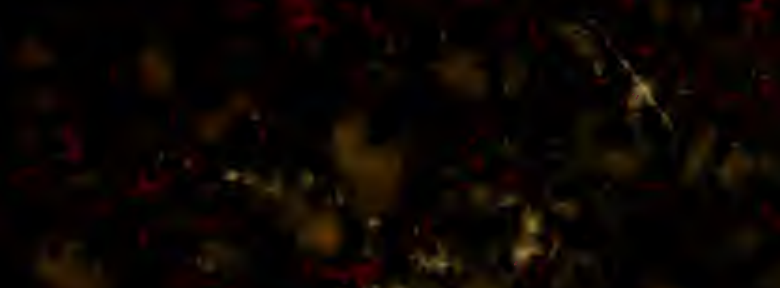

$$
y^{4}=1,20
$$




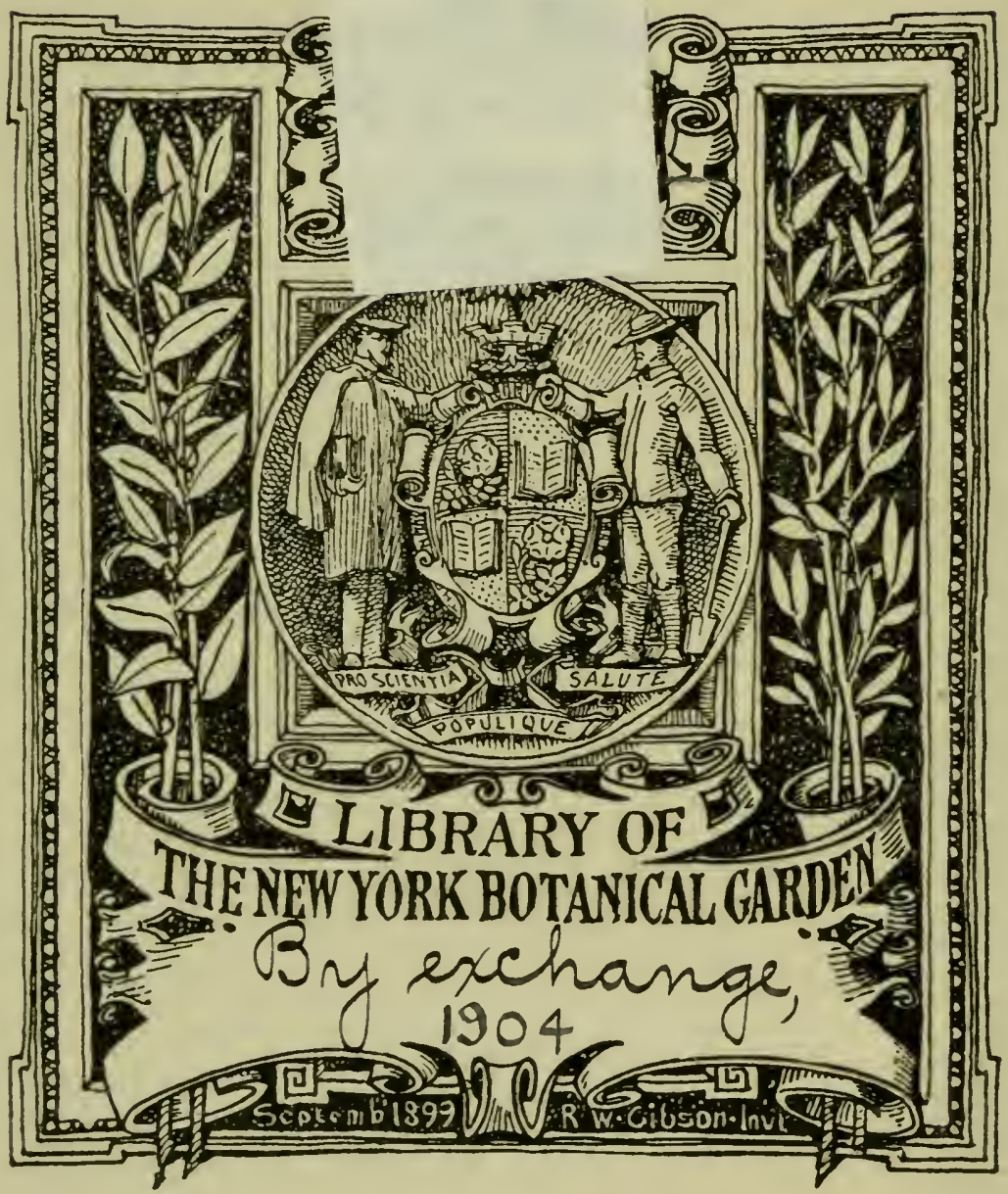




. 



\title{
PHILOSOPHICAL NOTES
}

ON

\section{BOTANICAL SUBJECTS.}

BX

\author{
E. B O N A I A, M.D., \\ BRIGADE SURGEON, I.M.D.
}

WITH 160 ILLLUSTRATIONS.

" The admitted superiority of French binders is partly owing to the practice of publishing" in paper cover's, after which, if the book is worth binding, it is worth treating the matter thoughtfully." "Plieasure," by Sir Herbert Maxwell, Bart., M.P., Blackwood's Mragazine, January 1892.

LONDON :

EYRE A ND S POT'T I W O ODE, gOVERNMENT AND GENERAL PUBlisiers, EAS'T HARDING STREET, E.C.

[All Rights reserved.]

Price $2 s .6 d$. 



\title{
PHILOSOPHICAL NOTES
}

\section{$0 x$ \\ BOTANICAL SUBJECTS.}

\author{
BY \\ E. BONA.VI, M.D., \\ BRIGADE SURGEON, I.M.D. \\ LIBRARY \\ NEW YORK \\ BCTANICAL \\ GAKDEN
}

WITH 160 ILLUSTRATIONS.

\section{'Is it Evolution or Revolution? It is both, for to accept Evolution is to} effect a Revolution in thought."

L O N D O N :

EYRE AND SPOTTIS WOODE, GOFERNMENT AND GENERAL PCBLISHERS, EAST HARDING STREET, E.C.

[All Rights reserved.] 1892. 


\section{QK4 .8569}

E R R T A.

live "Phwnogans," where it occurs, read "Phenogams."

For" Monccions" and "Diacions," where they occur, read "Monacions." and "Dixcions."

Page 108 (foot note), for "sporanguin" read "spuranginu."

Page 171, for "ancustromosing" read "ancistomosing."

Page 186, for " it floats" read "its."

Page 192 (note $\dagger$ ), for "tract" read "bract."

Page 218 , for "Zectrs" read "bear."

Page 221, for " or Aspidium " read "of."

Page 22i, for "In anthers" read "The."

Page 246 , for "became axillary" read "become."

Page 299, for "Ruta, Graveolens" read " $R$. yraveolens.'

l'age 305 , for "muciferous spores" read "pores."

Page 331, for " the Disk," read "Disk.*"

Page 332 (3rd para.), for "stipule" reau "stipel."

Page 334 (A), for "neutral surface" read "ventral."

Page 335, for "scientific meeting" read "meeting of scientific Committee."

l'age 341 , for " towards its rascular" read "towards it."

Page 345 , for "these figures" read "fingers." 


\section{O N T E N T S.}

Prefide.

I.-SCievce Aid Pinlosopiry

Definitions of Science and Philosophy by different authors -Discussion regarding their meaning-Endearour to come to some popular definition of them.

II.-Why do we stedy Plaxt Life? -

To learn the ways of the Deity-To bentfit ourselves and others-Because nature forces us to do so.

III.-VARIATION

Examples of variation on the same plant-Is variation solely dependent on the conjugation of sperm and germ cells? -Do the surroundings play any part in the creatiou of rariatious?-Other factors of variation.

IV.-Natural Selection

Views of Prof. Weismann-Further explanations to help the geveral reader to grasp this theory-Main factors in the direction of growth-Elasticity of organs-Does human intelligence follow the same lars of natural selection?Why man has been able to outrun every other animal in the race of life.

V.-Sume Factors of Modification ix Plixts -

Sexual conjugation-Surroundings, a necessary factor of modification-Climate and soil-Fusion-Fission-Transposition of segments-Abortion-Enlargement-Suppression of parts-Persistent organs with altered function.

VI.-COLOUR

The result of chemical combinations, brought about by electrical influence.

VII.Evolutios

A method of creation-Probable order of evolution in plantsAre all organs of plants new creations, or simply derivatives? -Is there any essential difference between vegctative and reproductive cells; between male and female cells?-Plants follow roughly crystalline forms-Seaweeds, the progenitor's of all land plants-Transition from sea plants to land plants - The embryo of text-books-Horticulturists, in adapting and selecting plants, act as nature does-Some examples of transitiou in seaweeds-In certain searreeds no need of differeutiation into root, stem, and leaf. 
VIII.-Stej, Braxch, Leaf, axd Cladopirl -

Derivation of the stem from the midrib of seaweeds-Genesis of the leaf from the cladophyl-Genesis of the cladophyl from the seaweed frond-The vascular system only a further development of the intercellular system-- Dichotomy of fern-veins identical with dichotomy of seaweedsDez̧emeration of lobes of leaves into teeth-Angles ,between serrations homologous with axillæ-Margins of fronds and leares, by coutraction, become a midrib-The teeth of landplant leaves descended from teeth of seaweeds-Teins and

- sub-reins also found in seaweeds-The leaf a repetition of the stem-Reversion of stem to leaf-Reversion of leaflets to stipels or teeth-Appendicular notes giving examples of atrophy of leaflets.

IX.-STEM AND RHzone - - - - - - -

Asa Gray's definition-Identity of the two-Possible genesis of the rhizome-Advantage of decay of internodes of the rhizome in the struggle for life-The rhizome a feature of the lowest forms of plants-Aërial roots hereditary descendants of rhizome roots.

X.-Roots AND IExDRILS - - - - -

Goebel's definition of root-No essential difference between root and stem-Phyllotaxis in roots not needed-On stem it is important-Roots give buds and stems-Stems give roots and buds-Radicle of seed identical with radicle of budThe disk of searreeds a rudimentary root.

Roots and tentriis, in many cases, homologous organs-Roots homologous with underground leaves - Advantages of rootbudding - The root a rhizome-Nodules of roots of Leguminiferæ said to be caused by microbes, not impossibly they may be the atrophied homologues of the floatiug bladders on the root-leaves of water plants-Floats of root-leaves of Utricularia-Nodules on roots of grasses-Appendicular notes, comparing roots and tendrils, and roots and leaves in different plants.

XI.-Stipules, Bun-Scales, And Cotrlenoxs - - - 
to a sorus-Method of comparison also needed to reach the truth-Anthers of coniferæ only indusiate sori-Frond of Porphyra laciniata a rudimentary stamen-Indusia considered as the confluence of hairs-Pinnule of Pteris aquilina by contraction and modification becomes a two-celled anther - Pinuale of Bleclonum Boreale by contraction becomes a one-celled anther - Anthers give rise to tetrads, just as fronds give rise to tetraspores-Glands on petiole of cherryleaf considered as the fusion of teeth-glands of suppresserl leaflets-Teeth-glands correspond to arrested terminal buds -Anther cells and ovular placentas interchangeable-Teethglands, pollen grains, and orules are homologons-Different forms of two-celled anthers may originate from one-celled anthers--Is the quaternary sub-division of mother-cells of any significance, except as a muans of identification?

XiJi.-Carpels, Placentas, Ovules, Buds, Embryos, and SPORES

Axillary bud-object and genesis-as a free branchlet of the petiole-as connatc with the base of the leaf-as connate with the stem-Seaweeds, type forms of existing phænogamsAsa Gray's definition of bud-Multiple axillary buds, like polyembry in seeds.

Orule-Warming's view of the ovule-The nucleus corresponds to the kernel of the seed-The gland on the teeth of - leaves provably homologous with an orule-Views of different authors, quoted by Warming-The lobes of Gigartina lanceolata, Fucus maryinifer (Esper), and Lenormandia marginata, when separated, behave like ovules-Marginal bud of leaf, and stem or midrib bud, one and the same thing Parthenogenetic ovules in no way differ from ordinary budsHenslow's view of the ovule-Fibro-vascular cords not necessary for the evolution of buds-Views of Ray Lankester on bud and ovule-Galton's view of Heredity-Comparison of terminal bud with embryo-Ovule of Hippuris vulgaris Anatropus ovule homologous with circinate frond-Ovule, the terminal bud of the vein that feeds it-Integuments of the seed compared to two raginas of the grass stem-Forms of placentas-Central placenta considered as homologous with the sorus of 'Trichomanes-The midrib of carpels quite capable of evolving ovules-Dehiscence can occur along margin, midrib, nerve, or vein-Fruit of Lardizabala, a phænogam, compared with that of Myriodesma, a cryptogam-Discussion on polyembry-Placenta of phænogams compared with sorus of ferns-The embryos of Citrus seed homologous with spores in a sporangium. 
yiv.-Triciroyes, Prickles, Glindular Hairs, Sporaxgia, \&C.

Spathels of Jouquil are trichomes-Trichomes and tentacles of Drosera are one thing-The epidermis not essentially distinct from the structures below it-Antheridia and spores of seaweeds are trichomes-Oogonium corresponds to a metamorphosed hair-Vascular bundles not necessary to reproductive organs-Glandular hairs comparable to reproductive hairs, and also to pollen and ovules-No distinction between prickles, glandular hairs, and ereu spines-Lenticels possibly atrophied prickles - Teeth of leaves only glandular hairs with a foliaceous stem, like those of the moss-rose-Globular hairs of leaves lomologrous with pollen and ovules-The ramelli of Dasga sarcocaulon and others are only branched hairs-Glandular hair's found also in intercellular sparesGlandnlar hairs of Drosera convertible into ovules, leaves, and branches-Hairs of Begonia Phyllomaniaca convertible into branches-Reproductire organs of Cymopolia barbata and Fucus are only hairs--Teeth of Agare and similar plants are only modified branches--Teeth of Desmaretia convertible into branches.

XV.-OIL Glandos axd Firs

Description and histology of an oil gland - vil gland probably a degenerated conceptacle of the seaweed-Analogous degradations found in many plants-Conceptacles of Myriodesma, Fucus, \&c. probably the grand-ancestors of oil glands-Conceptacles of different species of Fucus-Oil glands considered as remnants of concepticles turned to another purpose--The orange tree related to a Fucus-Like the splint-bones of the horse, the oil glands are remnants of former important organs-Oil glands of Citrus peel analogous to pores of Millipora. The fig (rceptacle of Ficus) is only a further development of the conceptacle of FucusBoth are monæcious and diæcious.

\section{XVI.-Si'Urs}

Are spurs the result of insect agency or of natural selection ?Spurs on petals and leaves can be spontaneously produced, without either of the foregoing agencies-Do spurs always contain nectar, or do they sometimes contain only water? -Teratological variations in Aquileyia and Aconitum.

IVII.-Genesio of Fibro-vasculate Srstear - - -

Rudimentary spiral threads in Algre-Spiral microbes of hacteriologists-I'ossibility of these gaining access to cellular plants, and laying the foundation of the vascular tissue-Two ways of viewing the origrin of the vascular tissne--lew operations connected with life appeai to be free from the infiuence of microbes. 
XVIII-The Disk, tire Citrus, the Ruta, axb the P.loxia

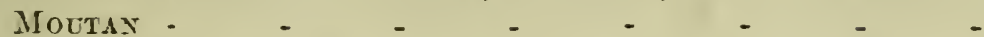

Definition and morphological position of the disk--The morphological position of the orangre-peel.

View (A).-That it is the outer lamina of the pulp-e:mpeli-Dbjections to this view.

View (r).--'That it is a distinet whorl of abortive carpels, or other plyilous members, independent of the pulp-Facts supporting this view--Fibro-vascular bundles of Van Tieghem not inimical to this view-Too much stress laid on the supposerl significauce of fibro-vascular bundlesImmense seaweeds can develop witlout any trace of fibrovascular tissue.

View (c).--That the peel is a continuation of the stem-bark, this view explained by diagrams.

It finally brings ns round to riew (B)-The bark does not receive special fibro-rascular bundles-The disk and peel according to Payer--Atrophy of parts learls to atrophy of ressels which nourish them-Absence of vessels eannot be accepted as indication that the peel is not of a phyllous nature -Homology of the orange-peel with the disk of other Rutacex-- Drawing of abnormal Citrus in "Gard. Chron." proves that Dr. Bonavia's view of the orange-peel is the right interpretation---'The sheath enveloping the earpels of Paonia Moutan is homologons with the orange-peel-Obserrations on the doubling of the Pæony, with depauperation of the carpel sheath-P'Pony sheath, the lomologue of the staminal tube of the Malvacea-- Further evidence to prove that the Citris disk is a whorl of suppressed stamensIdentity of the stamen filament uf the Citrus with its peel-Final disproof that the peel consists of the outer lamina of the carpels--Identity of peel oil-glands with the juice vesicles of the pulp, according to O. Penzig--Identity of these with the dermal oil-glands of Dictammu firatinella, and with the reproductive hairs of Cymopolia buriota. 
"Nothing is so childish or confusing as for either one of the disputants to attack the other for what he says, as distinguished from what he obrionsly means. The question is not which of two writers writes the best article; but which is stating or trying to state the strongest position; it is therefore well to abstain, as far as possible, from anything that may suggest a personal strife of wits, and to deal with whaterer arguments an opponent may bappen to urge, not as if they were arguments which had been used by him, hut merely as if they were arguments which it is possible for men to use.""Reason Alone," by W. H. Mallock, Fortnightly Revierc, Nov. 1890, p. 753 . 


\section{P REFACE.}

MY intention at first was to have given these Notes the humble title of "Botanical Notes," but that title might misrepresent their nature. They are in reality notes on botanical phenomena, viewed from the broad and philosophical standpoint of the modern theory of evolution, and hence the present title seemed more appropriate.

It may, perhaps, be objected that I have given too many quotations, but in attempting to handle such subjects as these, I had to show what others may have thought on the same points, lest it might be said, as has already been saicl on another occasion, that the irleas given forth are "wholly my own," in which state. ment there may be lurking an insinuation that they are therefore wholly worthless.

Now why do people publish a lot of things, which those who may be good enough to read them often think rubbish? One often hears it asked-what is the nse of adding another volume to what is already known to be so much lumber?

The fact is that, in this stage of human existence, certain thoughts are often a great worry. One often cannot get rid of them. They turn up by day, they turn up at night, they turn up in the moruing, they haunt one at all times, and the only remedy for mitigating this worry of cirilisation is to commit them to paper.*

* This is graphically illustrated by Sir Edwin Amolı. He says, "Sometimes the lines are importunate, and will be at once registered. lieading, smoking, driving, dressing for dinner, it rloe = not matter how yon may he engaged, the rerses will haunt you, fascinate you, dance hefore your imagrination, demanding to be fixed; and you must catch them then and there or they will go. Sometimes the right ideas will come as suddenly as if hy electric message."-Rev. of Rev., 15 Aug. 1892, p. 168. 
This done, there atre several ways of dipposing of your written thoughts:-

(a.) You can burn the papers they are written on, or otherwise destroy them;

(b.) You can leave them in a drawer, as a legacy to your heirs!

If by neither of these processes can you entirely give yourself repose, then the most effective way of ridding yourself of the wory of such thonghts is to have them published (if any pulbisher will perform this kind oftice), and to see them adrersely criticised, if anyone will take even so much tronble.

Then it will begin to dawn upon you that your thoughts may not have been worth the pen, ink, and paper consumed in recording them, and ly degrees they will fade into oblivion, and leare you in peace.

It does not follow, of course, that the critic is infallible. On the contrary, it has happened over and over again that the light of his lantern was climmer than that of the author's.

The whole mental process I have been reviewing is like that of a lover towards his lovee. In the morning, in the night, throughont the day, he is hamnted with the figme of her, withont whom, to him, there can be no peace. 'This persecution goes on until he marries her, when perhaps one fine day he finds he is criticised sorerely, and a sort of disillusion begins to replace his enthusiasm.

I would ask the realer to consider that these pages contain "Notes," and not a treatise. They are badly arranged, as notes often are, and badly digested, but they may be of use to some one who takes sufficient interest in the study of plant crolution.

The object of these pages is to endearour to simplify the conception of the living thing we call a plant; to exhibit in simple" language, as far as that is possible, the mity which underlies not only the infinite valuiations of plants of all sorts, but also the numerons valiations of the parts, which make up a plint; in short, to endeavour to lay the foumdation of a "philosophy of plants," after removing, if posiblble, from all plant lore the tronbles and obscurities engendered, not by the plants themselves, but by the multiturle of words, which have been inventerl to explain whit

"I had called them "botanical notes," hecause they concern plauts, and not hecanse I have any pretension to botanieal knowledge. 
we see, to smooth difficulties, and make things clear. Unfortunately these rery implements of thought now encumber to a large extent this most interesting and fascinating of sturlies, and tend to make it not only obscure, but to many, repulsive.

Human life has become so complicated, and the number of things to be learnt so multitudinous, that he or she, who may, in any way, help to simplify any part of any branch of knowledge, will, I think, be doing a service to his or her fellows. It is with the riew, first, of making things more comprehensible to myself, and second, of trying to make the whole conception of the plant, in howerer small a measure, with its infinite forms, characters, aud qualities, simple to the mind of the student, that I have ventured to pen these notes.

It does not seem to me of much importance whether we call the student of plants a botanist, a horticulturist, or a goldsmitl. 'The question is whether what he observes and infers in connexion with plants is true or somnd, and what he and others would think rational.

Prof. Max Muller* says, "In writing on religion, eren on natural religion, we must turn neither to the right nor to the left, but look at facts straight in the face to see whether they are facts or not, and if they are facts, to find out what they mean." 'The same may be said of the sciences.

Mixed up with science there has been, no doubt, too much of what might be called "theology." By this I mean an intolerance of any view, which might not square with the dogmas, or conventional notions of science, in spite of the facts that looked at us straight in the face. 'The science of hotany has not been fiee from such dogmas. Tuhappily togmas are often the mischief entailed by coining new termis.

Dogmas stick to them, and it is often difficult to clear one's mind of a dogma, when lepresented by what seems a rery appropriate term!

These pages are rather a record of notions, or suggestions, or speculations, than an attempt to put before the rearler a reasoned out philosophy of plants. 'Tley are an endearour to explain how an erolutionist looks at the facts of Botany, who cither was never troubled with dogmas, or if he were, rery early divested limself of 
them. Cogitations of how these plant forms came to be so, why they are there, and where they came from have bcen ever present in the author's mind. He tried to see in their different parts the embryo forms out of which they came to be as they are.

Many readers of these lines, no doubt will shut them up, and say, "what a lot of rubbish." Among this rubbish, however, a few not wholly useless notions may perhaps be found. The mind of man always has had to wade through a lot of mental rubbish, to get at a few possible plums. Many ideas, which at one time are looked upon as gospel, become at another time, antiquated rubbish, not unlike the fossils of past animal forms.

The aggregate human mind is ever throwing off bulbils, so to speak, that is, new ideas, which in some cases live and grow, while the old stems decay and die, or the new ideas may remain dormant, like seeds and buds, till the time and conditions come for their germination. It is with ideas as with everything else-a struggle for existence.

We hear it said that such-and-such an assertion is worthless because it is based on second-hand information. What is secondhand information with one is first-hand with another, and in that case this is also worthless, and so all books become worthless, unless we personally verify all they contain! Even then, what guarantee would there be that our supposed rerification is of any wol'th?

I have never been in Central Africa, but upon the authority of Stanley's first-hand observations I would not mind theorising on certain statements he has made. Of course I might talk nonsense on that basis, because it may turn out insufficient. If so, it cannot be helped. 'This has occurred before, and it will occur hereafter. We had been theorising for eighteen centuries on the supposed statements of the evangelists, which were supposed to have been made upon first-hand information. Nevertheless, criticism has already discounted a great deal of what they were credited with having written. Who knows how much more may yet be discounted?

For a century great anthorities har been pooh-poohing what others were giving forth as mesmeric facts. On supposed sound physiological data these anthorities consirlererl these phenomena as impossibilities. To and behold! now we are swallowing them so quickly that there is danger we may swallow more hypnotism than is good for us. Legislation is even proposed against these 
impossibilities. One is always comforted by remembering the fanous "eppur si muore" of Galileo. So much for authority !

We should remember that all scientific investigations are not science. Scientific men are explorers-the scouts of sciencefeeling and seeing in arlvance of the human army. What they see and theorise about has to be established by proving itself to be conformable with surrounding truths, and then it becomes sciencepakki batt, as they say in Hindostan, that is, a true word. It is incorporated with human knowledge, and eventually becomes the spring of thought and action. Even then a great deal of trimming is often needled, and has to be periodically done by the remorseless shears of philosophy. 'The philosopher's task is to look at things from a higher standpoint, so as to take in a larger number of facts in one view, and consoliclate ideas into a harmonious and organised body of truths.

As there are collectors of things, so there are collectors of ideas, to be woren into a fabric of philosophy in due course. The facts give rise to the ideas, and the ideas to the philosophy, which is an organised body of colligated conclusions or theories.

Philosophy, as I have stated elsewhere, is a weaving together of established facts by means of a theory. What is the use of theories, some one might ask? Here I would prefer to let Professor Weismann reply, who, in his book "On Heredity," has sprung some new icleas among thinkers.

At p. 297, he says:- "Facts must be connected together by theories, if science is to adrance."

"Science is impossible without hypotheses and theories."

"Just as theories are valueless withont a firm basis of facts, so the mere collection of facts, without relation and without cohesion is utterly valueless."

At p. 336, he further says :- "Nothing impresses the stamp of truth upon an hypothesis more than the fact that its light renders intelligible not only those facts for the explanation of which it has been framed, but also other and more distantly related groups of phenomena."

The process of getting at the bottom of the truths, reflected by isolaterl facts, is sufticiently indicated by the following statement of Weismann's :-

At p. 296, he says:- We cannot proceed synthetically and deductively builling up the phenomena from below; but we must, 
as a rule, proceed analytically and inductively, proceeding from above downwards." . . "It is not only permissible, but in the highest degree advantageous, for the different spheres of phenomena to be attacked simultaneously."

What has, for instance, made the science of Palcoontology? It is the theorics that have knit together and have given life to those dry bones, shells, and imprints that made it. The theory makes one see the derelopment of the living phenomena, of which those specimens are the isolated relics.

Hypotheses, theories, and philosophies are not made to order, but they grow in men's minds, out of cogitation on facts. Philosophy is the soul of our knowledge, while the facts are the raw materials, hypotheses and theories being the glue and fashioning implement:

Fortunate will that future stuclent be who, when he comes to the thinking age, and begins to ponder on the problems of life, in addition to books upon books of words, will find some one which mar contain the living soul of all botanical knowledgea Philosophy of Plants. Although with an intense passion for plants, in my students' dar's, botiny, for want of a philosophy of plants, appeared to me a chaos of words, which came into my mind without any cohesion, many of which went out again without learing behind anything that I could utilise.

Perhaps, with the help of Darwin and his fellow erolutionists, we may ret see this interesting branch of human knowledge emerge wholly out of the bondlage of metaphysics and words. We may yet see that in the myriads of foliage forms, flower colours, and fruit deliciousness, there is a unity, simple enough, when put before the student in simple language.

A philosoplyy of plants means a broad surrey of the whole regetable kingdom, and therefore much of the source of information must of necessity be second-hand, for it is out of the question that one's own observations and researches alone ean he sufficicint to form a basis of such a broad surrer.

I am aware that there are many weak points in these notes, but for the present they must go as they are.

Of these speculations and suggrestions some, perhaps, are sufficiently worked out; others may be still in the nebular stage of development. 
'To the rearler who may think what $I$ saly is al)surd, and not worth the paper it is printed on, I would suggest to read the parts he thinks most absurl, at different times of the day, for it is a well-known fact that in the morning we mentally see things which we do not see at midklay; later on, after tea, we see differently from either before or after dinner, aud so on. When the brain is in a different moor, it may see some truth in what at other times seems so absurd.

It is also interesting to note low differently two different minds will look at a thing or criticise a hook or any question. 'This comes from the personal equation, which in other works means a combination of heredity and training, plus the bias of acquired knowledge, feeling, and social influence.

If these notes will induce some one to take up botanical science from an evolutionary point of view, and treat the whole systematically, they will have served some goor purpose.

The thoughts contained in these pages may be considered provisional, as they may undergo much modification, and some may be abandoned. As there may be errors of observation, so there may be errors of reflection, so to speak, that is, supposing the fact observed accurate, the inference drawn from that fact may be wrong.

As these pages may possibly come moler the eye of some gencral reader, I thought the "preliminary notes" might perhaps be useful in helping him or her to understand what these notes are all about. It might appear that the "preliminary notes" have nothing to do with the hotanical notes, but nowadays the notion of evolution has infiltrated itself into every other notion, more especially into those connecterl with life.

Many men and most women laugh at you, when you attempt to speak of erolution, natural selection, \&e. All they know, or care to know, about this great revolution in human thought is that Darwin said we came from monkers, and that they do not believe!

There is a vast deal of poetry in hotany, which is lost in it bewildering maze of words.

In my opinion, mless botany be studied in an erolutionary sense, there can he but little interest in learning an infinite number of names, as labels to eertain forms of plants. Even their geographical distribution must be somehow fitted into their 
evolution. The only thing that can be studied without reference to evolution, and that only partly so, is their economic use, including their ornamental qualities, but this had been studied all along by savages, without the ghost of a notion of the science of botany.*

Modern economic botany is only a further development of the economic botany of savages, by the aid of chemistry, and the manufacturing arts, and æsthetic development.

In the course of these notes, when I say, "This is nothing but," or "This is so and so," it is only a mode of diction, and stands for "in my humble opinion," it is so and so ; or viewing it with the small light I possess, "I think it is so and so," or "think its interpretation should be so and so."

In the "Cultivated Oranges and Lemons of India and Ceylon," I simply sketched ont, in a vagne way, what I thought may be the origin of the teeth of leaves, the oil glands of the citrus, as well as its peel.

Since its publication, I have hunted for evidence in support of my theories, and I was not long in fincling, as I think, a great deal. In these notes, I have endeavoured to work ont those same points, as far as they are at present workable, besides other's connected with different parts of other plants.

In referring back, all the land plants we see around us, to plants lower down the scale, such as sea-weeds, we must not lose sight of the fact, that besides cross fertilization, fusion and atrophy, partial or complete, have been two of the great factors of modification in plants.

On one occasion I told a friend, a noted horticulturist, that all his roses and lilies were made ont of seaweeds. He said, "What is your authority for all this?" At first I felt rather small, because I could not quote any authority for what he thought an absurdity. But recovering myself, after a few moments, I said "L'autorité, c'est moi" in this particular instance; I am backed, however, by the conceivers of evolution.

On another occasion I was talking of fruits and such things, and repeated the statement that they were all made out of seaveeds.

* 'This only refer's to the economic uses of wild plants, because the evolution of cultivated plants could only have been hrought about by the advantuge that man derived from their ceonomic qualities. 
My listener jumped off his chair, in a fit of incredulity, took up his hat and said "Good morning"!

No doubt such statcments are rather startling, and to some minds sound much like "lunacy," but any one who is suffieiently" imbned with the spirit of evolution, camnot doubt that a lovely rose, or an exquisite peach have been claborated from seaweeds. It is absurl enough if you fancy the transition was effected yesterday, or in one man's lifetime, but if you allow a hundred million year's or perhaps vastly nore, for the seawced to become a rose, there is nothing to be startled about, viewing the transition with the lights we now possess.

Then one would again be tempted to ask what is the use of all this, if it do not change people's ways of looking at nature?

Well, on one occasion I was listening to an account of some interesting biological experiments made by the narrator, who is a noted scientist. He sail they were all published in the proceedings of the . . . . . . Society. Then I askedhow is it that scientists are not convinced by all these accounts, which to me appear so conclusive? "They do not read them," he said!

I would conclude this prefatory note with the following quotation from Lord Colerirlge's writings.

"Forget the rubbish, and if here and there you have had a good thought put before you, remember it, act upon it, and at once."**

* “ Thinking for ourselves."-New Review, July 1890. 
"The only use of authority in Science is to furnish men of less ability with suggestions, which, as suggestions, may properly be considered more worthy of testing by the objective methords, on account of their parentage in the mind of genin!s. But it is an eril day for Science, when such parentage is taken as in itself a sufficient warrant for the truth of the ideas which have been born of it ; for then it is that authority is allowed to Isimp the place of verification . . . ."- Anistotle as a Naturalist," ly Professor Romanes, Contemporary Review, Feb. 1891. 


\section{PRELIMINARY NOTES'.}

\section{I.-SCIENCE AND PHILOSOPHY.}

WHAT is the difference between science and philosoply?

Dr. St. George Mivart is reported to have said, at one of the lectures of the Royal Institute, that " a mere set of isolated experiments did not constitute science. It was when reason came into play, it was when we nsed that faculty, which involved the use of the word 'therefore' that there was science. . . Where an experiment had been repeated by many people, in different comntries and at different dates, and always gave the same results, there could be no reasonalle donbt that a fact had been established, and a gain added to our store of knowledge."

This means that time is needed for a fact to be establisherl. 'Time is needed for the repetition of an experiment, or an olservation, and for its cogitation. But this is not all. When a startling fact is put before the minds of scientific men, it often creates a shock by the disturbance of the disposition of thein alrearly formed and fixed ideas. Time is needed for this shock to wear off, and for the disturbance of ideas to settle down into the new conception. Furtlier observation and experiment, backed by sonnd reasoning, will help the brain to accept the new position. New ideas, like ererything else, have to strugghe for existenee, and beat off opposition by sound argument based on indisputable facts.

A recent writer-J. Copner-appears to consider science as the basis of philosophy, the latter being the superstructure. Science, he thinks, deals with phenomena-that is, what we see or feelwhile philosophy searches for their causes-that is, for somethingr beyoud what we see.

This definition of philosophy does not seem sufficient, for. philosophers, besites ferreting ont causes, have always, somehow, endearoured to mirestigate the relations of phenomena, not nnly 
their causes, and to make a colligated growing whole of all that is in us and outside of us, of which we can take cognizance.

A philosophy of any set of phenomena or of the whole connected universe without a theory is no philosophy at all. In fact, philosophizing without theorizing is inconceivable. Therefore, the philosophy of any set of phenomena would appear syuonymous with "a theory which explains the causes and the relations of that set of phenomena."

Dr. Whewell * says: "All received theories in science up to the present time have been established by taking up some supposition and comparing it, directly or by means of its remoter consequences, with the facts it was intended to embrace. Its agreement, under certain cautions and conditions, of which we may hereafter speak; is held to he the evidence of its truth. It answers its genuine purpose, the colligation of facts."

Prof. Bain almost endorses this in different words. He says : "Our reason essentially consists in using an old fact in new circumstances, through the power of discerning its agreement or disagreement with them."

Mr. C. F. Holder, in his "Life of Darwin," gives the following definition:- "Science is the discernment, discrimination, and classification of facts, and the discovery of their relations of sequence" (p. 210); while "Philosophy is the explanation of the phenomena of the universe" (p. 214).

Both science and philosophy are, therefore, often tentative, the one endeavouring to establish facts, the other, by speculation, endearouring to establish the facts into a colligated whole, intelligible as a whole, without which the facts might remain scattered and isolated.

Professor Knight has said that the more one is a specialist the less can he be a philosopher. This is, perhaps, true in a certain sense. There is, howerer, no doubt that some minds are both scientific and philosophic. Indeed, one cannot see how these two branches of investigation can well be separated. Some minds can dissect facts and find out other facts behind them, at the same time that they can take up a number of strands, and weave them into one continuous string.

* "Novum organon renovatum," ch. iv. sec. 11. 
Philosophy requires the aid of a vivid imagination, which the scientific investigator need not necessarily possess. Science, I take it, ought to furnish the facts, and philosophy ought to frame theories based on those facts. It would, perhaps, be an advantage if the scientific man were also his own philosopher, but this is not always possible, owing, perhaps, to the want of a sufficiently vivid imagination, or to the attention being wholly occupied with innumerable details.

The imagination has played a greater part in the advancement of our knowledge than many seem disposed to admit. Theorizing must of necessity be the work of the imagination. It is the result of the play, on the cells of our nerve-centres, of what is revealed to our senses, aided by the ideas already stored there.

From all this it would result that science provides the impressions on our senses, while philosophy imagines their causes and relations, and, therefore, their meaning. Of course, there can be both false science and false philosophy, and that was so to a large extent in past ages, but sound criticism should prevent a recurrence of false notions to any harmful extent.

The imagination of man invented many myths in past ages. We are far from being rid of their influence. The study of this mythical philosophy reveals that it always had some fact of nature for its basis; only the mind of man was then full of far more. poetry than science. We are reversing matters now, but we cannot do without the aid of the imagination.

Now, one might ask, -is there any difference between scienceand ordinary knowledge? None whatever, in my opinion, if ordinary knowledge is sound. An established fact of ordinary life is as much a scientific fact as one seen through the microscope or the telescope, or by the aid of any other of the numerous instruments and methods of human investigation. A fact is a fact, and accurate knowledge, of whatever nature, is science; nor does a fact become more a fact because it is established. This only gives it currency and makes it more generally useful. Nor, indeed, does a fact of science become more a fact than one of ordinary knowledge because it is given a Greek or Latin name. If an ordinary name will suit as well the classical name will only be an encumbrance. For instance, in microscopical botany we have sieve-plates, sieve-tubes, vascular bundles, \&c. I often $\triangle$ p. 1724. 
wonder why these bave not been "Greekified," to keep compan with their classical friends.

The first sarage who witnessed the fact that a seed, fallen from a tree, germinated and produced a tree like the one from which it fell, was making science as much as a Dallinger, who follows a monad with his miscroscope, and establishes the fact that, when it meets a wife it conjugates with it, and the progeny derelops into the parent form.

The sarage may have mixed up "fetishes" with his facts, but although his theories may hare been childish his facts may have been perfectly sound.

When, howerer, he learnt how to produce fire, his theory or philosophy had a new start, for whenever he wanted a fire he would use the same wood and the same action to derelop it. After haring learnt that such a seed will reproduce such a plant, he would carry the seed with him to new localities when he migrated. Thus, science and philosophy have gone hand in hand, aiding each other's derelopment from the beginning of human time.

At one time philosophy outgrew science, and the imagination was let loose to flounder independently of facts. With Aristotle, howerer, commenced a new era-the association of science and philosophy; but philosophy haring been discredited, science went ahead, recording facts heedless of philosophy. The two, however, cannot be dissociated without detriment to human progress. Science uses the senses to discover facts, while philosophy uses the imagination to discorer what they mean. Often they are almost one and the same process, for in some minds the discorery of the fact suggests its meaning.

Someone might say that the difference between science and philosophy is like that between the stem and the leaf, that is, a "difference without a distinction." In other words a difference of words.

It is a rery curious thing that I turned to the "Encyclopœdia Brittanica," (9th edition), to see what is said about "Science," and found it not in the work that is supposed to contain all human knowledge! so, I have had to define it without the aid of our "Great Treasury of Knowledge." 
Science, I take it, furnishes the facts, methodically arranged, while philosophy colligates them, and connects them with the rest of the universe into a theory.

In "Worcester's Dictionary," I find that "science is knowledge; that which one knows; the knowledge of many methodically digested, and arranged, so as to become attainable by one ; a knowledge of laws, principles, and relations."

While philosophy is stated to be the "science of causes and principles; the inrestigation of the principles, on which all knowledge, and all being rest."

As I said, this is rather a "distinction without a difference."

A great deal, however, which passes for science among the ignorant is not science at all, but "tackle," which causes endless mental friction. Instead of facilitating the grasp of the philosophy of a thing, it scatters the mind into numerous efforts of memory, and thus hampers the intellect, which is ever striving to connect facts, and comprehend their meaning.

The interminable words of Greek and Latin origin hamper the intelligence, much as a macadamized road hampers a wheeled carriage, before the road is rolled. One hears it stated that Greek and Latin are classical languages, and all science, to look learned, should be habited in classical terms, much, I suppose, as we use the top hat to stamp us with respectability, yet we find that the Hebrew, Arabic, Assyrian, Sanskrit, and Egyptian languages, were classical before the classical Greeks and Latins were born, and it would be just as logical if we invented hieroglyphic, cuneiform, or Sanskrit names to express what we observe and discover in science to-day. To a Sanskrit scholar, Sanskrit terms for things would be as easy as Greek terms would be to a Greek scholar, but to persons of ordinary intelligence, desirous of learning the truth, the foreign terms would be to the mind what the unrolled macadamized road is to a rehicle. To the young, they are deterrent, and to the old they are a worry. The middle aged may perhaps be amused or interested by difficult mental gymnastics, much as they are by climbing the Alpine mountains. But the end of climbing after all is to get to the top of the mountain, and survey everything from a new stand point. Therefore the easier the journey can be made, it would appear, the sooner one can make a philosophical survey of the facts that lie all around below. 
We have inherited from past generations of thinkers a number of useless words, and the erroneous ideas that stick to them, which now only hamper us, without in any way helping us, because other more important and useful words hare replaced them. Unfortunately, like the fifth stamen of a Bignonia, or like the stipels of leares, these useless remnants cannot be got rid of as quickly as one might wish.

It is now supposed to be incumbent on everyone, more or less, to read up the past literature of a subject, before he or she puts pen to paper, in order to learn what others have thought and said on that subject, but, in so doing, one has to keep alive these "hieroglyphics." It may take generations before we get wholly rid of them.

Now that we are becoming philanthropic, inventors of new words might be more careful how they impose worry on future generations.

One would like to ask is it only among the ignorant that a great deal passes for science, which is not science at all, but a "wrong scent," which a leader of a certain branch of thought has got hold of, and because he is a leader, and an authority, the wrong scent takes us out of the right track?

At one time, we heard a good deal about "Listerism," and if one then doubted it, he was looked upon as an ignorant fool. But now Lister says "I feel ashamed that I should have ever recommended the spray for the purpose of destroying the microbes of the air."* It is no doubt the most honest way of geting rid of a mental, and, in this instance, also a practical encumbrance.

Take another case. The retness on plants in the erenings and mornings, passed for a long period as a condensation of the moisture of the surrounding air, called "dew," until Aitken split this wetness into two distinct phenomena, riz., the condensation of the moisture of the air, and the exudation of moisture from the leares. He, moreorer, found out that the real dew was largely fed by rapour rising out of the warm earth, and that, therefore, the under surface of leares was sometimes bedewed when the upper surface was not.

* Provincial Medical Gazette.-October 1890, p. 570. 
We should admit that both science and philosophy are experimental. The one deals with experiments of facts; the other with experiments of inferences.

Once we thought that everything that theology asserted was true. Scientific investigations picked holes in that theology. Then the pendulum swung in the opposite direction, and we thought that ererything science asserted was true.

Theology picked holes in that science, now we find that a sceptical attitude on both sides is a very good thing, and that we cannot make any real progress without experiments, of both a physical and a mental kind. The ones are supposed to belong to science, and the others to philosophy, but whether there is any need for the distinction is doubtful. Nothing can be known to us until it becomes mental.

The mechanical sciences are in an enviable position. They furnish the machinery of human life. Any flaw is soon found out and corrected.

But speculative sciences have to pass through a long period of crudeness, before they can be hammered into shape by logic and criticism.

The fact is in progressire science, what is called science to-day, may become antiquated nonsense to-morrow. When this happens, the sooner we say so the better.

At every fortnightly meeting of the Royal Horticultural Society we are made aware that so called genera breed with other genera; that species breed with other species. A Cattleya breeds with a Lalia; a Lrelia with a Sophronitis; a Sophronitis with an Epidendrum; a Chionodoxa with a Scilla; a Philesia with a Lapageria; and so on.

What an overwhelming mass of crude material has been looked upon as pure science in the past! For how can we look with comfort upon this hair-splitting and founding of genera and species, with, not unfrequently, corresponding unpronounceable names, if these genera and species are so intimately related as to be physiologically identical, for if they were not, they could not interbreed.

The fact appears to be that systematic botanists have not kept pace with the revolution caused by evolution. It is not improbable that a great deal of what was supposed to have been 
completed will have to be done orer again, on the basis of evolution.

Just consider what difficulties scientific men, consciously or unconsciously have placed in the path of science learners.

Science, in the near future, will be supposed to teach us the scheme of creation, and therefore to form for us some sound conception of the universal energy, which moulds and moves all things. Not only this, but it will be supposed to teach us all that is knowable of ourselves and our surroudings, so that we may be in a position to utilize, as much of the universe as possible, for our own benefit, material, and so called spiritual, or non-material, and all this will hare to be taught in one's lifetime!

At the present moment science and philosophy too, are encumbered by such an amount of friction-tackle, that ages will be required to polish them down into some sort of intelligible instruments of instruction.

We have been shown that savage unpronounceable words have been simplified in course of time, to suit the needs of mankind, and to facilitate the acquisition of increasing knowledge.

We hare been shown that harsh sounds have been softened down; guttural sounds, probably borrowed from camels, and wild animals, transformed into civilised enunciations; long complicated words simplified into pronounceable and thinkable words; others cat down, first in speech, then in writing, to meet the intelligence of people worried by the turmoil of their struggle for existence.

Notwithstanding all this, scientific men, instead of following nature, and simplifying the means of acquiring knowledge, have encumbered it with difficult expressions, so that ordinary mortals, for whom undoubtedly God intended science also, are scared away from it, just as busy people are scared away from cuneiform and Chinese writing, wondering what they all can mean!

It should be remembered that the study of nature now means the study of a complicated process of erolution from the simplest forms with simple surroundings, to the highest animals and plants, with complicated surroundings.

The whole scheme of plant erolution would appear simple enough in essence, but owing to the sub-division of labour in botanical studies, and hair-splitting, each hair splitter inventing a multiplicity of new terms, the study of plant-life has been rendered unnecessarily difficult. 
Searchers after truth have thought it necessary to invent innumerable terms to make things clear, but which unfortunately often have the opposite effect. Possibly they may have thought that the invention of all these terms was the end of human exertion, instead of the means of acquiring what is to be the end of knowledge.

Every variation of an organ, or part has been given a new name, just as every variation of an individual was supposed to mean a new species.

There are not many minds, which have the power of keeping more than one idea before them at one time, therefore the more simple, the briefer, and the clearer the mode of expressing that idea is, the less chance it has of escaping the grip of human intelligence.

Hundreds of controversies have been and are caused simply by differences of words. Can it be denied that many hare a lore for coining new terms on the slightest provocation, for the sake of symmetry, regardless of the impediments they thereby place in the way of their thoughts being understood?

It was only the other day that Prof. Max Muller in a "Lecture in defence of Lectures" warned us* that, "Words will govern us, unless we govern them." He added, "How then can we account. for the fact that erery system of philosophy from Thales to Kant, is contradicted by another system ? It is chiefly, if not entirely, language that has thrown the apple of discord among us. We call the same thing by different names, and different things by the same name, and then we wonder that, as at the time of the Tower of Babel, so even now, we do not understand one another's speech."

One great function of philosophy is to unify and simplify the mass of human knowledge, and thus render innumerable words useless. There will come a time, I doubt not, when all this uselessness will be cast off like the old skin of a snake. One would, howerer, wish that that time were a little nearer.

The Rev. M. J. Berkeley, in his "Introduction to Cryptogamic Botany," at p. 6, said, "The difficulty is just as great, when in extensive and truly natural genera, it is desired to separate one species from another, as when the objects of separation and definition are the main or subordinate divisions of any one great

* Who can better warn us against the trouble that can be caused by words than Prof. Max. Muller? 
class, or even taking nature, as a whole, when the question regards the highest division into which her productions are evidently distributed."

Then in a note he remarks, "Botanists are not in general aware to what extent this fact is exhibited in the regetable kingdom, because for the most part they have only very imperfect materials, and therefore suppose that the distinctions between species are far more definite than they really are. In a large herbarium like that of Sir W. J. Hooker, in which species exist from every part of the world where a species may chance to grow, the truth of this remark will at once be apparent, and the veriest hair-splitter will pause before he inflicts on science a multitude of -uames which can lead to no useful result, but on the contrary, make botany a trackless wilderness."

I am aware that a good deal of this species making is dying out, nevertheless, morphologists and histologists continue to split hairs, and inflict on science an unnecessary multitude of names.* If science is ever to become popular, and a large part of its value will be lost unless it does become popular, the minds of students must be economised in order that they may comprehend the essence of things rather than have their mental energy scattered in remembering an infinity of names. After all each man's capacity for remembering names is limited, each according to mental constitution, and if he has to stuff at one end more than his brain will hold, something must go out at the other end. Not only our social and commercial life, but our religious thoughts must now, and in the future, be bound up with scientific thought, and therefore it is imperative that scientific investigations should not be unnecessarily encumbered with a "multitude of names which can lead to no useful result." $\dagger$

Placed in its simplest light, evolution, with its myriads of forms, is difficult enough to grasp, but to make it more difficult by encumbering it with unnecessary terms will hardly lead us to comprehend the universal energy which creates and modifies all things according to its own ways, and heedless of our words. cells.

* What has been truly said of species may be as truly said of organs and

$\dagger$ To the perplexing and unaroidable battle of life, they add an aroidable and useless battle of words. 
Dr. Masters, in his "Veg. 'Teratology," p. 348, referring to increase in the number of flower-stalks, says that Prof. Morren gave this phenomenon the name of mischomany, and adds "a term which has not been generally adopted." For this, one can only say, thank God!

Both science and philosophy are ever undergoing change, owing either to new discoveries, to new instruments of observation, or to surveying things already known from a new standpoint. So that it often happens that the science and philosophy of any branch of human knowledge, at any one period are neither wholly true, nor, as has been sometimes said of ancient science and philosophy, wholly untrue.

Not that things change, but we come to know more about them. So to speak, we climb to a point, from which we can take in more at a time, and therefore form a broader conception. The human brain changes its mode of looking at things, because it has ideas started in it, which it had not thought of before.* What it is ever trying to do is to piece the facts into a connected theory, which may stand before the judgment of those who may know, or think they know, all, or a good deal about the matter.

No doubt criticism ought to have aided science and philosophy more than it has done. It is owing to their great advantage for criticising scientific and philosophic work that scientific and philosophical societies are useful. But just hear what an earnest man, Andrew Lang, writing on the Science of Criticism in the New Review of May, 1891, says :-

"The writings of other critics daily and weekly, are often so ignorant, so prejudiced, so spiteful, so careless, that perhaps no printed matter is more entirely valueless and contemptible."

Scientific criticism, to do any good, must have not only truth for its sole object, but also the teaching of that truth to the people.

People often ask "What is the use of science? Scientific persons are not happier than others."

In the struggle for existence, it is not happiness, so much as being at all, which is the more important. It will be readily understood that if one ceases to exist, there cannot be much benefit in making inquiries about his or her happiness. And

* These are the revelations, old and new, which have been going on in the human mind from the beginning of time. 
undoubtedly, in the struggle, a truth has the advantage of a fiction . One has to be first, before he can think of making himself happy. Science has for its main object to replace fiction by truth.

Teach your children fiction, instead of truth, and in their struggle with those who are armed with truth, they will go to the wall. The "use of science" in the coming struggle is, therefore, not far to seek.

One might naturally ask-what place has "speculation" in science and philosophy?

Facts are such phenomena as present themselves crudely to our senses. Speculation involves a mental process, resulting from the crude impressions made on our brain by those facts.

Probably the facts, with some exceptions, are pretty much the same to all who can take notice of them. But speculation is a reasoning, or drawing of conclusions from crude facts, and therefore it is a process, which may be very different in different minds.

Prof. Agassiz intimated that, in their studies in Germany, he and his companion had to resist "the temptation to impose one's own ideas upon nature to explain her mysteries by brilliant theories, rather than by patient study of the facts as we find them."*

This is, no doubt, sound advice, but erery modern thinker will say patiently study the facts as you see them, through your own observations and those of others, and also theorize about them. For as Weissman has rightly said-simple isolated facts lead to nothing, unless they are bound together by a theory. It is this that makes them valuable. In addition, it utilizes facts which are loosely agglomerated round a speculation. A sound theory not only throws light on the facts, but throws light ahead of the facts already known. Just consider what light the Darwinian theory has shed over every biological fact. Moreover speculating, theorizing, and philosophizing--different degrees of the same mental action-are natural processes of the human mind. There comes a time when, after a number of facts have been established, the cultured mind evolves a theory by speculation, and eventually by enlargement a philosophy is evolved, all which mental processes are the outcome of thinking over the facts.

* “Scientific Papers" of Asa Gray, by G. S. Sargent, vol. ii., p. 485. 
I believe that every fact creates sooner or later a supposition, as Whewell said, or a speculation as to its cause, even in the minds of savages. Looked at in its proper function and in its scientific sense, one might say that speculation is a sort of "scouting in unknown regions," with the view of discorering some firm basis for a step forward.

Whether we draw a right and reasonable conclusion or not, will depend not only upon the collateral and other knowledge of things we may possess, but also on the quality of our brain fibre.

To give an illustration-the sun was seen as a fiery ball from the beginning of time, but it was not till a later period, when knowledge had accumulated and a more reasonable speculation began to unfold itself in the human mind, that the sun was seen to be not an isolated unrelated fact, but a branch of an infinite whole. Between our modern and recent times and former times an infinite number of conclusions had been drawn, and speculations attempted by man-that is experiments in speculation-until in somebody's mind the right one was suggested or rerealed. This was erentually considered the right one because it fitted in with other speculations drawn independently of it, all forming a reasonable whole. Whether the speculation be reasonable or not howerer will much depend, as I said, on the brain fibre, and on the extent of utilizable knowledge stored in the brain that speculates and reasons.

The microscope does rereal many things, but very often it can only give a hint, the real revelation-the connection with other parts-has to occur in the brain, the fact indicated by the microscope remaining only as an isolated fact.' It may also happen perhaps that some of what are called microscopic facts may be deceptive appearances, as Lindley called them.*

In my speculations I start by accepting the theory of evolution in its totality, commencing from the simplest unicellular alga-and this because further backwards I cannot go- up to the highest development in what are called flowering plants.

Curiously enough, under the heads of flowers, we group examples, such as the gorgeous flowers of Amaryllis, Victoria regia, Cattleya, \&c., and also the little better than cryptogamic flowers

* I know that great precautions are taken now with staining materials and polarized light to aroid deceptive appearances. 
of pines, cycads, grasses, sedges, \&c., simply because we have inherited the botanical notion that a stamen is essentially different from an antheridium, and that an orule is essentially different from a spore. To the evolutionist the difference is simply one of words.

I admit that evolution may "run mad" in one's mind, but if care be taken about the facts, and more care be taken about the legitimate inferences to be drawn from such facts, one may perhaps keep clear of such an imputation.

In conclusion, one may say of "speculation" that it is a tentative theory, which may be improred into a "working theory," if it proves, by further investigation, to hare any soundness in it, or entirely set aside, if found to be laseless. A speculation one day may become a theory the next, and a part of sound philosophy further on. Speculations may perhaps be more valuable as hints to others than to the original speculator himself. This note may appropriately perhaps be ended by the following quotation :-

"Without a hypothesis man discovers nothing." . . . . "By hypotheses reason and imagination are conjoined, and all the powers of the mind employed in research."-Dr. J. Powell.-LIFE ATD wORK OF Ch. Darwin, by C. F. Holder. 


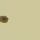


"But there are facts and facts-facts with value, and facts without value. The indiscriminate gathering of facts leads to no important discoreries.

" . . . . . There must be some method of selecting, some method of determining what facts are valuable, and what facts are trivial. The fool collects facts ; the wise man selects them."- John W. Porell, Ph.D. - Life of Darwen, by C. F. Holder, pp. 224 and 225. 


\section{II.-WHY DO WE STUDY PLANT LIFE.}

We study plant life, or let us say, nature in general, with several objects :

(a.) For the purpose of obtaining a better and clearer idea of the wars of what we call the Deity. The reader must not suppose that by Deity I mean a personal Deity, but only that universal energy which controls ererything. It may, for all we know at present, be ultimately established that, what we have been calling the Deity is that protean electrical energy which is capable of development ererywhere, and under all circumstances. Whaterer that may be, howerer, we cannot get the Deity out of our mind. It is part and parcel of it, and the more we learn of the ways of the Deity, the better and more suited our actions and thoughts will be to It.

It is rery doubtful whether man will be ever, free from agnosticism. All people are, strictly speaking, "agnostic," although most people fancy they are not so. If, howerer, you hunt them into a corner by a series of questions, they must end by replying "I don't know" to certain ultimate questions. A clergyman once told me that such questions are enough to upset any theology !

Let us then not quarrel about whether that universal energy is the Deity, or whether that is only machinery, and that the Deity is something at the back of it all.

Probably we shall not reach equilibrium, if erer man do reach it, till our mind becomes thoroughly attuned to what is outside of it, that is, till nature, and its reflection in our mental mirror become one, just as the figure and its reflection in a plain looking glass are one and the same thing.

(b.) Another object in studying plants is for the purpose of getting what benefit we can out of the study of surrounding nature, and of ourselres, as part of nature, 
in order that we may the better adapt ourselves to it, wherever and whenerer we are not able to modify, or control it.

(c.) The third reason why we study nature is because we cannot help ourselves. The whole history of vegetable and animal creations including ourselves, shows that they are forced, by circumstances to attune themselves slowly but surely to their surroundings, that is, to adapt themselves to them, or wither and perish in the struggle. It may be a matter of choice with some perhapsthose do not count for much in the struggle for life -but with the majority, it is a matter of "willy nilly." They are forced to do what they do, and think as they think, by the action of external nature on their organism.

The mind being a part of an organism is no exception to the rule. The human organism is born with a bias, which we call heredity. It is an amalgamation of two pieces of two different individuals. The mind of this organism is trained in a certain way; then surroundings act on this bias and training, and either help it, hamper it, or oppose it. How often does it happen that the struggle for existence, in man, is made up of two main factors, the necessity of working for one's "bread and butter," and a passion for some particular study. The former absorbs the time, and the latter the heart. And thus the conflict must of necessity end in the resultant of these two driving factors. In man the inherited bias, the training, and the surroundings, in which of course are included books, containing the thoughts of others, drive him into studying this or that, as the case may be. That is why some study plants, other study something else, and others again study nothing at all. 
"When will they learn that unity does not involve uniformity-that the highest unity manifests itself in diversity."-The CHURCH, by Dr. A. W. Momerie. 


\section{III.-VARIATION.}

Examinisg the flowers of Weigelia rosea one day, I found on the same branch, and all over the bush, flowers with three, with four, and with five petals.* These three forms were pretty common, although the majority were with five petals. There was another curious form, which, from its frequency, can hardly be considered accidental. The tube of the corolla was split up, and displayed something of the form of the upper lip of the honeysuckle flower.

Curiously enough, in each of the three regular variations, the stamens corresponded with the corolla divisions, and alternated with them. Wherever I have seen this Weigelia, the same variations in the flower occurred.

We cannot well suppose that the five-petalled flower turned into the four-petalled by fusion of a pair of petals into one; nor into the three-petalled by fusion of two pairs into two petals, for in each case all the divisions of the corolla were perfectly symmetrical, and of the same size. Moreover, it is hardly conceivable that fusion of petals would reduce the stamens to an equal number, and alternate them with the divisions.

No, these are congenital variations, each with a phyllotaxis of its own. Neither fusion in the one case, nor splitting up in the other, if we reverse the origin, will explain the appearance of an equal number of normally formed stamens, alternating with the petals.

Jackman's purple Clematis has four and also fire-petalled flowers on the same plant.

The Syringa (Philadelphus) has sometimes also five-petalled flowers among the usually four-petalled ones.

On Chironia palustris, I found flowers with six petals and six stamens, and on Chironia peduncularis I found one with seren

* "Sœpius 3-chotome divisas . . . . . . . Ovarium 2-loculare, rarissime 3-loculare." (Bentham and Hooker, Gen. Plant.)

1 p. 1724. 
sepals, seren petals, and seven stamens, although normally the flowers of the plant have sub-divisions in fives.

On one Streptocarpus, with the three lower petals marked and irregular, I found a flower which was quite regular and wholly unmarked. On another Streptocarpus (white with purple marks) I found a six-petalled flower with fire normal stamens and one aborted; while the others had five petals, with four normal, and one aborted stamen.

On another, there was a flower with four petals, and one normal and three aborted stamens.

The hybrid Streptocarpi have many leaves, while one of the original introductions at the Royal Gardens, Kew, I believe, had only one large leaf.

In the Begonias, we often find the male flower with four petals, and the female flower with five, with other variations.

Now, with reference to the origin of species, it is conceivable, in the case of the Weigelia, that each of those variations, on the same plant, would sometimes produce seed, which might inherit the peculiarities of the parent flower. If so, the next generation, say of this tripartite form, would probably have more tripartite flowers on the same plant. It would thus afford a better chance of this form becoming fixed in future generations, and eventually creating a plant with all the flowers tripartite.

Then, if one seed happened to be carried to a great distance from the parent colony, this variation, by becoming isolated, might not only become fixed, but might give rise to variation in leares and habit.* Eventually it would create what might be called a distinct species, more especially if surroundings and other changes were to bring about physiological changes also, which would not admit of its being crossed with the parent stock, eren if it had a chance of doing so.

I was examining some bushes of Raspberries. It is astonishing what variation they show in their leaves. The odd leaflet is often fused to either one or both leaflets of the next pair, forming an irregular or a regular tri-lobed leaflet. Sometimes the lobes disappear, and a large heart-shaped leaflet results. At other times there is a large five-lobed leaf and no side leaflets, indicating that the two

* G. Nicholson gives a form with verticillate instead of opposite leaves, which is evidently the result of fusion of two or more stems.- " Dict. of Hort." 
pairs of side leaflets have fused with the odd one, and formed a palmate leaf.*

One can fancy that a seed, having been transported to a new region, and producing a plant that could continue to live under those circumstances, would often produce as many variations as a wild plant often does, when brought under cultivation. Then a struggle between all the rariations would eliminate the weakest, and select the fittest.

If one keeps his eyes open, when looking at the flowers on the same plant, it is almost next to impossible not to meet with striking variations.

Among a mass of honeysuckle flowers, I found that the majority had four petals curled upwards, and either all fused together, excepting their tips, or the two middle ones fused and the two adjacent ones fused to only half their length, the fifth petal being curled downwards as a lip. A certain number had two petals curled downwards and separate, while three were curled upwards and fused. More rarely there are two lower and four upper, thus introducing an extra petal. More rarely still, all five are curled upwards and fused, up to their middle. One with six petals had also six stamens alternating with them. Whe six petals occurred there were six stamens. One, however, had seren petals, six up and one down, and only six stamens.

If we turn to the cultivated Gladioli, we often find on the same spike some flowers that have two outer petals below and one abore, or vice versâa; that is, one outer petal below and two above. $\dagger$ Curiously enough, it is always the three lower petals, which are distinctly marked, whatever the form may be, and the stamens and pistil are always arched under the upper petal or petals.

In the Hippeastrum we have a Gladiolus flower with its petals reversed, that is, the distinctly marked ones are upwards, while the bundle of stamens and pistil reposes on the lower petals. I hare seen a reversed Hippeastrum, but the stamens, and this is the extraordinary part, reposed on the lower petals, which in this abnormal case were those distinctly marked.

All these variations, often occurring on the same branch of the same tree, may, under certain circumstances, and through the seed,

* The leaf of Geum, may have easily resuited from the leaf of Potentilla.

† In another place I have endeavoured to account for this puzzle in the Gladiolus. 
be sometimes separated into distinct plants, having only one charactered flower.

Vegetable life might, with a stretch of the imagination, perhaps be conceived, in a vague way, as an everlasting rhizome of a compound nature, growing and varying indefinitely, and throwing up in its course, branches which represent orders, with their genera of all descriptions, and specific subdivisions and variations.

This supposed rhizome is the cellular basis of all plants, where they meet on a common level. M. J. Berkeley says :- "It must be recollected that in all plants the early embryonic state consists of cellular tissue only." One might add not only the embryonic state, but every other state, for all tissues, whether we call them vascular or woody, vegetative or reproductive, are either made up of cells in their pure and simple primitive form, or of modifications of cells. The beginning and ending of any part, in the living state, whether a root, a stem, a petal, a stamen, a carpel, is a group of cells.

We see how easy it is, through seed variation, for changes to occur in the different parts of a plant; and how fixed these changes can become by usefulness and repetition through inheritance for ages. When this fixity is loosened by repeated attacks of crossfertilization, an infinite number of new combinations of cells and modifications of form in the individual will again become possible.

The possibilities in the change of organs is exemplified by a Chrysanthemum flower now before me. I see how easy it is for a hair in one generation to be modified into a tooth, a lobe, or a blade in another; how easy* it is for a ray floret to be changed. into the form of a disk floret, and vice versâ; and how many intermediate forms can occur between the regularity of the one; and the irregularity of the other. The ray-florets, from their position, are naturally irregular. They are the circumference florets, and therefore the outer limb of each floret has no crowdinge to contend with, and to impede its cells growing in that direction.

"When I say " how easy," I do not mean, of course, that the ease is irrespective of time. This, in the working of the modifying forces of nature, is infinite. 
We can see how easy it would be for all the crowded florets of a composite head to become suppressed, except one of the ray, and that to become the irregular corolla of the Labiatce, Lobelia, and others; or for all the florets of the disk to become suppressed, excepting one, and that to become the regular flower of a Bouvardia and others. We are accustomed to look upon the compositæ as something different from other flowering plants, but scatter the head of composite florets, by giving each a lengthened peduncle, and you have the loose head of flowers or branch of a Russellia, and others, dispersed on an expanded and highlybranched stem.

As a matter of fact, we already have the composite head scattered to some extent in Centranthus, Valeriana, Ixora, Viburnum, and many others.

Curiously enough, in one of the Rutaceæ-Diplolcena Dampieri -we have the scattered flowers gathered up into a composite head!

It is impossible to behold a tropical forest, or the regetation of a desert or of some ligh altitude, and not feel convinced that surroundings influence rariation. If surroundings have no influence on rariation, why has Ficus repens, when grows. against a wall, one form of leaf, and when grown as a standard, a different form?* The same might be said of other wallclimbing plants.

There is a tendency now to attribute all variation to congenital changes, initiated by sexual conjugation, that is the union of a male and female cell.

What is a congenital rariation? It is (a.) a rariation which appears at birth, as a further derelopment of some atomic changes, which occur during the progress of foetal growth; $;$ or $(b$.$) a$ variation, which appears in after life, owing to some similar atomic change having occurred also during fœtal life, but which does not become apparent at birth, and, may be, not for many years after birth.

Now, is it true that sexual conjugation is the only cause of congenital variation, and that surroundings hare no influence whatever in producing it?

* See Gardeners' Chronicle, 10 January 1891.

$\dagger$ Under the name of "fœtal growth" may be here included the growth of seeds in their parental orary. 
We are, perhaps, too prone to look upon the individual, whether animal or plant, as something totally apart from its surroundings-as apart, as if the individual were at one end of the earth and its surroundings at the antipodes; or as if the individual were on this earth, and its surroundings at the other end of the universe!

The individual and its surroundings are so intimately connected and related, that for practical purposes they may be considered as one thing. This may be the reason why, when the individual changes place, it either suffers or benefits. In the former case it is out of tune with its surroundings, and has to retune itself, if it can. In the latter, the continued repetition of the same surroundings may produce what, for want of a better term, might be called atomic " ennui," and then a change may revive its energy.

Something analogous occurs in growing a plant repeatedly on the same ground. It will not thrice unless it gets a change, whether this be a change of soil or a change of place, which may mean the same thing. Food is, and always must be, one of the surroundings, and all ultimate adaptations are for the purpose of living.

Now, what produces congenital variation? We hare mentioned that the mixing of two heredities, by the conjugation of germ and sperm cells, resulting in a mixed individual, is certainly a cause of variation. Another factor must be admitted, and that is the influence of the surroundings on the individual. The play of the surroundings on the unformed parts of the offspring, still in its elementary stage, and forming part of the parent, cannot be excluded from having a share in causing modifications in the indiridual. The offspring is then in a highly plastic, impressionable; and modifiable state of existence. We must allow some influence, as one of the surroundings, to the nerrous system of the parent, where such exists, which nerrous system is in turn influenced by its own surroundings.

This play is often so subtle, that for want of a better name one might call it elertrical. We should not lose sight of the fact that every disturbance, of whaterer kind, may derelop synchronously an electrical movement, and considering that physicists admit the presence of an ether ererywhere, even surrounding atoms, it will be seen that there is ample means of communication between the surroundings and the innermost atoms of any body. 
If the heat of the flame of a candle at the distance of $1 \frac{1}{4}$ mile can be measured, by means of a sensitive galranometer, as has been stated at the Royal Institution; if the heat enitted by the human hand at the distance of six yards can be measured by the same instrument, as was shown there; if a bit of sealing-wax rubbed on one's coat and pointed at a fine spray of water, at the distance of two yards can cause the minute globules of the spray to agglomerate into larger ones, as has been repeaterlly shown by Lord Raleigh, at the same institution, it would seem very unreasonable to deny to the surroundings of living bodies any influence in modifying the atomic play of even their innermost cells. The influence of distant stars reaches us somehow, ${ }^{*}$ and therefore it seems hardly possible that the influence of surroundings, in intimate contact with living bodies, should not at least have some part in the modification of such highly plastic borlies, as embryos, howerer slow their influence may be.

If we reduce the individual to one of its ultimate elementssuch as a simple cell, floating about in water-we shall see at once how important and intimate is the relation of surrounding to individual, and how nicely balanced the indiridual life must be to its surroundings. In the case of the simple cell, the chemical and physical influences, the electrical and magnetic changes of the surroundings must act either advantageously or disadrantageously on the individual, or at all erents must act in some way as to produce a corresponding change in the cell. Now, considering that atomic attractions and repulsions are influenced by electrical changes, it will be seen how important a factor of modification are the surroundings, although their influence may be masked by the greater hereditary influence of the two parents.

Can anyone assert that the derelopment of the arms of the ourang-outang and the atrophy of his lower limbs, have not been influenced by his surroundings-that is, by the life he was forced to live, either to search for food on trees, or to escape from his enemies?

Can anyone assert that the derelopment of the legs in man has not been influenced by the upright posture he was enabled to maintain, and that the release of his hands from the function of

* Even those stars, which are invisible through the most powerful telescopes, can be photographed! 
progression has had no influence on the development of his brain ?

Can we assert that these influences have not been transmitted cumulatively, that is, with increasing effect every generation?

It may be that in the first instance the ancestors of the ourangoutang and the ancestors of man had in the one case congenitally stronger arms, and in the other stronger legs to begin with; but it is inconceivable that the life they were forced to lead, or, in other words, their surroundings had no influence in strengthening and further adapting their limbs to their mode of life from generation to generation.

The very fact that the ourang-outang had been driven to a tree life would make his children take to that life by imitation very early. This adaptation, becoming increased and strengthened by each generation, would end by becoming instinctive. Having become instinctive, it seems reasonable to suppose that it would be inheritable.

J. T. Cunningham quotes a much stronger case." Flat fishes have both their eyes situated on one side of their face, and one whole side of their body is coloured, while the other side is white. In these characters the adult flat-fish differs from its young stage.

He says : "To explain the evolution of these characters by " congenital" variation and selection, it must be assumed that, in the symmetrical ancestors, their beginnings occurred as variations in adults, which had not exhibited them during the previous part of their lives, and did not inherit them from their parents. And yet no one has even attempted to show that any symmetrical fish has exhibited a twisting of the eyes late in life, after having lived since hatching with symmetrical eyes. No symmetrical fish has been found in which, after the two sides had been similarly coloured all its life, one of them became less pigmented than the other. No variation in symmetrical fishes has been found which occurred late in life, and consisted in the growth of the dorsal fin or fins away from the median line of the body between one of the eyes and the moutl. Yet all these variations must be assumed to have occurred in the ancestors of flat-fishes, if their evolution is to be explained by congenital variation and selection."

* The "New Darwinism."-Westminster Review, July 1891, p. 25. 
"On the other hand, all the changes which have taken place in the evolution of flat fishes are such as must have taken place in accordance with known physiological effects in individual fishes which, after a certain period of development, adopted the habit of lying on their sides on the sea-bottom." ...

He concludes by stating that "all that is necessary to prove that acquired characters are inherited, in the sense in which the words ought to be used, is to show that an external influence of the same kind and the same degree produces more effect in every generation than in the preceding." And, it might be added, may produce characters which will become so fixed as to be congenitally inherited, even when the surroundings are eventually altered.

If the cells of the fotal individual are sensitive at all, there must be a continual play between it and its surroundings. If the fœtal enrelopes, whaterer those may be, are transparent, light will play upon them; if they are conductors of heat, this will play upon them. The most subtle of all agents, however, are electrical and magnetic influences. They penetrate everywhere, and are omipresent.

In animals which hare a differentiated nerrous system, the play on the atoms may largely take place through the nerve-cells and nerres, these being played upon by surroundings.

It is inconceivable that the changes during fœtal life, which must be so dependent on atomic electrical changes, should not be influenced by the electrical changes of the parent, and these in turn influenced by the electrical changes of the parent's surroundings.

Considering that the atomic compositions and decompositions of organisms are governed by electrical attractions and repulsions, the wonder is, not that surroundings should influence the changes which occur in fœtal life, but that seemingly they have so little influence, owing probably to the more potent influence of heredity. It is only the persistence of surrounding influences acting imperceptibly and by very slow degrees, which eventually overcomes the pre-established inherited influence. So that we can see any marked deviation only after long periods. Geological periods, although rery long, compared with human life, if measured by the clock of the universe, become comparatively short periods. 
'The fusion of germ and sperm cells as a factor of modification is conceivable enough. The more varied are the parents of these germs, the more variations are they likely to give rise to when they conjugate.

'There is, however, another factor in modification, which may not have attracted sufficient attention-I mean the fusion of two already conjugated pairs of germs. This fusion may be either complete or incomplete; hence, among animals we have, as a result, a lamb with two heads, two lambs with one head, a chicken with four legs, or hands and feet with six digits, or two bodies with one pair of legs, and so forth. It is even conceivable that the symmetrical bodies of vertebrates and articulate animals may have resulted from the fusion of two originally unsymmetrical individuals during their fœtal life.

Of this mode of fusion as a factor in the variation of plants I have treated elsewhere. In studying the beginnings of plants, such as we see them in seaweeds, it is not difficult to see, in spite of innumerable variations, that there is evolutionary progress from the simple to the complex.

It is now well understood that given "variations," whatever their origin may have been, and unlimited reproduction, what is called a "struggle for existence"* must ensue, and naturally the "surviral of the fittest" $\dagger$ will follow.

The plants we see in the water and on land are the survivals of the fittest, each in its own sphere. And the gaps between these survivals are biological valleys in which myriads of the unfit have been buried during the vast ages through which this rariation and struggle have been going on. Notwithstanding the gaps, the survivals, or biological peaks are all related by a common origin, which biologists consider to have been unicellular plants, of which the modern representatives are descendants.

To sum up then, in spite of the infinite variations we see in all directions in land plants, we also can note that there is a sameness underlying all this variation, and this sameness we can trace as low down as seaweeds. With a further use of the

* This expression is often used metaphorically, especially with referenee to plants.

$\dagger$ This term "fittest" has a very broad meaning. 
imagination we can trace the seaweeds to their components, the threads of cells, and finally reduce these to their unicellular elements.

In these pages I propose to take the seaweeds and ferns as the progenitors of Phœnogams, and see how far the different parts of the latter can be identified with parts which might be called homologous in the former. 
Reduced to its simplest expression, the doctrine of evolution merely states that the animal world as it exists to-day is naturally developed out of the animal world as it existed yesterday, and will in turn develop into an animal world as it shall exist to-morrow. This is the central belief of the evolutionist. . . . . . . Then at once arises the question, Does life remain the same yesterday, to-day, and to-morrow? A thousand indubitable facts at once make answer, No!-Aximal Life axd IxtelliGexce, by Prof. C. Lloyd Morgan, p. 182. 


\section{IV.-NATURAL SELECTION.}

"Ir has been very often maintained that natural selection can produce nothing new, but can only bring to the front something which existed previously to the exercise of choice; but this argument is only true in a very limited sense. The complex world of plants and animals which we see around us contains much that we should call new in comparison with the primitive beings from which, as we believe, everything has dereloped by means of natural selection. No leaves, no flowers, no digestive system, no lungs, legs, wings, bones, or muscles were present in the primitive forms, and all these must have arisen from them according to the principle of natural selection. These primitive forms were in a certain sense predestined to develop them, but only as possibilities and not of necessity; nor were they preformed in them. The course of development, as it actually took place, first became a necessity by the action of natural selection, that is by the choice of rarious possibilities, according to their usefulness in fitting the organism for its external conditions of life. If we once accept the principle of natural selection, then we must admit that it really can create new structures, instincts, \&c., not suddenly or discontiuuously, but working by the smallest stages upon the variations that appear. These changes or variations must be looked upon as very insignificant, and are as I have of late attempted to show* quantitative in their nature, and it is only by their accumulation that changes arise, which are sufficiently striking to attract our attention, so that we call them ' new' organs, instincts, \&c.

"These processes may be compared to a man on a journey who proceeds from a certain point on foot by short stages, at any given time, and in any direction. He has then the choice of an infinite number of routes over the whole earth. If such a man

* Essay on Heredity. 
begins his wanderings in obedience to the impulse of his own will his own pleasure or interest, proceeding forwards, to the right or left, or even backwards, with longer or shorter pauses, and starting at any particular time, it is obvious that the route taken lies in the man himself, and is determined by his own particular temperament. His judgment, experience, and inclination will influence his course at each turn of his journey, as new circumstances arise. He will turn aside from a mountain which he considers too lofty to be climbed; he will incline to the right, if this direction appears to afford a better passage orer a swollen stream; he will rest when he reaches a pleasant halting-place, and will hurry on when he knows that enemies beset him. And in spite of the perfectly free choice open to him, the course he takes is in fact decided by both the place and time of his starting and by circumstances, which-always occurring at erery part of the journey-impel him one way or the other; and if all the factors could be ascertained in the minutest detail, his course could be predicted from the beginning.

"Such a traveller represents a species, and his route corresponds with the changes, which are induced in it by natural selection.* The changes are determined by the physical nature of the species, and by the conditions of life by which it is surrounded at any given time. A number of different changes may occur at every point, but that one will actually develop which is the most useful, under existing external conditions. The species will remain unaltered as long as it is in perfect equilibrium with its surroundings, and as soon as this equilibrium is disturbed it will commence to change. $\dagger$ It may also happen that, in spite of all the pressure of competing species, no further change occurs because no one of the innumerable rery slight changes, which are alone possible at any one time, can help in the struggle; just as the traveller who is followed by an overpowering enemy, is compelled to succumb when he has been driven down to the sea. A boat alone could save him, without it he must perish; and so it sometimes happens that a species can only be saved from

* By natural seleetion is meant the course most suited to the well-being and continued existence of the individual at that time.

$\dagger$ That is a new selection will begin to occur. 
destruction by changes of a conspicuous kind, and these it is unable to produce.

"And just as the traveller, in the course of his life, can wander an unlimited distance from his starting point, and may take the most tortuous and winding route, so the structure of the original organism has undergone manifold changes during its terrestrial life. And just as the traveller at first doubts whether he will ever get beyond the immediate neighbourhood of his starting-point, and yet after some years finds himself very far removed from it-so the insignificant changes, which distinguish the first set of generations of an organism, lead on through innummerable other sets, to forms which seem totally different from the first, but which hare descended from them by the most gradual transition. All this is so obvious that there is hardly any need of a metaphor to explain it, and yet it is frequently misunderstood, as shown by the assertion that natural selection can create nothing new, the fact being that it so adds up and combines the insignificant small deviations, presented by natural rariation, that it is continually producing something new."-Aug. WeIsurans, "On Heredity," p. 136.

I have given this long extract because I have not met with a more lucid exposition of the probable way in which changes are brought about in organisms.

I do not think that sufficient credit has been given to living matter for sensitiveness. Living things are forced by an internal energy to grow. We are not now concerned with the why living matter grows--we may never know that-but with the how it grows, and assumes different forms. All evolutionists admit that it does grow and change.

In growing, this sensitive plastic matter acts as a set of elastic feelers or tentacles would do, to ascertain in which direction it can grow and develop. What the higher animals can do through the help of their eyes, ears, \&c., and their complete intelligence, this sensitive matter* can do with its simple apparatus. The direction of growth is determined by two main factors, viz., the external conditions, which may be changeable, and the internal power of adapting itself to those conditions, while

1 p. 1724.

* Commonly called “protoplasm.” 
the internal growing energy leares it no alternative but to go on.

Organs are elastic. They can either expand and derelop in the direction in which conditions are favourable, and act as feelers for further progress, or they are withdrawn, like tentacles, where conditions are unfarourable, and kept in abeyance and reserre, that is, in a rudimentary and dormant potential state. Among the factors of restriction of growth we must place also the inadequacy of the sucking apparatus to nourish all the existing parts, so that some, from want of sustenance, will abort. There may be organs, which once dereloped, although they may have ceased to be useful, either encumber or hamper the individual as useless limbs, or are turned to some other account, in an infinity of ways, as helpers in the struggle for life.

Like the mobility of water, this plasticity of living matter, with sensitiveness, enables it to occupy every nook and corner and crevice, so to speak, of its surroundings wherever these allow it to flow. Unlike water, living matter may have a concreteness which interferes with parts being always retraced into a homogeneous body, and therefore as I said, organs, once dereloped and become useless, may remain to hamper the indvidual, or they may be retracted into abortions, or possibly they may be turned to some other useful account, than the one they were originally grownn to suit.

All growth is like a river, which has continued to flow without interruption from the same source or sources. But as little bits of it have been perpetually letached, to lead an independent life, as we see them around us, whether in the animal or regetable world-we seem to forget that they are, and hare always been, like a river, learing little independent pools to fill the crevices and suit themselves to the undulations of the surface, each portion may happen to occupy.

So much unprofitable thought appears to have been expended on the question of whether a man's intellect is, or is not, subject to the same laws of natural selection, as other parts of the regetable and animal creations-that it may not perhaps be out of place to end this note with my own thoughts upon this interesting subject. 
What is the origin of the so-called "spontaneous variations," upon which natural selection works, and enables the fittest to survive?

Whatever the origin of spontaneous rariations may be, it now seems a truism to say that in man up to a certain stage of derelopment, natural selection in the individual must have had its way, as in other animals; and that these variations, when useful, were perpetuated by 'transmission from parent to offspring. After a certain stage of adrancement, however, the same law does not appear to hold good, for, according to J. E. Nisbet* and others, any spontaneous good variations of the brain, engendered by molecular combinations, are not of much value to the race, for they are not usually inherited.

It is inconceirable that the same number of atoms, producing the same combinations, should recur in the conjugation of male and female cells, which go to form the entire new individual, and a fortiori it is inconceirable that the same atoms should recur in the same way in the brain of the offspring. No, it is not conceirable that the qualities of so unstable a mechanism as the brain should be inheritable, but this certainly does not mean that nothing is inherited from any particular brain.

A genius may not transmit to his offspring his brain qualities, and there, some argue, the selective operation stops, for it cannot be shown that any accumulated good qualities of brain can be transmitted from parent to offspring, as the shape of a leaf or a petal can be transmitted from parent to child. Yet man has continued to improve, in spite of the spontaneous rariations of his brain not being usually inheritable, and, therefore, not following the laws of natural selection.

Then, by what sort of magic has man improved so much, as to be enabled to conquer nature, and be what he is to-day, if every advance in his brain power is thrown away and lost by the death of the individual. If every time he attempted to climb the ladder he tumbled down to the level of the first step there could obriously have been no adrance, according to the theory of erolution, throngh natural selection.

If Nisbet's facts are unimpeachable, we may have to ask another question. Why are good spontaneous variations of one brain not transmissible to the descendants of their possessor? 
The reply is-simply because, after a certain advance in civilization, such a transmission-from father and mother to son and daughter-was no longer needed, and might be injurious to the community. Nevertheless, the good brain qualities of the individual are not lost to the community, for speech, and now the press, can transmit their products to any receptive brain of any individual who can interpret those symbols. It is then that individual who becomes the inheritor of any advantages, resulting from any "spontaneous rariations," which may occur in the brain of a genius!

Among mechanicians, it is the commonest thing for one man, through speech or press, to inherit another man's inventions; and now, all biological thinkers have inherited the advantages resulting from Darwin's genius.

Man as a wild, solitary animal would be nowhere. It is his social aspect which gives him his power, not only over nature, but also over himself. And, therefore, when we talk of inheritance, it is the community that we have to take into consideration, and not the children only, which are the immediate descendants of the possessor of useful spontaneous variations.

Ideas are obviously not like bones and muscles. They can, like magnetism, be transmitted from one end of the earth to the other, through their symbols, and enter another person's brain, and work their own sweet will, independently of the brain and person in whom they originated.

Nisbet seems to think that molecular changes in the brain of a genius, being too unstable, cannot be inherited as horns, and hoofs, and muscles, \&c., are; and that, therefore, neither sexual selection nor natural selection can have anything to do with them. It is said that they are spontaneous variations, following an atomic law in the individual and not transmissible by heredity.

What does that matter? They may not be transmissible from parent to child, but their results-ideas-can be and are transmitted from the brain of one individual to that of another. Nay, this mode of transmission is far superior to that of heredity, for good ideas can be transmitted to many brains of different races, without the mixture of other bad qualities, which might come with inheritance, and so they stand a vastly better chance of falling on good soil, which may be fitted to enlarge and improre them! What man requires to inherit now is his erect position, and the freedom 
of his hands, in addition to a mental aptitude, which irradiates its influence orer his whole frame, and enables him to avail himself of the "rain of ideas" from all brains capable of erolring anything useful, without any direct inheritance from any particular individual. A genius can give the community much, but it is no longer necessary that he should transmit through a son or daughter.

This is how man has been able to outrun every other animal in the race of life. Spontaneous rariations, which by degrees enabled him to stand erect and easily move on two legs, released his hands from the function of progression. This accident became the instrument of further modification and improrement in his brain. Another spontaneous variation enabled him to transmit his ideas readily by means of speech, and afterwards by writing, so that numbers might be thinking the same thing, and acting together. By this means, a mutiple brain was incessantly at work modifying and improving, not only the conditions that surrounded man, in conformity with his wants, but also his own brain.

These three instruments, the brain, the hand, and speech, with all the other subservient organs hare made him, and are continuing to make him more and more fitted to his surroundings, whether of nature or society. The individual is now largely merged in the society, and will continue to be so more and more, as long as this state of things is adrantageous to him and to society. Spontaneous variations, although occurring in the individual, now become social, and the survival of the fittest society will and must continue to occur.

Nisbet quotes some very extraordinary cases of the same idea occurring synchronously in the two brains of twins, although the one was in Scotland, and the other in England. If there be no doubt about these cases, we must begin to admit that there is some mysterious, and at present inconceivable, way of transmitting ideas, besides speech, action, the press, and telegraphy ; that is, in some such way as the heat and electricity of the sun are transmitted to the earth, or that one magnet affects another magnet at a distance.

From our present knowledge it is not possible to consider this synchronousness of ideas in twin brains, as caused by the fact of their being twins. The law of association of ideas is opposed to such consideration, for the chances would be infinity against one, 
that the twin in England should have the same idea roused in his brain, by the same associated idea, at the same time!

Nevertheless, the twin brains are associated during intra uterine life, almost as much as the cerebral hemispheres of one brain are associated. Moreover, during their childhood, the twins continue to be associated, and must have their ideas continually roused in the same way, and at the same time, so that one brain becomes thoroughly attuned to the movements of the other.* Howerer this may be, it does not seem easy to understand how, when two brains are located in different towns, the same idea can occur synchronously in both of them, unless there be some other means of intercommunication, at present unknown to us.

In the lower animals, watural selection has occurred through the shaping of other parts of the body aided by an advancement in the complexity and power of the brain. But in man, after natural selection had shaped his other parts up to a certain pitch of suitability, as in other animals, through inheritance, his further advancement had to be done through spontaneous rariations of the most important organ-the brain-that regulator and director not only of self, but of others combined in a society. Inheritance was still of the first importance, but it was shifted from the son and daughter to all the members of that society, or at all events to all those who may have been fitted to assimilate and utilize any spontaneous and useful variations, which occurred in the brains of any of its members. Natural selection continued to exercise its general directive functions for good, with many ups and downs, which did not always seem good. There does not seem to me any necessity to look upon natural selection as haring failed in its career, when applied to the mental development of man.

* There are striking examples of similar urroundings, creating similar thoughts in two distinct brains, and the most striking instance is that of Darwin and Wallace. This may account for the members of one family or of any small community often having all their minds cast pretty nearly in the same mould. 


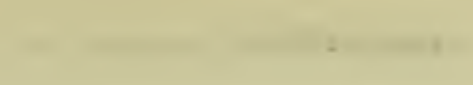


“But Darwin's investigations have not ended research, or completed philosophy. He brought scientific men to the frontier of truth, and showed them a path across the border. Yet more than this he did. He pointed out one of the fundamental methods of research. Before his time philosophers talked about deductive methods and inductive methods. Darwin has taught us that both are fruitless. . . . . . . . It would perhaps be better to say that deductive and inductive methods have been superseded by the method of working hypotheses. Working hypotheses are the instruments with which scientific men select facts. By them reason and imagination are conjoined, and all the power of the mind employed in research."J. W. Powell, Ph. D.-Lire of Darwis, by C. F. Holden, pp. 224 and 226. 


\section{V.-SOME FACTORS OF MODIFICATION IN PLAN'TS.}

\section{Conjugation.}

THE coming together of the sexes appears to have but one universal object, both in animals and plants. This object is the conjunction of two differentiated cells-a sperm cell with a germ cell. This union is now acknowledged to be the mainspring of modification in living things, although very probably not the only one. The longer the series of ancestors which is at the back of each of the cells that conjugate, the more rariation is likely to ensue.

Therefore, multiplication by sexual processes, in contradistinction to that by axesual processes-that is, multiplication by fertilized seed, as distinguished from multiplication by ordinary bud-would appear the main factor of modification.

\section{SURroundixgs.}

Then there is climate, with its heat or cold, dryness or moisture, \&c.; soil, with its looseness or hardness, its rockiness, its regetable mould, its dampness or total want of moisture, and its variety of mineral ingredients.

I am aware that many do not admit that surroundings of this kind can so influence an organism as to enable it to transmit any acquired modifications to its offspring. But it is not believable that, when the organism is unicellular it is modified by its surroundings, as Weismann says, and when these unicellular bodies aggregate, those that become reproductive cells are no longer modifiable, through surroundings, either directly, or by way of their nurses, which are now the somatic cells.*

I know it is difficult to prore that any modification has occurred through the transmission of any acquired character due

*. Or body cells, as distinguished from the reproductive cells. 
to surroundings; but I would say that it is as difficult to disprove that what is called a congenital modification has been brought about originally by any other factor than that of its surroundings.

Some might say that, if the struggle for existence and survival of the fittest is enough to explain all the adaptations we see, where is the advantage of supposing that the surroundings too act as modifiers of living things?

It is forgotten that struggle for existence is a part of the surroundings, and that the whole of the universe is perraded by electrical influence, which, in turn, influences the polarity of atoms, and, therefore, must act as a modifier of living things, whether this influence act directly on the reproductive cells, or indirectly on them through their surrounding somatic cells.

No one who has seen the characteristic forms of plants in digenous to rocky, arid countries, to deserts, to mountain surfaces, to tropical damp climates, can have any doubt whatever that climate and soil have been two great factors in modifying plants. What but the dryness of climate and soil could have so depauperized branches and leaves as to gradually reduce them to thorns and spines? There is no more proof that congenital variations, uninfuenced by climate and soil, became eventually fitted to the surroundings, than there is proof that climate and soil acting on a plastic, sensitive, body caused congenital modifications to develop. But I do not see how we can throw aside surroundings, and lean entirely on congenital rariations produced solely by the union of male and female cells. In the case of animals, for instance, we would be throwing aside the whole of the nerrous influence, which is of the most searching and penetrating kind!*

All modifying factors, whatever these may be, would have caused variation to "run mad," were it not for the restraining force of heredity, by which the preservation of useful qualities has been effected.

No one can walk through the streets of London and come face to face with the thousands of persons he may meet, and not be struck with the astonishing fact that although no two are alike, there is a characteristic type underlying the whole of them. Variation is limited by this force of heredity. Just imagine, then, how many millions of years were needed to bring about the

* I have discussed this question further under Variation. 
myriads of modifications we see in the whole of the animal and vegetable worlds!

We find, too, that certain parts of organisms have on them the stamp of persistent heredity, while other parts have varied without end. Take, for instance, the seven cervical vertebræ, which run through the whole of the mammal series with but trifling exceptions, while other parts have raried immensely.

The column of a large section of orchids, combining the male and female apparatus, has persisted hand in hand with innumerable variations in other parts. The leaf and flower of the genus citrus have changed little, excepting in [size, while the fruit has varied very much. So of many other plants. The leaf of Phonogams, although it has undergone modification without end, has, nevertheless, persisted in an extraordinary manner, as far as its position on the so-called stem is concerned. Galton calls the persistent cause, "family likeness," and its opposite, "individual variation." He exemplifies these two factors by two miniature gardens full of plants, giving rise to other miniature gardens by the scattering of seeds from the first two. It would be next to impossible to have the infant gardens exactly like the parent gardens, for the different proportions of seeds would give rise to variation in the general feature, although each infant "garden might comprise all the species of the parent gardens.

This, however, does not seem very different frcm Darwin's Pangenesis, if we replace plants by germs. Indeed, the largeness or sinallness of the elements makes little difference, when the whole process is an imaginary one.

Now, in addition to all these factors of modification, with their restraining heredity, there are two others which, in my opinion, have largely influenced the production of the vegetable forms we see. These factors are fusion and fission.

\section{Fusiox.}

The modifications produced by fusion must have been rast, although perhaps not sufficiently recognized. Passing over the innumerable cohesions of carpels, stamens, petals, sepals, leaves, \&c., we find that two separate ovaries may fuse into one, forming a larger ovary. This, we find, is not an uncommon occurrence in the citrus genus, where two ovaries amalgamate and are enclosed 
in one continuous and common peel. It is not improbable that many of the large forms of citrus were orginally so produced. At all events, there is sufficient evidence to justify such an inference. The phenomenon of growing together (fusion) of two or more distinct parts, and so forming an amalgated whole has been, I believe, of greater frequency and of more importance in creating modifications than may hare been suspected.* Of course, we may not believe that the peel and the pulp of the citrus are two separate whorls fused together. It is a rery natural disbelief. Have we, howerer, nothing analogous to this supposed fusion of two whorls in other plants?

Take for instance the lily and the amaryllis, they are very closely allied by derivation, yet apparently very distinct by virtue of the superior ovary in the one and the inferior ovary in the other. But is not the amaryllis ovary a superior one, with the base of the petals fused to it, thus becoming what is called an inferior orary. On the other hand may not the orary of the lily be considered an inferior orary released from the adhesion of the base of the petals. Take the hyacinth, its ovary is at the bottom of a tube, but not adherent to it. How easy it would be for the tube to adhere to the ovary and thus form an inferior ovary.

The cultivated tomato is especially subject to fusion of two or more oraries, indeed in former days it was rare to find a tomato which was not the result of fusion, unless the exception had been

* I have a suspicion that the origin of the symmetrical bodies of vertebrate and articulate animals may have been the fusion of two unsymmetrical indiriduals, such as we see them in certain mollusca, for instance; and that, the double individual, if it could exist at all, might in time by selection become the symmetrical animal we see to-day. It is very strange that we should have a pair of almost every part; two brains, two lungs, two hearts, a liver, and a spleen, and that the large intestine should be divided into two parts by a suture. It is natural to suppose, from an evolutionary point of view, that this symmetry should have been initiated by a fusion of two unsymmetrical bodies. If two animals, which are already symmetrical, can fuse more or less into one body, as we very often see in newly born animals, it would appear as a possible phenomenon for two orules of an unsymmetrical animal to fuse and form a double and more symmetrical one. In the infinite number of experiments that nature may have perhaps made in this direction, one or more might have proved to be perfectly symmetrical, aud if this symmetry mere inherited, the foundation would have ;been laid for the almost perfect symmetry we see in the animals around us. Natural selection could be trusted, then to perfect that symmetry, and make it what it is to-day. 
brought about by selection. This result of fusion is particularly inheritable in the tomato, as I suspect it is in the corolla of the auricula. Experiments on the tomato ought to yield interesting results, for not only do its ovaries readily fuse, but the number of carpels are readily reduced to five, three, and two.

I have before me a bunch of "forget-me-nots." Almost every flower open is a fusion of two flowers. It is rare to find a normal one with five petals. The rule is seren, eight, nine, and sometimes ten petals, with a corresponding number of stamens and sepals; the carpels are sometimes a fusion of two ovaries and sometimes apparently only one ovary is present. The shape of the flower has consequently changed from a circular to an oval one. This fusion is evidently inheritable in this rariety.

At the meeting of the Royal Horticultural Society on the 12th May 1891, I saw a yellow tulip ticketed "Sylvestris," which evidently was the fusion of two flowers. It had five outer petals, five inner ones alternating with the former, nine stamens, two of which had their filaments fused into a broad one, and an ovary consisting of four carpels, instead of the usual three.

Another tulip, of the bizarre rariety, had seven petals, nine stamens, and four stigmas. This was evidently a fusion of two flowers. What is curious in these fusions is that petals aggregate with petals, stamens with stamens, and carpels with carpels. One would expect a confusion of parts. This may sometimes occur in the first instance, but the seedlings of such fusions* would tend to have their parts re-arranged, so that different parts of the flower become associated with their like, and thus form whorls consisting of more units than each of their component flowers. Anemone decapetala may only be the result of fusion of two pentapetalous anemones.

On another occasion I saw a daffodil with eight petals and a large crown, consisting of more than six lobes and eight stamens. 'This was evidently a fusion of two flowers, and inheritalle, as the owner told me he had many of them.

I do not think growers sufficiently appreciate these so-called monstrous forms. There may be a lingering notion in their minds that they are monsters, and therefore unholy. Be it said once for

* When I say seedlings, I include any possible seedling, resulting from the transfer of pollen of these to other stigmas. 
all, that monsters are undoubtedly the basis and genesis of many variations in nature, and therefore ought to be made use of for the creation of similar variations in art. A symmetrical monster may be far more fascinating than an unsymmetrical orthodoxy.

There is nothing more insensate, I think, and wasteful than the eradication and destruction of every so-called monstrous form, which does not exactly come up to our ideal of what might be called "tailored" flowers. Monsters are eridently inheritable, and therefore reproducible; they would teach us a great deal about the methods of creation and would gire us additional, and often acceptable, and interesting rariations.

Then there are the Hyosciamus niger, the Mespilus Germanica, and all the Pomacex, the composition of the fruit of which might be considered as a calyx whorl adherent to, or fused to the orary whorl.

I know that there is another way of interpreting the fruit of the Pomacex, viz., that it consists of a carpel whorl engulfed in the bark or calyx tube, while the divisions of the calyx surround the orifice of this fig-like tube.

The rose-hip is a fig-like receptacle, containing akenes, or female florets only, while the stamens, which represent the male florets, are arranged round the orifice, as in some figs. The bracts which close the orifice of the fig are here represented by the rose sepals and petals.

Howerer we may interpret the fruit of the roses and apples, there is an erident fusion of the tube or base of the sepals with the carpels.

Then what is fusion of parts? It is the adhesion or agglutination, or union of contiguous parts. As two ovules can fuse into one body, so two contiguous closely packed parts may fuse into one, more especially if their contiguous surfaces are not hairy. In grafting and budding the scion fuses so completely with the stock as to become often indistinguishable from it.

There is evidence that this phenomenon of fusion has played a large part in the modification of plants. Take, for instance, the crown of the narcissus, it is eridently the fusion of an inner whorl of petals into a cup or tube. I beliere these are not considered worthy of being called petals, but simply appendages, having an origin homologous to the fringes in the throat of the Hippeastrum. Nevertheless, when the narcissus flower doubles, the crown often 
splits up into its component parts, which are indistinguishable from the petals proper. This occurs markedly in "Telamonius plenus."

I think we can trace the genesis of the narcissus crown. The "forget-me-not" at the base of each petal and forming a circle round the throat of the flower, has a two-lobed nipple. Sometimes two adjacent nipples fuse into a broader one. Some varieties of Primula polyanthus have a diminutive lobed crown at their throat. The Hippeastrum, as I said, has fringed appendages in its throat; all these by modification and selection might be coaxed into small crowns similar to that of "Narcissus poeticus," and others, which hare very small crowns. Compare the crown of the latter with that of the "Glory of Leyden."

Then the crown of Eucharis, Pancratium, and others, may be formed by the fusion of the stipule-like appendages of the stamens. They are not only stipule-like, but probably are the homologues of stipules, for we have no right to suppose that, because a leaf has been transformed into a stamen it has lost all power of reproducing stipules. Stamens with stipule-like appendages are found in many plants of various affinities, and they are almost a copy of the stipules of the leaf of Brayera Abyssinica. In Eucharis and Pancratium it appears that the fusion of the margins of the staminal stipules makes a continuous crown.

Flowers with many petals and many stamens may have originated from the fusion of two or more flowers, consisting of a much smaller number of segments. The eight-petalled daffodil, the tenpetalled tulip, the nine or ten-petalled "forget-me-not" are examples of what can happen, and broad hints of what may hare happened during the long ages and processes of Creation.

Among the Rosacex, for instance, we have plants with flowers containing only one akene and four stamens, as in Alchemilla, or two akenes and fire stamens, as in Agrimonia. If two flowers of these fused, and by doubling the carpels and stamens formed a symmetrical flower, we would hare one with two akenes and eight stamens, and another with four akenes and ten stamens. If this doubling happened to go on now and again through the millions of generations that hare passed orer plants, from Alga to the higher Phœnogams, it is quite conceivable that we might ultimately obtain a rose, a strawberry, or a raspberry, with an indefinite number of akenes and stamens. 
Again, in the Papareraceæ, we have species with an ovary consisting of two carpels, such as Glaucium, while in Papaver somniferum we have an ovary with a multitude of carpels fused into one large head. It is quite conceivable that this head may hare originated by repeated fusions of simpler ovaries.

If you glance over a number of flowers of Papaver nudicaule, you will find the ovary with stigmas, varying from five to ten, while curiously enough the petals are rarely more than four.

In the Ranunculacex we have a similar state of things. There are species with two or three carpels, and others, as in Ranunculus, Anemone, Trolius, \&c., with a multitude of carpels, which might bave easily arisen by fusion of flowers with a simpler structure.

The same might be said of the Anonacer, Dilleniacec, and a number of others.

It is enough to glance at the figure of Sharpless' seedling strawberry giren in the Gardeners' Chronicle of 12th July 1890, p. 43 , to be convinced that its calyx is made up of a large number of sepals, which do not normally belong to the wild strawberry. The latter has five large sepals, with five intermediete smaller ones. And this seedling strawberry, in its calyx and receptacle, undoubtedly gires indication of being a fusion of many flowers.*

In the Composita we have Lactuca muralis (Fresem). It is composed of a very small number of ligulate florets, without any disk florets. It is quite conceivable that a fusion of such minute heads, in course of generations, would produce the head of a Sonchus, Taraxacum, or other similar composites, which have many whorls of ligulate florets, and no disk.

It is also conceirable that the genesis of the disk of composite flowers may have come about by fusion after fusion of ligulate capitula, the florets of the central portion becoming regular and dwarfed for want of space, while those of the ray retained their irregular ligulate corolla.

Under cultivation and luxuriant growth, as in the Pyrethrum, the disk florets enlarge and produce what are called double forms. The double Zinnia and double Dahlia are remarkable cases of reversion of the disk florets to the ligulate form.

* The strawberries Auguste Nicaise and Sir Charles Napier bear distinct evidence of the fusion of two or more receptacles. 
The reader might ask-how is it that, when two separate flowers fuse, all their parts do not exactly double?

There may be various reasons for this: but

(a) As a matter of fact we know that when two flowers fuse, this multiplication by two of all the parts of the component flowers rarely happens. They do not always double their parts all along the line. Sometimes they do, but oftener there is some suppression of parts.

(b) The sepals and petals are comparatively of little importance to the individual, and therefore, in the struggle for life, many of these parts may disappear altogether, without affecting the fertilization and the maturation of the seed.

(c) Want of space and sustenance may be two great reasons why, in fusing, certain parts are suppressed, and this may not impossibly be one of the reasons why, in crossing certain flowers, the seedlings produce occasional double flowers. The doubling may be a reproduction of the petals suppressed by the act of fusion in some ancestral form, and kept dormant by heredity until disturbed by crossing and pushed forth again by luxuriant cultivation.

What determines the complete doubling of all parts, or the doubling of some parts and not of others, or the amalgamation of some parts of the one and the whole of the other, or the symmetry of disposition of the various parts, is more than I can say. All that can be said is that flowers do fuse, and that the resulting. amalgamation may be the exact double or not; and that such fusions may have been important factors in the modification of plants belonging to the same alliance.

Look at Diplolena Dampieri (Rutacer). To my mind its inflorescence gires distinct evidence that it originated in a fusion of a number of single flowers; or it may be that it was originally a capitulum, and in other genera is split up into a raceme, and Diplolæna has remained as a relic.

In Diplolaena a large number of bracts, forming an involucre, and representing probably the fusion of the original calyces, enclose a crowd of stamens. This is what Baillon says of it:"Its inflorescence recalls a veritable composite capitulum; the floters have no calyx, are sessile, and crowded together on a plane surface, and enclosed in an involncre formed of a large number of imbricated bracts."

$\triangle$ p.1742.

E 
I would ask "Why have the flowers no calyx ?" The reply is, because all the calyces have become fused into a common involucre.

Two stems of hyacinth growing close to each other may, in their very young and soft stage, become fasciated into one. Two hyacinth corollas may become fused into one. Two lemon ovaries may similarly be fused into one larger and more complex ovary, while the peel is one, which encloses both ovaries.

Dr. Masters* says :- "It is certain that many of the recorded instances of increased number in the organs of a flower are really the result of fusion of two or more flowers, though frequently in the adult state, but few traces of coalescence are to be seen." $\uparrow$

Who can tell how many wild flowers have owed their present form to a fusion of two or more flowers, containing a smaller number of segments. Subsequent inheritance and selection may have so trimmed them as to leare no trace of their origin. I feel convinced that many of the larger varieties of Citrus have been brought about by the fusion of two ovaries, having one common peel. Their present spherical form, without any trace of the fusion, may then have been brought about by inheritance, through the seed, and further changed by human selection from a fruit with an oval section to one with a perfectly circular section. $\neq$

The multiplication of teratological specimens, in which fusion of parts or whole branches has occurred, will soon convince us that this factor in the production of species is likely to have been an important one.

Prof. Henslow ("Orig. of Fl. Struct.") says :- "A single coincidence has little or no scientific weight, as indicating cause and effect. It is only when coincidences can be multiplied that they furnish a probability of a high order, which, even if they do not admit of a verifiable experiment, still furnish a moral conviction, which, by the rules of philosophy, is equivalent to a demonstration."

* “Teg. Teratology," p. 363.

$\dagger$ This fact so plainly stated appears to have been insufficiently considered in studying the evolution of species and genera.

¥ In the animal kingdom we have something similar to two lemons becoming enveloped in one skin, for in the paddle of the seal, we have all the digits enveloped in a common bag-like skin. 
That fusion is an important factor of variation in nature could, I think, be easily verifiable. It is certain that many of the large-flowered Auriculas exhibited are a congenital fusion of two, with a smaller number of parts. This ought to be verifiable where so many Auriculas are raised from seed, which are the result of crossings. We would then have moral conviction made certain by verification.

What we have to do is to leave dogmas to the one side, and "look at facts straight in the face, and find out what they mean."

The fusion of cell to cell, hair to hair, leaf to leaf, bud to bud, petal to petal, flower to flower, ovary to ovary, has, there can be little doubt, been one great factor in the modification of plants throughout nature.

Indeed, it seems possible that this same phenomenon of fusion may help us to explain other more recondite phenomena.

If two monads of great microscopical minuteness can fuse to form a larger monad, with the germs of each intermixed in the fused bigger monad, there appears no good reason to deny the possibility of some of the germs fusing also. Dallinger and Drysdale have not seen any of the germs fuse, but they have seen the parent monads, presumably male and female, fuse. The fusion of two germs, one from the mother and one from the father, would naturally develop a combination of features in the progeny, while those that remained unfused, would derelop features of either the one or the other parent. We know that two ovules can fuse; that, as a matter of fact, two microscopic monads have been seen to fuse; we have therefore to extend, in imagination, this phenomenon to the germs of monads. It requires only an extension of inference.

I have made a series of observations on a single variety of crimson Pyrethrum, which are very suggestive and instructive. I shall place rough drawings of the phenomena observed before the reader, so that he may see how easy it may have been for species with small capitula to have originated, through fusion, species, with larger and larger capitula." There is no good reason to suppose that a large sunflower, could not have been produced from a flower as small as the common daisy, or as small as that of

* Vide Dr. Masters "Veg. Teratology," p. 38. 
Achillea, simply by fusion after fusion through countless generations.

Fig. 1 shows two capitula of Pyrethrum fused only by their peduncles, the flower heads remaining separate. Each of the disks has a dimple in its centre.

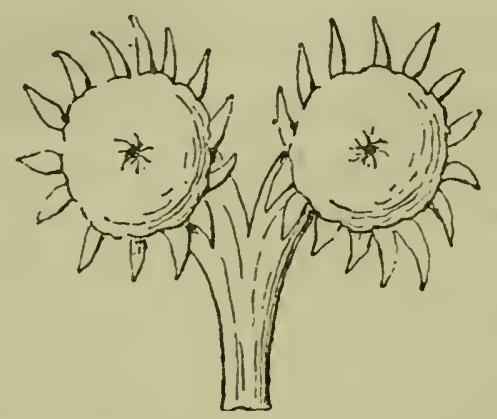

Fig. 1. Incomplete fusion of two circular Pyrethrums (shown in plan).

Fig. 2 shows the complete fusion of two capitula; with the ray florets irregularly disposed, and the disk florets fused into an oblong mass. The line in the middle indicates a depression between the two dimples.

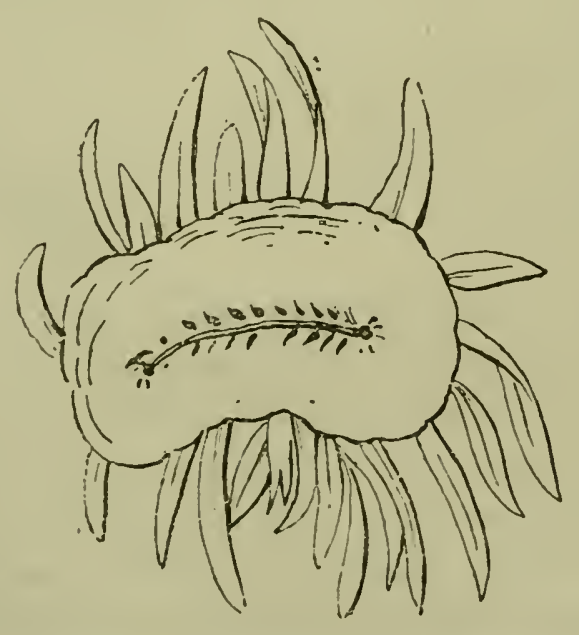

Fig. 2. Complete fusion of two heads, producing an oval disk (shown in plan). 
Fig. 3 shows two heads (which are themselves originally the result of fusion), fusing into a more elongated head, so as to resemble the crest of a cockscomb amaranth. The line of junction of the two disks is traceable in this case.

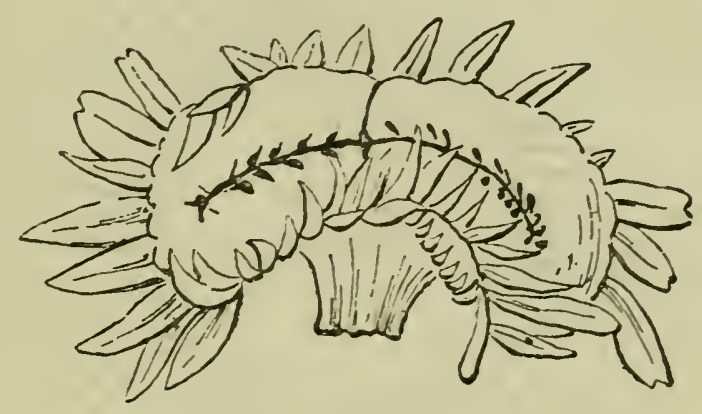

Fig. 3. Fusion of two already fused capitula $=$ four heads.

Then Fig. 4 shows a still more elongated head, the fusion of two, which may have been already fused many times over. Both the peduncle and the disk show the line of junction.

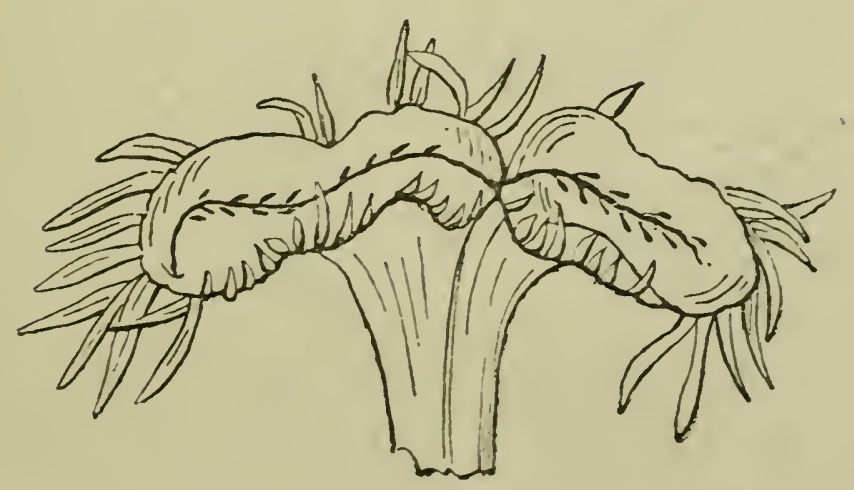

Fig. 4. A fusion of fused heac's, l roducing a rery elongated disk. 
Fig. 5 shows a large flower which, by its elongated dimple is clearly the result of previous fusions, but which is gradually altering to a circular form.

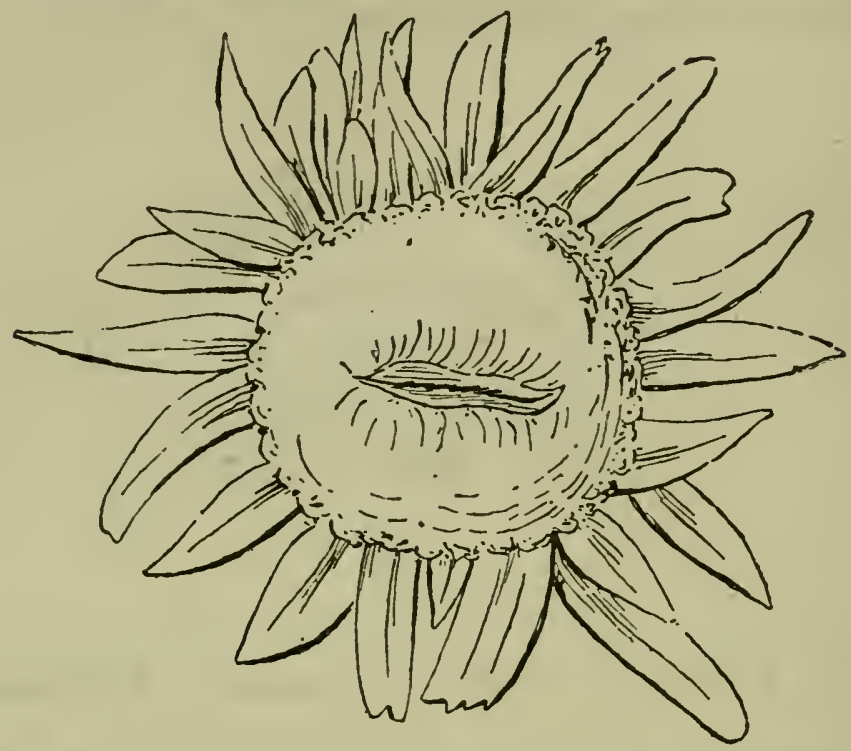

Fig. 5. Large Pyretheum flower, with elongated dimple.

Finally, Fig. 6 shows a large circular Pyrethrum, with a perfect circle of ray florets, and a circular disk with a dimple in its centre.*

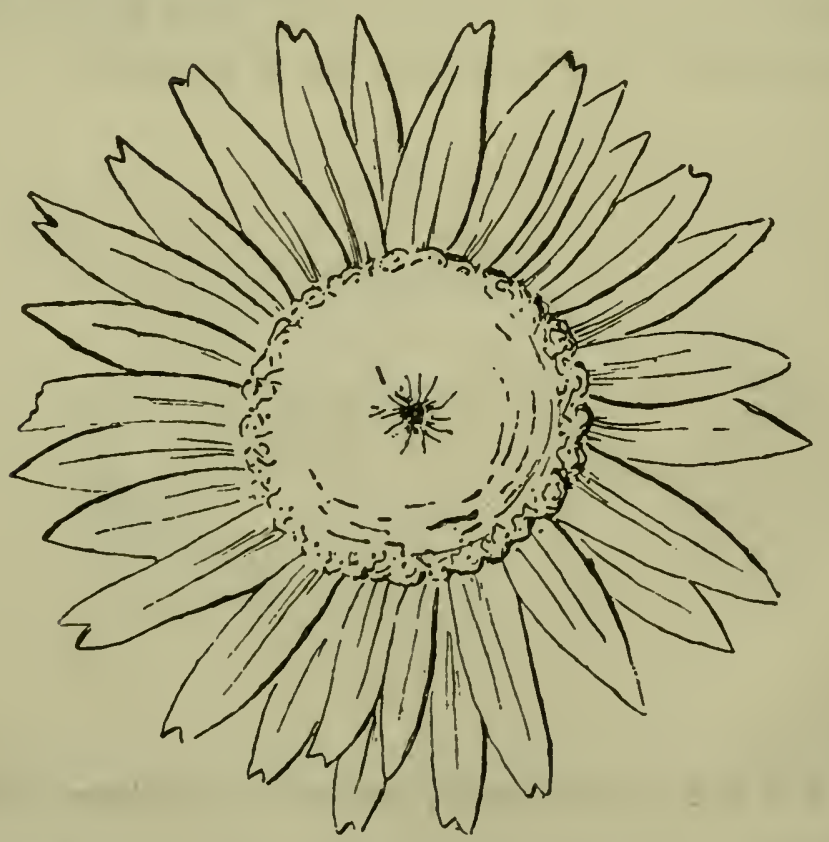

Fig. 6. Disk become wholly circular after fusion, with a round dimple in the centre.

* This is the finished flower, the result of ancestral amalgamations. 
It is evident that, once a fusion of two or more capitula has occurred, producing an elongated capitulum, by degrees and through subsequent generations, it can be changed into a perfect daisy-like larger capitulum. That is, out of a monstrous head, a regular and circularly symmetrical head of florets can, by degrees, and through many generations, be produced.

Several other composites are liable to fusion. When one begins to search for traces of fusion of whole flowers, or of other parts of plants, one begins to find them in abundance, as factors of modification.

Fig. 7 shows a fusion of the pale yellow Marguerite of the shops; and Fig. 8 shows a more complicated fusion of three

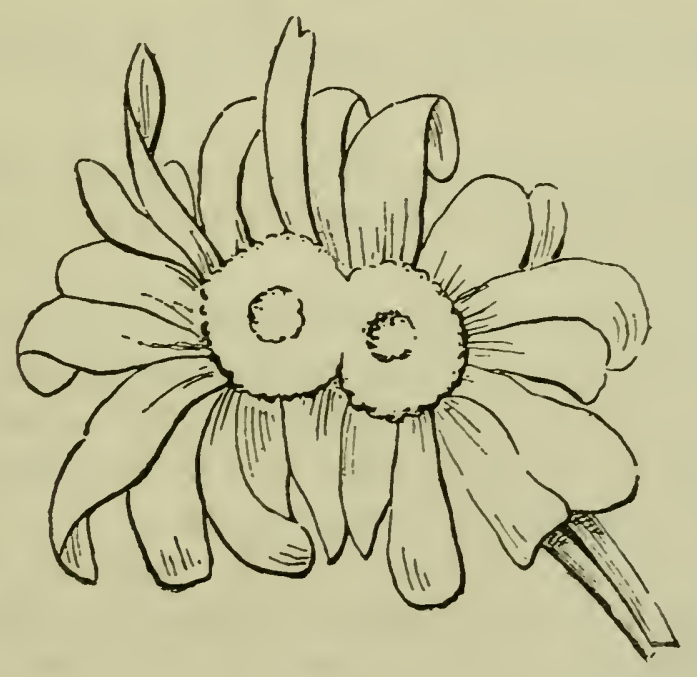

Fig. 7. Fusion of two heads of pale yellow Marguerite.

capitula. The seedings of this, if any of them inherited this fused form, would naturally take many more generations to right themselves, that is, to become circular. Each fusion would add size to the combined head.

I have noticed signs of fusion in another composite-Hieraceum Aurantiacum. 


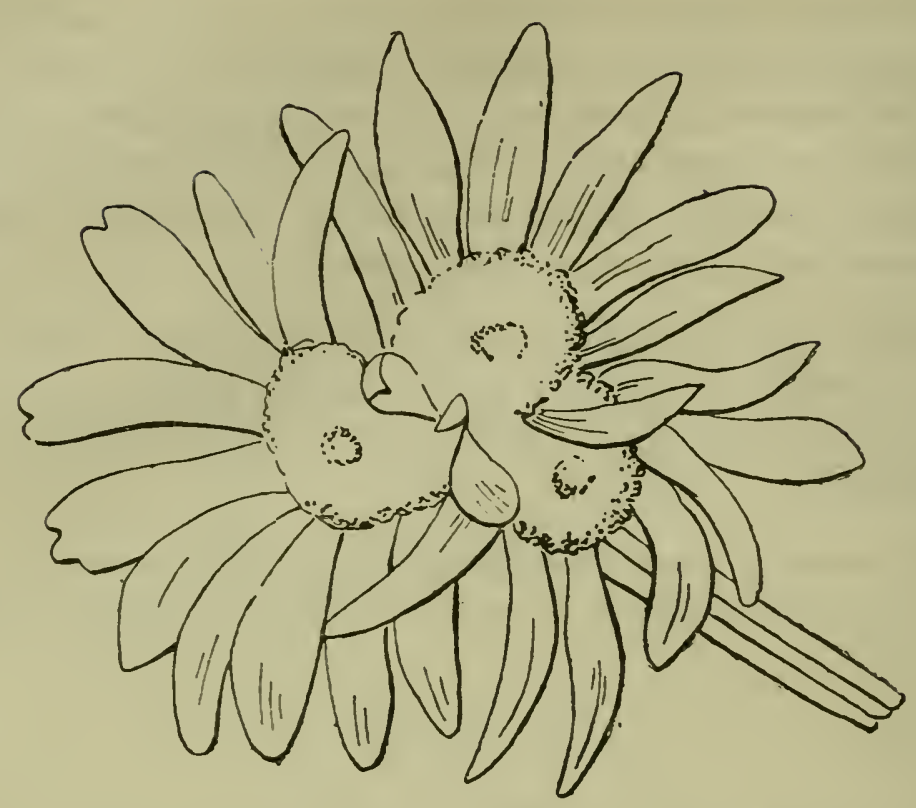

Fig. 8. Fusion of three heads of pale yellow Marguerite.

Mr. J. Kelway, junr., has sent me a series of similar transformations in Chrysanthemum lacustre, a hardy perennial.

It consisted of :-

(a.) Two fasciated stems, with the capitula back to back. The ray of each was complete, and the disk quite separate;

(3.) Two fasciated stems and two capitula as above, but the disks ran into each other by a narrow bridge; orer the bridge the ray florets were absent;

(c.) All the parts as above, with the exception that the two disks were fused into an oblong disk forming a sort of saddle, the involucres and the rays being continuous all round the margin of the saddle.

A further modification would be one oblong capitulum, the seeds of which would tend to produce more and more circular capitula, till a large, but perfectly regular head resulted.

In one of the London shops I found that the Michaelmas laisy (Erigeron) is rery subject to similar fusions. One head was the fusion of three, and almost every flower on a large branch bore traces of duplicity.

I lave noticed that the central flower, in two species of Sedum was the fusion of two. 
Although fusion of two or more capitula is so common in many cultivated composites, I have been unable to trace this mode of modification in wild composites.

In Perth, along the road sides, where the large white Marguerite (probably Chrysanthemum leucanthennum of Syme) was very plentiful, I searched in vain for traces of fusion in the capitula. Every flower was perfectly circular.

Again, on an extensive lawn, which in winter is turned into a skating pond, there was an immense number of another white Marguerite (probably Chrysanthemum inodorum of Syme). Among these I also failed to find traces of duplicity. Nor have I been able to find traces of this mode of modification in the composites grown in the herbaceous plot in the Royal Gardens at Kew. Presumably most of them are wild species, although not under the same unrestricted competitive conditions of composites growing in a state of nature.

It does not follow, howerer, that because one has not been able to discover such modifications in a cursory inspection of wild and semi-wild composites that, therefore, they never occur. The reason may perhaps be starration, from close competition with selfs, and other plants.

I have entered a little more fully into this point further on, but must leave its further investigation for some future occasion.

With regard to the cultirated Pyrethrum, which has given rise to such a large number of fine varieties, it is not difficult to imagine its genesis from the wild $P$. firutescens, with a very small disk and a small ray, through this process of fusion. Indeed, the genesis of the wild $P$. fintescens itself is not difficult to imagine, as resulting from a fusion of the still more diminutive capitula of Achillea, more especially as there is one species of Pyrethrum called Achillecefolium. The leaves of the cultivated Pyrethrum seem nearer to those of some species of Achillea than to the leares of the wild $P$. frutesi'tns.

Senecio Doria is described by Mr. G. Nicholson as having "five or six ray florets," but I have seen at the Royal Kew Gardens a whole plant, the flowers of which had either no ray florets, or either one, or two, or three, or four, or five ligulate florets, where the ray ought to be. Its character was irregularity of the ray florets. One can easily imagine that the fusion of several of these might in time produce the regular and larger heads, say of 
S. pulcher. Indeed, one can imagine the whole corymb of small capitula transformed through this process into one large capitulum.

Senecio Doria, as I saw it at Kew, appeared to me as if it might be considered a link between the non-ligulate composites, that is, those without ray florets, such as groundsel, and Cacalia, and those composites which are furnished with a ray. The common groundsel itself, according to Syme, has two varieties, one with and one without the ray florets.

Nothing, perhaps, would be more interesting than to gather all, or as many as possible, of the British composite plants and study them from an evolutionary point of view.

No doubt in fusing, some of the ray florets may be suppressed, or squeezed out of existence, for the ray of two fused heads has often little more ray florets' than the one head, although those of the disk may be almost doubled, or there may be two rows of ray florets, as I have seen in several duplicated capitula of Erigeron.

It may be naturally asked, "How is an elongated disk of two fused Pyrethrums, with a line for its dimple, changed into a circular disk, with a round dimple in its centre, and without any trace of its having been the result of a fusion of two or more heads?

The phenomenon of conversion from the oval to the circular form would appear somewhat puzzling; but a little consideration will show us that the force which effects the conversion is of a polar nature, or the same as that of gravitation.

Of course the individual oval head is never changed into a circular head. It produces seeds which result in flower heads, which are more and more circular each generation, until the ovality is entirely extinguished.

The circularity is shaped by polar force, or force of gravity, while the head is still in a "fluid" cellular stage. The same force which makes a liquid suspended in the air, or in space, take the globular form, will make the unformed oval flower head, take on by degrees and through several generations the circular and perfect shape. The parts, when free to move, aggregate round a common centre, which is afterwards indicated by the central dimple. That is, the disk and ray in composite flowers, when they are still cellular and unformed, tend to arrange themselves round a common centre, and thus produce a circular capitulum. 
However distorted a form the fusion of composite heads may at first produce, its seedlings will tend gradually, and generation after generation, to reproduce the circular form.

Similarly, two fused oranges or lemons will eventually produce, through the seed, a perfectly globular though larger form.

Then we may look upon it as pretty well proved that monstrous forms, which occasionally occur in plants under cultivation, and are thrown away as unholy, may, in a state of nature, have laid the foundation of new varieties and species on monstrous lines!

There is no such thing in nature as an abnormality. The apparent abnormality is as normal a phenomenon, as what we call a normality. We may as well call a planet abnormal, because it has one satellite, or because it has none, or more than one!

The question remains, why are all wild Composites circular in form, whether the flower heads are small or large?

First.- We do not know that oral forms do not now and then occur in the wild state. They may, if erer met with, hare been orerlooked as monstrous. Second.-Fusion under cultivation occurs associated with luxuriance, and luxuriance in a wild state can rarely occur where seeds are scattered without number, and the resulting seedlings have to struggle for their life with each other and with other plants. Consequently they are starred, and that luxuriance which tends to fusion is generally absent.

If by chance a seedling were to fall on very farourable soil, and be surrounded by rery farourable conditions, fusion would not occur of a sudden, because heredity would oppose it. If fusion did, by some chance, occur under such circumstances, every trace of it might be extinguished, in a certain number of generations, by the polar force, to which I have just alluded, and which is always acting, if unopposed by some stronger force, such as that of heredity.

Whaterer the reason may be, I think that this phenomenon of fusion may help us to conceive how composites with small capitula can erolve others with larger and larger capitula ; and in it we have eridence that sexual conjugation is not the only source of variation.

The fusion of stems in the cockscomb is very instructive. It shows that stems originally terete and slender can be kneaded into a flat blade, without any trace of its component stems. The 
united apices of the stems instead of showing distinct points, show only one continuous frilled edge.

The axillæ of the lower leares (bracts) of the comb are furnished each with a flower. Higher up the flowers are suppressed, and the leares become dwarfer and dwarfer till along the margin of the comb they are nothing but hairs. This shows us how easy the leaf passes through rarious atrophied stages into that of a hair, and may be erentually totally suppressed.

By studying the cockscomb we can see in imagination seaweeds consisting only of filaments, turning into blades through this process of fusion, and we can see how an important and very prominent organ can be dwarfed into a mere unimportant remnant such as a hair, after passing through some millions of generations, and after changing its whole character, so as no longer to be recognized as the same species or eren genus.

We see fusion, as a modifier of forms in the leares of the Iris, Gladiclus, and similar plants. Iris Sindjarensis has leaves of the ordinary kind, with a blade on each side of the mid-rib, thus giving an upper, and a lower surface. While the leaf of the ordinary Iris, Gladiolus, Ixia, \&c., is sword shaped. This form has been probably brought about by the cohesion and fusion of the upper surfaces of the two side blades, just as the two leares of a book might cohere. By this fusion the mid-rib would become the outer margin of the sword-like leares, now depauperized, while the inner margin is made up of the agglutinated free margins of the side blades.

This transformation will be better understood by noting the the difference between the leaf and the spathe of a Cattleya. In this orchid, the leaf is like that of Iris Sindjarensis, while the spathe is sword-shaped, like the leaf of Iris Germanica, Gladiolus, \&c.

From this we can understand how it is possible for the hollow leaf of the Sarracenia to have been brought about. The leaf may have been duplicated and become fused by its margins, only to a certain extent, leaving the rest tubular. It is conceirable that the tube is only a bladdered mid-rib, but the margin in the middle of the tube is suspicious, and with evidence of the leaf of one Iris changing into that of another, we may be justified in considering the genesis of the Sarracenia leaf, as similar to that of the Gladislus, \&c. 
The pitcher of Nepenthes may possibly be explained by a somewhat similar process. We have an ordinary leaf, changing further towards its extremity, into a simple mid-rib, and finally again developing a blade fused by its margin into a tube.

I know that some have considered the pitcher as a transformed water-gland, at the tip of the leaf, but the two toothed margins or wings of the pitcher are to my mind indications of imperfectly fused leaf margins.

The lid of the pitcher does not appear to be the terminal leaflet. That is represented by a mucro, behind the lid. The lid of Nepenthes Rafflesiana is bilobed, and gires indication of a fusion of two parts. It may represent the fusion of two leaflets, learing the mucro, or the end of a mid-rib projecting behind them.

The morphology of the leares of Sarracenia and Nepenthes are not easy to make ont, and any new idea, aided by some teratological specimen, may help on a better conception of the development of these strange leaves.

It is erident that the lower sepal of Cypripedium and Selenipedium is made up of the fusion of two sepals. In Cypripedium spectabile I have noticed that some specimens had the lower sepal with two teeth, indicating its origin. It is curious that this fusion, like that of the sexual organs, should be so persistently inherited.

There are in almost every direction, indications of fusion having been a great factor in modifying plants.

$\mathrm{Up}$ to recently, garden varieties were considered ralueless for botanical studies, but whether we call them garden rarieties, or field varieties, or prairie and mountain varieties, they come within the scope of Biology, and as such, they are not only interesting and very instructive, but from an evolutionary point of view very important.

\section{Transposition of Segarents.}

There is another factor which must have been a great modifier of the forms of flowers. I mean transposition of floral whorls, in what is called the perianth of Endogens. Botanists often call the outer segments sepals, and the inner ones petals, and Lindley gives them this appellation, in describing orchids. Now, I maintain that these two whorls are sometimes inter-changeable, 
that is, the inner becomes the outer whorl. I shall proceed to develop this idea further, with the hope of proving that this transposition must have been one of the factors in modifying the forms of flowers, independent of any other factors.

Some of these endogens have three of their segments with distinctive marks, and in the Iris, it is the three segments of the outer whorl (falls) which are marked. Of course the Iris flower has become so modified, both in its outer and inner whorls, and also in its styles, that it posesses a distinct and characteristic feature. But in Iris Robinsoniana we have all the six segments lying on one level, the three outer, ones or sepals, being marked with a yellow crescent.

Now in Calochortus, it is the inner segments (what might correspond to the standards in the Iris), which are the marked ones. By what magic has this shifting been brought about? My reply is that at a certain stage in the evolution of these plants, the inner whorl of the ancestor of Calochortus, became the outer whorl of the ancestor of Iris.

The reader may say that these two plants are so totally distinct,* that he cannot believe that the petals of Calochortus are homologues of the sepals of Iris.

Well then I shall take two other flowers, belonging to the same order, the Orchidacex, $\dagger$ and see if any transposition of whorls can be traced.

Disa grandiflora has a large upper sepal shaped like a pointed coal-scoop, with a short spur, and beautifully veined; the lower sepals are two large brilliantly coloured wings. These are the three sepals. Then of the three petals, the upper two are small, spotted, and embrace the column, which, with the two petals, is ensconced in the large spurred sepal, while the lower petal is a dwarfed and insignificant strip.

Now Angracum leonis has its modified segment uppermost, $\ddagger$ as in Disa grandiflora, but it is one of the petals that is spurred,

* Calochortus is classed among Liliacea, and Iris among Iridacea.

f It should be noted that Lindley's view was that Lilyworts approach so closely to Amaryllids that "there is perhaps nothing to separate them except the free ovary of the one, and the inferior ovary of the other!""Veg. Kingd.," p. 202.

I It matters little how the modified segment became uppermost or lowermost. 
a segment of the inner whorl, and not of the outer whorl, as in Disa.

Therefore by transposition of the petals of Angracum into sepals, we may obtain a Disa. But the reader might say, is it conceivable that the two petals of Disa which are enclosed in its scooped sepal can be made to become exterior? Quite conceivable. The reader should, however, note that I said an Angræcum might easily become $a$ Disa, and not D. grandiflora; for if he will take the trouble to look up Disa Macrantha, he will find it has the following structure:-three sepals, the upper one of which is large, like a cowl with a long spur, and that the two upper petals are not ensconced in the cowl. It would therefore seem that when the flower is in lud, and the segments in the stage of nipples, nothing would be easier than a transposition of petals into sepals, in growing, and the modification of an Angræcum into a Disa.

I am aware that in Disa spathulata, opposed to the spurred cowl, there is a much modified petal, which may represent the labellum of other orchids, but it is the spurred segment of these orchids which appears to me to be the morphological homologue in both. In the one case it is called a petal, in the other it is called a sepal.

I have elsewhere* shown that a spur can be formed all of a sudden, without being inherited, but when once formed we cannot avoid taking into consideration the fact that it is more readily inherited than newly formed.

Here, then, I think, we have two genera which are almost interchangeable by the mere transposition (when in bud), of inner into outer segments, or vice vers $\hat{a}$, and I should not be at all surprised to hear that Disa and Angrecum would inter-breed, more especially as the Messrs. Veitch have been so successful in breaking down anatomical genera into physiological varieties.

I have in store, however, better proof than all I have adduced in support of my statement, viz., that transposition of petals to sepals is not only very probable, but that it does actually occur.

The hybrids of Gladiolus Gandavensis have exercised my thinking faculties for some time to account for a phenomenon that so frequently occurs among them. It is this: The Gladiolus is an irregular Irid, with three segments above and three below.

* See chapter on "Spurs." 
The latter are the marked segments. I have often obserred, and others have done so also, that on the same spike some of the flowers hare one labellum, and others two labella.*

No amount of twisting will account for this curious feature, for a twist would bring all the three marked petals uppermost, as we have them in the Hippeastrum. This never does occur; moreorer the stamens and style of the Gladiolus are never twisted, but are always arched under the upper one or two petals, as the case may be.

Transposition of whorls is what I wish to prove, and therefore I shall not discuss how the three lower segments of Gladiolus became the marked ones. Suffice it to note that, among the fine lot of Gladioli exhibited by Messrs. Kelway and Son at the meeting of the Royal Horticultural Society on the 25th August 1891, there were spikes which had an occasional regular or peloric flower, and one new variety more prominent than the rest $\dagger$ had all three inner segments marked. If in this regular Gladiolus the inner whorl were to become outer by transposition, we should have an Iris much like Robinsoniana.

Then how is it that in these hydrids two varieties of flower occur in the same spike? The solution of the puzzle is in the transposition of the outer to the inner whorl, and in no other way. The segments of the two whorls alternate, and it is plain that by transposition sometimes one and sometimes two segments will be the inner lower ones.

If the reader will consider that all the six segments of the Gladiolus are cellular nipples, when the flower is in its first formation in the bud, he will perceive how readily this transposition may occur by a mere infinitesimal displacement of the nipples. The reader might say, if this were possible it would surely sometimes occur that not all the three segments belonging to a whorl would be displaced at the same time. True, and this is exactly what sometimes occurs, for I have before me a Gladiolus flower with one of its segments neither in nor out, that is, one half of it belongs to the outer whorl and one half to the inner whorl! It is

* I call them labella for brevity sake; in the one case there is one lower and two upper inner segments; in the other there are two lower and one upper segment in the inner whorl.

† Called "Thales." 
in the same position that all the segments are, in the twisted corolla of the Apocinacex-it is imbricate.

There are other puzzles connected with the Gladiolus which await solution, viz., $(a$.) Why are the lower segments the marked ones, when, in the Iris and peloric Gladioli, the three segments of the same whorl are marked? (b.) What causes the exposed labellum or labella in the irregular Gladiolus to be more brilliantly coloured than the remaining two or one lower segments, as the case may be? (c.) Why are the three lower segments of the Gladiolus so often smaller than the three upper ones?

One might be tempter to reply to the latter question (c) by saying that this feature was inherited from some form like that of G. Namaquensis, G. Viperatıs, and others. But this explanation only calls forth another question-Why have these that feature? Therein lies puzzle $(c)$.

The lower petals are the landing place of insects that visit this flower for its nectar, and, according to Prof. Henslow's theory (if I read it rightly), the constant pressure of an insect will cause the part pressed to enlarge.* Just the reverse appears to be the case in these forms of Gladiolus! What other sufficient reason can be adduced for the reduction instead of the increase in size of these lower petals which form the landing place of insects? Were they large or small insects that produced this feature, or was the divarfing totally unconnected with insect action?

A few diagrams will explain the matter I have been endearouring to prove more readily than a whole chapter of words.
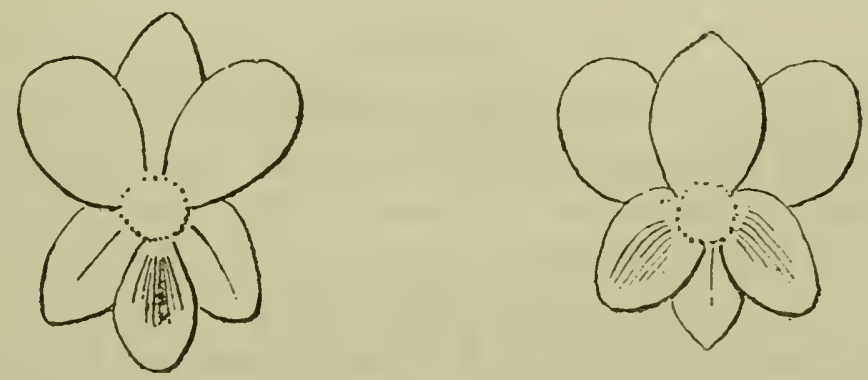

Form of Gladiolus with one labellum. Form of Gladiolus with two labella.

* Are not insects a part of the surroundings? If so, Prof. Henslow's theory admits that surroundings do tend to modify organisms, or at all events they tend to induce congenital mordifications.

A p. 1724. 


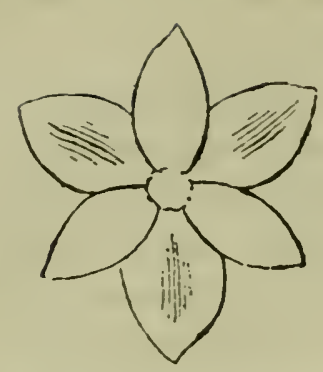

Diagram of the Iris, with the sepals (falls) marked.

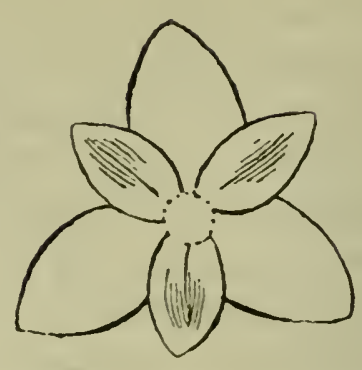

Diagram of a peloric Gladiolus with the petals (standards) marked.

Transposition of sepals into petals, while the segments are in bud as cellular nipples, will effect the transformation of an Iris into a Gladiolus.

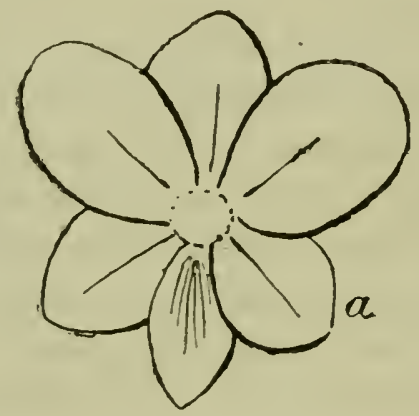

Form of Gladiolus in which the segment $(a)$ is neither a sepal nor a petal; half of it belongs to the sepal whorl, and half to the petal whorl.

\section{Fission.}

This is the opposite of fusion. But if, in the first instance, a fusion of two parts had occurred, and then a subsequent splitting up of that fusion, as in the case of the crown of Narcissus telamonius plemus, we would have to deal with what is called a reversion, or a return to some original form.

Prof. Henslow (" Origin of Floral Structures," Fig. 10) gives an interesting case of a Mimulus flower splitting up into a large number of separate petals, thus reducing it from a monopetalous to a polypetalous flower. 'The difficulty in such eases is to trace out which was the original, a polypetalous flower, reduced to monopetaly by fusion, or the reverse. Calystegia pubescens, flore 
pleno, shows a similar splitting up of the bell-shaped corollat of a Convolvulus.

Who can tell how often, in the history of the descent of a plant, its flower had been subjected to this opening and closing of its parts like the lamine of a fan, or the tail of a bird. 'The study of the different forms of leaves will leave little doubt that the morphology of an immense number is nothing but, either a fasciation of their veins by the mesophyl, or a splitting up of veins into separate leaflets by fission of the mesophyl. Entire and cut leaves, palmate, digitate, pinnate, bipinnate leaves, and so forth, can easily be explained by the fusion or fission of the veins which malie them up.

Fission has been also denoted by the names of chorisis, dialysis, and adesmy; while fusion has been ealled adhesion, cohesion, fasciation, synophty, synspermy, syncarpy, synanthy, ${ }^{*}$ and so forth. But these terms, invented by learned men, do not make the cause of fusion or fission a bit clearer. They only add to the trouble of the student.

Again, polymorphy, heteromorphy, heterophylly, and polyphylly are nothing but the result of either fission or fusion.

Whatever we may call them, there is little doubt that both these phenomena have been important factors in the modification of plants, although probably not so recognized. A modification, however originated, has only to be inherited to lead to further and further modifications and re-arrangement of parts.

\section{Suppression, Abortion, and Enlargenent.}

The abortion or dwarfing of certain parts of plants is a very common factor in the modification of plants, as also its reversethe enlargement of parts. Among the Papilionalcaa we find any number of examples, in which some parts of a flower are dwarfed, and others enlarged; so in many other orders.

The total suppression of parts is also a great factor in morlification. We have total suppression of petals, stamens, \&ce.

As an instance of gradual suppression in the parts of the same genus may be quoted that of Begonia.

* Yide Dr. Masters "Veg. Teratology." 
The female flowers have five petals, and most of the male flowers only four petals. In B. Knoulesyance I found a male flower with the rudiment of a fifth petal, indicating that the male flowers may at one time also have had five petals.*

Begonia metallica has male flowers with two large and two small petals. B. semperflorens has the same feature, but $B$. semperflorens gigantea has only two petals in its male flowers.

Here is a very distinct genus which may have had at one time both its male and female flowers five-petalled; it passes into a type, which now includes the majority of the species, with four petals in the male flower. Then two of these are dwarfed in some species, and erentually suppressed in others, so that now we have also types with two petals in the male flower.

Just the reverse of this of course may also have happened.

We have innumerable instances of dwarfing and total suppression of stipules, and enlargement of them in other cases. What are called stipels in leaves are only abortions of leaflets, as is clearly seen in Hardenbergia Comptoniana, where leaflets are often replaced by stipels, and vice versâ. In other cases stipules are only visible during the expansion of the bud. They drop off very early. In many cases this might be a stage prior to total suppression.

In the Cactacea, leares are reduced to mere apologies of such organs and drop off early, the stem enlarging and taking on the leaf-function. In some genera, the leaves, even in their dwarfed state, never appear. In flowering stems, leaves are dwarfed into bracts, and are often as minute as stipels.

Then we have an infinite variety of what are called teeth on the margins of all clescriptions of leaves, such as the teeth of roseleares, holly-leaves, agare-leares, aloe-leares, \&c., \&c. All these must hare had some common descent, that is, they must have all originated from homologous parts in some very distant ancestor. The thing is to find out what that ancestor was, and what these remnants could have originally meant.

In Nicholson's Dictionary of Gardening, under the heading of Teeth, the only definition I find is "any kind of small divisions." Naturally these teeth, like many other parts, are sometimes totally suppressed, and then we have what are called entive leaves.

* Begonia Socotrana has normally six segments in its female flower. 
Sometimes the mesophyl that fasciates the veins of leares and petals aborts, such as in the petals of Trichosanthes anguina, where the small petals are fringed with branched veins.

In Mussanda, however, one of the segments of the calyx is enormously enlarged, while the remaining segments are mere teeth. In "Jack-in-the-box" Polyanthus, we have all the segments of the calyx becoming ealarged, and taking on the character of leaves.

Modification of persistent organs, with altered function is another source of variation. Nany of the secreting organs of plants are simply modification of function.

Then we have the action of insects, birds, and animals, which are factors in modifying plants. Insects have perhaps had more influence in modifying flowers; birds in modifying fruits, and the large animals in modifying leaves and stems.

Prof. G. Henslow, in lis "Origin of Floral Structures," discusses the action of insects in distorting, amplifying, and hypertrophying the different parts of a flower in search of nectar, which is the only food of many species.

In Dr. Masters "Vegetable Teratology" will be found a rast array of what in olden times were considered monstrous forms of plants, but which now are beginning to be considered as possible origins of forms which are not usually called monstrous, but normal, owing to their persistence through whole genera.

The terms abortion, suppression, atrophy, diminution, duarfing, depauperation, degeneration, stasis, arrest of development, have all more or less the same meanings. They are terms invented to express different degrees of diminution-from simple reduction in size to total suppression, such as to leave no trace that any organ had existed there in any ancestral form.

We should look on the several parts of plants, both cellular and rascular, and the whole plant, as elastic bodies. Heredity is ever struggling with the variation caused by sexual reproduction, \&c. The former tends to keep things as they were; the latter is always tending to change them. Being elastic, so to speak, the parts of a plant, which are repeated through the fertilized seed, are ever having their equilibrium disturbed, and so we find some parts cnlarging, lengthening, or shortening, dwarfing, and entirely disappearing for a more or less long period. Adaptation to 
surroundings makes the change more or less permanent. So that in one instance we have the immense leaf of the Victoria regia, the Musa, \&c., while in the other, by almost a total abortion of the mesophyl, we have the leares of fennel, asparagus, and similar plants. In one instance we have a large corolla, in another it disappears. So of crery part, including the root, stem, leares, cotyledons, hairs, \&c. One term-suppression-means disapjearance of a part; the others mean greater or less diminution. As Dr. Masters shows, a diminution in one direction is often counterbalanced by an increase in some other direction, the energy of the plant remaining presumedly the same. So that in Achillen and Senecio we have hundreds of small capitula, while in the mammoth sunflower we may have only one.

Reversion is a form of indirect inheritance. It is only a return of some modified organ to a simple form from which it arose, or through which it passed, such as the return to parts of a flower to the leaf form (phyllody). Or it may mean re-inheritance of some ancestral form now belonging to some other plant, and which had been suppressed or atrophied for a long time. A study of seaweeds will probably show many parts, from which those of Phænogams may have been directly inherited, or to which they may have reverted, after passing through various morlifications. 
"All these series of faets were such as would have been the result of the derivation of existing types from previous ones. But the possibility that the seeming was the real did not eommend itself to the eonsideration of naturalists."-Liff of Darwix, by C. F. Holder, p. 198._(Theodore Gill.) 


\section{VI-COLOUR.}

There was a notion that colour was brought into being by the action of light. It is quite true that we cannot see colour in the dark, but it does not follow that it is not there because we cannot see it.

When one hegins to think for himself, he finds that the crimson colour of the nutmeg arillus is crimson, as soon as the pulpy part of the nutmeg is cut open; the seeds of Abrus precatorius are of an intense scarlet and black, before the pod bursts; the grains of the pomegranate are crimson although enclosed in a thick leathery skin; the claret colour of the blood orange appears the instant the peel is cut open; the seeds of the Cassia fistula have bright green cotyledons, even when unripe, and enclosed in a tube of pulp; so have those of the pistachio-nut, and so on.

Colour appears to depend on chemical action. No doubt it may be intensified and accelerated by light, but it can be brought about quite independently of it, for no one can pretend to say that if you mix solutions of iorlicle of potassium and bichloride of mercury in the dark, the scarlet iodide of mercury will not result, unless you expose the mixture to the light.

Mr. J. Berkeley* says that_-"The colour of alga does not " require much inteusity of light for its development. Many " species of beantiful colours grow at depths, where the light must "be so small that no phoenogam could exhibit anything of its " proper hue, supposing it possible for its blossoms to be developed " under such conditions."

Gems and other minerals have their brilliant colours at whaterer depth they may be; and we do see that pliœnogams, such as the carrot and beetroot, develop their orange and crimson colours in what we would consider as total darkness.

* Introd. to "Cryptogamic Botany," p. 97. 
Our very blood is of a brilliant colour, although it is in total clarkness, unless let out. It is true that on our lips and our skin light may penetrate it, but we camnot pretend to assert that light panetrates the blood of the black bear, with its thick covering of black hair. 'The blood of the mother does not mingle with that of the foetus, yet that of the latter, although in total darkness, derelops its rerl colour.

We cannot say that colour is a physiological phenomenon. For in the melons and other allied cucurbits, we find red, orange, yellow, and white coloured pulp, with yellow, red, or black seeds. There may be some physiological difference in these variously coloured pulps, but it is impossible to look upon this difference as of any importance in fruits so closely allied.

There was another notion, viz, that the greenness of foliage is an indication of health in plants, and of great importance to them, but in the Coleus and Calcidium foliage, there is often not a particle of green colour. If we can have healthy petals of all colours, it stands to reason that we could have healthy foliage of all colours, even blue, if we conld only produce it.

We can exclude light and still have colours. WVe cannot, howerer, exclude electrical influence, which traverses solicl opaque borlies, and reaches the darkest recesses of a fruit, or any other body. And, for all we know, it may be this electrical influence, whether it comes from the sun, or from other sources, which brings about the chemical changes, which result in the colours we. see; and with chemical changes, physiological changes will follow.

The student of colour in plants may derive interest from Capt. Abney's book on "Colour Measurement." He makes out that the primary colours are red, green, and riolet, and not red, blue, and yellow, as artists thought. As green is a universal rolour among plants, the green leaf may possibly be not only the founclation of all form in plants, but also the foundation of all colour. Rerl in leaves and bracts is a common colomr. And many of the young leaves of plants, such as the Rose, the Mango, Jonesia, and many others are of a reddish or purplish brown. From green, with a mixture of red or violet, all the innumerable shades of colour in plants may be manufactured. 
"Life is continuous and not periodically interrupted; ever since its first appearance upon the earth in the lowest organisms it has eontinued without break; the forms in which it is manifested have alone undergone change. Every individual alive to-day-even the very highest-is to be derived in an umbrokem line from the first and lowest."-Weismann, "On Heredity," p. 159 . 


\section{VII.-EVOLUTION.}

A Collectios of facts has been recorded which is sufficient to enable us to form a conception of how the lowest forms of regetable and animal life have grown into more complicated forms. That is to say, by the contemplation of these facts we are enabled to form some conception of how that universal power we call the Deity has worked to bring about the highest forms we see around us from the lowest, which must have solely existed in the beginning of time, and representatives of which still continue to exist.

Darwin's whole life was spent in collecting facts, by the help of which he was enabled to frame a theory of Evolution. By the light of this theory we are now enabled to form some conception of the process by which the Deity worked in fashioning what we call the creation of plants and animals.

Physicists and astronomers hare, in another direction, collected a number of facts which, when colligated, enabled them to conceive how the raw material of the universe could have been worked up into stars, suns, planets, \&c., that is, worked up to a stage fit for the development of what we call living things.

Of course this theory of Evolution has for its whole basis the assumption that the elements of life exist in an amorphous* state in the inanimate raw material of the universe; otherwise, how could the one be exolved out of the other by a continuous process of aggregating and refining and improving and organising and adapting?

Philosophers seem now inclined to believe that evolution among living things has occurred from the amoboid unicellular boclies to the oak, the date-tree, the horse, and man, \&c. That it has

* That is, life is potential in the so-called inanimate elements of the universe. 
also occurred froin the nebulous state of matter to the orgamsed hearens filled with moring bodies. They, however, refuse to admit that any such transition has occurred between the inanimate and the animate bodies. This is not only unphilosophical, but simply unbelievable. If the theory of Erolution is worth anything, it must be capable somehow of accounting for the passage of what we call non-living to the living state. All that can be said is that hitherto no fact has been discovered that will help us to bridge that gap. But bridged it must be, if the conception of Erolution, as a method of Creation, is to stand.

We are pleased first to classify the universe into non-living and living. Then we say that these two divisions are quite distinct, because one is non-living and the other is living!

What, if what we call inanimate nature is also living! Is it necessary that our conception of life should be the right one? Far from it I should say, considering the multitude of blundering conceptions that man's mental history has gone through. What, if the whole universe be quivering with life proceeding from those universal agents (we call them forces) which are convertible one into the other, and of which perhaps elcctricity is the most mobile and most universally present.

However all this may be, there are no facts known which bridge the two evolutions, and therefore we have to wait till that bridge is completed, not only mentally, but de facto.

It would appear erroneous to suppose that evolution means only change with progress, that is, an ever-increasing complexity. Evolution may mean this, but it may also mean retrogression, that is, a reduction from a more complex to a less complex form. A better definition of evolution might perhaps be- a tendency to occupy every available place on land and in water, in every possible way.

To effect such an occupation, infinite rariation is needed, taking into consideration all the surroundings of each place, in order that this tendency may become actual fitncss to every place.

This fitness then is brought about, or "tailored" by a struggle for life, which naturally would lead to the selection of the most fit for any particular place.

As every spore, seed, or bud is a piece of some previous body, which may have occupied a different sphere, it is evident that these offsets need be plastic, that is, they require to possess a power of 
variation. This plasticity is supplied chiefiy by sexual conjugation of different but allied individuals. It is necessary also that this fitting should be slow, to make it stable.

'This slowness is provided for by heredity, which restrains a too rapid variation. Nerertheless, "jumps" or "breaks," as horticulturists call them, now and again occur, in the process of multiplication, which may fit boclies more quickly to their surroundings, than by the slow steps severely controlled hy heredity.*

Galton, in his " Natural Inheritance," p. 34, says, "Evolution need not proceed by small steps only," but also by jumps. Although intermediate forms may be in existence, it does not at all follow that they had anything to do with the evolution of the type we call a jump. I do not find anything to disagree with in all this. We may not exactly know the cause of the "jump," but we know that in the crossing of cultivated plants, "breaks" or jumps do occur, both as regards form and size of foliage, habit of plant, form and colour of flower, \&c.

Without the faculty of seeing what is beyond our immediate senses, that is, without the helpful faculty of a discriminating imagination, we cannot understand a possible state of things which may somehow have occurred prior to the present state of things, which we can see and understand. To an evolutionist, some previous state or states, out of which the present has come, must have existed. The difficulty is to discover what lines evolution took, from a simpler to a more complicated state. For this purpose a vivid imagination, held in control ly facts, is indispensable, so that we may frame before the mind's eye a period and conditions long anterior to the present mode of evolution. WVe have to take into consideration that the present state of things is the result of millions of generations. By persistent inheritance, variation through sexual crossing, and through other factors of variation, and by the strictest selection, they have evolved characters, which apparently mask and belie their true origin. A clear view of a possible past is needed to understand the present phenomena, because the present is often only a more complicated mode of blooming of the past. Therefore, somehow or other, unless all past forms and structures have become irretrievably extinct, and totally new creations have all along come out, we ought to be able to trace back at least some of the present structures to more 
primitive ones, of which, there is reason to suppose, there are still many surviving representatives.

I feel convinced that the student of the higher forms of plant life will be able to understand them better by a study of seaweeds and of still simpler and lower plants. For it is reasonable to suppose that at a certain period of evolution there could not have been other plant life than seaweeds. In other words, our modern Phœnogams must necessarily have descended from forms, of which the seaweeds of to-day are representatives.

From the nature of the plant cell, it could have had no other commencement than in water; therefore, the stages of development of the vegetable kingdom would appear to have been roughly in this order :-

(a.) Marine plants;

(b.) Fresh-water plants ;

(c.) Plants which had became partially water and partially air plants;

(d.) Plants living in a misty damp atmosphere, and also on marshy ground;

(e.) Plauts on dry land, at various altitudes;

(f.) Plants on barren lands and deserts.*

I am aware that Ch. Darwin found the Protococcus nivalis on the perpetual snow of the Andes, but $I$ am also aware that he found marine shells at 14,000 feet above the sea-level. The conclusion is, therefore, that the lands at these heights must have been, at one time, under the sea. His having met with one of the simplest cellular plants on perpetual snow, at that height, does not at all mean that it did not originate in the sea.

Many of the stages sketched ont may have been developing at one and the same time. Intermediate links must have existed in abundance, but in many casos they subsequently perished and risappearerl.

It is not impossible-nay, it is very probable-that plants having once emerged from water on to dry land may have been again degraderl, if we may call such a transition a degradation, into semi-aquatic plants. But, originally, it is hardly conceivable that protophyta could have been born in any other medium than that of water.

Now-a-days we must look at all nature, including ourselves, from an evolutionary point of view. We must look upon every

* To which might be added plants on other plants, as epiphytes and parasites. 
form, or any part of a form, which exists at present, as only a further development or modification of something that has gone before it, lower down in the series.

We are only concerned in these pages with the evolution of plants. The question is how to account for all the parts of plants we see around us, stems, branches, roots, leares, buds, flowers, fruits, seeds, \&c., on the principle of erolution, and all emerging out of the same raw material of unicellular bodies, or out of their near relatices the multicellular bodies found in sea and fresh water, such as seaweeds and others.

Are all organs of plants new creations, or are they simply derivatives? They are an unfolding of less complicated material into a more complicated structure, such as the unfolding of a branch and flower out of the cellular material of a bud.

The theory of erolution must be accepted in its totality, otherwise it is not erolution at all, but some other theory. If we are to bring in the help, at odd intervals, of a Deity, to account for what we do not understand, it would be much simpler to say at once that He, She, or. It did it all from beginning to end.

I do not think that the last word has been said regarding the different organs of plants found in books on structural botany. I do not consider that the origin of the different organs or parts of a plant have receired an exhaustire treatment, based on erolutionary lines, so that nothing further can be said about them.

I think Weismann is right in considering all life as commencing in unicellular bodies, haring the property of feeding and reproducing themselves. And that, as they aggregated into multicellular bodies, it was to the adrantage of the whole colony that a sub-dirision of labour should erolve; that some should give their individual attention to the one function, and perfect that, and some retain only the other function, and perfect that.

The upshot was that, in an aggregation of cells, some became what we call regetative, as feeders of the whole colony, and other became what we call reproductive cells, that is, nurseries of new colonies. We must not suppose, howerer, that each set of cells had lost its twin function in perpetuity. Not at all. The one function of the original cells remained in abeyance, because the other function had a preponderating energy.

$\triangle$ p. 1724. 
In Porphyra laciniata,* Thuret observed that the regetative calls of the frond, by segmentation, became transformed into either spores or antheridia. This was not all. For in abnormal cases the contents of the primitive cell changed partly into spores and partly into antheridia, so that there does not appear to be any fundamental difference, not only between regetative and reproductive, but also between male and female elements.

After the differentiation of regetative and reproductive cells had become established, inheritance produced by ages of fixed and advantageous habits would normally prevent the ones from exchanging functions with the others. But, as we observe in abnormal cases, these functions may, under certain circumstances, be exchanged.

The sex functions appear to have been separated at a rery early period of living bodies, for Dallinger has shown thac unicellular bodies, at certain periods, become what might be called sperm and germ cells by fission. At all erents, two simple cells floating about in water, and indistinguishable from each other, combine or fuse into a larger cell, which after a time bursts, and liberates a number of germs. These develop into unicellular bodies, which after multiplication by fission for a time, conjugate, and repeat these phenomena.

So even in these primitive bodies we hare multiplication by buds and multiplication by seeds or variable buds, just as we have in the highest and most developed and complicated tree on land.

Separation of the sexes in distinct individuals must have occurred also at a rery early period, for we find it in seaweeds. This separation might hare very readily occurred accidentally, as one might say. The atrophy of germ-cells in one individual and the atrophy of sperm cells in another individual would have soon established a diœcious race, if this separation were beneficial.

The adrantageousness of their separation would make this feature permanent. Then inheritance, to a large extent, would lock the door, and prevent the recombination of the sexes. In other words, the complex conditions, under which organisms were multiplying in their struggle for life prevented a return to conditions suited to a simpler life, and in many cases the disadvantage

* “Etudes phycologiques," pl. 31, p. 60. 
of combined sexes in the more complex lite kept that feature extinguished in diœcious races. *

We must not, howerer, suppose that the power of re-appearance of a sex, where it was atrophied, became totally annihiliated, for teratology shows us that not only can male organs replace female organs, but the vegetative can replace the reproductive organs, and vice versâ.

The ordinary axillary bud appears to contain the germs of both seres, for after going through the combined state in a dormant condition, as leaves or vegetative cell-structures, they are separated at the end of the branch as polliniferous and oruliferous leares. In ferns, they are called barren and fertile fronds.

With the light of evolutionary ideas, strengthened by Weismann's idea of continuity of germ-plasm, I do not see any good reason why we should any longer hesitate to consider ferms, for instance, as direct descendants of seaweeds. The latter might indeed be called sea-ferns.

There is abundant eridence to show that they are closely allied. The ferns gradually emerged from a water life, becoming adapted to an air life.

There is sufficient evidence to show that not only ferns, but also phœnogams, owe their forms to derivation from seaweeds.

From all we know of the evolution of our earth, we are justified in supposing that vegetable life commenced in water, and that all subsequent derelopments of plant forms had their origin in these primitive water forms, many of which, as I said, may still be in existence now under the general name of seaweeds.

We do not know why primitive plants have taken the forms they have, rather than others, but some faint notion of how certain low forms of regetation may hare come about may perhaps be obtained by the study of mineral forms of crystallisation.

The molecules of crystals appear to arrange themselves by the force of polarity. We see some kinds arranging themselves in what are called dendritic or tree-like forms, others are like moss; some are pinnate, others lobed, \&c. It would appear as if magnetic influence were acting on the crystals as they formed, forcing the molecules to take up places in a way somewhat similar

- Probably most dinecious plants are subject to polygamy, that is, reversion to hermaphrodite flowers. 
to fine iron filings when mored in the atmosphere of the pole of a magnet.

If we consider the cell as a sort of vegetable crystal, we may perhaps obtain a clue to the disposition of vegetable parts as a parallel to the crystalline parts of minerals.

I admit that this would give a very inadequate notion of how vegetable forms were originally brought about, but a peg to hang a notion upon is, perhaps, better than no peg at all.

Whatever all this may mean, one frosty morning on the street parement, where, in the previous evening, there had been a film of water I observed the following form (Fig. 9). On

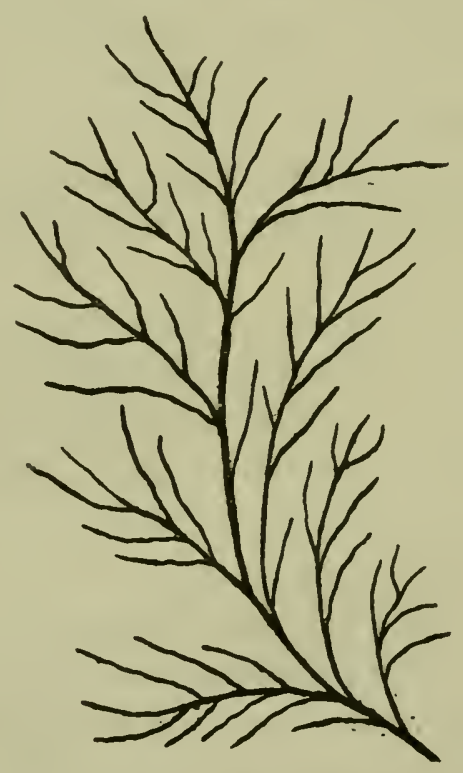

Fig. 9. Form of ice crystallization seen on street pavement on 12 March 1891.

another frosty morning, on the glass of a shop window, which had been bedewed the previous night on its inner surface, I observed another form of the same crystalline genus, but of a different species, which I give in Fig. 10. I only wish I could have photographed these interesting forms, which are here inadequately copied. 


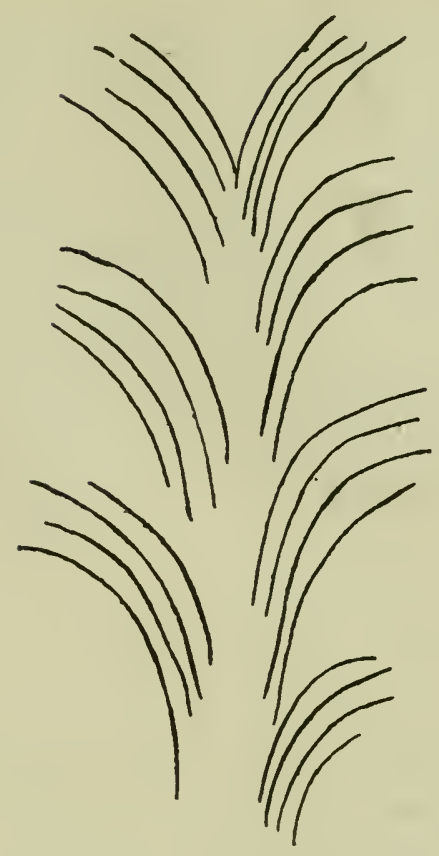

Fig. 10. Form of ice crystals seen on a shop window on a frosty day of 1891 .

The varieties of forms we now see in seaweeds are either inherited from similarly aggregated cells of primitive times, or have been much modified in their descent by the struggle for life. Be that as it may, we cannot well aroid the inference that the seaweeds of modern times erolved out of more primitive seaweeds; and that all forms of land plants erolved from seaweeds. As I said, the protophyta of modern times can endure only in a water medium, or where there must have been much surrounding moisture, and therefore the inference that the original protophyta also were water plants seems legitimate.

In phænogams we have to deal with variations of organs, which are evidently formed on one type, as much so as the skeletons of all the vertebrata. How did they originally obtain those forms? The theory of descent, with modification, which has been accepted by most thinkers, leaves us no alternative. They obtained them by inheritance from anterior forms, being pieces of anterior forms.

However masked these derived forms of land plants may be, by modification, accruing from selection in the struggle for life, 
we ought somehow to be able to trace their connexion with seaweeds, their ancestral prototypes. This, I think, we are able to do in a large measure.

Driven on land, as plants must have been by a keen struggle for life under water, the transition from a wholly water-medium to a wholly air-medium sufficiently explains the difference of texture and rascularity, and other characteristics of land plants. Then the struggle for life on land, driving them again from swampy localities to drained land, and from this to mountains and deserts, sufficiently accounts for the innumerable rariations we see in land plants.*

Ferns-cryptogams themselves-may, I think, be taken as links between seaweeds and phœnogams.

In the still keener struggle for life on land, we find plants not only occupying very dry and high land, but taking root on other plants, and becoming epiphytes and parasites, such as ferns, fungi, orchids, aroids, amaryllids, bromeliads, dorlder, mistletoe, Loranthus, Rafflesia Arnoldii, \&c.

The latter is the most striking of all. The whole plant is the flower only. It has dispensed with stem and leares. Its root, or what performs the function of root, has become amalgamated with the tissues of the plant on which it feeds-a species of rine. This parasite flower is said to measure nine feet in circumference, and weigh fifteen pounds!

We find other plants so modified as to be able to lead a large part of their life underground.

If we try to follow mentally the further transition of seaweeds to an air life, with such varying surroundings, we shall not find it so very difficult a task as might at first appear.

Let us imagine that at first all plants were submerged, that is, surrounded entirely by a water medium; although suited to a submerged life, tides must have frequently left them uncorered. Their ripe spores, ready for dissemination, would be either scattered by the wind on to drier land, or during submergence, with the flowing tide, the spores would be carried to the land and

* It should be remembered that geologists have established the fact that land has altered its altitude many times, and plants on low lands had to alter to meet the changed surroundings. 
left stranded there during an ebb. They would germinate in this sort of half-and-half medium, and would live a semi-aquatic life, if suited to the new conditions, or perish if not suited. Some might survive owing to difference of constitution.* Moreorer, this transition must have occurred in times when the face of our earth must have been totally different.

There are many filmy ferns known which cannot exist except in a perpetual spray of water, or in a perpetual surrounding of mist.

Although we may be inclined to suppose that epiphyte orchids became plants living on trees, owing to a struggle for existence, this may not have been exactly the case. Of course we must suppose that there were trees for orchids to grow upon. The seed of orchids is like fine powder, and can be blown anywhere by the wind. Supposing that some of the seed settled on the fork of a tree, where there may have been an accumulation of dust and leaf mould, moistened by rain, in a suitable climate, it would germinate and possibly live, and gradually suit itself to such conditions without having been driven to them by a struggle for life.

In the transition of seaweeds to land plants, the survirors would in due course reach places where their roots only, or their roots and lower leaves, would be submerged, and their higher parts be in an air medium. Ranunculus aquatilis, for instance, and sereral other plants, may be survirals of this transition state. They have leares which are suited to a submerged life, and others suited to an air life. Even before insects, birds, and other animals came into existence, the tides would appear to have been sufficient to belp the evolution, first of semi-aquatic, and then of wholly land plants. Subsequently the wind would carry their spores and seeds further inland and up mountains.

In this transition from water, through palustral, moist, and finally to dry land; from low alluvial soil to rocky highlands and deserts, in addition to needing water, with mineral ingredients in it, as of old, plants would have had to gradually adapt themselves to a multitude of new surroundings.

As plants passed from a water to an air life, a circulation of fluids would hare become a sine quâ non, because the roots would

* We continually see a difference of constitution in the seeds of the same pod, and in the young of the same litter. 
be the main organs of suction, and the fluids would hare to be forced to the extremities of the branches and leares. Hence there would be the beginning of the elaborate fibro-rascular system of the higher plants. It would derelop pari passu with an elaborate root system. An epidermis also would have become a necessity, to protect the softer parts from the inclemencies of the air.

In this way we may form some conception of the emergence of seaweeds from water into the air, disseminating themselves in myriads of modified forms, in countless ages, orer the land, their different parts becoming modified to suit new and rery distinct surroundings. Myriads of experiments, of course, must have occurred, and myriads of failures must have been gone through, until some modification, more suited than others to the conditions which beset it, could live.

What one has to do is to allow unlimited time, and an unlimited number of rariations, in order that vegetable organisms might very gradually become adapted to new surroundings.

Evolution, as I said, does not always mean a forward progression of any organ once formed. It sometimes means just the reverse. A striking instance of this is the erolution of our modern horse. Starting with five digits, he was modified into an animal with three digits, and eventually became the modern horse, with only one digit.*

We notice erolution in a similar retrogressive way in many other plants. Plants with five stamens lose one, two, three, or four stamens, and are transformed into one-stamened plants; others, with petals, become apetalous; leafy plants become aphyllous.

Important organs in one set of plants are tracerl to mere teeth, or bristles, or hairs in others. While minute, insignificant organs in one set become enlarged and important organs in others.

Plants seem to have various ways of adapting themselves to new conditions. Now they retract one organ and protrucle another, much as if they were sensitive organs, governed by some central superrising and adaptation-discorering ganglion.

* The orchid must have started with three or six stamens, but now many have only one. The pea is supposed to lave started with many carpels, but now has only one. 
Then by erolution is meant not only a forward morement, but also a backward morement. So we hare to consider depauperation and final extinction of organs as part of the tactics in the battle of life. It is as if the bow and arrow and the rifle had become obsolete by the growth and sufficiency of the policeman's baton.

Asa Gray* says:-_"Phænogams are manifestly of one type, while cryptogams differ among themselres almost as widely as they do from the higher series."

In the following pages I shall endeavour to investigate whether this is so; that is, whether phænogams differ materially from cryptogams. From an evolutionary point of view, they ought not to differ essentially.

Asa Gray further says :-- "As respects the organs of regetation, the higher classes of cryptogams exhibit this same type; but it is only in the most general or in a recondite sense that this can be said of their organs of reproduction."

Now, I think that it is in the organs of vegetation that the higher plants differ most from the lower, while they differ least in the organs of reproduction. Moreorer, according to Weismann, these organs of reproduction are pieces of their ancestral unicellular bodies.

In the lowest plants - the Saprophytes - according to Dallinger and Gobel, the whole plant is one cell, either male or female. The conjunction of these two produce infant germs, which derelop into the parent forms. This operation is evidently the marriage of two cells of opposite sex, and in no way differs from the union of germ and sperm cells of the highest plants, howerer the organs bearing the reproductire cells may, in these, be modified, and howerer the whole may be masked by regetative organs. The only difference is that, in the latter plants, an elaborate apparatus is dereloped for producing the germ and sperm cells, and also for bringing them together.

As to multiplication by division, it is common to all plants, from the lowest to the highest. The former split into two, each repeating the operation, and goes on reproducing itself in this way. The latter diride by bulbils, or buds, by cuttings, offsets, \&c. This mode of reproduction being nothing but a division of the parent into pieces, each containing a reproductive centre or bud. The fertilised seed itself is nothing but a bud, plus a sperm cell 
incorporated with it. In what is called reproduction by parthenogenesis, we have a seed even without amalgamation with a spermcell; that is a simply unmarried bud.

Now, in studying the lowest multicellular seaweeds, we find a cellular basis, out of which leaves develop. Some of the cells of these leares contain reproductive male and female cells.* In essence they do not differ from the sperm and germ cells of the higher plants. How can they differ, when they are no other than repetitions or pieces of the lower forms, only more differentiated, and varied in myriads of ways?

The cellular basis, from which the fronds of the seaweed emerge, appears to be the same thing as the cellular placenta of the ovary, from which the seeds emerge. The frond of the seaweed is vegetative and reproductive organ in one, the differentiation being only in the cells of the same frond; while in the higher plants differentiation has progressed further, and the vegetitive and reproductive cells have come to occupy separate organs.

This cellular basis, which gives rise to special organs, whether vegetative or reproductive, runs through the whole vegetable kingdom as a sort of universal placenta, or mother structure, out of which all other organs evolve. We may, of course, call these by an infinity of different names for the purpose of easy (or difficult?) intercommunication with our fellow-beings, but Prof. Weismann has shown that, however we may call the vegetative part somatic cells, they are nevertheless essentially germ and sperm cells, turned to another purpose for the sake of economy and better equipment of the individual for the battle of life.

Wherever we turn in the stully of plant life, we find homologies, which, in plain English, mean the sume parts, varied for different ends, the whole being a sort of paste, elastic and sensitive, and modifiable, according to circumstances.

'The higher plants are nothing but an unfolding of the simpler forms of cryptogams into more complex combinations, in order to meet the needs of more complex surroundings. In the transition, innumerable forms of plants are developed, in a medium very different from water, and, pari passu, innumerable insects and other animals are developed, to which the plants liave to adapt themselves, the whole being subjected to changes of temperature, and geological, climatic, and other disturbances.

* Vide Porphyra laciniata in Thuret's "Études Phycologiques." 
One cannot examine any embryo of a plant without being convinced that its parts are only a continuation or repetition, with modification, of parts belonging to very distant ancestors. In text books the embryo is divided into radicle, caulicle, cotyledons, and plumule. But by reference to the bud of Asplenium decussatum (Fig. 42) it will be seen that these parts are also traceable in the leaf buds of ferns!

Neither has the root sprung from the stem, nor the stem from the root, nor the leaf from either, but all from some common basis. 'That basis may be the homologue of the cellular placentalike structure which forms the disc of attachment of certain seaweeds, or, if one would care to call it so, a primordial node.

The stem and the root must be considered as two buds of the same cell mass; that is, a further expansion of it with cell modification. The stem, of course, has dereloped into a medium different from that, which receives the root, and therefore, and as a matter of course, the nature of each, has in the course of descent been modified, both in form and function to suit surroundings.

So much are the root, stem, and leaf of one nature that probably there is no part of the living root, stem, or leaf which under certain. circumstances might not evolve buds. There may be good reasons why ordinary buds come in places where we find them. It is an inherited habit which was originally forced on the plant by competition.*

Then, as ordinary buds are produced indifferently on root, stem, or leaf, all three must be different forms of the same thing, however varied their structure may be, and howerer obscured their nature may be by the nomenclature of authors. Can anything be more leaf-like, or stem-like, than the leares of Phyllocladus, Xylophylla, Ruscus, and others?

Even if we were not able to see all this with our imagination, the theory of evolution, once accepted, leaves us no choice.

Asa Grayt says, "There are, however, reduced forms, in which there is no distinction of axis or foliage, but most of these are clearly leafless rather than stemless, and not even in Lemna and Woolfia can the stem be said to be wanting (!)."

If we remain wedded to the distinction between stem and leaf, except in form, we must call Lemna and Woolfia either stem or

* This point is worked out further under the heading of axillary bud.

$\dagger$ Struet. Bot., note to p. 45 . 
leaf. They are neither or both! A mass of cells evolve what we call stamen and pistil, a little more complex than the antheridia and spores of a Fucus, but which happen to be the essential elements of the flowers of the higher plants and, therefore, we call Lemna and Woolfia phænogams (!).*

In Woolfia we have a vegetable form which may be a direct derelopment from seaweeds, or a degradation from a higher derelopment. This minute, green, globular mass is root, stem, and leaf in one, or if the reader would prefer it-a sort of prothallus from which the sexual elements have erolred, as occurs in the prothallus of ferns.

In surveying broadly the vegetable kingdom from the erolutionist's point of view, one readily sees that certain groups of plants, such as are included under the Rosacee or Ranunculacex, for instance, form natural families. Speaking generally, the characters of the individuals composing such groups have much in common. Nerertheless, we see that now one character is dropped, now another. We see that instead of a fleshy root, some have a fibrous root; instead of a compound leaf, some have a simple leaf, others drop their corolla, and so forth. Nevertheless, there remains so much in common, that the idea of close relationship and of a common descent are inevitably suggested.

This, however, is not enough now. One desires to know how one group is related to another, so different from it; how phænogams are related to cryptogams; that is, how the socalled flowering plants are related to those which bear not what we call flowers. In short, we wish to find out, if possible, how the higher forms erolved out of the lower.

Although the connexion may often not be clear, still to an erolutionist it is evident that there must be, not only a connexion, but the phænogam must be simply a continuation of the cryptogam. There must have been a growth of the regetable world from the simple to the more complex, into the most differentiated forms. It is also evident that greater and greater complexity and diversity of form would arise, as more varied agencies were brought to bear on the moulding and selection of plant forms, through the struggle for existence. With all this, the essential parts would be, and must be, a continuation of their originals,

* The anther of Lemna is as much a sporanguin as that of Lycopodium. The difference being that in the former we have pollen grains and in the latter spores. 
howerer masked the relationship might be by outward forms and adaptations.

In the beginning of regetable life, as long as plants remained simple cells, the temperature, and nourishment held in solution in water, were perhaps among the few agencies that took part in their modification, besides their own polarity, and the force caused by cell-multiplication.

Howerer simple the surroundings of these simple forms may appear, a rast variety of ingredients may have been held in solution, and variations in eren the simplest forms* might readily have been the cause of new selective powers. Therefore, simple as these monads may have been, some may have had the means of elbowing out other competitors by their greater fitness for occupying certain places.

Cells aggregate to form more complex plants, and whole forests of seaweeds must have been in one continuous war with each other, and with the animals that occupied the same element.

As soon as plants began to emerge from water into air, the modifying agencies which surrounded them began to multiply. They continued to need water, holding in solution nourishing ingredients. This want would have given rise to circulation, and a rascular system, and as I said, a complicated system of roots.

In addition, they would hare to adapt themselves to whaterer surroundings they may hare been born in, or perish. There can be little doubt that myriads must hare perished in the attempt to occupy and establish themselves in different places. Nature must have used up and wasted an infinite number of individuals, $\dagger$ in making experiments to suit plants to new surroundings, in order to people the earth with the millions of forms so raried, and yet so related.

Nature did and does exactly what the horticulturist does when he gets hold of a new plant that he desires to possess and to propagate. He tries this and that experiment, giving the plant this and that surrounding, and watches results, until he succeeds in finding a comfortable home, in which it will thrive and feel

* As Dallinger has shown.

$\dagger$ We call these individuals because they become separated from their parents, but at the same time we should not lose sight of the fact that they are all branches of the same stem. 
happy. Who can tell how many thousands of orchids have been experimented on and wasted, in England and other places, until someone discovered the way of keeping them alive and in health, so as eventually to fascinate everybody with the beauty and originality of their blooms.

Their successful cultivation, when known, appears now as easy as that of other plants. It is a repetition of the story of Columbus and the egg. This is not all. The way of propagating them, crossing them, and rearing new forms has been got at, so as to confound botanists, who had made up their minds that there were more species and genera among them than nature herself had made.

The adaptation of cultivated orchids to their new surroundings, except where smoky fogs prevail, appears in many instances to be now perfect. Their struggle for life is not so keen as when they were left solely to nature's care. Man's intelligence is there to attend to their wants, to protect them from enemies, and to bring about new variations, independent of struggles and surroundings of insects. Now that the fact has been pointed out to us, insects evidently had a great deal to do with the interminable variations of orchid flowers.

In endeavouring to follow what I have to say, the reader should be prepared to discard from the botanical dictionary the word impossible. In the evolution of plants there appears to be no such thing as an impossible combination of cells. We see all sorts of unexpected combinations, not only of different cells with different functions, but of different parts, the cells of which have already been differentiated into rarious organs with different functions.

The bias of schools and teachers, of books and words, have kept our minds too long chained to one or another authoritative theory, excluding as impossible any other riew, while in reality, in nature, there is apparently no such thing as either authority, or a fixed law, which forbids every other view as impossible in what concerns life. There are, doubtless, branches of development in certain directions where least resistance may be felt, but such branches are infinite, and tied down only by heredity, by the medium in which cells are developed, and the amount or nature of impediments or helps, which the surroundings may furnish.

In seaweeds we seem to have an almost complete series of forms, from the simple cell to aggregates of cells, comparable, without 
much stretch of the imagination, not only with land ferns, but also with the higher phænogams, or "what are commonly called flowering plants. It should not be forgotten that while in phænogams colour and great variation of form are oftener limited to the flower, in seaweeds the whole plant may be coloured, as we see it in Coleus, Caladium, and others.

It is enough to glance orer any work on seaweeds, such as "Harrey's Phycologia Britannica," or "Australica," to obtain an idea of the gradual complexity of cell aggregation and growth, which has occurred if not in the whole plant, certainly in its parts. Nothing, in my opinion, can give us a clearer conception of erolution than the contemplation of these organisms. We seem to see most of the types of land plants foreshadowed in these simple metaphyta.

It must not be supposed that because phycologists and other cryptogamists have given various names to all the parts of these cryptogams that therefore they are not really homologous with the different parts of the higher land plants, and essentially the same. things.

From simple cells we can pass to simple aggregates of cells, such as in Monormia intricata.* The cells in this are disposed in threads, and some of the component cells are already differentiated for special functions. Lyngbia flusca $\dagger$ has, in addition, the erolution of hairs, or roots, or leares, or branches. Calothrix ccespitulat is made up of cellular threads which at first are independent and afterwards reunite as parasitic branches, like the Cladothrix dichotoma of Dr. Klein. In Calothrix fasciculataई the parasitic branches adhere round a certain point so as to resemble the leares of certain fan-palms. In the hairs of Calothrix luteola $\mid$ and $C$. confervicola we get distant adumbrations of the pines and horsetails. In Porphyra rulgaris** we have aggregations of cells in tapes, or leaf-like expansions, such as we find in many ferns. In this seaweed we have the derelopment of

\begin{tabular}{|c|c|c|c|}
\hline$\dagger$ & :" & " & pl. 300 . \\
\hline & ", & , & pl. 305. \\
\hline & " & ", & pl. $58 \mathrm{a}$. \\
\hline$\|$ & " & ", & pl. 342 . \\
\hline T) & , & , & pl. 254. \\
\hline$* *$ & , & , & pl. 211. \\
\hline
\end{tabular}


tetraspores, which may be looked upon as adumbrations of pollen. Harvey says that the fructification is dispersed through all the cells of the frond. If in imagination we contract this frond to the size of an anther, we can form some conception of the erolution of the stamen. Then in the species of Enteromorpha* we get not only adumbrations of stems, branches, and leares, and roots, but of hairs and spines. The whole plant may be considered either as a root or a frond. Moreorer, we find that certain cells of the frond become specialized as tetraspore bearers, that is, as reproductive organs. As in ferns, we begin to find that only at certain points of the frond are reproductive organs dereloped, the other cells remain as abortive reproductive cells, or simply regetative cells.

It may be interesting here to note that in some of the simplest organisms, such as the Giant micrococcus and Sarcina-micrococcus, $\uparrow$ the cells group themselves in fours, like the tetraspores of algæ, and the mother-cells of anthers in phrenogams, the four cells contained in each mother-cell of the anther becoming the pollen grains.

In these simple seaweeds, the whole plant is roots, stem, and branches, in one. There is yet no need of any differentiation into root and stem, the whole being surrounded by one medium. All that is needed is an organ of attachment, which enables them to be fixed. In Cladophora Rectangularis, $\ddagger$ however, instead of a disk we find a root-like organ of attachment.

If one would care to follow the development of seaweeds further, so as to obtain a conception of the differentiation into special organs, which characterize the higher land plants, he might, with adrantage, glance at the following:-

Rhodymenia cuneata gires an idea of the origin of the sori on ferns. Bostrychia Harveyill will show him where ferns may have got their circinate rernation. Callithamnion formosum 1 may gire him some iclea of what the glands on the teeth of rose

* "Harvey's Phycologia Brit." v. 4, pls. 263, 245, 340, 43, 344.

† Dr. E. Klein's "Micro-organisms and Disease," p. 39.

f "Harv. Phyc. Brit.," v. 4, pl. 12.

§ “Harvey's Phycologia Australica," v. 5, pl. 295.

II

" $"$ pl. 292.

",$\quad$ pl. 281. 
leaves and the pinheaded glands on the tips of hairs may mean. Dasya sarcocaulon* may gire him a hint that compound hairs were originally branches of primitive plants. Delesseria crispatula $\dagger$ will give him some notion of the origin of wings on certain stems and petioles, as also of the sori on the terminations of reins in ferns, as well as of the carpels of higher plants, here called sporophyls. Halimeda macroloba $\ddagger$ may gire him some idea of the curious derelopment of the stems of the Cactacex. Polysiphonia rostrataई might suggest to him how the glandular hairs, which we find on so many plants, may have degenerated into their present condition, from reproductive hairs. On land plants we often find them mixed up with ordinary hairs, just as they are in this Alga.

Further on in Phacelocarpus complanatus | we begin to meet with the erolution of a midrib and lobes or teeth, and reproductive organs on the teeth. 9

In Cystophora monilifera** we see a distinct stem and branches, and a fructification differentiated from the frond, but nerertheless, a modification of it. We see similar progress towards the types of land plants in Cystophora Sonderi, $\uparrow \dagger$ and in

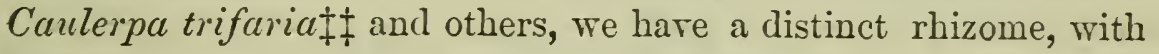
branches in one direction and roots in another.

In giring the foregoing examples there is no pretence of showing derelopment step by step, but only of giving examples which show progress from simpler to more complicated seaweeds, and a transition from these to land ferns, \&c.

In these seaweeds we seem to be able to trace the gradual erolution of rhizome, stem, leaf, branch, lobes of leares, teeth, hairs, midribs, reins, catkins or spikes of sexual organs, roots, \&c. We find that these seaweeds at first hare no roots. They are

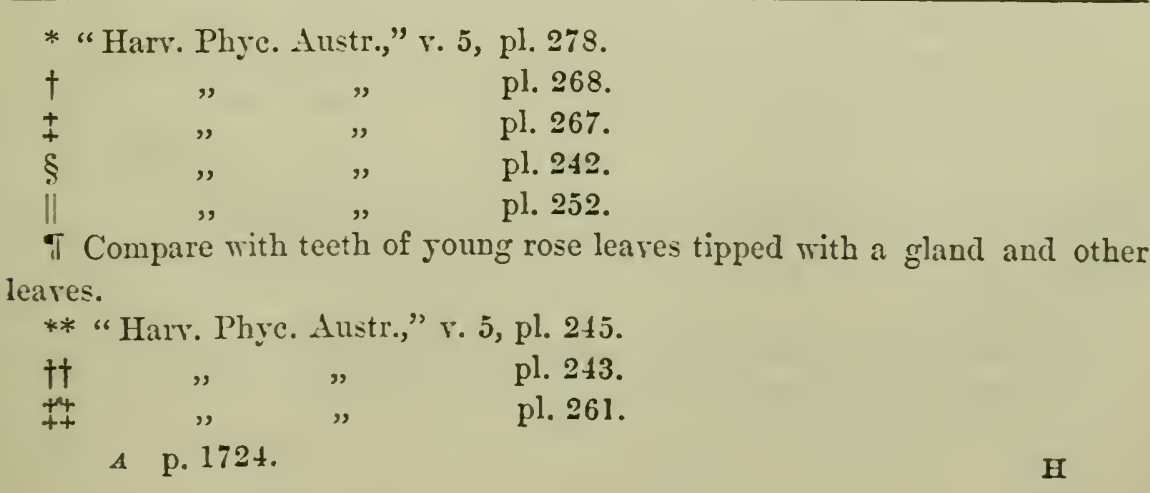


mere expansions or flattened aggregates of cells, and others are mere strings of cells, which, by fasciation, can easily become expansions. They issue from a disk or cellular basis, by which the plant is attached to other bodies. Out of this basis, as if from a placenta, common to both leaves and roots, we see the so-called roots evolving. In some, these beginnings of roots remain as simple nipples; in others, they grow into longer roots, until we find whole masses of roots like mops.

In the rhizome of seaweeds, as if from a common lengthened placenta, we find roots at intervals exactly as we do in ferns and phænogams. In Sargassum lacerifolium* we have adumbrations of some of the higher land plants, both in foliage and fructification.

In Macrocystis pyrifera $\dagger$ we get adumbrations of our Cycads and Palms. Some seaweeds develop tendrils as in land plants.

If we compare two rery distinct plants which are placed by systematists at a great distance from each other, we find that, on close analysis, they differ very little from a morphological point of view. Monarda didyma, at the apex of the stem, has a whorl of leaves, then a whorl of involucral bracts, within that a whorl or whorls of flowers, and in the centre of all the continuation of the stem with a repetition of the flower head. $f$

Now in the horsetail we have a stem, then at each node a leaf-sheath, out of which another stem projects, and then another sheath and another stem, and so on, till the apex develops a

* “Harvey's Phyeologia Austr.," v. 4, pl. 208.

$\dagger$ "Harvey's Phyc. Austr.," v. 4, p. 202. This seaweed has an immense range, from Cape Horn to California, according to Darwin and Hooker. Its stem does not appear to be a carrier of nourishment from the roots, at least to any extent, for Ch. Darwin, in his "Voyage in the Beagle," says: Its stem seldom has a diameter as much as an ineh, yet it can grow from a depth of 45 fathoms to the snrface and spread itself many fathoms on the surface. It must be largely fed by the surrounding medium through the cells of its frond. He adds, the immense quantities of it act as natural breakwaters, and that the number of living ereatures whose existence depends on this kelp is wonderful. Numbers are attached to the frond, and on shaking the tangled roots a pile of all sorts of animals falls out.-("Darwin's Voy.," p. 255, new edit.)

‡ The drawing shown in "Nicholson's Dict. of Gardening" does not show the continuation of the stem. 
reproductive head consisting of peltate shields, which do not differ materially from the indusia of ferns.

Let us make a comparison of these two very distantly related plants-the Monarda and the Equisetum. The calyx of the Monarda is almost indistinguishable from the leaf-sheath of the horsetail. Instead of a stem within the calyx, it has a whorl of fused petals; within that a whorl of stamens, and then a whorl of carpels. The flowers of each whorl correspond to the branches round each node of the horsetail. The difference is that in the horsetail the nodes and whorls are repeated ad infinitum, much as the whorls of the Primula japonica are repeated at intervals on its stem; while in the Monarda the flower axis is very short, and the internodes are obliterated.

The essentials are the same throughout, but they admit of much variation. The Monarda has leares proper and involucral bracts, which are entirely suppressed (or have never developed) in the horsetail. The calyx sheath is coloured, so is the corolla sheath; while in the horsetail the sheaths are repeated without variation. The whorl of branches in the horsetail corresponds to the whorl of flowers in the Monarda, while the central stem* is repeated only once, if at all, in the Monarda, carrying at its apex another flower head. As the leares proper in the horsetail are suppressed, its energy is expended on a repetition of stems.

In the course of the following pages it will be seen that I have little regard for the classification of plants, at which many botanists have worked for ages; not because it is not of great use, for classification has for its basis a common descent, and therefore a proof of erolution, but because it is an artificial mode of grouping natural affinities. This would seem a paradox. The alliances are natural enough for the reason that the members composing them have probably branched off from a common centre of parentage. But, owing to the extinction of many groups in the race for life, there are gaps between groups which might lead the student to think that these different groups had little or nothing to do, in origin, with each other.

In order, however, to show what modern naturalists think about evolution, I shall end this part by quoting a passage from C. F. Holder's "Life of Darwin," p. 203.

* In the specimen under observation and in those I saw at Kew. 
"Evolution denotes the derivation of living things from preceding ones in endless succession. Variation in progeny, limited heredity, and time are its correlatives. These being conceded, the peopling of the globe with its life, past and present, is conceivable." 


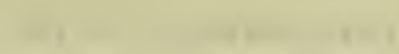


. . . "That phenomena go on in endless consequences, and that erery act has been preceded by some other act, and that every act will be followed by some other act; that the causes of all the phenomena of the universe that we wish to explain in a system of philosophy run back into the infinite past; that the consequences of all of the phenomena which we may now observe in the unirerse will run on into the infinite future. This is evolution."-Life of D.swix, by C. F. Holder, p. 224.-(John W. Powell.) 


\section{VIII.-STEM, BRANCH, LEAF, AND CLADOPHYL.}

What is the genesis of the part of a plant we call the leaf? It must have had a beginning in its present form somewhere. To meet with its beginnings we must go back to forms which are now wholly submerged, viz., to seaweeds. Seaweeds had no such organs as leaves, that is, in the sense botanists consider them, but only what they term cladophyls, reversions or continuations of which we see in land plants, such as Xylophylla, Ruscus, Phyllocladus, Phyllocactus, and others.

In the beginning there was no such thing as a differentiation of stem and leaf. The whole plant was either a simple or a compound cladophyl, that is, a branched stem-leaf.

In its simplest form the seaweed cladophyl is a cellular expansion, growing out of a corm-like cellular mass, or disk. If we want anything simpler than this, we must go for it to the spore. In Fig. 11 we have the spore of Asperococcus bullosus,

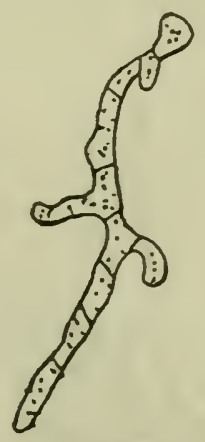

Fig. 11. Germination of spore of Asperococcus bullosus, Lamour. (Thuret, "Etud. Phycol.," pl. vi.)

Lamour. It is a cell which germinates, and throws out root-like or frond-like processes, and floats about, becoming a multicellular body. Erentually it attaches itself to something and leads a fixed life. 
Simpler than this even we have the unicellular body, which retains throughout its life a spore-like character, and reproduces itself without becoming a multicellular body.

The cladophyl of seaweeds then, from which both stem and leaf of phænogams descended, consisted originally of a simple midrib, which was a condensed cellular chord. From both sides of the midrib less condensed cellular expansions were given off, forming the lamina of the cladophyl. The midrib, where it existed, and the margins of the lamina, where it did not exist, were the budding organs. The raison d'être of the midrib seems to have been originally as a stiffener of the cladophyl, to keep its limp structure from collapsing. Afterwards, besides a stiffener, it became a carrier of vessels, when the leaf in an atmospheric medium had to draw its principal nourishment by way of the root.

We find an interesting example of the genesis of the stem from the midrib of the cladophyl in Delesseria coriifolia, Fig. 12. This is what Harrey says of this seaweed:- "Frond at first consisting of a linear-oblong or sublanceolate, midribbed leaf,

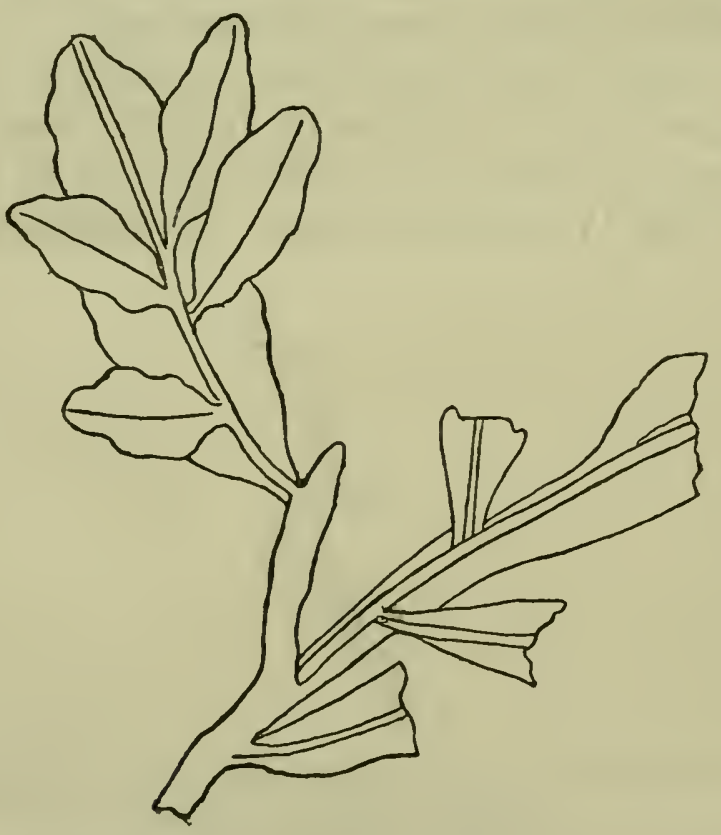

Fig. 12. Delesseria coriifolia ("Harrey's Phyc. Austr.," pl. 150).

which, on the decay of the lamina and thickening of the rib, is gradually changed into a compressed or imperfectly winged stem. 
This primary frond emits numerous similar leares which issue irregularly from the thick midrib, and in their turn emit secondary, and often tertiary similar, but smaller leaflets."

It is erident from this that there is no distinction between stem, petiole, midrib, reins and veinlets. They are smaller and smaller sub-divisions of the stem. Indeed, this is what Le Maout and Decaisne say ("Syst. of Bot.," p. 130).

"The relative position of the fibro-vascular bundle, which passes from the stem into the leaf, shows clearly that the leafblade may be compared to a flattened stem, the fibres and ressels of which have been spread out, and thus allowed plenty of room for the derelopment of parenchyma between their ramifications."

In the case of this Delesseria, the stem was first a midrib, and then after being divested of its lamina by decay, it became a stem.

At first there was no such things as fibro-rascular bundles. The stem, midrib, and laminæ were simply cellular, as in Delesseria, and the network of their cellular interspaces was their rascular system-an adumbration of the more differentiated rascular system of the higher plants of to-day. Fig. 13 gires an

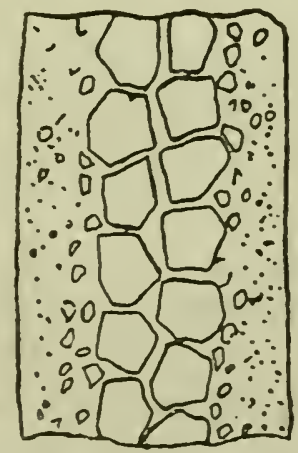

Fig. 13. Cross section of frond (magnified) of Rytiphloea simplicifolia, Harr. ("Harrey's Phyc. Austr.," pl. 246).*

idea of how the fibro-rascular system of phænogams may have dereloped out of the spaces left between the cells of cryptogams. These had no other circulatory channels but the spaces between their cells. Indeed, they had not much need of a more elaborate system of circulation for not being encumbered by a so-called

* In Polyphacum proliferum, Ag. pl. 188, the same vascular-like intercellular spaces are seen. 
epidermis, the circumambient water no doubt supplied the outer layers of the cladophyl with nourishment.*

Delesseria coriifolia has irregular or alternate budding, but D. Dendroides, shown in Fig. 14, has opposite budding from its midrib. The latter seaweed, in addition, affords us an adumbration of the origin of nodes and internodes. Cladhymenia conferta, shown in Fig. 15, has a winged stem and branches throughout with irregular budding.

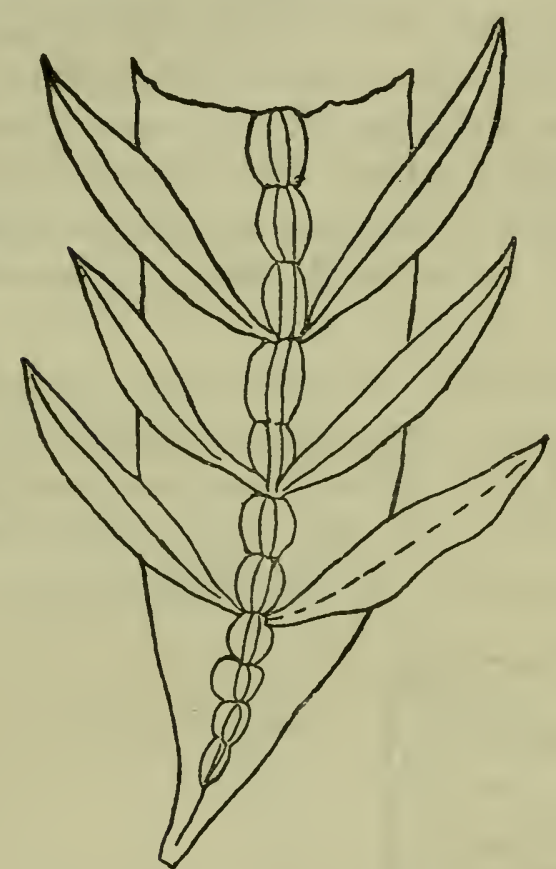

Fig. 14. Delesseria Dendroides

("Harv. Phyc. Austr.," pl. 137)part of cladophyl.

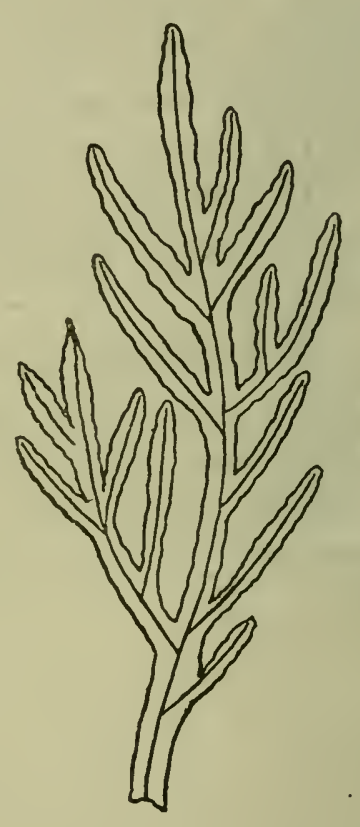

Fig. 15. Cladhymenia conferta ("Harv. Phyc. Austr.," pl. 144)-winged branches or cladophyls.

Another seaweed, Fig. 16, without having apparently a trace of midrib, shows that the margin of the seaweed cladophyl is equal, as far as budding is concerned, to the midrib. It is in fact, a flattened midrib. It also shows us how leaflets, lobes, teeth, and ovules of phænogams may have originated. D' Uvvillea potatorum ("Harv. Phyc. Austr.," pl. 300) has a similar structure. It is, however, many fathoms long, and broad in proportion, and its fertile fronds are studded with conceptacles. Of a like structure is Phyllospora comosa (pl. 153, Op. Cit.).

* Under the heading of "Fibro-vascular system," I have endeav oured to account for its genesis by a somewhat novel hypothesis. 


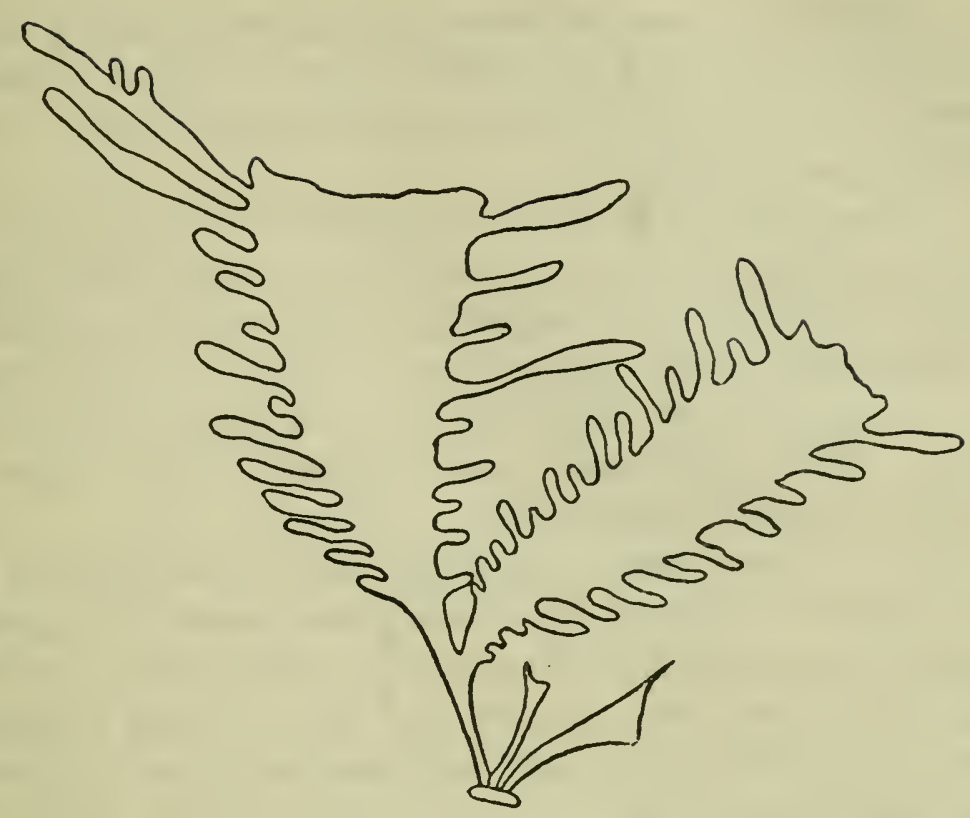

Fig. 16. Gigartina lanceolata ("Harv. Phyc. Austr.," pl. 288)-portions of cladophyls.

The reader who is imbued with the spirit of the evolutionary theory will see that in these seaweeds we have rudimentary stages of the stem, midrib, lamina, and other parts of the stem and leaf of phænogams. They are so simple in their structure because the medium in which plants commenced their evolution did not necessitate a more complicated structure.

We must try and get rid of the artificial and antiquated distinction of cryptogams and phænogams. If we accept the theory of evolution, the only meaning we can apply to them is analogous to that of stone and steel as applied to the erolution of a knife or axe. If we cannot find any sufficiently satisfactory links between these two so-called divisions of the regetable kingdom, it may be either because they hare disappeared or because there is no such thing as a gradual transition between plants inhabiting two so distinct media as water and air, unless they be those which inhabit swamps or a moist atmosphere, such as filmy ferns can live in.

In many species of Ranunculus, such as $R$. aquatilis, we find that the submerged leaves have no epidermis. The moment its leares are born into the air they have an epidermis. Therefore, 
this epidermis cannot morphologically mean anything different from the subjacent cells, which in an air-life it protects by becoming hardened. Le Maout and Decaisne ("Syst. of Bot.," p. 131) state as follows:-

"Submerged leares have no epiclermis, stomata, fibres, or vessels; their parenchyma is reduced to elongated cells, arranged in few series, and it is consequently rery permeable by water."

From this it would appear that an undue stress has been put by botanists on the distinction between cellular and vascular plants. We might with equal cogency divide plants into epidermic and non-epidermic.

We will now turn to another form of leaf, that of ferns. First, however, I should like to say that although it is generally true that the renation of the leaves of dicotyledons is reticulate, that of monocotyledons parallel, and that of ferns dichotomous, there is no hard-and-fast law that does not permit of deviation from these general rules. We have plants classed among monocotyledons, such as Smilax, which have a reticulate renation. The leares of the Elm, the petals of the Rose, the Gladiolus, the Tulip, the Begonia, and many others, as well as the leaves of Strangeria (a cycad) and Salisburia (a conifer) have a dichotomous venation, similar to that of ferns. The renation of the frond of Ophioglossum, as given in "Hooker's Brit. Ferns," pl.46, is certainly reticulate. Then the renation of the India-rubber plant is pinnate and parallel like that of the Canna. Near the margin of the leaf the parallel reins anastomose into a continuous vein, which festoons itself along the margin. There the renation is slightly reticulate.

How did the dichotomous renation of ferns and of the petals of phænogams originate? If we turn again to seaweeds we shall probably find a solution of this question. Some seaweeds consist of nothing but dichotomous threads of cells, strung together end to end, without any parenchyma whatever. Gymnocongrus fastigiatus, Fig. 18, Jania fastigiata, Challithamnion Griffithsioides, and others consist of nothing but fronds which are like fern veins. If, for instance, we took the frond of the filmy fern Trichomanes reniformis, Fig. 17, and dirested it of the intrarenous parenchyma, we would have something rery like Gymnocongrus fastigiatus and others. Fig. 18 represents the latter seaweed having the fronds or cladophyls 


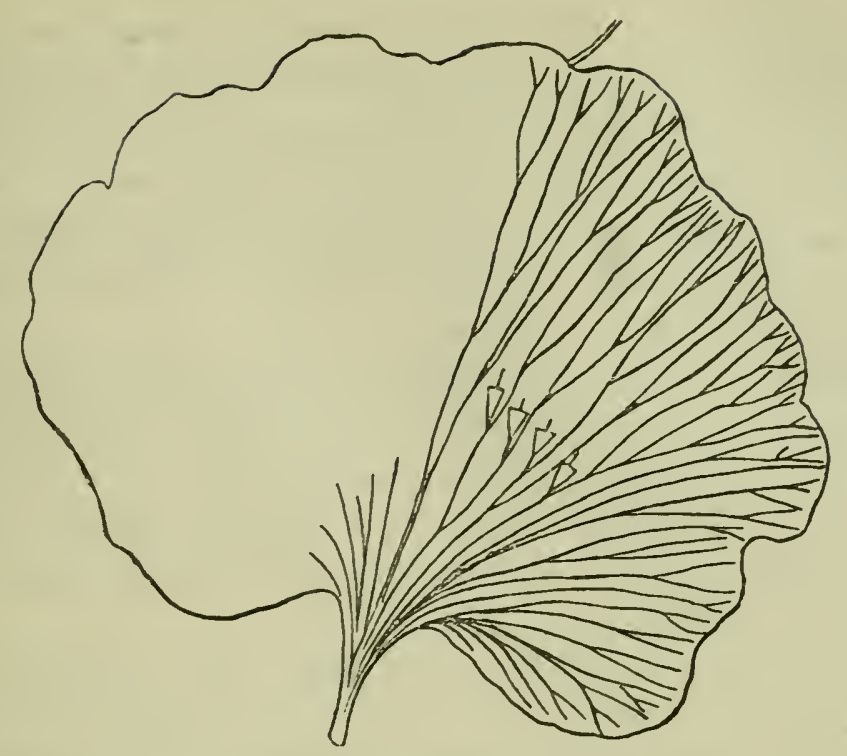

Fig. 17. Trichomanes reniformis filmy fern. ("Gard. Chron.," 26 July 1890.)

filiform, and the root a small disk. The reins of Trichomanes may have become first slightly winged, such as the branches of

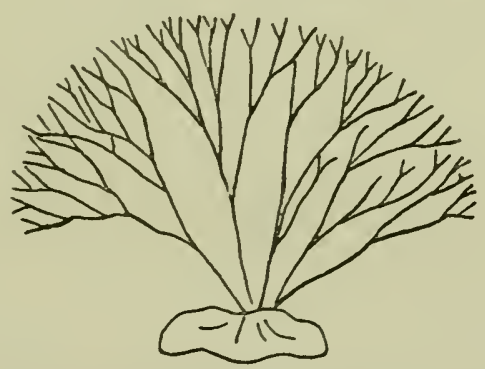

Fig. 18. Gymnocongrus fastigiatus ("Harr. Phyc. Austr.," pl. 290).

Cladhymenia conferta, Fig. 15, and then fasciated into a fan-like frond. So that, whether we take a fern frond or a cladophyl, we find their rudimentary forms among seaweeds.

The reader might, however, ask how did the leaf of a phænogam come out of a cladophyl ?

To answer this, I shall now try to show that the leaf, so called, is nothing!but a cladophyl. Indeed, there has been no transformation of the one into the other, but a continuation of the one into the other. The only modification has been that which would naturally occur, owing to a transition from a water to an air medium. 
All this, however, is hardly necessary to prove, for if, on evolutionary principles, it is admitted that the first beginnings of life must hare occurred in water, where we now still find descendants and modern representatives of those ancient beginnings, it will follow as a consequence that the air-leaf is a descendant of the water-leaf-the cladophyl of ferns being the connecting link. But let us go on.

Asa Gray* says that cladophyl is a branch assuming the form and function of foliage, such as in Ruscus, Myrsiphyllum, asparagus, \&c. Phyllocladium is a branch assuming the function of foliage, as in cactus, Xylophylla, and others. Phyllodium is a petiole usurping the form and function of a leaf-blade, as in the Acacias, Oxalis, Sarracenia, \&c.

It will-be seen at a glance that all these mean the same thing. I have already endeavoured to show that originally the stem, petiole, and midrib were one and the same thing, as in Delesseria, so that the petiole, being a branch, the phyllodium returns to its original form, the cladophyl.

Ruscus, Myvrsiphyllum, and others first acquired the form we call the leaf proper of phænogams. This then became abortive, and assumed the functionless form of tooth, or stipel, when the axillary branch reverted to the form of the seaweed cladophyl.

In the Acacias, howerer, where, according to Asa Gray, phyllodia "form the adult folinge of orer 270 out of less than 300 species," it is the leaf itself (or its petiole) that reverts to the cladophyl form, from which it originated. Curiously enough, it aequires the same position, with regard to the stem, that it has in seaweeds, its blade being somewhat perpendicular, instead of horizontal.

A large portion of the animal forms of Australia hare continued up to the present day their low type of marsupial origin. So, it appears, have large numbers of regetable forms continued the forms of seaweed eladophyls, from which they originated.

The phrnogamous plant, called Phyllanthus Chantrieri (Xylophylla) consists of leaf-like expansions of the stem. They are pinnate branches, or claclophyls, as they are called in botanical books. They are furnished with serrations or teeth on their margins, like those of leares proper. In the angles between the 
serrations of these expansions, flower buds are dereloped. Why the leaf-like expansions of the Fucus, the fern, the Fhyllocactus, and Opuntia are not also called cladophyls I do not know. If it be only a certain thinness of the branch leaf which gives it a claim to be called "leaf," then the leares of Cotyledon, Crassula, and others have no right to be called leaves.

I would now ask "What is the difference between the cladophyl of Xylophylla, with its flower-buds between its serrations, and the rose-leaf, which has lost the power of producing flowerburds between its serrations? The difference cannot surely consist in the one haring parallel veins and the other reticulated reins. For then all leares of endogens would be cladophyls.

The difference would appear to consist only in the one having been called a cladophyl and the other a leaf! In other worls, one has been called a cladophyl because it retained the power of producing buds between its serrations, and the other has been called a leaf because it lost that power!

But as flower-buds and branch or leaf buds are interchangeable,* the leaf of Bryophyllum calycinum should logically be called a cladophyl, for it has retained the power, though it does not always exercise it, of producing buds between its leaf-crenations.

The curious feature of all this is that the branches of Xylophylla are deciduous, that is, they behare exactly like leares, although they have never been honoured with that name! One cannot look at the sub-divisions of a fern frond, say of Woodwardia, the subdivisions of the stem of a Xylophylla, the sub-divisions of the stem of an Australian acacia, and those of a seaweed, without considering them all as one and the same thing, although they have been sererally distinguished by the names of frond, cladophyl, and phyllodium.

* The interchangeability of flower and leaf buds is well known to horticulturists. If at a certain stage of a fruit tree, when the buds are neither flowers nor leares, but embryos of both, manure and elements of luxuriant growth are given, they run the risk of getting plenty of leaves, and rery little fruit. The tree very often does this of its own accord every second year. This shows that the same bud will produce leares or flowers according to circumstances. Therefore, the cells which produce leaves must be essentially the same which produce sepals, petals, stamens, carpels, and orules! That is the regetative cells are identical with the reproductive cells. 
Asa Gray ("Struct. Bot.," p. 66) says:-" The cladophyl of Ruscus rereals its character further by bearing a flower on the middle of its face, in the axil of a scale-leaf, so that this may consist of two internodes; or else the flower-stalk may belong to an accessory axillary bud, bearing the scale-leaf close to the flower, and be consequently adnate up to this point with the axis of the cladophyl.* In Myrsiphyllum, the cladophyl exactly counterfeits a leaf in form and texture, as well as in function, and it never bears either scale-leaf or blossom (on its face); but the flowers are on slender stalks from accessory buds out of the same axil. 'The true leares are represented by thin and minute scales, which may escape notice," that is, the leaf proper has atrophied into a tooth or stipel.

The fact appears that, in Myrsiphyllum, the scale-leaf, the cladophyl, and the flowers are all branches from some archaic node, which has continued to develop more than two branches from one node (the leaf and the bud) as still happens in the lower plants.

Ruscus androgynus has pinnate branches, with alternate lanceolate cladophyls. The cladophyls have a cluster of male flowers on each margin, while Ruscus aculeatus has them on the midrib of the cladophyl. Midrib and margin, as will be seen further on, are, morphologically, one and the same thing. Reference to Gigartina lanceolata, Fig. 16, will show that it is nothing but an expanded midrib.

From all the foregoing it would appear that the distinction into leares and cladophyls will not bear scrutiny.

The grounds upon which the distinction was made appear to be because it became a dogma that each alternate node normally gave off two branches only-the leaf and the axillary bud.

Whenerer a stem became a cladophyl, that is, when it took up the functions of a leaf, the leaf proper naturally dwarfed into a tooth. Structural: botanists then insisted that, because what they called the leaf did not wholly disappear, it was something different from the stem. They might as well insist that because a leaflet dwarfs into a stipel, it is different from the midrib. They brought as evidence of their right conclusion the fact that the cladophyl of the Xylophylla produces flowers between its teeth,

* By reference to Delesseria, Fig. 12, it will be seen that the midrib of a cladophyl is quite equal to giving off leaves, and, therefore, also flowers. 
thereby proving that the angles botween the teeth were only dwarfed axillas.

In the Bryophyllum, however, we have a fleshy pinnate leaf proper, like those of other Crassulacex. It camnot be maintained in this case that it is a clarlophyl, because there is no subtending dwarf leaf proper. Nerertheless, the Bryophyllum leaf behaves like the cladophyl of the Xylophylla and that of Ruscus androgynus. It produces bucls between its inclentations. You may call it leaf or cladophyl, as you choose. The venation of the Ruscus cladophyl is parallel, like that of the leaves of other Liliacea. The two are one thing.

Helwingia ruscifolia has flowers on the midrib of its leaves. It belongs to a different order from that which includes Ruscus. Its leaves lave stipules. It would, therefore, come under Asa Gray's definition of leaf moper, yet on its midrib it bears flowers like the clarlophyl of Ruscus!

For the purpose of inpressing the rearler with the homology of leaf and stem, I will show that the leaf of phrnogams, in many cases, is, to all intents and purposes, a clarlophyl.

As an illustration, I take the Centanrea Babylonica. It has decurrent leaves, that is, a winged stem. In other works, two of the wings rum up the stem, and become the two sides of the leafblade. Further up the stem the leaf is depauperized into a midrib, which is just margined.

'To my mind, the wings on the stem indicate that it was originally a cladophyl, like that of Delesseria coriifolia; that in spite of the myrarls of transformations through which this plant has gone through-fiom seaweed to Centunrea-its cladophyl character has stuck to it, and, unlike many other plants, it has not been able to shake off, either from its petiole or its stem, the traces of its low origin, viz., the cladophyl of seaweeds. Call it leaf as we may, the leaf of this Centaurea is essentially a cladophyl. Its stem and leaf are to each other as stem and branch. These wings are remnants of seatweed wings or margins. In my opinion, all seaweed branches ocenpy the morphological position of phyllodia, and the axillary bud occupies the position of a branch of the phyllodium. 'There are four wings to the stem of this Centaurea, but they are not continuous throughout. 'Two fresh ones commence at each norle, and end by becoming the leaf-blades or margins of the next leaff. Curiomsly enomgle, the mirloils of this 
Centaurea leaf continnes down the stem, between two wings, or ridges, to show us that the leaf is only a continuation of the stem!

In other works, each internode, with its leaf, is the terminal burl of the internode below it, so that each pair of wings and internode are only the lower part of the next leaf, the whole forming a cladophyl, which in botanical language is sub-divided into stem and leaf.

Perhaps a diagram (Fig. 19) may explain better what I wish to

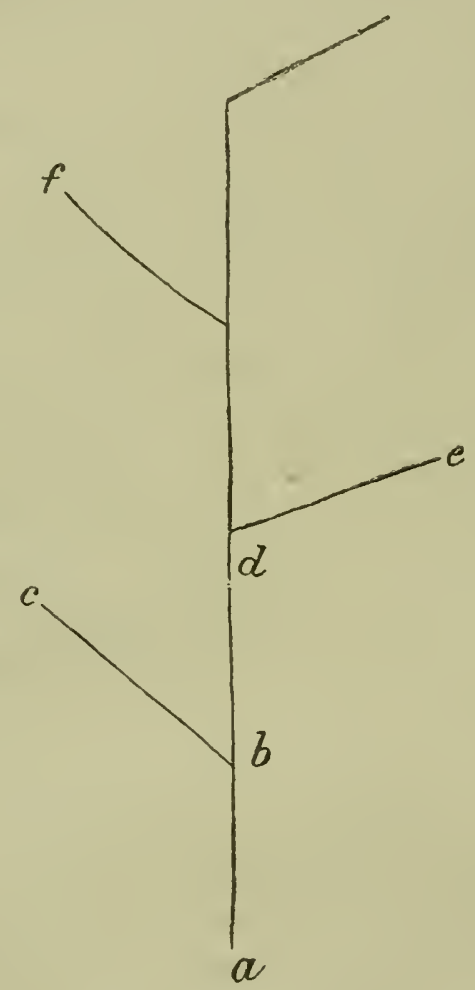

Fig. 19.

convey, in absence of a real plant. $A, b, c$ is a cladophyl-that is, a winged midrib. Then at $b$, a terminal bud continnes the stem ; $b, d, e$ is another cladophyl, and so on. In botanical language, however, we call $a d$ the stem, and $c$ and $e$ leaves. Now, at $b$ and $d$ there are also axillary buds proper. But these and the terminal buds are both branchlets of $a, b, c$, and $b, c, c$.

Eucalyptus globulus, when young, has four ridges on its stem. 'The leaves are then opposite and somewhat decurrent, a pair of ridges at each nole becoming, as in the Centaurea, the two sides of 
the leaf-blade. 'The ridges of this Eucalyptus stem I take to be remnants of stem-wings, inherited from the cladophyls of seaweeds.

As the Eucalyptus globulus grows older, instead of opposite leares, it gets alternate phyllodes, which we have seen are nothing but cladophyls.

The Centaurea the reader may, perhaps, not consider a good example of cladophylly, and for this reason. Let us suppose the stem to be undereloped, that is, like a closed telescope, and the leaves, with a slightly decurrent lamina, crowded together. It might follow that as the stem lengthened the decurrent part of the lamina would remain attached and stretched out with the stem, and thus become a pair of wings. That would be no proof that the leaf received its lamina from the stem.

The cladophyl of the Ruscus, one miglit also say, is evidently a branch in the axilla of the abortire leaf. The phyllode of the Acacia is evidently only a part of the leaf.

No such objection conld, however, be made to the phyllode of the Eucalyptus globulus. Here we have an ordinary horizontal leaf, without petiole, and with slightly decurrent margins, turning, further up, into a perpendicular phyllode with a long petiole, having a bud or branch in its axilla.

Apart from all this, which I admit is not very elear, when we once admit that the leaf is a branch, and a cladophyl can be substituted for a branch, it would be absurd to contend that the phrnogam leaf is not the homologue of the eryptogamic cladophyl.

Many of the compositre lave the petiole furnished with wings, which are a continuation of the blade, or as they would be called, apetiolate leaves. Indeed, a very large number of plants, although they have a marked petiole, have two more or less prominent ridges on its upper aspect, such as in horse-radish, beet, \&c. These ridges are nothing but remnants of ancestral petiole-wings, continued into the blade, indicative of their cladophyl origin.

The young pear-leaf has glandular teeth on its margin, and also along the sides of its naked peiiole, though here they are not so plentiful. This shows that originally the pear petiole had wings also, which are now aborted, the minute teeth only remaining. These are sparsely placed, because the potiole, in lengthening, has stretched the spaces between the teeth. Wherever we look, we find that facts tend to the conclusion that the stem 
of phænogams was originally at cladophyl, and that its midrib (now the stem) budded out into branches, like those of Delesscria. In cases where a midril had not yet developed, the edges of the cladophyl budded out, as in Fucus palmatus of Stackhouse, and D'Urvillea potatorum of Harrey, \&c. Among phrnogams we have the same occurring in Ployllocactus biformis and others, and Phyllocladus glauca (conifer). In the latter we have a fine example of the main leaf-branch aborting, and in its stead a branchlet (the axillary bul) taking its place. The true leaves are minute and scale-like, that is, they have aborted into stipels. In their axillæ, cladophyls have developed, as secondary branches, and again in the axilla of the teeth of these the inflorescence develops.

The expansion of the petiole of the Australian Acacias is nothing but a partial reversion in the young leaves, and a total reversion in the adult leaves, to the seaweed phase, although botanists have chosen to call them phyllodes. The Acacia leaf is often a combination of the cryptogamic and the phænogamic leaf. In Phyllanthus Augustifolius, Ruscus, Phyllocactus, Phyllocladus, and others, the phænogamic leaf proper has degenerated into a mere trace. Although they have reverted to the leaf-stem of their distant ancestors, they have retained the inflorescence of their nearer progenitors.

To an evolutionist it is hardly necessary to quote any more examples in support of the theory that the leaves of phænogams are distinctly traceable to the cladophyls of seaweeds, such as Delesseria and others. I, therefore, need not do more than refer the reader to the works of Esper, Harvey, Thuret, and others, on seawceds.

We can now trace the cladophyl a little further in phænogams. I will first refer again to Gigartina lanceolata (Fig. 16) and Fucus palmatus, marginifer (Fig. 20). These show us the origin of teeth, teeth glands, which so many plants possessing teeth have, and of orules on the margins of carpels.

With regard to marginal ovules, Le Maout and Decaisne ("Syst. of Bot.," p. 68) say: "Some German and French botanists regard the carpellary leaf as a protective organ merely, denying that it has the power of producing buds,* and limiting this power to the floral axis."

\footnotetext{
- The reader should note that they call ovules, buds.
} 


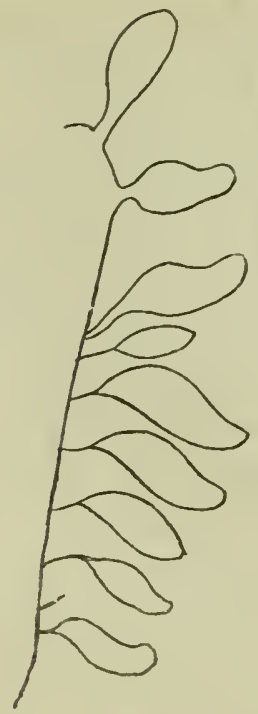

Fig. 20. Part of the margin of Fucus palmatus, marginifer (pl. 12, Stackhouse, "Nereis Brit.")—“The margins are proliferons, with hairs or rather stipitate plintlets, along the whole margin."

If the carpel is a leaf, and the leaf a branch, and a branch the satme thing as the cladophyl of a seaweed, it is evident that the margin of the carpel is homologous with the margin of Gigurtina lanceolata (Fig. 16) and others. The German and French botanists who "denied that the carpel had the power of producing buds," dicl not recognise that the carpel, the leaf, the branch, of phonagams, and the cladophyl of the seaweed were all, not only

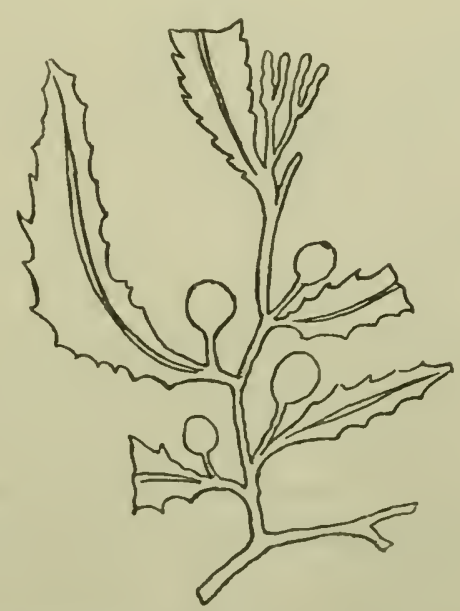

Figr. 21. Sargassum vulgare, Ag. (Harvey's Phyc. Brit., pl. 343). 
homologous, but the former the descendants of the latter. Moreover, is it not cnough to know that in teratological specimens the orule is transformed into a leaf??

In Sargassum, Fucus, and many other seaweeds, we see how the teeth of phrnogamic leares may have originated, without going the length of supposing them inherited, as atroplied lobes, of Gigartina. For in Sargassum, we have the leaf teeth already altered, and therefore may have been inherited directly and tale quale by the phænogamie leaf, supposing it to have descended from the seaweed cladophyl. It is more than probable that in Sargassum vulgare (Fig. 21) and others, the teeth are merely the depauperized lobes of some such ancestor as Gigartina lanceolata (Fig. 16) or Lenormandia marginata (Fig. 22).

In the latter, on the same cladophyl, we have fully developed branches, and also their atrophied representatives, the teeth. It undoubtedly also gives us a notion of the possible origin of

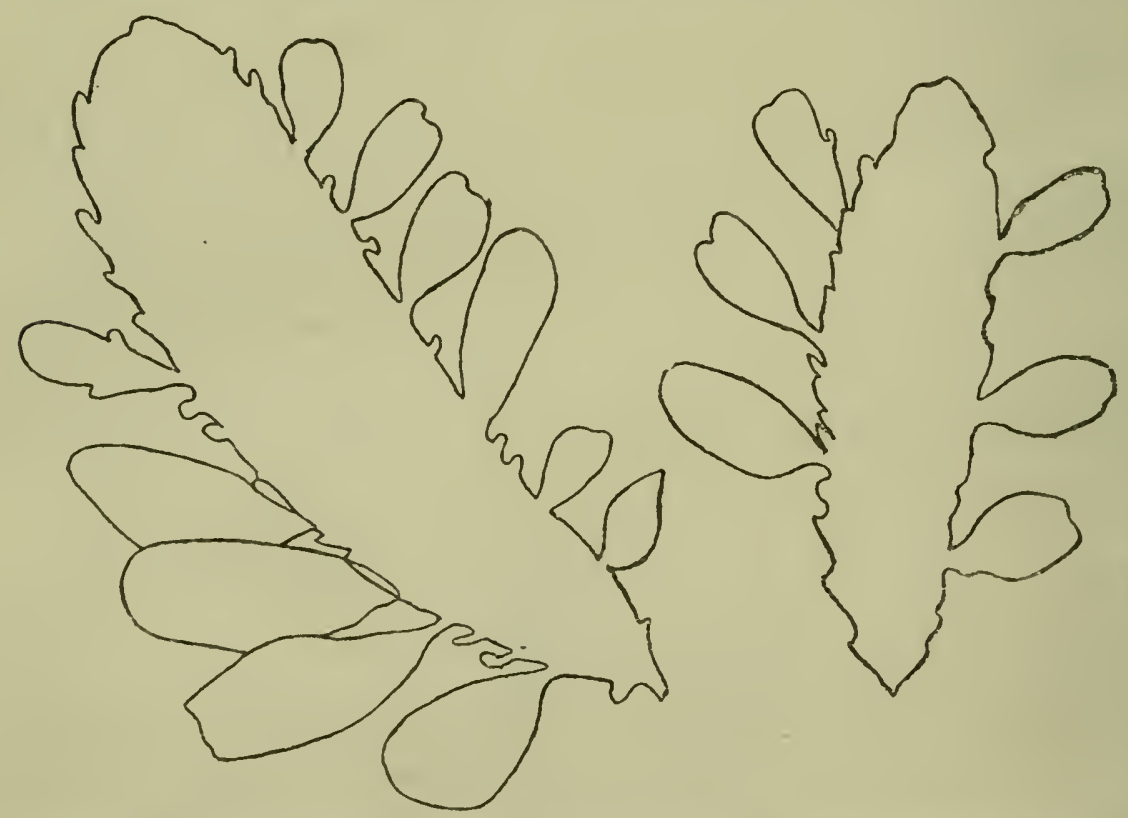

Fig. 22. Isobes, lobelets, and teeth of Lenormandiu marginata-H. I. \& II. ("Harvey"s Phyc. Austr.," pl. 235).

finnate leaves in phrnogams, the midrib being a depauperized biale of the cladophyl, and the pinne its branches.

Serrations or crenations on the margins of leaves are a very common feature indeed, in a vast nmmber of plants of very diverse 
natures. These undulations of the margin have been given various names, according to their size and form. We have the terms serrate, serrulate, dentate or toothed, crenate or scalloped, repand or undulate, sinuate, incised, and so forth. What apparently are more different in nature than a rose, a holly, and a chestnut tree? Yet the margins of the leaves of all three are dentate or serrate, the serrations being of clifferent size.

I am not aware that anyone has tried to work out the genesis of this feature, so general in leares. In the "Cultivated Oranges and Lemons of India and Ceylon" (p. 17 $\bar{i}$ ), I threw out the notion drawn from other sources, that the crenations and serrations of Citrus leaves meant leaflets or branches, but then I did not know that in seaweeds I could find the cradle of a feature so common in the leares of phrnogams. Seaweeds must have been the forms of plants, from which all our land plants have descended.

I feel certain that the serrations in the seaweed cladophyl are due to atrophy of branches, which in these ancestral plants were often giren off from the margins of the cladophyl, as in Fucus

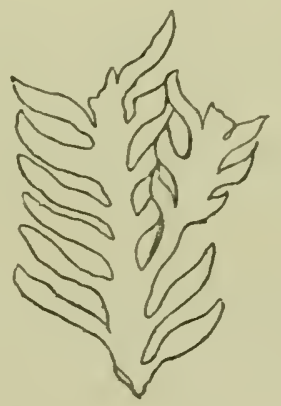

Fig. 23. Caulerpa tuxifolin (var.), Arr. ("Harvey's Phyc. Austr.," pl.17s)part of a fromr emerging from a rhizome.

palmatus, marginifier (Fig. 20), and Lenormandia maryinata (Fig. 22). In Caulerpa íaxifolia (Fig. 23) and Ptilota plumosa, Ag.,* we actually find the simple divisions of the margin transformed into more compound branches. And in Ilesmarestia ligulata (Figr. 126), we find eren the minute "spinelike teeth" transformed into hranches. So that branches and teeth may be regarded as homologous organs. 
As the lower plants evolved into the higher, and organs of reproduction became more differentiated and specialized, the leaves became a subordinate part of the cladophyl or stem. In Sargassum we see the branches not only already atrophied into teeth, but the future leaf, the inflorescence, and the axillary bud of plianogams adumbrated.

In the so-called entire margins of plants, these teeth may have become altogether suppressed, if their ancestral leares had them. But there are also seaweeds without any teeth, or margin buds.

These atrophied branches or serrations, like many other parts of plants, have been a feature which, although apparently useless in phanogams, could not be got rid of, but like the splint bones of the horse, have been inherited through millions and millions of generations.

In Sargassum lacerifolium (Fig. 95) we further see where the enliurgement on the petiole of many water phrenogams, and at the hase of the leaves of eertain cycads, \&e., may have come from. In seaweeds and water plants the bladdering of the petiole acts as a float.

Then this subsidiary idea of the derivation of phrnogamic leaf-teeth from eryptogamic eladophyl teeth would further support the main idea, viz., that the leaf and the eladophyl are essentially one thing. E. J. C. Esper (Icones Fucorum, 1800) shows Fucus sanguincus, * 'Tab. 33, as not only having a midrib but also veins and subveins.

Looking at the whole question then from an evolutionary point of view, I think the notion of the derivation of the phænogamic leaf from the seaweed cladophyl is not only highly probable but irresistible.

I think I have sufficiently shown that, morphologically, there is no essential distinction between the leaves of flowering plants and the leaves of seatweeds. But in further support of this conclusion I should like to quote the opinion of a botanist, who has been claborating a similar idea.

While in India, and before I had any facilities for reading what others had thought and written on the subject of the leaf, and from simple observation of the plants around me, I had come to the

* In Esper's time every seaweed appears to have been called Fucus. The thing is there pictured however, the name is of secondary importance. 
conclusion that there was no essential difference between the leaf and the branch. 'The last, of course, everyone recognizes as a repetition of the stem. The leaf I considered was, like the branch, only a sub-division of the stem, greatly modlified to meet the changed conditions to which plant life had been subjected.

It may be objected that the leaf is deciduous by a sort of joint, and the stem is not. The answer is-firstly, that all leaves are not desiduous. Some decay and remain attached to the stem, like dead branches; secondly, that in a family so well defined as that of orchids, some species have deciduous leaves and others not; thirdly, the joints or internodes of the stem of Begonia argyrostigma become deciduous by a sort of joint, like that of deciduous leaves, when, through some cause, the internode decays and dies; forthly, the branches of Xylophylla are deciduous. $\dagger$ Begonias probably teach us more about the nature of hairs, leares, and buds than most plants.

Asa Gray ("Structural Botany," p. 45) says : "In Begonia, a leaf, used as a eutting, will root from the base of the petiole, stuck in the soil, and produce buds on the blade, at the junction with the petiole or elsewhere."

The nerres of the Begonia leaf are like rerticillate branches, fasciated by means of mesophyl.

It would appear that not only are leaves homologous with stems, but, as Prof. Caruel observes, that the very hairs $\neq$ of Begonia phyllomaniaca ean make themselves homologous with branches, by dereloping into leaves and buds. The hairs of Drosera have, under certain cirecmstances, done the same thing.

After all these speculations of one's mind, it is comforting to find that I have not been thinking out and elaborating heresies, for in a paper on the "Comparative morphology of the leaf in the vascular Cryptogams and Gymnosperms," by F. O. Bower, communicated to the Royal Society by W. F. Thiselton Dyer, $\$$ the following is the conclusion come to, "Now the leaves in the lower forms naturally lend themselves to a treatment throughout as branch systems, while there is even in some complieated fern leares no structure which can warrant a distinction of the foliar base

\footnotetext{
* Baner's illustrations of orehid plants.

$\dagger$ As also those of Quercus Robur.

¥ Vide Discussion on Mairs.

$\$$ Vide "Proc. Roy. Soc.," vol. 37, p. 61 (1884).
} 
from the upper leaf. On these grounds, and in the light of this comparative study, it is concluded that the recognition of the phyllopodium, * and treatment of the whole leaf, as a simple branch, or as a branch system, is in accorlance with the true nature of the leaf, as seen in all vascular plants; while at the same time, if this method were adopted, the whole shoot (or developed bull) would then be subjected to consistent morphological treatment, since the relation of the pinnce to the phyllopodium is similar to that of the whole leaf to the axis, which bears it."

'The bud in growing and developing itself would sub-divide into leaves, and the plyyllopodium of each leaf would sub-divide into pinne, or, in other words, the shoot divicles into axis and leaf, and the latter into phyllopodium (which is an axis) and pinna (which are smaller leaves).

What clearer exposition of the morphological nature of the leaf is needed in spite of the accompanying unnecessary technical terms? 'The leaf is a branch like all other bianches, and the pinna or leaflet is to the midrib what the leaf is to the main stem.

Nothing can more clearly show the identical nature of the mirlrib and stem than the case of rerersion quoted and pictured by Dr. Masters in his "Vegetable 'Teratology," p. 88, where the main flower stem of a Gesnera has reverted to a midrib, and the flower peduncles to leaf veins-all fasciated into a leaf by means of the mesophyl! 'This shows that the midrib of the leaf is homologous with the main stem of a plant, and the leaf veins homologous with the sub-dirisions or petioles of that stem.

Lindley, in his "Veg. Kingd.," p. 223, says that Miquel regarded the leaf of Crcads as a sort of branch, so that the Cycad ovules would really be homologous with axillary buds.

Goebel ("Outlines of Classif.," p. 209) considers the stem of Lyyodium among ferns to be the midrib of an indefinite leaf, its apex growing for a long time after the lower pinna are fully developed, as in the case of Nephrolepis, and others. 'Those parts of Iygodium which were consilered leaves, are only pinna, which go on repeating themselves indefinitely in the same form. 'The apex of each leaf-like division remains like a dormant terminal hul, while the midrib contiunes to lengthen indefinitely, and becomes the main stem, and gives off similar leaf-like divisions or compound pinna.

\footnotetext{
* Petiole and mirlrih.
} 
Le Maout and Decaisne ("System of Botany," 1873, p. 130) write thus: "The anatomical structure of leaves is the same as that of the stem; they consist of a fibro-vascular bundle and parenchyma ; this lundle, which is wholly formed before leaving the stem, spreads into a blade, as it emerges, in sessile leaves, or remains undivider for a certain distance before expanding, in petiolate leaves. The nerres of the blade are formed of fibres and ressels; both it and the petiole are covered with a layer of epidermis bearing stomata on every part, excepting the nerres and petiole. . . . . . The relative position of the elements of the fibro-rascular bundle, which passes from the stem into the leaf-blade, may be compared to a flattened stem, the fibres and ressels of which have been spread out, and thus allowed plenty of room for the derelopment of parenchyma between their ramifications."

On p. 131 they further say that, "The leaf originates as a small cellular tumour, which afterwards dilates into a blade, the cells on the median line of which elongate and form fibres, then, as in the stem, first trachex, and lastly other ressels."

Asa Gray ("Structural Bot.," p. 4T) says in a note: "In phænogamous plants only the ramifications of axes should take the pame of branches, that is root and stem branches; and the term may without confusion be extended to hairs, and all trichomes when compound, but not to leares and their morlifications (!)."

With the light thrown by Bower and others on the nature of the leaf, Asa Gray's statement is no longer tenable. Where is the line to be drawn? Leaves are undoubtedly branch systems, and evidently a further development, in a different medium, of the cladophyls of seaweeds. Their sub-divisions are as much branches of the petiole and midrib as the root divisions are lranches of the root axis.

Why the reins are in one plane, and not all round the midrib, as they generally are round the stem proper (but not always, as in the common yew) is because they inherit that morle of emergence, owing to the necessity of exposure of the parenchymatous surface to the light. To do this, the leares must be horizontal and look upwards, although there are many exceptions to this rule, owing to other disturbing circumstances. This necessity, being forced 
on the leaf from generation to generation, has become a fixed inheritance.

One cannot stand under a lime-tree in leaf, and look up, without noticing the homology of its branches with decompound leaves. The branches of the lime-tree being horizontal, the identity of the two becomes much more striking. The branch corresponds to the petiole and midrib, the secondary branches to the secondary petioles, and so on till we reach the ultimate foliar expansions, which are the leaves proper; both in the lime branch and in the decompound leaf the sub-divisions are homologons, although in the latter the ultimate sub-divisions would be called leaflets. 


\section{CONCLUSION.}

Then, after all this discussion, which threatened to become interminable, the reader might ask, What is the upshot?

In a few words the inevitable conclusion is :-

(a.) That in the passage of plants from a water to an air medium, the cladophyl or frond of seaweeds has become the leaf of land plants, with its infinite modifications of texture, \&c.

(b.) That the midrib of Delesseria coriifolia, in turning, by decay of the lamina, into a stem, shows us that the midrib of the leaves of flowering plants is nothing but a stem, and that there is no morplological distinction between the cladophyls of land plants and their leares.

(c.) That it is the commonest phenomenon in seaweeds for the margins of their leaves to give forth branches, and that the atrophy or non-derelopment of the latter is represented by marginal teeth, both in seaweeds and phænogams.

This being so, it follows that the teeth of phrnogamous leares represent atrophied branches. In other words, the stem of a plant corresponds to the midrib* of its leaf; the leaf is to the stem what a tooth is to the leaf. When a leaflet atrophies it becomes a tooth, as in Vicia hirsuta (Fig. 36), and when a leaf atrophies it also becomes a tooth, as in the depauperized leaves of Ruscus; although the leaflet and leaf are transformed into teeth, they do not always lose the power of giving off buds (branchlets) from their axilla, such as are those of Xylophylla and Ruscus.

* The gnarly and erooked stem of an old oak certainly does not look like the midrib of one of its leaves. Age and the old bark have masked the stem's irlentity with tho midrib. 
All teeth of plants correspond to atrophied leaflets and leaves, or, homologously, to atrophied branches. This is the reason we find "vascular bundles from the ribs and nerres of leares extending into the serrate projections of the margin."*

This means that the serrate projections we call teeth, and which receire a rascular bundle, are comparable to branches of the leaf, and, as such, comparable to branches of the stem.

The reader might say and "What about glands and hairs"? These I hare discussed elsewhere.

* Bower, "Pract. Bot.," 3rd edit., p. 124. 


\section{APPENDIX TO SECTION VIII.}

\section{Notes ox Leates.}

1. Hardentergia Comptoniana has a trifoliolate leaf, with two stipels to each leaffet, and two more at the base of the pair of leaflets, as shown in the accompanying Fig. 24. But on the same plant I found

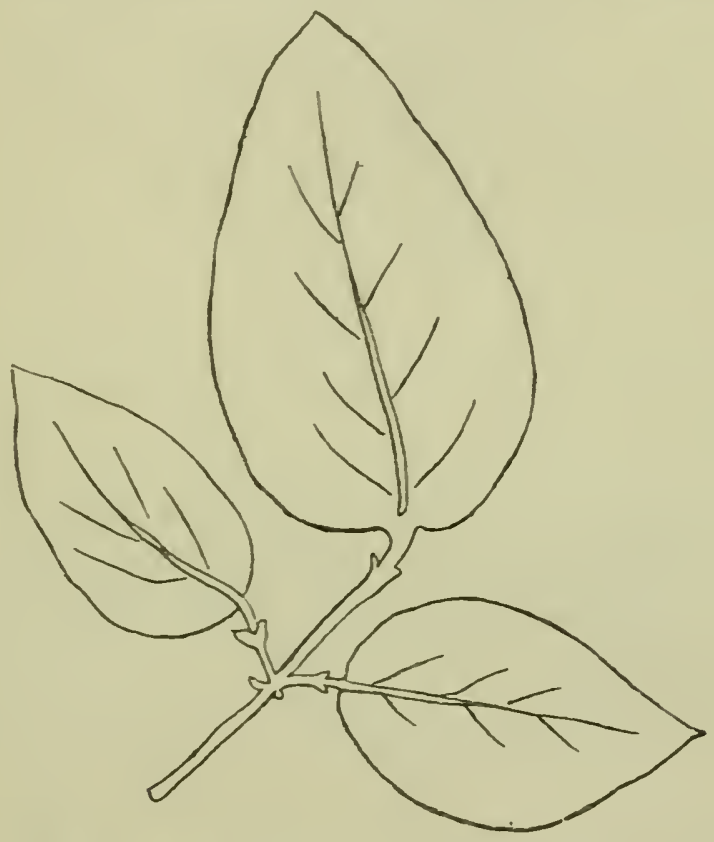

Fig. 24. Trifoliolate leaf of Hardenbergia Comptoniana (Roval Gardens, Kew).

some leares that were like Fig. 25. This showed at once what the stipcls mean. Thes are abortice leaflets, there being no room for them in the disposition of the leaf that,this Hardenbergia has now. The original leaf was something of the nature of the accompanying diagram, Fig. 26, and by the contraction of the petiolets all the secondary leaflets became atrophied into stipels, and the leaf reduced to a trifoliolate type instead of a bipinniate type. In many instances not eren stipels or glands are left to tell the tale of the ancestral type, as in the opposites of $(a)$, which bave been entirely 
suppressed, without leaving any trace of their former existence in that position.

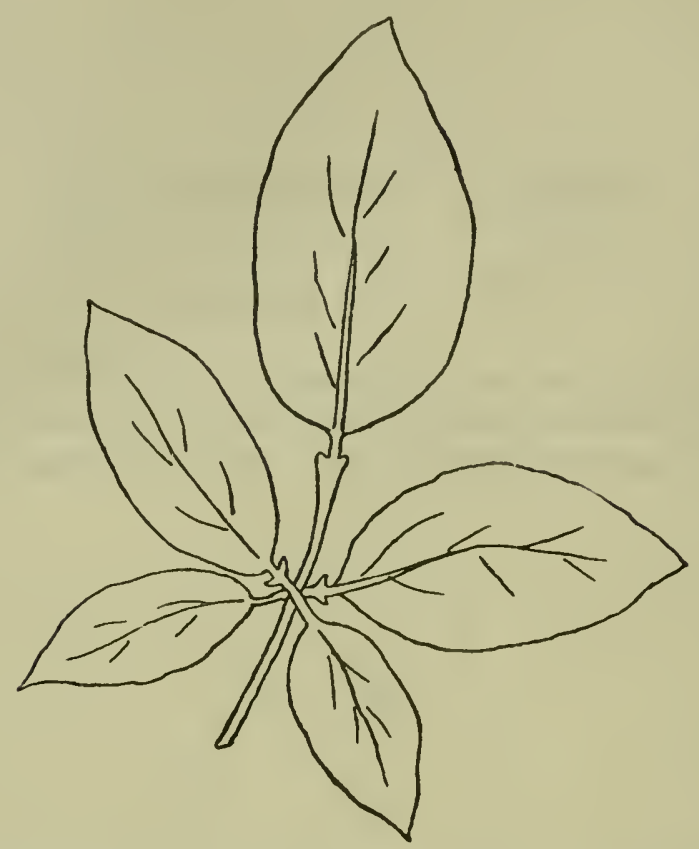

Fig. 25. Occasional leaf of Hardenberyia Comptoniana.

2. The Wistaria leaf (Fig. 27) has several pairs of leaflets and an odd one. Each leaflet has a stipel, and the odd one has two, as shown in the accompanying diagram. What do these stipels mean ? They are depauperized leaflets, the Wistaria leaf having probably descended f $1^{\circ}$ om one with trif'oliolate pinnr. 'They are not needed now in this plant, but, like the splint bones of the horse (depanperized

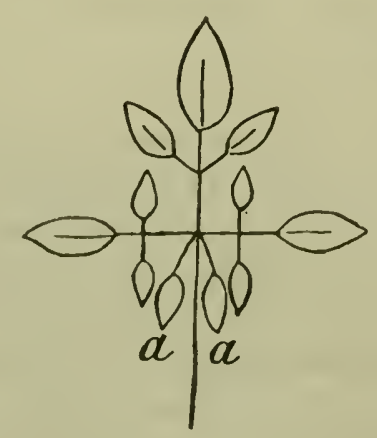

Fị. 26.

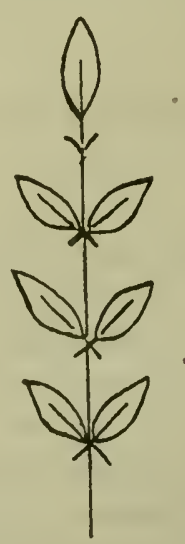

Fị. 27. 
digits) they are still inherited, as remnants of bygone parts, because the force of heredity is too strong for their total suppression. The accompanying diagram (Fig. 28) is an attempt to reinstate the original form.

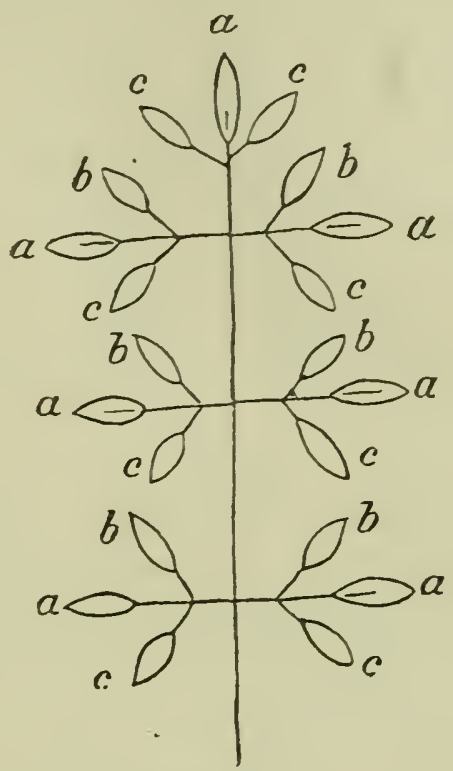

Fig. 28.

In the Wistaria (a) remain, (b) are entirely suppressed, (c) are aborted as stipels, and all the petiolets have disappeared excepting that of the odd leaflet. The leaflets $(a)$ hare become sessile, leaving no room for leaflets (b), and of (c) only abortions remain as stipels. So that the simple contraction of the petiolets has caused this transformation.

3. In Erythrina the leaf is trifoliolate. It has two very small stipels at the base of the pair of leaflets. There is, in addition, a pair of glands just above the pair of leaflets and two more at the base of the odd leaflet. The diagram (Fig. 29) shows the probable

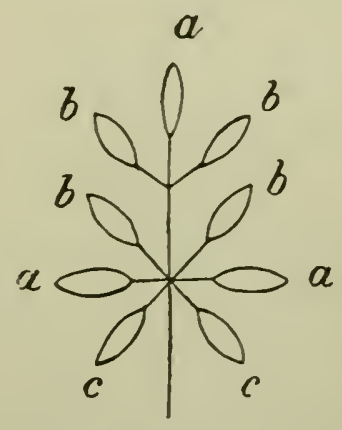

Fig. 29.

$\triangle$ p. 1724. 
original form. The leaflets (a) remain, (b) are aborted into glands similar to the petiole glands of apricots, cherries, \&c. and $(c)$ are aborted into stipels.

4. A Spircea had the form of leaf shown in diagram, Fig. 30-(a)

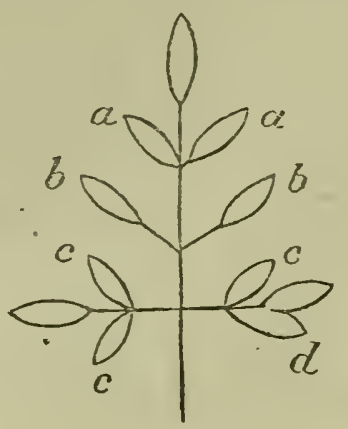

Fig. 30.

were sessile, (b) petiolated, (c) secondary sessile leaflets, and (d) only a lobe of the odd leaflet. This shows how unimportant the forms of leaves are, except as a means of identifying plants for economical and other purposes. They are elastic, as if it were. They can either spread out, and form independent petiolated leaflets, or contract into separate sessile, or eren into lobed laminæ. If this Spircea leaf were shortened, it might assume something of the form of the Erythrina leaf. It also shows that a lobe of a leaf is interchangeable with a secondary leaflet, as in the variegated maple, raspberry, and others; and that it may be no other than a main tooth, and the toothlets no other than abortive leaflets.

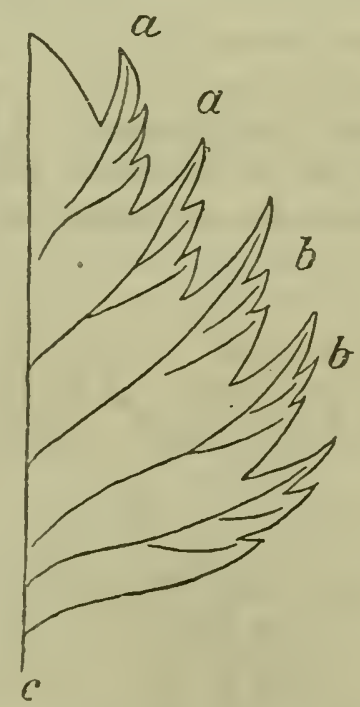

Fig. 31. Margin of Spirca ieaflet; (a) abortive secondary leaflets, (b) abortire tertiary leaflets, (c) midrib of entire leaflet. 
The renation of this Spircea is as in Fig. 31. The midrib of the leaflet corresponds to a branchlet, a vein to a secondary branchlet, and a veinlet to a tertiary branchlet, indicating that the teeth of this leaf are abortive secondary and tertiary leaflets. The fasciation of the reins reduced the secondary and tertiary leaflets to teeth. Or the reader may reverse the process. If this leaflet were further spread out, the teeth would be liable to become independent leaflets.

5. A whole branch may be suppressed, and only a scale left to show that it was ever there, or a whole whorl may disappear learing nothing but alternate scales to show us what happened, as in the Thalictrum leaf. A whole leaflet may be suppressed and leave no trace of its former self, except a minute stipel or gland. Similarly, lobes of leaves may be reduced to teeth, and even disappear altogether. In the genus Ilex we hare I. aquifolium with very large teeth, or spiny lobes; in $I$. crenata and dipyrena we have regular small teeth, and in I. aquifolium Bessoni we have neither teeth nor crenations.

6. In a Pyrethrum I found that some of the leaflets were opposed, some alternate, and some had two small leaflets at the base of the petiolets, as shown in Fig. 32. This shows that the secondary

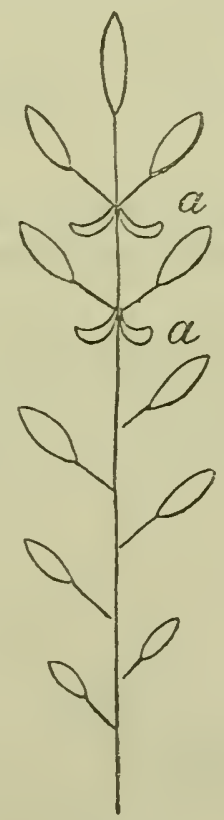

Fig. 32.

Ieaflets $(a)$ are in a transition state between leaflets and stipels. Also that in the other leaflets all the secondary sub-dirisions hare been suppressed. Moreover, it shows that the character of opposite and alternate leares has little significance, beyond, as I said, the advantage of identifying plants for economical purposes, and studying their possible relationship, as most of these characters are inheritable, and would gire indication of community of descent. 
7. In the potato leaf, between the pairs of opposite leaflets, there are pairs of smaller leaflets. 'l'he latter are opposite or alternate if the former are opposite or alternate, and sometimes they are altogether wanting. I think this disposition would admit of being explained as follows:- The potato leaf descended from a bipinnate leaf, the intermediate (c) being the secondary leaflets left behind by the extension of the midrib. The two diagrams, Figs. 33 and 34, will explain what I mean: $(b)$ are the secondary leaflets of $(a),(c)$

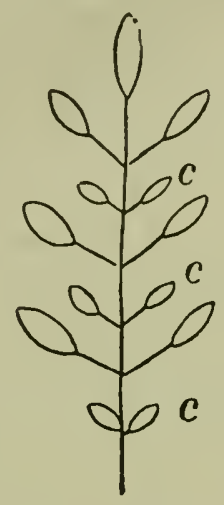

Fig. 33. Diagram of potato leaf.

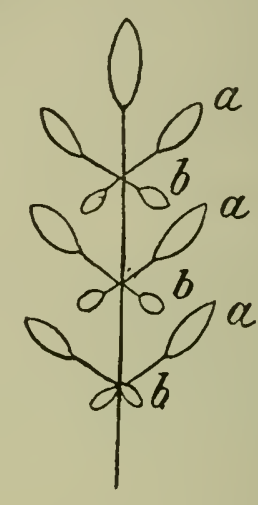

Fig. 34. Diagram of leaf from which it may have deseended.

the same, left behind by the extension of the midrib. In other instances $(c)$ would have disappeared altogether, or become atrophied into simple stipels.

8. This mode of reasoning is not entirely without foundation, for Dimorphanthus mandschuricus, with a bipinnate leaf, has a pair of sessile leaflets on the midrib at the emergence of each pair of pinnæ, as shown in the accompanying diagram (a) Fig. 35: (a) are

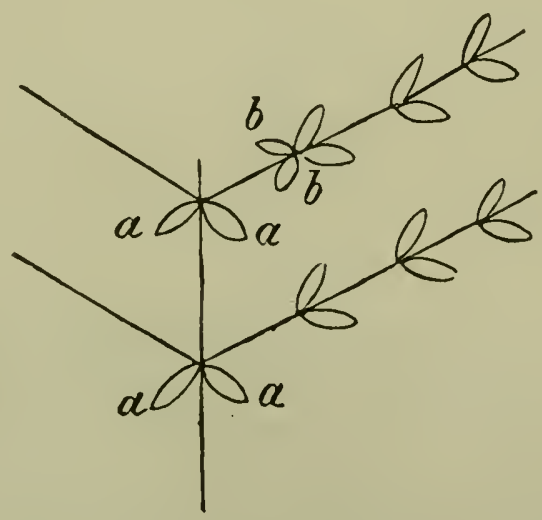

Fig. 35. 
the pairs of leaflets which should not be there, as there is no room for them; (b) are the secondary pairs of leaflets, which should not be there either, as they belong to a decompound leaf and not to a bipinnate one; $(b, b)$ are there by reversion, in this particular abnormal pinna, which I copied from nature.

9. One of the most interesting examples of the abortion of leaflets into stipels I have come across is in the drawing of Vicia hirsuta, given in Syme's "Brit. Bot.," Fig. 36. The two lower leaves

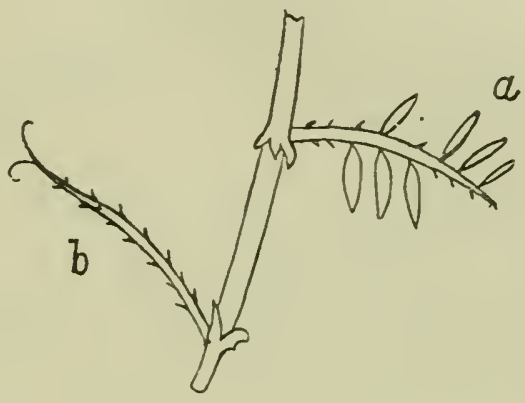

Fig. 36. Lower leaves of Vicia hirsuta (Syme, "Brit. Bot.," pl. 382):(a) leaf with some of the pinnæ atrophied, (b) leaf with all the pinnæ atrophied and converted into stipels, or teeth.

have their leaflets either totally or partially converted into stipels or teeth. This and the leaf of Hardenbergia Comptoniana show without doubt how the stipels of leares and teeth should be interpreted.

10. A palmate or digitate leaf is nothing but a pinnate leaf, shortened. The palmate leaf is only a partial fasciation of the digitate variety. If digitate or palmate leaves were upright, they wonld be verticillate divisions of the petiole or stem-branch, as in Rodgersia podophylla. The leaves of the latter are erect, because the stem proper is recumbent, as a rhizome. If the stem were, on the contrary, erect, and the leaves horizontal, then the leaflets would have arranged themselves, as in the horse-chesnut, with those nearest the petiole smaller. Why they are smaller it is not easy to say, but we find that the leaflets nearest the petiole are often subject to starvation, and consequent depauperization and atrophy, as in the stipels of Wistaria.

11. Similarly, Diphylleia cymosa has a palmately lobed leaf, when horizontal, but when erect it becomes peltate, and dirided into two equal portions, as in the diagram, Fig. 37.

Begonia carolinicefolia has leaves similar to those of Rodgersia, but with eight verticillate leaflets, and a potential bud in their 


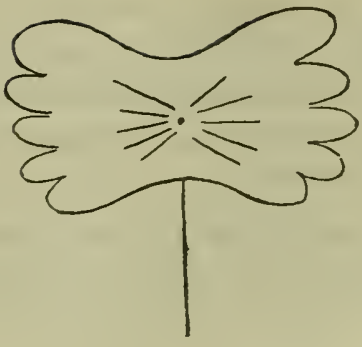

Erect peltate leaf of Diphylleia cymosa.

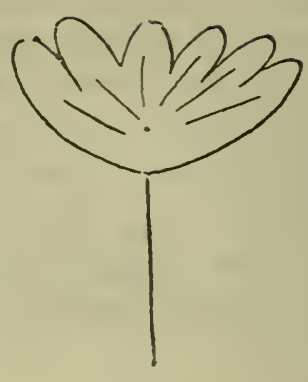

Fig. 37 .

Horizontal palmately lobed leaf of the same.

centre, so that this leaf is not unlike a branch of Woodruff (Sherardia) with verticillate leaflets.

12. A pinnate leaf, if it were erect, would be a branch with either opposite or alternate leaves.

13. Amorphophallus Rivieri, Titanum, and others have only one decompound erect leaf, and its divisions are placed regularly all round the main petiole. This leaf is the whole tree.

14. The leaves of Thalictrum aquilegifolium and purpuratum are among the most interesting examples of leaf-branches. At the point of emergence of each sub-division there are three bract-like scales alternating with the sub-divisions. As the division of the leaf is trichotomous, these scales are evidently abortive divisions, for which there would be no room in this horizontal leaf-branch. Make it erect, that is stem-like, and its nature is at once revealed. The pinnæ become branchlets, and the alternate scales become abortive branchlets, so that the system was originally a branch with
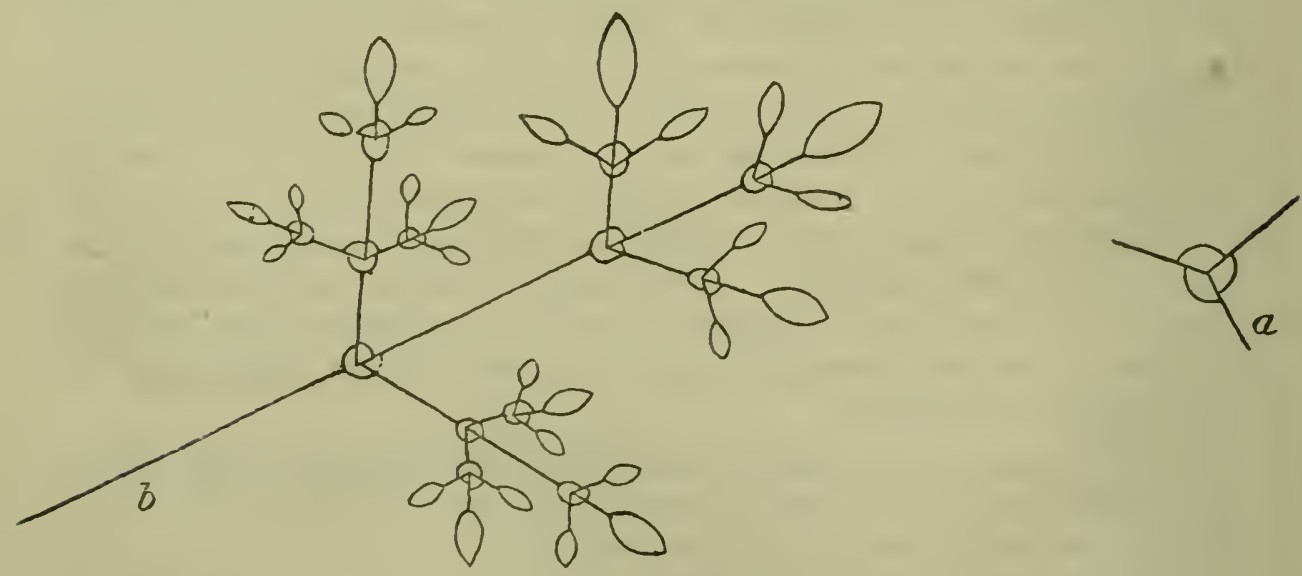

Fig. 38. 
verticillate leaves, in two whorls, the leaves of one alternating with the leaves of the other.

The accompanying diagram (Fig. 38) may give the reader a better idea of what is meant: (a) represents each rode of the Thalictrum leaf, as wonld be seen from above, if the leaf were erect, that is, three divisions of the petiole, with three alternating scales; (b) is a diagram of the leaf, with three alternating scales at each node or division.

In some species of Thalictrum these nodal scales hare entirely disappeared, so that the whole leaf looks like an ordinary decompound leaf while in reality it is a branch pure and simple, functioning as leaf.

15. In many cases we find plants inheriting the leaves of another order, only distantly aliied to it, that is to say, of an order not recognised by botanists as closely allied. For instance, in Dendrobium Falconeri delicata, the leaves have an ochræate ragina and blade indistinguishable from the leaves of certain grasses, although the latter are placed by systematists a long way off. Then Dendrobes in their flowering stems have only ochræate vaginæ, without blades.**

16. In other cases it would appear that an organ in one order has been depauperized to the level of a homologous organ in another order without their having had any proximate relationship, other than that they descended from a common and more distant centre.

17. The fact is there appears to be in nature no such thing as order's of plants. This term only means an artificial grouping of indiriduals because they resemble each other in some of their features. There is no law to prevent a leaf of one order, for instance, growing like the leaf of another order, except the restraint put on it by heredity, but this restraint may be frequently interfered with by crossing, or by some other, at present unknown, influence. It is enough to read through the order of Sapindacce, in Lindley's "Veg. Kingd.," to see how little resemblance there may be in plants even of the same order. He says, "This order is composed of a great diversity of species, which assume appearances widely different from each other; so that botanists have not unnaturally supposed that it really contains the elements of several distinct natural orders. . . . The true character of soapworts resides in their unsymmetrical flowers (the stamens never agreeing in number or power with the sepals), in their anthers bursting longitudinally, and in the petals having an appendage, while the

* Such as we see in young bamboo stems, viz., vaginæ, without blade or with only an abortive blade. 
seeds have an aril, and the embryo is curved or spiral. But none of the latter characters are constant, and consequently the definition of the order becomes rery difficult (!)."

18. It is no wonder that botanists are sometimes puzzled about the true affinities of a plant, considering that fusion and suppression of parts may have frequently masked their derivation. If it were not for the persistent inheritance of certain characters, which often occurs, botanical classification would hare been impossible, or little better than a chaos.

19. Just look into another order, that of the Liliacece. Who would suppose that the onion, the asparagus, the butcher's broom, the dragon-tree, and the grass-tree are all made to claim relationship with the lily and the tuberose. It would seem that Aspidistra can be included in the same category only by a sort of botanical courtesy.

20. Eren in such natural groups as the Limes and the Oaks, we find foliage so distinct that it might as well belong to totally different plants. An inspection of the collections of these genera in the Royal Kew Gardens is very instructive.

21. Asa Gray* gives a drawing of the summer shoot of the Barberry. The lower leaf is normal, and only toothed, and stipulate; the next has the blade more contracted, and the teeth longer and broader, the stipules having disappeared; by greater contraction the whole blade disappears, and the leaf is reduced to something like a branched hair.

* "Struct. Bot.," p. 117. 

. . . . "till finally we are almost at a loss to tell whether it is a horse-like, a rhinocerotoid, or a tapiroid animal that is before us, and they become lost in earlier forms, with special characters of their own."-LiFE of Darwin, by C. F. Holder, p. 206. 


\section{IX.--STEM AND RHIZOME.}

What is a stem? Asa Gray says, "The stem is an ascending axis seeking the light"; while the "rhizome is a stem, which lies on the ground, or is buried beneath its surface." There is really no other distinction between the two than that of position.

Asa Gray also states that "roots spring from the stem, not the stem from the root." It would appear to me that it is neither the one nor the other. Both are continuations of the same thing. What is called the radicle in the embryo is a continuation of the caulicle, and the prolongation below the cotyledons may be called either a stem or a root.

In "Baner's Illustrations of Orchidaceous Plants," Lindley says that when the tubercles of terrestrial orchids are deep in the earth, they send up a root-like stem, which produces true roots, until it reaches the light, and then develops leaves, such as Coryanthes and others.

Now, have we any means of getting at the genesis of the rhizome? If we can do this, we have the origin of the stem, for the latter is nothing but an upright rhizome.

Dallinger in his "Minute forms of Life" has perhaps given us a hint of the genesis of the rhizome in plants. He and Drysdale have watched, with great patience and perseverance, through the microscope, the derelopment of several monads, and have thus given us their life-history. Fig. 39 shows us the various stages in the process of multiplication of a monad by fission. At first this monad is a simple cell with only one nucleus and a pair of cilia. Then the nucleus becomes double as at $(a)$, and the one pair of cilia splits up in two separate pairs. The next steps are a further separation of the nuclei with their cilia, as at (b) and $(c)$. Finally $(d)$ shows us their condition before the separation into two distinct unicellular bodies takes place. 

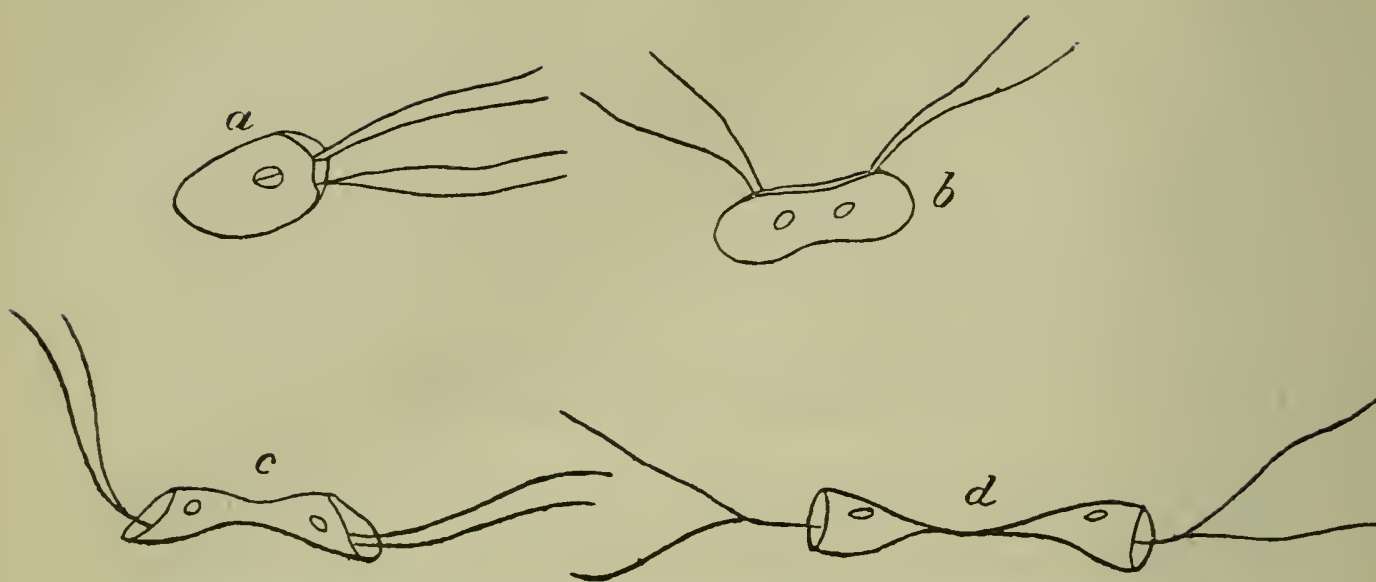

Fig. 39. Monad from Dallinger's "Minute Forms of Life," $(a)$ commencement of division into two cells, (d) stage previous to final separation, (b) and (c) intermediate stages.

Now, with these figures before us, we may perhaps be able to understand what I conceive to have been the genesis of the rhizome. Each nucleus represents a growing point. Each pair of cilia represents two hairs, or rudimentary leaves. In the nucleus and the hairs we have the elements of a node, with leaves, or roots.

If the reader will now use a little imagination and fancy that this monad at the stage $(c)$ is ever trying to split itself into two independent parts, but never succeeding, he will picture to himself a primitive rhizome, for each cell or node would again try to split itself into two, and fail, so that a series of cells with their cilia will be strung together, the interspaces being the internodes of this primitive rhizome. We would have eventually something of the nature shown in the diagram, Fig. 40.

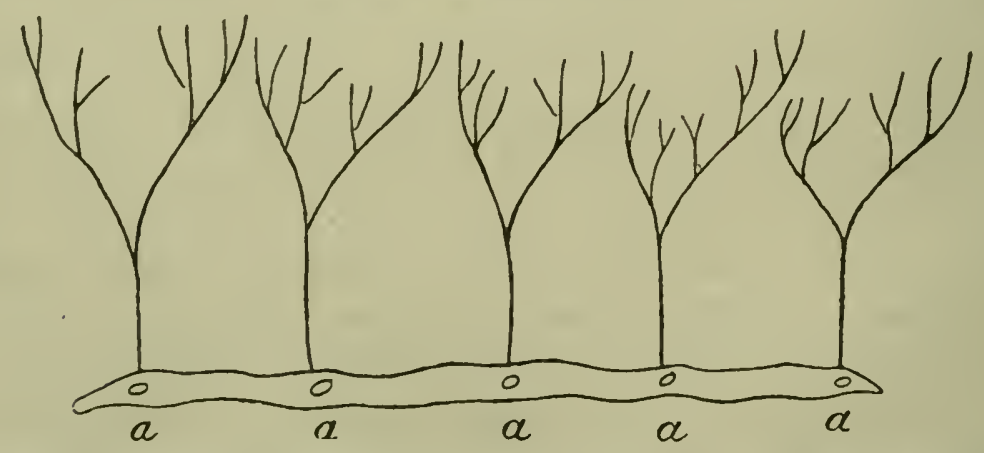

Fig. 40. Diagram showing how a monad might develop into a primitive rhizome, $(a)$ the nucleated points, with the cilia developed into branches. The spaces between the growing points remain as internodes. 
What are called internodes in the rhizome or stem are the least important parts of a plant. The nodes are the centres of action. They are repetitions of the elements of the stem, and held together by the internodes.

One can imagine in primordial times a swampy piece of land swarming with rhizomes of different kinds struggling with each other for mastery, like tentacles thrown out in all directions, by a crowd of polyps. One can easily see that the rhizome, which could bend itself upwards, grow into the air, and become a stem, would have immense advantage of light and air. The aërial stem would help its rhizomes, and these, the stem, and the whole colony would flourish, not of course without modifying itself to suit the change of medium.

The principal function of internodes is to separate the nodes, according to needs, for the purpose of better aëration and illumination in a crowded space, while at the same time they keep the colony together for mutual support.

In some cases, however, the internode decays, leaving the node, or group of nodes, isolated as a tuber, or tubercle, with a store of food for commencing an independent life. This excision of nodes by decay of internodes will be seen to be of great importance. It preserves to the species any useful qualities already acquired, while, at the same time, it disseminates growing points or buds, and thus exposes them to new conditions, where the nutritive elements have not been already exhausted by that plant.

This process is imitated by the horticulturist, when he chops up a vine-stem into nodes. These, howerer, will always produce the same rariety.

The foregoing conception of the genesis of a rhizome is such as might come about by the arrested fission of a monad.

$\mathrm{Now}$, let us suppose a seaweed already developed into a form like that of Jania fastigiata (Fig. 48), with only a small disk of attachment, all the rest being filiform fronds, dividing dichotomously, or dereloped only a step further, into the form of Callitham. nion Griffithsioides (Fig. 49), with the disk of attachment splitting up into fibrils; is it possible for a rhizome to have its genesis in su ch root-disks as these?

It will be evident, on a little consideration, that the separation of the bunch of fronds, when these have become too crowded, would result in one of two things. Either the disk would split up 
and form a number of independent plants, or the interspaces between the frondlets would lengthen and so form a rhizome, with tufts of frondlets at intervals. Moreover, in the case of Callithamnion, there would be tufts of roots opposed to the tufts of frondlets. Such rhizomes we see in Polysiphonia (Fig. 46) and Caulerpa (Fig. 47).

We must not suppose that exact copies of the stems and rhizomes of the higher plants are not to be found among the lowest cellular plants. Fig. 41 shows a microscopic fungus

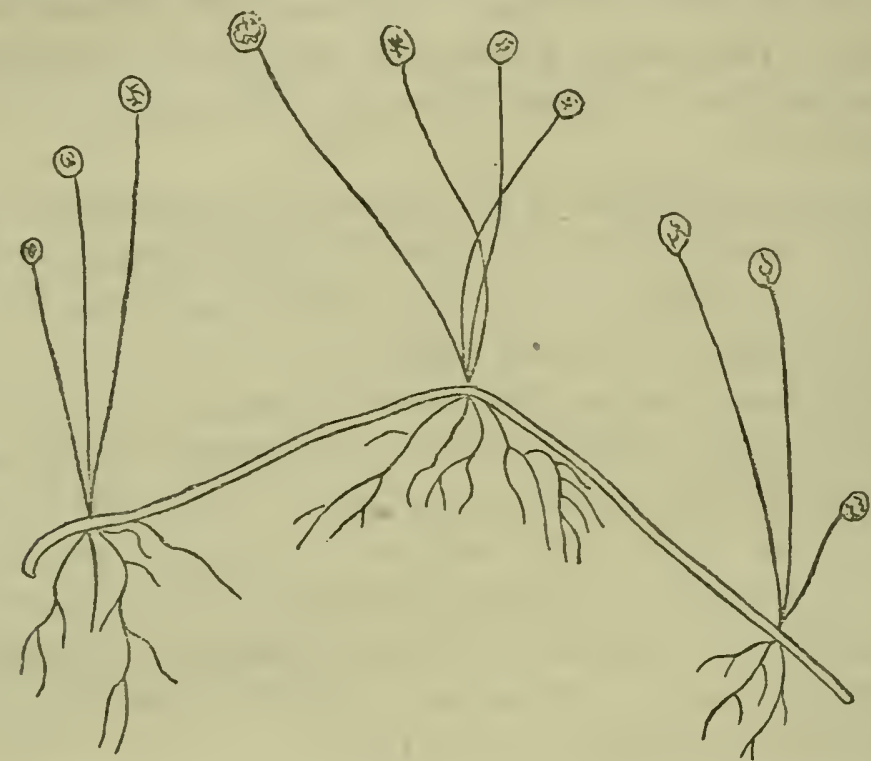

Fig. 41. Mucor stolonifer, from decaying lemon. O. Penzig, "Studj sugli agrumi," pl. 47 , fig. 5 .

which grows on decaying lemons. It is wholly cellular, with a filiform rhizome, consisting of nodes, which give off roots from one side and reproductive hairs from the other. It is evident that the reproductive hairs of this fungus correspond to branches and fruit in the higher plants, as I have endeavoured to show elsewhere. But the important point I wish now to dwell upon is that this microscopic beginning of plant life has a distinct rhizome, which, if it were erect, would be comparable with the stem of an orchid,* or any other phænogam.

Penzig gives a large number of microscopic fungi, which appear to be nothing but reproductive parasitic hairs.

* I say orchid, because many orchids give off roots from their leaf-nodes. 
In the rhizomes of seaweeds and ferns there does not appear to be any such thing as an axillary bud. It is the terminal bud which is axillary-like to the tipmost frond. This terminal bud by further lengthening leaves the tipmost frond behind without an axillary bud. In the section on axilliary buds I hare endearoured to put in words the conception of the genesis of the axillary bud of phænogams.

In the potato tuber a group of nodes become independent by the decay of the internode which supported them. The same happens in Vitis Pterophora, according to George Nicholson. The group of nodes at the end of its branch grows into a tuber, which falls off and forms a new plant.

The rhizome being a prolongation of the cellular basis of the frond has acquired the habit of producing roots opposite the frond. This habit we see is still inherited in many plants, whose stems no longer creep along the ground, but are erect. There are innumerable examples of plants which give off aërial roots from the nodes of their stems, as a habit inherited from the rhizome stage. Ferns, grasses, arads, orchids, and many others have this habit. These aërial roots now mostly serve the purpose of attachment and fixation or support of the weak, erect stem, which originally was a creeping stem with roots in the ground. Peppermint has both creeping and erect stems, the latter being only branches of the former. The potato, the vetch, and others have the same. In some, roots are still developed from the nodes; in others, this habit is temporarily lost, though under certain circumstances it is easily revived. In the case of the mint, the suppression of roots on the upright branches may be partly due to the energy being taken up wholly by the leaves, and partly to atrophy by disuse.

Cuttings of plants placed under favourable conditions form a callus at the cut end, from which roots are emitted. This callus may correspond to the cellular corm-like body, called the disk, by which rootless seaweeds are attached to rocks. It appears to be the mother tissue of roots.

The corm of the Cyclamen would also correspond to the seaweed disk of attachment. According to this riew, we would have the stem equal to a rhizome, the rhizome to a corm, and the latter equal to the minute stump of cellular tissue at the foot of the seaweed frond. 
If this be so, plants that are not attached to anything, but float about in water, ought not to be distinguished into root and leaf. We find some of these. As a tpye of this stage Woolfia may be quoted. It is a plant classified among phenogams.

It floats about and has no trace of root. Lemna is a type of u stage in advance of Woolfia, I do not say that all higher plants are a derelopment of these, for these may possibly be a degradation from a much more complicated and highly developed stage.

It is possible that in Welwitchia mirabilis we may have a tree Woolfia or Lemna-a direct descendant, without much modification, except enlargement and lignification of the tissues, owing to land surroundings, of these curious and primitive plants? 

"Respect authority, distrust yourself if you find that after all you cannot agree with it, but if you cannot, say so like a man."-Lord Coleridge, "Thinking for Ourselves." 


\section{X.-ROOTS AND TENDRILS.}

WHAT is the root?

After stating that in Thallophytes there is no differentiation into stem, leaf and root, that is, the thallus is functionally all three in one, F. Goebel ("Outlines of Classif.," p. 3) says, "A true root, " such as that of vascular plants, is, howerer, always wanting in " the Thallophytes, though certain organs are usually present, which " in a physiological and functional* sense we may designate as "roots."

Here we have the botanist first calling true roots those appendages which have in them a rascular system and other structures, and then discarding the term as inapplicable to appendages, which, though functionally identical, hare no ressels, but are simply cellular!

If the reader will turn to Fig. 41 , he will see that the root of that simple Mucor stolonifer is as true a root as that of Peppermint, or other stoloniferous plant. It occupies the same position, and has the same function. Nerertheless, its whole structure is of the simplest. The rhizome is a hair, the roots are hairs, and the branches are hairs. Then what is the difference between a true root and a false root?

This is one of many puzzles in botanical nomenclature which are not easily solved, viz., a distinction without a difference. The one is as true a root as the other.

When a cellular structure is of the simplest, it naturally has no need of ressels. Seaweeds admit of a complicated structure, without ressels proper, because their apparatus of circulation is

* Physiological means functional.

4 p. 1724.

L 2 
mainly the water that surrounds them. It is only as the cellular mass grew, and became more complex, and much more so after it emerged from a water into an air medium, that a circulatory and stiffening system (fibro-vascular) became a matter of life and death to the plant in its struggles in this new medium. In its transference from an aquatic to a land existence, water, with minerals in solution, was still a necessity to it, but this had to be sucked up from the soil, and forced into clistant parts, surrounded by air instead of water, for the nourishment of the whole colony. The higher plants have not only a system for circulating fluids, but also a system for air and transpiration, all three being functionally identical with the blood, lung, and perspiratory systems of animals.

If the roots of Thallophytes act as roots, whether they are made up of simple cells, or of these, plus a complicated vascular system, as in the higher plants, we are not justified in giring them any other morphological position than that of roots. The distinction between rascular and non-vascular plants seems rery unimportant, for after all the fibro-vascular bundles are nothing but tissues of cells further modified to suit a higher or more complex derelopment of a plant. We surely call carpels all those parts of plants which hold a certain physiological position, whether they be $d r y$ as in the pea, or pulpy, as in the plum. We nerer think of saying the carpel is not a carpel because it is dry, or because it is pulpy.

Authors have insisted so much on the distinct natures of cryptogams and phænogams, and have impressed us so much regarding the total separation of cellular from vascular plants (M. J. Berkeley insisted on it), that we have unconsciously acquired a repugnance to consider them in any way related. Yet reflection must teach us that these apparently essential differences are after all of trivial importance, from a morphological point of view.

On evolutionary principles, I repeat, we must admit that all land plants, whether cellular or vascular, descended, with modification, from water plants, the higher representatives of which are the seaweeds of to-day.

In his "Outlines of Structural Botany" (p. 13), Asa Gray says, "Roots are naked, not producing as they grow, either leares or " any organs homologous with leaves. They commonly branch 
" or divide, but in a rague manner, and their new parts bewr what " are called root-hairs."*

The stem, I would remark, does little more than this. Its phyllotaxy is probably due to the need of illumination of the leaves in an erect stem. The rhizome of the seaweed and fern has no phyllotaxis, because the leaves are all on one side and the roots on the other. Roots give off leaf-buds just like the stem, though, owing to the absence of light, phyllotactic regularity is not developed. Stems, whether recumbent or erect, also give off roots. The difference between roots and leaves therefore appears to be one of words, respecting the medium in which each develops, and respecting the function or division of labour which each assumes.

Regularity in the disposition of underground nodes of course is not needed, as it is in the abore-ground nodes, for purposes of full illumination. In the root, if it ever existed, phyllotaxis has ceased to be inherited, as useless, while in the stem the phyllotactic disposition is most useful, and continues to be inherited.

The potato, Jerusalem artichoke, and many other plants, from the points, which must of necessity be homologous with nodes, give off not only underground stems or branches, but also roots from those same nodes, just as the above-ground stems of orchids and other plants do. So that, although the root may be functionally different from the stem, it is morphologically the same thing, that is, an off-shoot of a common placenta, which we call node. In like manner, the stamen is functionally different from the leaf, but morphologically it is the same thing, and under certain circumstances is interchangeable with it.

To begin by defining the stem as essentially one thing, and the root essentially another, and then affirming that the one is not the other, is much as if one defined the petal as a coloured organ inside the calyx and the leaf as a green organ on the stem, and then maintained that the petal is not a leaf! By giving a thing a

* "These delicate root-hairs are the only organs which absorb the water, containing small quantities of substances, such as salts of potash, lime, nitrogen, phosphorus, \&c. in solution, and they are utterly incapable of performing this work of absorption in the absence of oxygen."-Prof. H. Marshall Ward (New Review, August 1891, p. 185).

$\dagger$ Although rudimentary phyllotaxis is apparent where there are no leaves, but only nodes and internodes. The ridges of one internode of the horsetail alternate with those of another, and the internodes of Chara have often a spiral twist, which may be the foundation of phyllotaxis. 
nickname we seem to cheat ourselves into believing that it is essentially different from its homologue. Some roots and buds we call adrentitious, and then we think we have made them different from other roots and other buds, especially when we have settled in our minds that the root proper is only that which develops at one end of the caulicle of the embryo, and the bud proper that which derelops in the axilla of a leaf.

The radicle of the seed-bud is no other than the same commencement of a root, which we see in the leaf-buds of Bryophyllum or Asplenium decussatum, shown in Fig. 42, or in the aërial roots of orchids, which function only as organs of attachment.

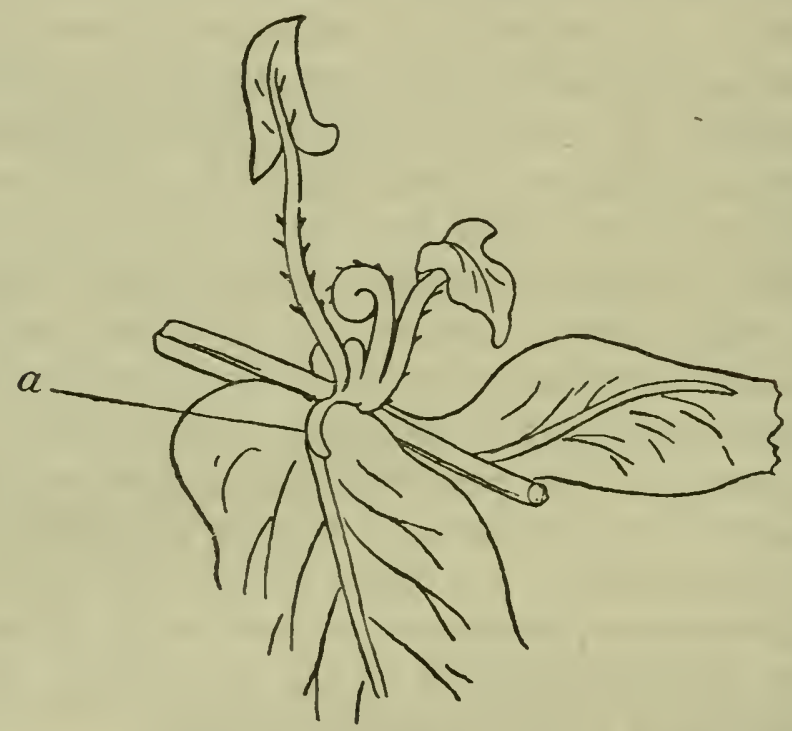

Fig. 42. Bud in the axilla of pinna of Asplenium decussatum, with radicle at (a).- (Goebel, "Outl. of Classif.," Fig. 159.)

In the strawberry runner, a root-bud is given off from each side of the leaf, or of the axillary bud, or of the node, as we might choose to call that from which leaf, bud, and root or roots emerge.

In the germination of the lily-seed, according to Duchartre, the radicle withers, and in its stead, two side rootlets appear at the base of the leaf. These are evidently the homologues of the pair of rootlets which appear at the nodes of so many plants. They are made different from the radicle only by being called adventitious roots. 
The tap root of a potato appears to be no other than an underground stem, which develops branch buds from its irregular nodes, with or without tubercles, at the same time that it derelops roots from those nodes. Whenever one of these underground branches lengthens and reaches the surface, it develops into an above-ground stem, with leaves instead of roots from its nodes. Other underground branches may be arrested, at various stages, and do not reach the surface of the ground, but remain, as storage stems (potatoes) for use next season. The young underground shoots of the potato are hairy, like young roots proper.

In the mistletoe, the root end of the caulicle penetrates the bark of its foster parent, and incorporates itself with the sap-wood. The incorporation is like that which takes place in grafting and budding.

In some of the lowest plants the root is simply what is called a disk of attachment, as in the root of Cystophora Sonderi (Fig. 43). In this the fronds are leares and roots in one, while the root proper is only a disk of attachment.

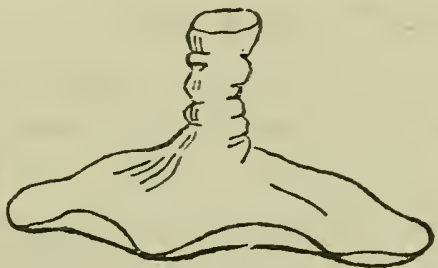

Fig. 43. Disk of Cystophora Sonderi, T. Ag. (pl. 243, “Harv. Phyc. Austr.”).

As long as plants remained small, the disk was quite sufficient for their anchorage. When, however, the plant became more complicated, compound, and weighty, owing to its colonial extensions, a larger anchorage, with a broader base was needed, in order to

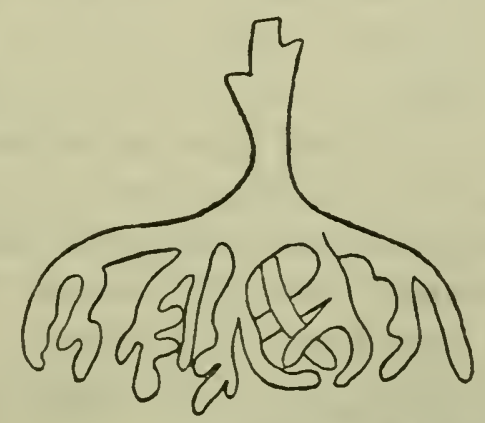

Fig. 44. Root of Cystophora paniculata, T. Ag., pl. 247, O.C. 
resist the tearing force of tides, wares, \&c. We see this disk then splitting up into fingers and extension processes as in Fig. 44, for the purpose of a safer grasp of the surface, on which it became attached. It must not be forgotten that any little advantage gained in this way would enable it to remain fixed in a feeding water suitable to its needs, instead of being carried away into deep water by the tide, and be eaten up by herbirorous animals, or otherwise perish. The root disk of Cystophora paniculata (Fig. 44) gives us an idea of the development of roots out of the disk of seaweeds.

In course of time, with the development of the function of anchorage, there grew up simultaneously a function of suction of water and surrounding materials in solution. This new function of suction helped on the growth of the head of the plant, forming the colony. The growth of the head above ground in land plants needed a parallel growth in the organs of anchorage and suction, the former to counteract the force of wind and storms, and the latter to counteract the transpiration caused by the sun, wind, and hot air, and extend the " grazing field."

Now, aërial roots of orchids, and other plants, and tendrils of weak plants do for them what the extension and lignification of underground roots do for most plants. In Vitis pterophora, we have tendrils and also aërial roots. The latter, like those of Ficus Benghalensis, lengthen almost unbranched till they reach either water or moist earth, and then they bud out like ordinary roots. Functionally, if not botanically, they are tendrils which do not serve the purpose of attachment, but of suction, while the tendrils proper are aërial roots, which do not serve the purpose of suction, but only of anchorage.

Many phænogams now grow on dry land surrounded by air instead of water. Naturally, a large proportion of their nourishment is derived, through the roots, from the moisture of the earth, holding in solution mineral and other ingredients, so that in land plants these organs have developed into very important features, while the nourishment of seaweeds may be mainly derived from the circumambient water, holding in solution the ingredients of their tissues, and in contact with their leaves.

We can understand that, under certain cireumstances, the surrounding water might not contain all that the seaweed might 
want, and that therefore its roots might be able to help it on by dereloping, in addition to anchorage, a suction action, which would enable it to obtain from the ground it fixed itself on whatever it could not get from the water. Thus a beginning of root suction would have been evolved pari passu with root anchorage. We do not know that the disks of seaweeds do not suck up something from the ground on which they are attached. The mistletoe, the dodder, the Loranthus, the Rafflesia, and others evidently suck up a good deal from their foster-parents, although they hare no roots, but it would appear that the disks of seaweeds are mainly organs of attachment like those of the tendrils of Ampelopsis Veitchii, and others.

The root or rhizome of the orchid, called Corallorhiza innata, R. Bn., Fig. 45, is another example of a root and stem organ, that is to say, it shows that there is no essential difference between the root and the stem. Fig. 46 shows that the rhizome of Polysi-

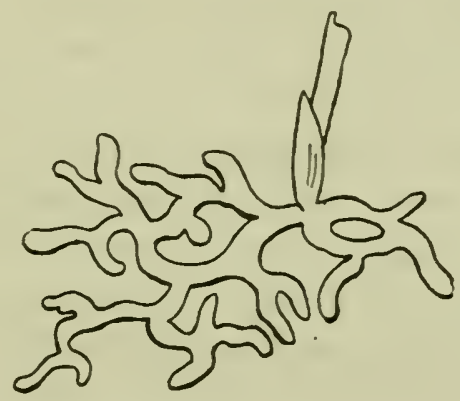

Fig. 45. Corallorhiza innata, R. Bu. (Syme's "Brit. Bot.," vol. 9, p. 132).

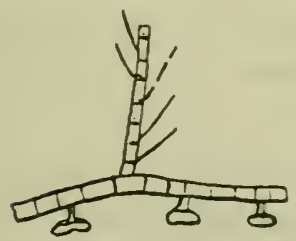

Fig. 46. Disks of Polysiphonia rostrata, Sond. ("Harv. Phyc. Austr.," pl. 242).

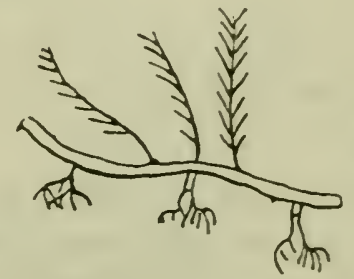

Fig. 47. Roots of Caulerpa trifaria, Harv. (pl. 241, O.C.).

phonia rostrata, Sond., instead of roots, has disks, by which it attaches itself to other algæ, while Caulerpa trifaria, Fig. 47, has these same disks split up into root-like fibres. 
From all this it would seem that there is no essential distinction between the stem and the root. One is a prolongation of the other. They appear to be both off-shoots or sub-dirisions of the common cellular and original placenta-like organs of seaweed fronds - the disk of attachment. The roots of phænogams now do for land plants a great deal of what the fronds alone did for many seaweeds.

The study of the roots of terrestrial orchids, as shown in Syme's "British Botany," will not leare us much to desire in support of the notion that the stem and root are essentially one thing.

Some of the roots of these orchids become arrested, and swell out, as storage roots, as in Orchis and Ophrys, while the remaining roots function as roots proper, but which Syme calls stolons.* In some cases, at the extremity of the root, a small storage tubercle (really a terminal bud) is formed, as in Herminium monorchis. In others, most of the roots become enlarged.

In Epactitis latifolia, the only roots are those given from an underground stem with bracts on it, from the sides of which the roots emerge, exactly as the aërial roots do in many orchids, from the vicinity of the leares. In Epipogum aphyllum the roots branch like those of Corallorhiza, "but the branches have a few small scarious scales," observes Syme. The most convincing of all are the roots of Neottia Nidus-avis, which has its root-stock " densely closed with thick cylindrical pale fawn-colour simple root-fibres, from the point of which it is stated new plants are produced. (See Leight, "Fl. Shrop.," p. 434.)

It is next to impossible to study these terrestrial orchids, and not be convinced that the stem and the root are one continuous organ, the two dirisions of which are adapted to two different media.

We might, therefore, regard the sub-divisions of the roots of plants as underground leaves, devoid of mesophyl, which is not needed, owing to darkness. On the other hand, leares might be considered as above-ground roots. In the latter the mesophyl (a tissue erolved in connexion with light) has dereloped, and fasciated the reins of the leaf, which are homologous with the root fibres of the roots proper. Or, we might look upon the leaf-

* If these stolons are not roots, then these ground orchids are rootless. 
veins as roots, growing in a medium of mesophyl, where the changes influenced by light and air occur, and the result sucked up by the leaf rootlets (the reins), and distributed in the same way that the soil rootlets suck up mineral water and distribute it.

In Ouvirandra fenestralis, we hare anastromosing leaf-roots (veins) with a minimum of mesophyl. In fennel, and others, the veins do not anastomose, and they also have a minimum of mesophyl. In several water species of Ranunculus, the submerged leaves are only reins, without the mesophyl, such as in $R$. heterophyllus, and others, while the floating leaves exposed to the air have their veins fasciated by mesophyl, although from the nodes roots proper are also given out. It would appear very probable that the submerged leaves of this Ranunculus do not function as leaves, but as roots.

If this be so, why do these leaf-roots retain the character of true leares in their phyllotaxis, and petiole? Because they descend from the leaf-form of root, and heredity keeps them in that groove.

No doubt this form of root-like division in these plants has been inherited from leaves, but we should always bear in mind that originally there were no roots, but only numbers of dichotomous veins spread out in the fashion of a fan, and all attached to an anchoring disk, and functioning both as leares and roots, as in Jania fastigiata, Fig. 48, Gymnocongrus fastigiatus, Fig. 18, and others.

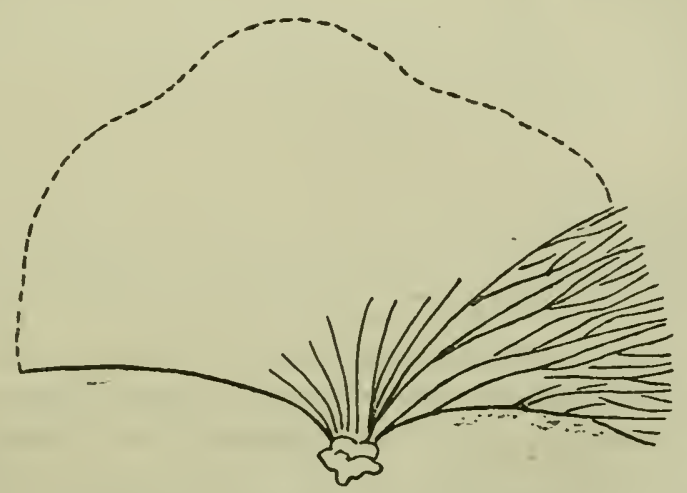

Fig. 48. Part of Jania fastigiata, Harv. ("Harvey, Phyc. Austr.," pl. 25l).

It is in Callithamnion Griffithsioides and others, Fig. 49, that we begin to find the disk fringed, and split up into root fibrils. 


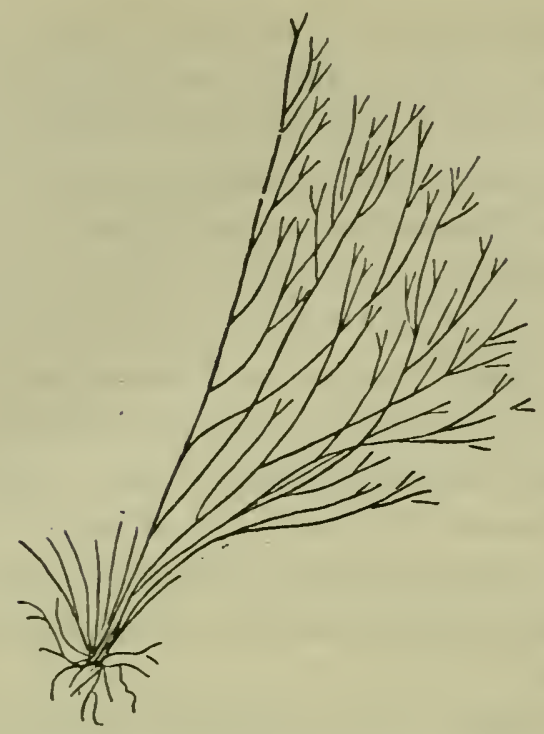

Fig. 49. Part of Callithamnion Griffithsioides, Sond. ("Harvey, Phyc. Austr.," pl. 150).

In order to understand in some way the evolution of roots, we must first understand that they have two functions in the fully developed tree;-

(a.) The function of anchorage, as a protection against being upset by storms; and

(b.) The function of sucking water and other ingredients contained in it. The organic and inorganic constituents of the water, sucked up by the roots, affect not only the plants themselves, but also the animals and insects that feed upon them.*

* I do not think that there is room for doubt that, besides congenital variations, the surroundings, on which plants and animals feed, must, through them, largely affect the individuals, and in time, the race. We cannot for a moment suppose that something comes out of nothing, and, therefore, we eannot suppose that a pasture, which does not contain abundant ingredients for bone and horn making, would tend to produce large bones and horns in animals that feed on it. Nor can we suppose that anything can be assimilated and manufactured into the organ of intelligence. To develop this fully a very varied diet appears to be needed. Man is one of the animals that has the most varied diet, and another is the pig. Sir Samuel Baker asserts of the latter that, of all the animals he has had experience, the most intelligent is the wild pig. 
Although these two functions of the root appertain to one and the same organ, they must be kept mentally separate, in order to comprehend the erolution of the root.

There are many seaweeds which float about, like many animals, without any organ of attachment. Their cells are fed directly by contact with the feeding medium. They are surrounded, and constantly bathed by it. It is obvious that when the floating plant came into a region which contained plenty of nutrient material, it would be to its advantage to become fixed there, so that it might not be carried away into barren water by the morements of the ocean.

At first, the evolution of a root, which, after all, is only a modified bud, may have had no other use than that of fixing the abode of the plant on stones and rocks. The only conceivable advantage of this fixation would appear to be that there the nourishment might be more suitable and plentiful, and that the plant might be in shallow water and out of the way of marine herbivora. In other words, the advantages of anchorage-buds (or primitive roots) would be in preventing that particular modification from being washed away by ebbing tides and ocean currents.

Oceans and seas are fed by rivers, which bring down various ingredients, so that being anchored in the vicinity of the mouth of a river might mean living in the midst of a rich pasturage. And it seems very probable that in simple seaweeds the root had the sole function of anchorage, first as a simple disk, and then as a fingered or fringed disk. In those seaweeds which have more complicated roots it is likely that the function of suction is added, both of mineral ingredients contained in the ooze and also of organic matter furnished by dead seaweeds.*

As the struggle for life forced new generations to creep up into swampy ground, and then into dry land-floods and tides combining to disseminate germs-the root began more and more to be of essential service to the plant, the land plant being largely dependent on the soil for its nourishment. As the aërial portion of the plant developed, the underground portion kept pace with it, becoming also woody to resist destruction by hurricanes. It is

* Ch. Darwin relates that among the roots of Macrocystes Pyrifera are entangled innumerable marine animals. These may have there some unsuspected function. 
only when plants had become parasites that they again dispensed with roots.

That the frond or leaf portion of the plant was anterior in erolution to the root portion seems more than probable, but $I$ do not think there is any grounds whaterer for considering the root and branch as essentially different.

In a large number of plants buds are giren off by the roots, and in many others roots are given off by the stem and branches. All this shows that, morphologically, there is no clistinction between the root and any other part of the plant.

In Vanda and other orchids there are aërial roots at the base of each leaf, but as these are in an air medium they retain the general character of the terete leares of some orchids. These orchid adventitious roots often serre as organs of attachment, like the fingered disks of seaweeds. Vanda has a tall stem weighted with many leares. In a storm it would be blown down and destroyed. Natural selection has developed in it long aërial roots, you may call them tendrils-which grow in search of something to adhere to, as props to the stem. As the primitive roots of seaweeds originally served only as a means of attachment, so these orchid roots serve a similar purpose now.

Why have many plants lost the potrer of giving off root-buds from the stem unless artificially coaxed to do so by the horticulturist? We do not know. We might ask similar questions about other parts of plants. For instance, why has the Ncusturtium lost the power of producing stipules, when its first leaves have them? The loss may have occurred either through their not needing them, by atrophy, or through congenital variation.

Certain plants either need shoots on their roots, for battle purposes, or they do not need them, haring other weapons. Then the energy of the plant, being direrted into other weapons, the power of root-budding atrophies. If the total energy be great, the habit of root-budding may be maintained, and then the struggle for life has a greater chance of success, for, howerer, much the above-ground portion may be destroyed by animals, storms, fire, or other causes, the underground portion will reproduce the very same plant, with whatever accumulated advantages for struggle it may have already possessed, through inheritance.

By root-budding the plant has not only an alternative mode of producing seed, in case of total destruction of the branches, but 
the chances of learing progeny are thereby immensely increased. Just fancy what advantage the Dalbergice Sissoo and Millingtonia hortensis have orer many other plants. If the upper portion of the tree be in any way destroyed, a forest of root-shoots are ready to continue its life, without the slow process and serere struggle of continuing it through the seed-buds. The latter would have to find a suitable place for germination, and have to wait for rain, while the roots are there ready made, independent of rain, and burst into energy the moment they are released from the branches which have undergone destruction. The roots of the Dalbergia, Millingtonia, and a hundred others are to all intents and purposes rhizomes, or underground stems.

If the plant do not need the underground buds for reproduction, they become useless encumbrances and absorbers of energy. Thus, in many instances, they are likely to disappear, but may re-appear by horticultural coaxing. In the struggle for life any hampering nuisance, unless it cun be turned to good account, is obriously a drawback.

Let us now turn to the rine group of plants and see what botanists think of their stem, and other parts dereloped thereon. Asa Gray says: "In the grape rine the tendril is homologous with stem, for the uppermost tendril is seen to be a direct continuation of the stem. The small bud, which appears in the axil of the uppermost leaf, will in its growth produce another internode and leaf, the present terminal tendril will have then become lateral and opposite the leaf." In a note he says: "This forms what is called a sympodium, which is morphologically made up of a series of superposed branches (originating from the axillary buds), in contradistinction to a monopadum," which is a stem made up of nodes originating in the terminal bucls.*

Now is the rine tendril a branch? Asa Gray gires a figure at page 54 of his "Structural Botany," in which the lower nodes have no axillary bud. This is supposed to have continued the stem, and therefore has disappeared. I have examined a large number of rine stems. There is a long row of rines and Ampelopsis in the Royal Kew Gardens; I cannot say I hare found one axilla without its bud, and, therefore, the rine stem appears to me

* Le Maout and Decaisne think this tendril a branching peduncle opposed to the leaf, but it has no subtending bract. 
just as much monopodial as in other plants. It is possible that in some varieties the axillary bud may be suppressed, and, therefore, the real terminal bud may have been mistaken for the axillary, and the tendril for a terminal bud.

I do not beliere that the morphological position of the vine tendril has been rightly interpreted. I have invariably found it opposite a leaf, the stem being continued, as in other stems, by the terminal bud, and the axillary bud of the leaf being always present. In fact, this axillary bud is the propagating eye of the vine. I have always found that each tendril, like the stem, subdivides into subordinate tendrils, each being opposed by two minute stipules. Here, therefore, we have a repetition of the stem, and the rine tendril might be interpreted as a branch. I beliere, however, that it admits of a different interpretation, which I shall now endearour to make clear.

If the rhizome is a stem it will follow that the stem is a rhizome. In rhizomes, whether of seaweeds, or ferns, or other plants, we often find a leaf growing in one direction, and a root in the opposite direction, and I see no. reason to come to any other conclusion than that the vine tendril is to the stem what the root is to the rhizome. The two appear homologous.

Now the stipules on the vine tendril would appear a valid objection to this view. But on closer cogitation we perhaps will find that this objection is a weak one, for if the underground root is capable of producing buds, which can turn into branches and leares, it is of no use our objecting that the rine tendril cannot be a root, because it bears stipules. Syme has told us that the branches of the roots of Epipogum aphyllum have a few scarious scales.

I consider the vine tendril to be an aërial root, serving the purpose of attachment only, like the aerrial roots of Vanda. And my view of stipules is that they can be, and often are, simple bud scales.* 'Therefore, as roots develop buds, it is nothing out of the way to credit them with the power of dereloping bud scales also, more especially as in this case the stem being erect the aërial root. is under different conditions from what it would be if it were an underground root.

* Vide Discussion on Cotyledons and Bud Scales. 
From a conventional point of view, to regard the vine tendril as homologous with a root seems preposterous, considering that it bears stipules. But my contention is that it has stipules because it is a branch which dereloped in the air, and not a branch developed in the soil. If the rine stem were a creeping rhizome it would probably hare at each node a leaf turned uppermost, and opposed to it a root growing into the soil.* As, however, the stem is erect, the same elements continue to be inherited. On one side we hare a leaf, and opposed to it a root, transformed into a tendril, which is another term for an organ of attachment, like the roots of many seaweecls, and the aërial roots of orchids. Why the rine tendril should become a different thing because the stem happens to be erect, and because this particular branch has been called a tendril, I do not in the least see. It seems to me that we think too conventionally, while in nature the only conventionality appears in the way of heredity.

The tendrils of Vitis often terminate in flower-buds, and the whole bunch of grapes would therefore be nothing but a very compound tendril, with each sub-division ending in a flower-bud and subsequently in a grape. When they do not end in flowerbuds the ends bear a slight disk-like enlargement.

The tendrils of Ampelopsis are like those of the vine, furnished with minute stipules. But in the former, each sub-division ends in a berry-like sphere, which afterwards becomes the disk of attachment, such as we see in the seaweeds called Cystophora Sonderi (Fig. 43), Polysiphonic rostrata (Fig. 46), and others. The disk of seaweeds I have shown is only a fused mass of rootfibrils, or the roots are only a fimbriated disk (vide Polysiphonia and Caulerpa (Figs. 46 and 47). We may therefore regard the tendril of Ampelopsis, with its berry-like endings, also as an aërial root. The inference to be drawn from this interpretation would be that the bunch of grapes, the rine tendril, with or without its terminal expansions, and the tendril of Ampelopsis are all homologues. Further, we would have the Ampelopsis disks

* In the Naral Exhibition there was a vine on the wall of the printing room. Its branches projected from the wall. All the tendrils of these branches were directed downwards, and all the leaves upwards, towards the skylight.

s. p. 1724. 
homologous with grape berries, the former being arrested berries or flower-buds turned to other purposes.

Now, there is no doubt that the Ampelopsis and vine tendrils are also branches, so that we come round again to the conclusion that roots and branches, though different in function, are essentially the same thing, and that the vine tendril, in spite of its stipules, may be more strictly interpreted as an cërial root. And by a process of putting two and two together, the disks of the Ampelopsis may probably be considered as arrested flowerbuds, although I do not maintain that they are so.

We find the large group of the Cucurbitacex also furnished with tendrils. In these there is one tendril, either simple or branched, on the side of the leaf, although I have observed, as an exception, that Bryonia dioica and another hare sometimes two tendrils, one on each side of the leaf.

Mr. Naudin considers the tendrils of cucurbits as depauperized stipules, one of which has been suppressed. With due deference to so great an authority as Mr. Naudin, I think it more reasonable to look upon them as aërial roots. In support of this riew I would state that in the underground axilla of a horse-radish, I have observed a minute long root-fibril on each side of the axillary bud. In a ranunculaceous weed on the roadside, which gives off stolons, as in the strawberry, I have observed at the base of each leaf two roots, similar to the two tendrils of the exceptional case of Bryonia dioica. In this weed there are at first two rootlets. Afterwards the node often gives off more than two.

If we look upon the stem of the Cucurbitacex as a rhizome, we might be justfied in considering their tendrils as so-called adventitious roots. There may have been originally two, as in Bryonia exceptionally, but, functioning as tendrils, two would not be needed, and in time one would sometimes be suppressed as a useless encumbrance.

In some cases the tendrils of cucurbits are all suppressed. In many they are branched, the branches being rerticillate. In others they are irregularly disposed with reference to the leaf. What might be now called the normal state is that of one tendril on the side of the leaf.* The tendrils of cucurbits have no stipules as in the vine tendrils.

* See appendicular notes to this section. 
All such teratological cases as are quoted in the Appendix tend to incline me to look upon the tendrils of cucurbits rather in the way of aërial roots than in that of stipules. In wild forms, no doubt, heredity keeps them single, and on the side of the leaf, but in the garden forms, heredity being disturbed by crossing, variations are often produced, which "let the cat out of the bag," so to speak, and gire us a clearer conception of the homology of certain organs. In my view, however, aërial and ground roots, branches, leaves, and stipules are all either branches or branchlets, so that the morphologist has an "embarras de choix."

The point is to find out which parts are the nearest relatives. In the case of cucurbits, it would seem the tendril is nearer the aërial root than the stipule.

We have now to examine the roots of another large group of plants, the Leguminiferæ.

What are the tubercles which are so common a feature on the roots of this group of plants?

In "Nature" of 25th December 1890, p. 189, there is a notice of certain "Field experiments at Rothamsteadl," conducted by Sir John Lawes. It is there stated that "In recent years the question of assimilation of free nitrogen by growing plants has assumed quite a new aspect. . . . . The results of experiments made by Hellreigel and Wilforth, so far obtained, show that when a soil growing leguminous plants is infected with appropriate micro-organisms, there is a devellopment of the so-called leguminous nodules on the roots of the plants, and coincidently, increased growth and gain of nitrogen. . . . . . There is no evidence that the leguminous plant itself assimilates free nitrogen."

The revietwer hastens to label this micro-organism as a fungus of the "class Ustilagince, which exists in and is the carse of the tubercles, or root nodules, found upon the root-fibres of leguminous plants."

Are we to understand by this that all leguminous plants do not assimilate nitrogen without the help of these micro-organisms? Are we also to understand that these organisms are the sole originators of these tubercles?

Surely there are other plants which contain nitrogen in their composition. The seeds of grasses, and the alcaloids of many 
different plants, contain it. Are all these furnished with nodules on their roots?

Now is there no other way of accounting for the tubercles on the roots of the Leguminiferæ, except through these microorganisms? Supposing these micro-organisms to exist at all in the tubercles, may it not be possible for the latter to be otherwise accounted for, and that these low organisms take up their abode there, if it be proved that they do not exist anywhere else in the plant.

We should not, howerer, be startled by this statement, for recently Dr. Cunningham has told us that the tickling of an insect causes the orule of the Ficus to develop parthenogenetically.

I find that in Lathyrus tuberosus the roots bear largish tubers, from one to two inches long,* and are eridently enlargements of the base of root-fibrils (Fig. 50). I think it more natural to conclude that the minute tubercles on other leguminiferæ may be atrophied tubers.

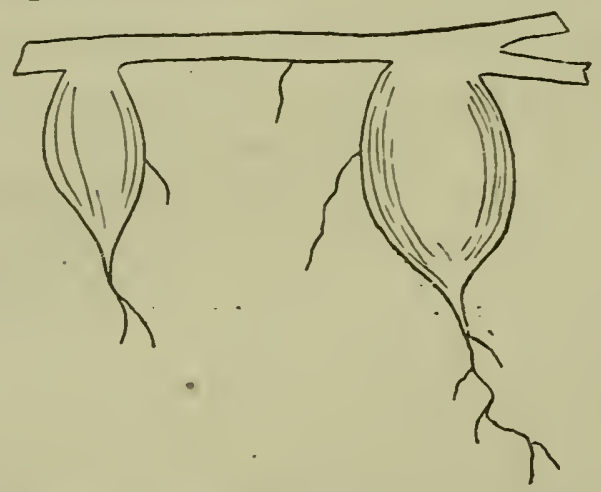

Fig. 50. Tubers on roots of_Lathyrus tuberosus ("Syme's Brit. Bot.," pl. 401).

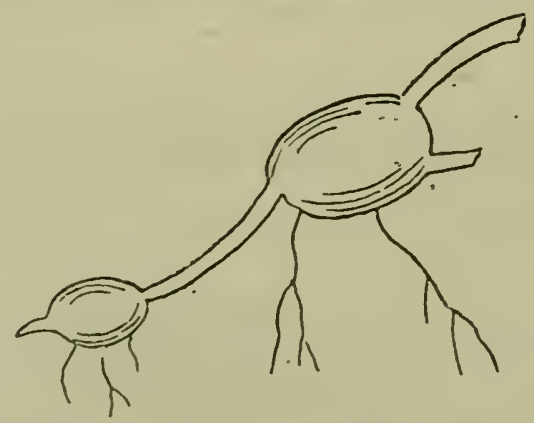

Fig. 51. Tubers on roots of Lathyrus macrorhizus ("Syme's Brit. Bot.," pl. 406).

* The tubers of this retchling might possibly be enlarged and improred, and so become useful for food. 
In Lathyrus macrorhizus (Fig. 51) the tubers are from the size of a pea to that of a small cherry, and would appear to be enlargements of the root-nodes.

In most leguminiferæ, howerer, the tubercles are rery minute, varying from the size of a pin's head to that of a mustard seed, and such as we find them in Vicia augustifolia and others (Fig. 52).

Curiously enough, the Lathyrus with large tubers does not appear to possess the minute one, ${ }^{*}$ so that the theory that the latter are factories of nitrogen assimilation, through the low

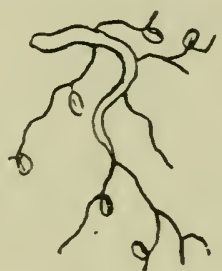

Fig. 52. Minute tubercles on roots of Vicia augustifolia ("Syme's Brit. Bot.").

organisms within them, would be very much reakened; for we see that the minute tubercles in the one are replaced by the large tubers in the other (if this be so), so that one begins to think that the minute tubercles may possibly be only atrophied representatives of the more useful tubers.

This question, howerer, naturally arises, why have the leguminiferæ tubers or tubercles at all, when so many other plants have them not? The following answer suggests itself. The flower of the leguminiferæ is one which has undergone great modification. It is, therefore, conceivable that when it began to modify, there was not present a. sufficiently modified insect, suited to fertilize its orules. It had either to perish or, so to speak, accept the help of such accidental storage of energy in its roots. This accidental storage may in time have dereloped into what we now call tubers. In short, it had to lire and wait until something turned up by which its flowers could be fertilized, and so produce further rariations more suited to its surroundings. When seed began to be annually perfected by insect agency the tubers atrophied by transfer of energy, but, nevertheless, they continued to be inherited as remnants, much as the

* At all events they are not shown in Syme's figure ("Engl. Bot.”). 
teeth of the rose-leaf are now inherited as atrophied branches, although they are of no conceivable use whatever. Lathyrus tuberosus may have been one of those fortunate beings who had "two strings to its bow," for it is both an annual, as far as its leares and flowers are concerned, and also a perennial, through its roots.

The flowers of orchids have also undergone great modifications, and in these plants also we find storage organs, both in the terrestrial and in the arboreal species. The fact that in terrestrial forms the storage occurs in the so-called roots, and in the arboreal forms in the so-called stem, brings us a step nearer towards accepting the notion that the stem and root are only modified forms of the same thing.

I am aware that the potato has tubers, although its flowers have not undergone so great a modification as that of the pea. Now I am not, howerer, arguing the case of the potato but rather that of the pea, and my suggestion in no way excludes the possibility of a hundred other reasons, why other plants hare erolred storage organs. It is quite conceivable that every group of plants with a common descent may have had its own reasons for haring acquired storage underground organs, whether we call these a bulb, a corm, a tuber, a tubercle, or a fleshy root.

We might conceive three forms of leguminiferæ:

(a.) Those in which the storage tubercles were fully developed and the plant practically perennial, reproducing itself every season by underground buds. It may have been that the flowers and seeds were imperfectly developed, or it may have been that the above-ground portion was eaten up by animals, and had no chance of reproducing itself.* Therefore, the only hope of that particular species being continued would have been in its re-appearing through the dormant life of its roots or underground branches. $\dagger$

(b.) Those in which, while the underground tubercles still continued to play their part with rigour, the flowers and seeds

* The immense herds of herbivora we hear of, and the clouds of locusts which often settle on the land, would devour everything green in a very short time.

$\dagger$ In other words it had to live an underground life, hiding itself from the cold and other enemies with the chance of better luck next season. 
became fully developed by the help of insects. By absence of herbivorous animals at the season of maturation, these forms of leguminiferæ had a chance of becoming disseminated. These forms would hare a decided advantage because their weapon would have been two-edged. If the seed failed the root reproduced the plant and gave it a chance of maturing seed next season, and so continuing whatever adrantages that particular variety may hare accumulated. On the other hand, if the seed succeeded, it might not only reproduce the same variety, but other rariations also, which might possess superior adrantages.

(c.) Those forms in which the flowers and seeds had been so perfected and their floral weapons of struggle so effectire that they could dispense with special underground storage organs. The whole energy of the plant would then have been directed towards the perfection of the seed, and the storage tubercles would have become atrophied, as we see them in most leguminiferæ (if these are atrophied tubers), or lost altogether, as in other plants.

Whether these hare been really the stages through which these interesting plants hare passed is impossible to say, nerertheless, it is conceirable that this might have been so. It is evident from the great irregularity of their corolla, that insects must have been to a large extent their constant allies and helpers in the struggle for life.

In spite of the supposed atrophy of the tubercles of the common retch (a garden weed), its underground portion retains so much vitality that a bit of root left in the ground will enable the plant to re-appear next season. It is not impossible that the tubercles, although atrophied, may still retain some storage power. It is also possible that they may hare some other function unsuspected by us, and the ritality of the root dependent on some other cause.

Another view of the origin of the tubercles on the roots of the leguminiferæ is that primitively they were floats in water plants. The whole of our dry land regetation must hare passed through a stage suited to a water life, first wholly submerged, as in seaweeds, and then partially so, before the individuals became suited to a wholly dry land life. And, therefore, it is conceivable that the leguminous plants of to-day may hare descended from 
some aquatic leguminous or semi-leguminous, or other plant, of ancient times.

Howerer, this may be, in the Utricularias (floating plants) we have in their floats, if not homologous, certainly quite analogous bodies. Fig. 53 shows the root-like leaves of Utricularia vulgaris, with its large floats, while Fig. 54 shows the leaves of Ltricularia minor, with much smaller floats.

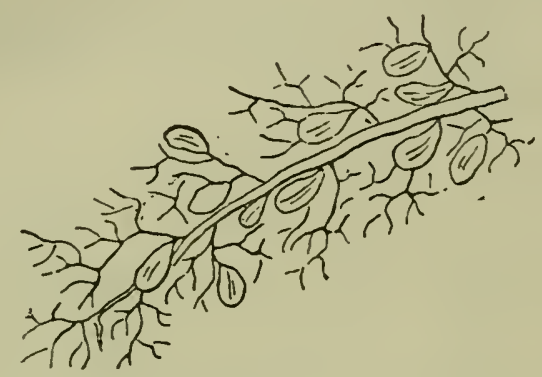

Fig. 53. Leaves of Utricularia vulgaris ("Syme's Br. Bot.," pl. 1125).

The tubercles of the leguminiferæ may well be atrophied remnants of similar floats in some ancestral water-plant, much as stipels and teeth are atrophied remnants of leaflets. It might be considered a sort of heresy to mention scrophulariaceous plants (the Utricularias) in the same breath with leguminiferous

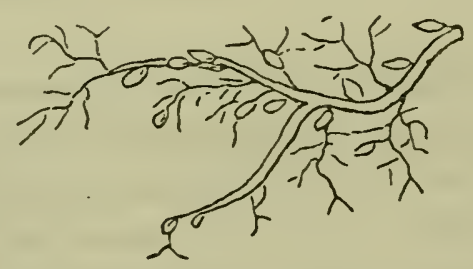

Fig. 54. Leaves of Utricularia minor ("Syme's Br. Bot.," pl. 1126).

plants. But it should be remembered that we are now treating of evolution. What can be more different than an amaryllis, an orchid, and the wheat plants? Yet nothing is clearer to my mind than that all three are closely related.

Syme calls the root-like appendages of the Utricularias leaves; but to a mind unbiassed by botanical conventionalities, they would be nothing but roots. The appendages of $U$. neglecta (Syme, pl. 1125, bis) might he considered as an apology for leaves, but 
neither those of $U$. vulgaris, nor those of $U$. minor, can in any way be considered leaves more than roots except by way of "courtesy"! If the appendages of the Utricularias are leaves, these plants are rootless. The so-called stem is a continuation of them, as the stem of any other plant is a continuation of its root. Moreover, they have no semblance of any phyllotaxis whatever; and the stem of $U$. intermedia, as delineated by Syme, shows first leaf-like appendages, then root-like appendages with bladders, and then again leaf-like appendages. So that in this same plant the leaf-like appendages and the root-like appendages are interchangeable. Lindley, in his "Veg. Kingd.," says they "resemble roots." And this is what Bentham and Hooker, "Genera plantarum," say of Utricularia (rol. ii., p. 988).

"In his speciebus radicula (brevissima crassa) iners remanet, et planta adulta omnino arhiza et, squamellis minutis $\mathrm{v}$. foliis primordialibus eranescentibus exceptis, aphylla, nisi pro foliis habendi sint utriculi. Rami submersi capillaceo-multisecti a variis auctoribus perperam ut videtur nunc pro foliis nunc pro radicibus descripti sunt."

In plain English this means that they are either roots or leaves, according to one's conventional bias. The leares or roots of the Utricularias, in my opinion, strongly support, if they do not prove, the view I have taken in the foregoing pages, viz., that leares are aërial roots, and roots underground leares.

There are other plants which bear corpuscles analogous to those of the leguminiferæ, but which are very distant from them. Syme in his "Brit. Bot.," pl. 1760, shows Poa annua with corpuscles on its roots. As he does not allude to them in the text, it is impossible to say what they may mean. They may be remnants of floats in some ancestral water-plant, as he says this Poa can only be adrantageously grown in "dlamp pastures." There are many grasses which are aquatic, or semi-aquatic, such as Catabrosa, Glyceria, Oryza, Arundo, and others, with their near relatives sedges, and Irids.

It should not be forgotten that in the life of any group of plants time as a factor in rariation may have been almost unlimited. A grass may have been originally a floating plant, it may have crept out of the water and up a mountain, changing its character and losing its floats; then by a subsidence of the ground it may have returned to water, and never have re-acquired 
it floats, but may hare become provided with other adaptations to enable it to hold its own position in the battle of life.

I hare commenced this discussion by stating that it was suggested that the nodules on the roots of leguminiferæ were the result of the action of micro-organisms. It is also stated that when these microbes were prerented from having access to the soil, the nodules were not developed. This would appear conclusive, but we have other plants which assimilate nitrogen, without the help of microbes, being traceable, and therefore this function does not appear at present a sine quâ non for the absorption of nitrogen.

There is rather a "rage" just now about microbes, and it seems that nothing can happen without their interference. If the existence and function of this nodule-microbe should become established of course there would be little further to say about it, but one is always reminded that "Listerism" was well established, and erentually became disestablished.

Under any circumstances, eren absurd objections sometimes suggest something of ralue, and so in spite of the explanation of the nodule by bacteriologists, I leare the foregoing lines as they are, although they may run the risk of being so much waste paper.

\section{Sumiare of Chapter.}

After due and unbiassed consideration of the whole question of roots and branches, we seem to arrive at the "moral conviction" that the radicle is only a prolongation or continuation of the plumule stem, with functions suited to a life in the soil, and no essentially different from the stem. We might say that the radicle derelopes into an underground stem, and the plumule into an abore-ground stem.

We may therefore look upon the finished and highly developed article-the tree, as we see it now on land, as consisting of two main branches, emerging out of the same node. The one growing in the soil and the other growing in the air, the tap-root being the main branch of the one and the stem proper the main branch of the other.

The air branches are given off regularly, because they have inherited the habit of twisting, in order to expose their leaves as 
much as possible to the light, this being of the utmost importance to their function. In other words, the leaves have inherited the habit of avoiding each other's shade by the twisting of the stem into a spiral. Naturally, this is only when the stem and branches are erect, for when they are horizontal or otherwise situated, the disposition of the leares is much modified.*

The soil branches or roots are given off irregularly because their function, although on the whole similar to that of the leares, is niinus the influence of light.

The root fibrils are leaf reins, minus the mesophyl, or chlorophyl cells, which are supposed to have a function connected with light.

Root hairs absorb tvater, just as the hairs of the aërial parts of plants absorb rapours of water and gases. It is more than probable that the pores of the soil are often filled with gases, so that in this case the hairs of the roots would often come in contact with gases also.

In certain aquatic Ranunculi, we have roots proper functioning in one medium - the ooze of the bottom of the pond ; then we have the root-like submerged leaves, functioning in another medium - the water; and, finally, leaves proper, functioning in a third medium-the air. All three appendages are homologous. They are sucking organs.

It is not easy to escape from the conclusion that a rootlet is to the main root what the petiole is to the main stem, and that the sub-divisions of the rootlets correspond to the nerves and reins of the leaves. In other words, as I said, we might consider the roots as underground leares, and the leares as abore-ground roots, both being modified to suit the medium they grow in, and for sucking in materials from those media.

Buds are given off by-both the stem and the root. The socalled flowers are not produced directly by the root, because they hare become organs suited to surroundings which are only found in the air, and in the light, such as wind, insects, \&c. Therefore, they are only produced on root-buds when these come to the surface and become aërial stems.

* It is not impossible that botanists hare made too much of a "fetish" of phyllotaxis. 
Without elaborate illustrations it is difficult to convince the reader of what one puts forth, and that there is no real difference between the stem and the root, or the plumule and the radicle. The reader requires to be saved the trouble of thinking and recalling to his mind the facts otherwise than by simple words. He may be convincible, but may not hare the time or the patience to follow in thought what is written without the help of illustrations. 


\section{APPENDIX TO SECTION $\mathrm{X}$.}

1. The aërial roots of Nephrolepis are only modified hairy branches or tendrils, which gire off buds when farourably situated. They are comparable to rery slender rhizomes.

2. In Cucurbita Pepo aurantiformis the tendrils have verticillate branches. In others, such as the "potiron" and "yellow mammoth pumpkin," the sub-dirisions of the tendril form a spiral whorl.

3. Some rarieties of regetable marrow, such as the "small flat eustard," appeared to hare no tendrils.

4. A jellow pyriform cucurbit, with a green circular apex (without name),* had abnormal tendrils. Some were on the side, some opposite the leaf, as in ritis, some were in pairs, one on each side of the leaf. Sometimes the tendril was below the leaf.

5. In the Passion-flower and Tacsonia the tendril is axillary and might be an abortive peduncle. It may, howerer, be the tendril of the cucurbit displaced from the side of the leaf to its axilla. The riew of its being a depauperized pedancle would receire some support from an obserration I made in Cypripedium hybridum Youngianum. It had a large lower braet, subtending an abortire flower, which was like a simple filiform tendril, and in no way different from the axillary tendril of Passiflora sicyoides and others.

6. Iry gires off roots just below the stem-node, both back and front. The latter, hotrerer, do not derelop. The internodes also give off roots, like the internodes of the tap-root of many plants.

7. In the common retch of gardens, on the lower part of the root proper, I found a shoot with stipules at its base. The usual little nodules were on the roots. Some of these stipules had incipient leares far below the surface of the ground. It appeared to me that roots proper without stipules, and shoots proper with stipules and leares, were given off indifferently from the so-called root, or. prolongation of the radicle, in the same way that the orchid stem at its nodes gires off leares, buas, and routs. Under some of the root nodules of the retch I could distinctly see what might be

\footnotetext{
* I made all these obserrations at the Royal Ker Gardens.
} 
taken as a bract-like appendage, as if the minute nodule were an abortive bud. The underground shoots or stems of the retch at their nodes developed roots or trifid bracts (two stipules and an abortive leaf?) indifferently, although the above-ground stem never develops roots at its nodes. I also observed that the roots on the underground stems had, at their base, a cup-like appendage, which may, perhaps, be the fusion of abortive bud-scales, like the integuments of the seeds. There appears to be room for some interesting experiments in connexion with these wild retches. A hundred or more seeds might be sown in as many small pots, one seed in each. After germination the earth might be carefully shaken off, and the root of each examined at intervals of a few days or so, with the view of ascertaining the relation of the underground buds to the roots. Possibly the root-buds might not be giren off till the green stem and leaves died off, and the warmth of the returning spring stimulated the root into life again. This, however, might possibly be imitated by artificial heat. In such experiments it might also be possible to obtain some clue as to the nature of the nodules on the roots of the leguminiferæ.* My observations were made on the roots of the wild vetch of the gardens, and it was impossible to ascertain whether the plants were seedlings or the buddings of bits of roots left in the ground from previous weedings, so that what I said in this connexion may be worthless.

8. In the underground shoot of a potato I saw buds with a branched root on each side of the bud, like stipules, the bud seeming like an abortive leaf. The shoot itself ended in the usual tuber. Another underground shoot of the potato had nodes, which gave off a bract subtending a dereloped bud, with a root on each side. Other nodes had a third root. All the terminal buds were bent backwards, like the barb of an arrow, apparently for easy progress through the soil. In the potato, some of the underground shoots develop a tuber at their extremity, and all the "eyes" are gathered there, while the pedicel of the tuber is a long bare internode. In other cases the long thin pedicel has buds on it. Other shoots have buds and roots at every node, but do not develop tubers. Then, when they reach the surface, they develop leaves only. I have seen as many as six tubers emerge from a single node, and many roots surrounding them, as if that point were a fusion of nodes. At other times every bud of an underground branch is a taber.

9. In the underground stem of the horse-radish the bracts enclose a bud, on each side of which a root emerges. Sometimes

\footnotetext{
* It is stated elsewhere these nodules are eonsidered as products of mieroorganisms.
} 
there is a third root, which emerges above the bud. At other times four separate roots appear round the bud.

10. The same occurs in the potato. Its underground stem has bracts-subtending buds, with $\&$ root fibril on each side. Frequently a third fibril is given off above the bud. This, I observed, was the general rule, but often root fibrils were given off all round the bud like the verticillate leaflets of a Begonia leaf, with abud at their centre.

11. Although in an underground stem it might be an advantage for roots to develop all round the bud, it is obrious that in an overground erect stem any appendage which developed immediately above the bud might interfere with the development of the bud, and if the stem were sufficiently stiff the side roots or appendages would be equally in the way, as they would not be needed as tendrils; so the only organ required would be the leaf, which acts as an atmospheric root. The other roots, which, in the vnderground stem, usually develop round the bud, would be suppressed. Even the leaves themselves abort to the depauperized condition of bracts, should the rhizome or stem be able to replace the function of the leaves, as in Epipogium aphyllum,* or most of the cactaceæ and others; or when some other plant furnishes the needed nutriment, as in the dodder and broomrape.

12. The aêrial roots of orchids are adapted to adhering to other bodies like tendrils. They consist of a woody and rascular axis, surrounded by cellular tissue. They are not unlike the terete leaves of Scuticaria Steeli. The leaf must be considered not only as a branch system, but as an aërial root system, differentiated specially for the suction of gases and the eiaboration of juices under the influence of light. The root is the same thing, differentiated specially for the suction of liquids, containing minerals and other materials in solution. When the plant is submerged, as in seaweeds, some ranunculi, Utricaria and others, the leaf probably acts both as leaf and root, and the root proper may often function solely as a tendril for anchorage. There are several floating plants without any roots in the ground. They have only leares on the water-surface and roots in the water. The latter act as waterleaves, the former as air-leaves. It may astonish the reader, perhaps, to meet with the notion that a root with its fibres is considered the same, morphologically, as a leaf with its veins. But is it not equally astonishing to find that an axillary bud is now a leafy branch and then a magnificent flower, say, of Lilium speciosum or auratum, or one of the grand roses of horticulturists?

13. Some terrestrial orchids, such as Coryanthes and others, $\uparrow$ push forth an underground stem, which forms a bud at its extremity,

* “Syme's Brit. Bot.," vol. 9, p. 131.

$\dagger$ “ Bauer's Illustr.," pp. 2 and 3. 
so that every year it shifts its place, much as grasses and certain lilies do. When the tubercles of these orchids are deep in the earth they send upwards a root-like stem, which produces roots only until it reaches the light, and then derelops only leaves. Lilium Ireichtlini does the same thing. Its underground shoot throws out roots only until it reaches the surface, when leaves are produced and no roots. Curiously enough, its bulbils emerge from the axilla of one of the roots, which are often verticillate, like the leaves of many lilies.

14. Lilium Philadelphicum has either alternate or verticillate leares. At the base of the stem, abore the bulb, it has verticillate roots.

15. Litivm croceum, in the underground part of its stem, gires off whorls of roots, and sometimes a bulbil from their axillæ just as a $L$. bulbiferum would do from the axillæ of its leaf-nerves, these in the upper part of the stem being the homologues of the roots in the lower part. Other liliums do the same.*

16. We should not lose sight of the fact that in the beginning of time there was no such thing as ground roots, or roots of any sort, but only leaves. In reality the size or breadth of a leaf does not change its nature. It is the petiole, midrib, and veins which count most, for we can have leaves of immense breadth, and leaves which are mere reins, just margined, and others where the margin wholly aborts, as in Ferula, and in the submerged leares of Ranunculus and Cabomba. In the latter the submerged leaves are indistinguishable from thready roots. Therefore, when we speak of a bud being axillary, we really mean the axilla of the petiole, or midrib, as the case may be, so that there would appear nothing very preposterous in considering the underground bulbils of Litium croceum or Leichtlini as axiilary buds of underground leaves (roots).

17. The idea of the homology between the roots and leaves is supported by the foilowing facts :- .

(a.) The rerticillate roots on the stem of Lil. Philadelphicum and others corresponding to the verticillate leares;

(b.) The axillæ of stem-roots prodncing bulbils in Lil. longiflorum, croceum, and Leichtlini, as do the leares of Lil. Tigrinum, $\uparrow$ and others.

*H. J. Elwes" "Monogr. on the genus Lilium."

† I have not had the opportunity of cxamining lily plants in their green state, and therefore what I state may require verifieation, or rejection.- I only judged from H. J. Elwes' monograph. From these plates it is impossible to make out whether the bulbil is subtended by a root or by an atrophied tract. In the potato, I think the underground bud is surrounded by roots. 
(c.) Plants with verticillate leaves often have verticillate roots, as Hippuris vulgaris and others. Asperula taurina* has four leaves in a whorl, and curiously enough, the creeping rootstock is shown with four roots in a whorl, insiead of leares, in its underground course. Galium palustret has four leaves, and the underground part of the stem is shown with four main roots at each node, instead of leaves, but they are not so strikirg as in Asperula.

18. It is interesting to study the germination of the lily seed, as given by MI. P. Duchartre. $\neq$ At first the radicle lengthens. On a part of it, which is not yet cleterminable, is afterwards formed the first bud-siale. Afterwards the cotyledon releases itself from the seed integuments, and raises itself above ground. Finally, on a part of the radicle, already referred to, an enlargement appears, which is the first scale of the bulb. Then, from the side of this, as from an axilla, another scale arises, and from this a third, and so on. ' 'he first radicle is transitory and disappears. Then below the first bulb enlargement other roots bud out. These Duchartre calis adrentitious roots. Here we see that the caulicle is a part of the radicle. It is known that it is a so-called caulicle at all because the first scale is formed on it. When the so-called radicle dis. appears, new so-called adventitious roots bud out of the base of the scale. So that we have a leaf (scale) forming on the radicle, and roots forming at the base of this leaf. The study of Duchartre's obserrations lead one to conclude that the sub-division of the germinating plant into radicle and caulicle is a botanical conrentionality, and much as if we took a round ruler, and drew a line round its middle, and then determinined that one-half of the ruler should be the caulicle and the other half the radicle!

19. It would appear that at the node, whether of a stem or rhizome, or rcot, may be developed either stipules or bud-scales, leares, or branches, and also roots. Sometimes all three are developed, sometimes one or the other. When the nodes are on a horizontal stem the roots and branches are opposed, when erect the roots are likely to become whorled, as in grasses.

20. In Nitella glomerataई the rerticillate roots are hardly distinguishable from the branches.

* "Syme's Brit. Bot.," vol. 4, p. 229.

$\dagger \quad$ " " $\quad$ p. 221.

$\ddagger$ Notes et mem. “Jourl. Soc. Imp. et centr. d'Hort.," 2nd Sec. 'Tom. 8, p. 554.

$\S$ “Syme’s Brit. Bot.," vol. 12, p. 185.

A p. 1724. 
21. Cabomba aquatica* and C. Carolinaria have peltate floating leares, and àlso submerged and dissected capillary leares, which are more like root-fibres or leaf reins than anything else.

22. Goebel ("Clutlines of Classif.," p. 239) gives a drawing of Salvinia nataus. The hairy submerged leares of this plant are indistinguishable from roots. He calls them submerged leaves with teeth, and some of these teeth are fertile, that is, they contain sporocarps. As these submerged appendages have been called leaves, at p. 244, he says "Salvinia is rootless!"

23. Again, in Pilularia globulifera (p. 236), Goebel calls the appendages growing upwards leaves, and those growing downwards roots, but there is no difference between them.

24. In axillary buds there are often two lateral roots and a middle one. T'his is what happens in the germination of some seeds, and is well shown in Goebel's Fig. 249, of Zamia spiralis. 'There is a downward primary root, and an upward primary leaf. Between the two there is a pair of cotyledons, or storage bud-scales, which feed both the upward and downward appendages. Then at the base of the radicle there is a pair of lateral sprouting roots. Compare with this Duchartre's germination of the lily seed.

25. In Vitis astivalis and others, the tips of the teeth of the young leares have an expansion similar to that of the tendril ends of Ampelopsis quinquefolia and Veitchii, which afterwards become disks of aitachment. It is, therefore, conceivable (bearing in mind the view I hold) that the expansions of the tendril ends are homologous with the teeth glands of leares. Or, in other words, the branches of the tendril are homologous with the reins of the leaf. The disks would correspond to the more developed tubers at the ends of the branches of Vitis Pterophora.

If the reader of this appendix, and indeed of many other pages, is not an erolutionist, and has not a ririd imaginatiou, he will, without doubt, think the notions there expressed preposterous.

* Lindl., "V. K.," p. 412.

† Le Maout and Decaisne, "Syst. of Bot.," p. 209. 
"Before all else, the spirit of Science must be free; it must be unfettered by the chains of prejudice, whether these be forged by our own minds or manufactured for us by the minds of others. . . . . . .- "Aristotle as a Naturalist," hy Prof. Romanes, Contemp. Rev., Feb. 1891. 


\section{XI.-STIPULES, BUD SCALES, AND COTYLEDONS.}

What are stipules, and how do they fit into the theory that leares are modified branches?

If we look upon them as protectors of young tissues, we may perhaps better follow the discussion I have entered on in this chapter.

It is erident that as long as plants remained in the condition of seaweeds, they had no need of stipules as protectors. The whole plant then had a habit and structure suited to a water surrounding. But as soon as erolution progressed, and water plants began to emerge into an air surrounding, the need became urgent of protecting the young tissues from diryness, heat, cold, and, erentually, after becoming much modified, of protecting them even from excess of moisture until they became suitably hardened. So we have hairs, scales, and stipules, \&c. evolring as useful organs of protection, much as we have hair, wool, scales, and feathers as a protection to animal tissues. In the case of stipules, they may have acted in many cases, not only as protectors, but also as nurses of the young leaf branches or terminal and axillary buds.

In seaweeds we meet with no part that we can call a stipule. Everything there is plain sailing. We have cladophyls, and sub-dirisions of cladophyls.

We begin to find something approaching to the nature of stipules in ferns. We find something that might be alled stipules in Marattia, and in another; but it is not clear what purpose these expansions at the base of the frond petiole can serve in Marattia.

In phænogamous plants, however, we find whole orders with these appendages, whatever they may be, and we find that sometimes they are the sole representatives of leaf organs. 
Botanists look upon stipules as appendages of leaves, and, indeed, Asa Gray, at p. 106 of his "Structural Botany," says :"Between salient expansions or wing-like margins of the base of the petiole, such as those of the Saxifrage tribe, and stipules adnate to the margins of the petiole, as in most Rosacex, there is no clear limitation. But presence or absence of stipules generally runs through a natural order.* Yet what are called stipules in one order may pass for expansions or appendages of the petiole in another."

If we look upon the leaf as a special structure, unconnected by inheritance with the stem, we shall often be puzzled to discover the morphological position of this appendage called stipule. On the contrary, if we look upon the leaf as a stem, and the axillary bud as only a branchlet of the leaf, we shall, I think, more readily be able to find the morphological position of the stipule. It would be rather puzzling to make out how the spathe-like stipule of Ficus elcstica can be merely an appendage of the leaf rather than of the stem and terminal bud.

In the phænogamous division of land plants we find such a rich variety of the stipulary organs, often holding an important functional position, that in many instances they take the place of leares.

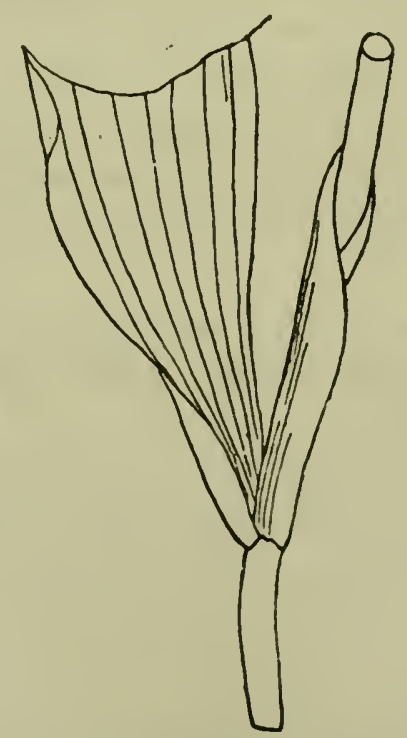

Fig. 55. Stipule of Potamogeton Rufęcens ("Syme's Brit. Bot.," pl. 1402).

* Heredity readily accounts for this. 
In the grasses, for instance, we find the stipules adnate to the leaf petiole, and forming: the vagina, the ligule being evidently no other than the free upper ends of the stipules.

The study of the genus Potamogeton is very interesting and instructive from a stipulary and vaginal point of view, for in its species we find several gradations between the independent stipule, such as we find it in Ficus elastica and the adnate vaginal stipule of grasses.

For instance, in Potamogeton Rufescens (Fig. 55) we find a

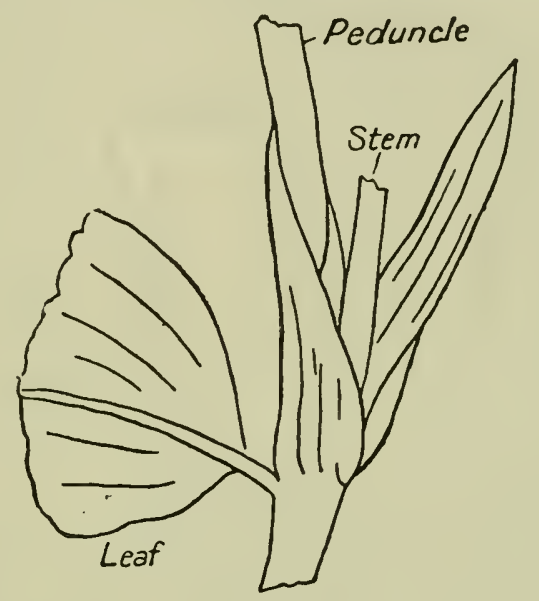

Fig. 56. Potamogeton Lucens, Linn. (Syme, pl. 1409.)

vagina which is totally inclependent of the leaf. It envelops the main stem, and evidently served as a protection to the young terminal bud.

In Potamogeton Lucens (Fig. 56) we find a similar stipule invaginating the peduncle, and, in addition, a second stipule, which appears to belong to the main stem. Here it is evident that these stipules are bud-scales. It is, however, conceivable that, with a little twisting, these two bud-scales might easily become stipules to the leaf, one on each side.

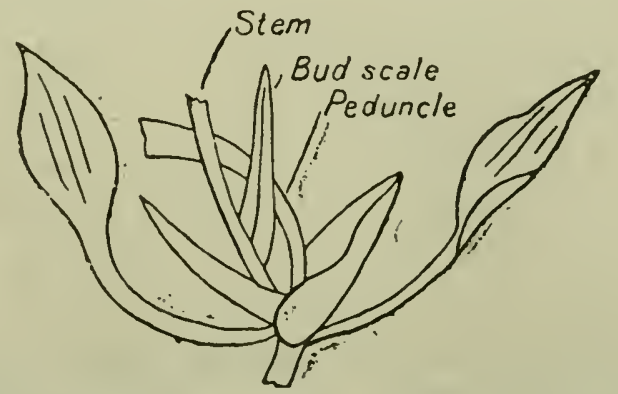

Fig. 57. Potamageton heterophyllus, Schreb. (Syme, pl. 1406.) 
In Potamogeton heteroplyllus (Fig. 57) we have bud-scales which might also be considered stipules.

In Potamogeton natans (Fig. 58) we find a similar variety of well developed bud-scales, some of which might well be stipnles. We see an independent stipule $(a)$, a stipule adnate to the petiole $(b)$, and a third stipule raginating the main stem $(c)$. This figure does not show clearly whether $(b)$ is adnate to or independent of the petiole.

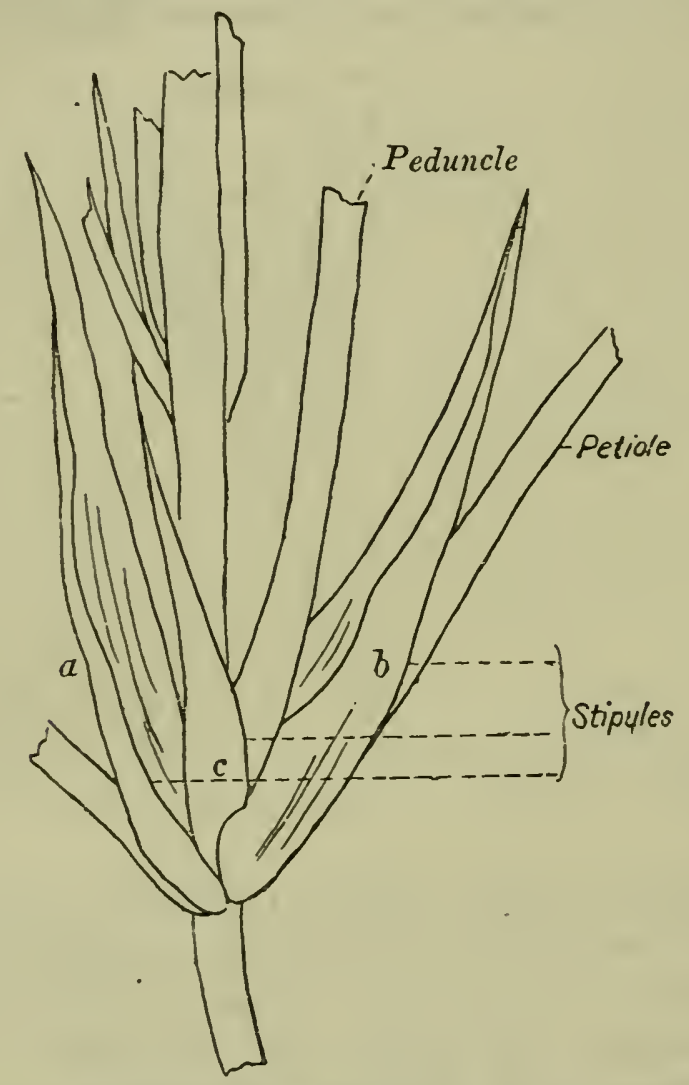

Fig. 58. Stipules of Potamogeton natans, Lin. (Syme, "Br. Bot.," pl. 1399.)

Anyhow, the three following species of Potamogeton, shown in Figs. 59, 60, and 61, do not leave us in doubt regarding the origin of the ragina and ligule of grasses. Whether the ragina comes from one or two stipules is not perhaps easy to make out, nor is this of much importance, considering that some species in the genus Ficus have two, and some have only one; but what is not difficult to make out is that the ragina of grasses is the adnation of a stipule to the leaf petiole, and the ligule only its free ends. 


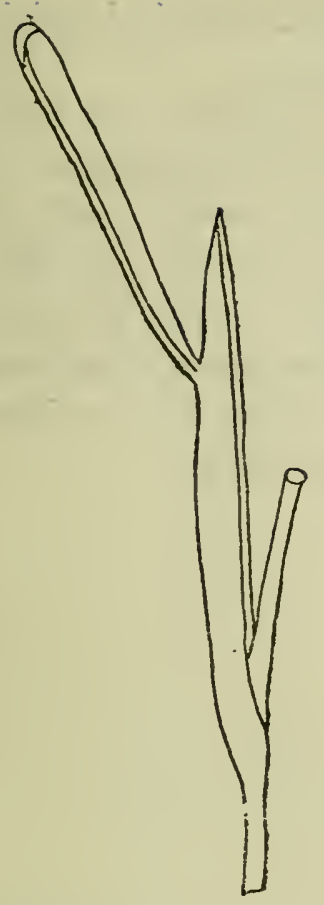

Fig. 59. Stipule and ligule of Potamogeton flabellatus. (Syme, "Br. Bot.," pl. 1421.)

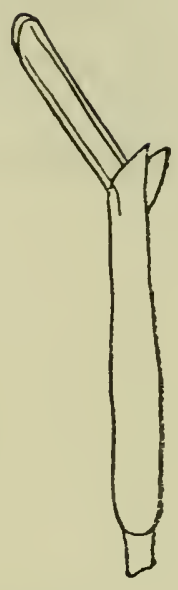

Fig. 60. Stipule and ligule of Potamogeton eupectinatus. (Syme, pl. 1422.)

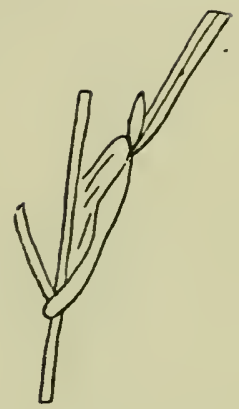

Fig. 61. Stipule and ligule of Potamogetor flabellatus, Lin. (Syme, pl. 1421.)

Then the vagina of Typha latifolia (Fig. 62) shows the same thing, and the adnate stipules of Sparganium simplex (Fig. 63)

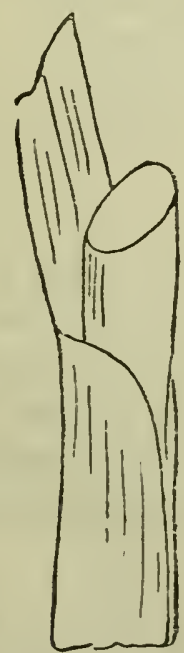

Fig. 62. Vagina of Typha latifolia,

Linn. (Syme, "Br. Bot." pl. 1385.)

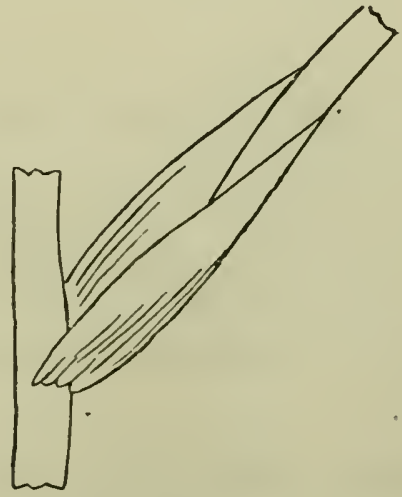

Fig. 63. Adnate stipules of Sparganium simplex, Huds.

(Syme, pl. 1388.) 
show us how easily they might invaginate the stem if the leaf petiole did not form such an obtuse angle with the stem.

Nor is it Potamogeton alone that gives us indications of what the ragina of grasses really means, for in the Polygonaceæ we have a ragina, called ocrea, enveloping the stem, independently of the leaf. The ragina of Polypogon Monspeliensis (Fig. 64) sufficiently shows us that in this species the ragina leares the stem and becomes adnate to the petiole, as in Potamogeton flabellatus (Fig. 59), while in Potamogeton Rufescens (Fig. 55) we have the homologue of the ochrea of Polygonum orientale.

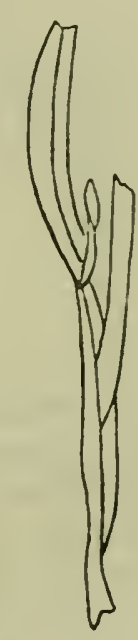

Fig. 64. Adnate stipule with ligule of Polypogon Monspeliensis, Desf. (Syme, pl. 1713.)

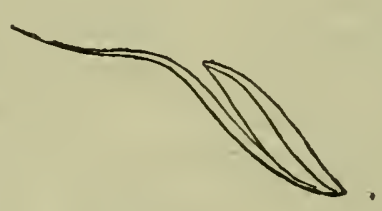

Fig. 65. Glume and awn of Alopecurus bulbosus, Linn. (Syme, pl. 1702.)

If we follow the vagina of grasses further up the stem, we find that it no longer enrelopes the stem, but becomes the glume and the pale of the spike; and the leaf or leaf-petiole becomes the awn. The following Figs., 65, 66, and 69, remore all doubt about this, for they are only reduced copies of the adnate stipule of Potamogeton Aabellatus (Fig. 59) and Polypogon Monspeliensis (Fig. 64).

If further evidence be needed of the identity of the glume and pale of grasses with their leares, we find it in teratological species, when the orules revert to ordinary buds. In Poa alpina (Fig. 68) 


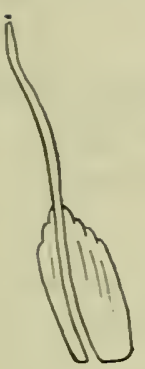

Fig. 66. Glume and arrn (enlarged) of CarexRupestris, All. (Syme, pl. 1593.)

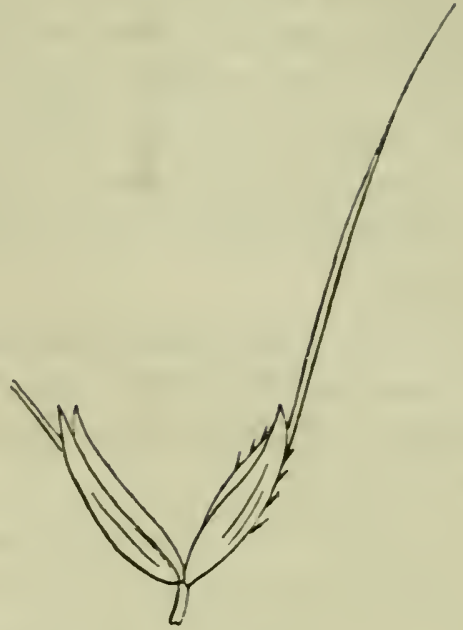

Fig. 67. Glume and awn of Polypogon Monspeliensis.

(Syme, pl. 1713.)

and Poa stricta (Fig. 69) we hare such rerersions. Beyond the glumes, we again get leares, instead of stamens and orary, and the glumes take their places as bud-scales. Such species are called viviparous, that is, they throw off living active buds, instead of dormant seeds.

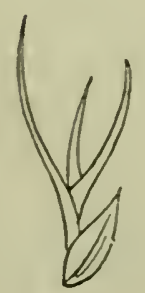

Fig. 68. Glume and bud of Poa alpina. (Syme, pl. 1762.)

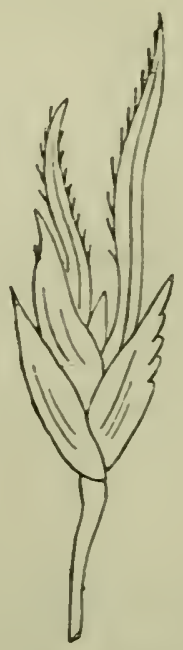

Fig. 69. Glumes and bud of $P o a$ stricla. (Syme, pl. 1763.) 
In the Zea Mays (Indian corn) the female spike of flowers is enveloped in a great number of these enlarged stipules, the blade of the leaf being entirely abortive or partially so, as in many American varieties of Zea. The so-called bracts of the young bamboo shoot, like the bracts of the maize cob, are only raginas of leares, without the blades, or we might call them enlarged glumes or bud-scales.

The sheath at the base of the Arad leaf appears similar to that of Sparganium, Fig. 63. And the flower-spathe of Calla Ethiopica and others is only a repetition of the same part, with the blade undereloped.

If we consider the sheathing petiole, or the ragina of grasses as two distinct stipules (or even one stipule) adnate to the petiole, the ligules, as I said, fall into their natural places, as the free ends of the stipules, and it will not be necessary, as Le Maout and Decaisne have done, to consider the ligule "as an axillary stipule, situated at the separation of the blade from the sheathing petiole."

I said that the ragina of grasses might have originated in either one or two stipules, because in certain species of Ficus we find two separate stipules and in others only one, as in $F$. elastica. The latter may no doubt be the union of two originally separate ones, or the former may be the splitting up of one originally undivided stipule. The spathe of Calla, of Anthurium, and of other Arads may have originated in stipules such as that which ensheathes the terminal bud of $F$. elastica. The invaginating base of the leaf of many umbelliferæ may be considered as having the same origin.

Can we now follow the stipule a little further, and discover how it originated in the first instance? We have, in a way, been able to see that the stipule of Potamogeton, the ochrea of Polygonum, the vagina of grasses, and therefore of sedges, and their glumes, and the flower-spathe of Calla, Amaryllis, and others are all homologous parts, but can we trace the origin of the stipule further?

In text books, stipules are said to be appendages of leares, but, if we reverse matters, and call the leaf an appendage of the stipule, we may perhaps be nearer the truth. Let us endearour to make a rough survey of the different kinds of stipules. 
In seaweeds we do not meet with any. It is only when plants, as I said, began to emerge from a water life into an atmospheric life, that stipules evidently were of service as means of protection. It is true that we find them in plants which are half aquatic and half atmospheric, but one can never tell whether these nave been directly erolved from seaweeds, or have degenerated from dry land plants into swamp and semi-aquatic plants, and have inherited their stipules.

Among cryptogams, we first meet with organs that might be taken for stipules in ferns.* Marattia has two expansions at the base of what might be called the petiole of the circinate frond, which probably are the homologues of stipules. In the Marattia these appendages appear to be distinct from the frond. Indeed, if we look upon the frond and the leaf as stems, or, at all erents, as branches, which comes to the same thing, we shall see the original function of stipules may have been as bud-scules, that is, protectors of the young undeveloped bud against heat, cold, \&c. The reason that so many ferns hare them not may. well be that they are often well furnished with protecting hairs or scales.

If we examine Begonias, we very frequently find that the so-called stipules are really well dereloped bud-scales, which form a complete protection to the terminal bud and are repeated as flower-bracts. The bud-scales of the White Poplar are indistinguishable from the stipules of the same. The bucl-scales of certain oaks are of the same tan colour as the stipules, and indistinguishable from them.

Asa Gray says that bud-scales can either be stipules, as in Magnolia, 'Tulip-tree, Beech, \&c., or the base of leares, as in the Horse-chesnut. In this tree, it is not easy to say whether the bud-scales are more of the nature of a pair of connate stipules, with the blade nndereloped, like the glumes of certain grasses, or of the nature of undereloped leaves proper, the scale forming the base of the leaf, as Asa Gray supposes, for the order to which the Horse-chesnut belongs is with or without stipules.

That stipules are often unimportant appendages, indeed remnants of once important organs, is quite evident; for they are frequently insignificantly small, and drop off as soon as the leaf is Gard.")

* Nicholson says that stipules are found in one or two ferns.-("Dict. of 
somewhat expanded. Indeed, in whole orders they are entirely absent. That, at other times, stipules, as bud-scales, are important is also evident enough, for internally they are frequently coated with hairs as a protection against cold, and externally glazed with a resinous exudation, as a protection against wet and consequent freezing, and possibly also against insects.

That stipules sometimes wholly monopolize the office of leares, as in Lathyrus Aphaca, is quite true, but we find that any part which can expose a sufficiently broad surface to the light and surrounding medium can function as leaf. And the conclusion that might be drawn from this fact is that neither leaves nor stipules are a necessity to phænogamous plants.

The importance of the stipule as a bud-scale is seen in the Ficus elastica. It is wrapped round the terminal bud, and protects it completely, being quite independent of the leaf. As soon as the bud begins to expand, this huge bud-scale drops off. Of a similar nature is the so-called bract, which protects each group of flowers on the Banana stem, like the flower bracts of Aponogeton distachyon. Here it functions as a bud-scale, and may indeed be a connation or fusion of several bud-scales. As soon as the ovaries of the Musa begin to derelop, this huge budscale drops off, having accomplished its purpose.

What is then the morphological position of the appendage we call stipule?

I think that there are perhaps three views which might be taken of the stipule.

(a.) That it is a bud-scale pure and simple. This we plainly see in the genus Ficus, Potamogeton, and many others. In such cases it acts as a protection to the terminal bud, and the next young leaf, which in my view is a branch. In the Ficus elastica it does not give one the idea that it belongs to the leaf, which opposes it;

(b.) 'That the stipules, at the base of the leaf, are bud-scales of that same leaf, the latter of course being considered as a branch, which in its young state is a bud requiring protection. That in such a case stipules may remain, as permanent appendages, can have little weight, because we know that most parts may remain permanent, or may be dropped off, after accomplishing their office, or become atrophied, as remnants of important organs, 
or finally may disappear altogether congenitally as if they had never been there.

In Spergularia it is evident that the so-called stipules are nothing but bud-scales. In "Nature," of 5th Sept. 1887, V. 18, p. 507, Prof. Alex. Dickson specially calls attention to those of $S$. marina. He says the stipules are free from the petioles, and by connation become interpetiolar. "Lastly (and this is the important point), these stipules are united to each other round the backs of the petioles, so that a sheath is formed completely surrounding the axis and the two leafbases. This connation of stipules round the backs of the petioles is rery interesting, as being a rare phenomenon." It is interesting indeed, for it shows us plainly that the stipules of Spergularia are no other than bracts or bud-scales to the leaves. And, as a matter of fact, in Syme's "Engl. Bot.," V. 2, pl. 256, these same interpetiolar stipules are higher up the stem, shown as bracts of theflowers. In Spergularia marina the stipules by connation form at the node a sort of protecting cup or involucre to the young leaves and terminal bud. The only other case of this kind that Prof. Dickson could find was in Astragalus, mentioned by St. Hilaire in his Morphologie.

(c.) That stipules may also be considered as portions or lobes of the leaf-blade left behind, connate with the stem, when the leaf has become petiolate, that is, when the blade has retired towards the apex of the leaf. The potato-leaf has many of these detached bits or lobes on the leafipetiole. Any pair of these might be transformed into stipules, if the petiole were shortened up to their level. In fact, Lindley calls the appendages on the petiole of Pyrus communis stipules, but they are so high up that one would be justified in considering them as atrophied leaflets, on their way to becoming stipules, as in Hardenbergia (Figs. 24 and 25), more especially as this genus (Pyrus) has both simple and pinnate leaves.

'Then Salix fragilis, às shown in Nicholson's "Encyclop. of Hort.," shows the leares as trifoliolate, without petioles. The 
side leaflets may pass for stipules, raised to the grade of leaves or leaflets, more especially as in Salix vinimalis he shows two small stipule-like appendages, and under the genus Salix, he says, "stipules variable."

Similarly, the stipules of Heartsease may be considered also as the two side leaflets of a trifoliolate leaf.

'The tendrils of the Cucurbitaceæ by some botanists are considered as modified stipules, and by Le Maout and Decaisne as leares. With regard to these, however, see "Discussion of tendrils of Cucurbitacex," in Appendix to Section X.

Among the Compositæ and Crucifere we meet with many forms of leaf which are apetiolate, the blade being connate with what might be considered its leafy stipules; they often form the amplexicaul base of the leaf.

The cauline leares of Cineraria cruenta are described as auricled at base. These auricles might well be leafy stipules, adnate to the petiole.

'Then from the leafy expansions, which monopolize the function of the leaf, as in Lathyrus Aphaca, we may pass, through many gradations and variations, down to simple setee, or even hairs, as representatives of stipules, and even to total extinction.

In the membranaceous spathe of the Jonquil-which may be considered either as a stipule, or bract, or bud-scale-are enclosed a number of flowers. Each flower is subtended by a long hair, in

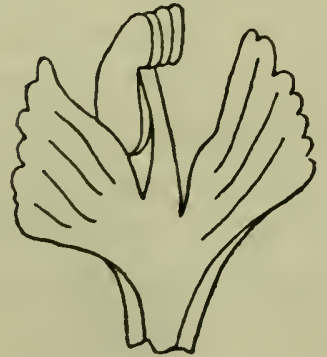

Iig. 63. Stamen of Heteria pygmea.

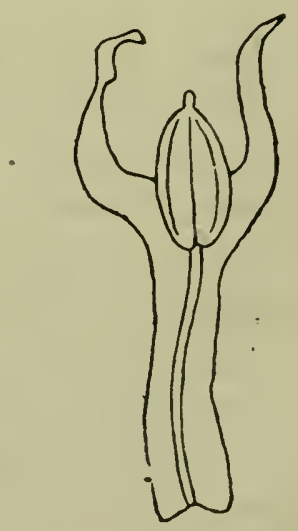

Fig. 64. Stamen of Fendlera Rupicola (tab. 5, Plantæ Wrightianæ, Smith's Inst.). 
some cases so fine, that in examining it, it became attracted by the ebonite mounting of my lens, as any other very fine hair would be. Nerertheless, this fine hair was serrated by still finer teeth. Other spathelets or bractlets were a little thicker, and their serrations more visible. We see that any part, however huge it may be in some cases, may have only a hair, as its homologue, in other cases.

We are accustomed to read of stipules as appertaining solely to leaves, but the most cursory glance over the different forms of stamens will show us that identical appendages are met with on those organs. Figs. 63, 61, and 65 do not leave much doubt as to the nature of the appendages on those stamens.

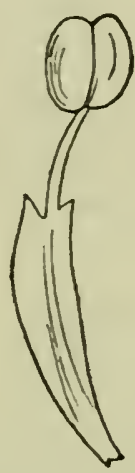

Fig. 65. Stamen of Aconite (mag.) (Le Maout et Decaisne, p. 185).

\section{Cotyledons.}

The discussion of the leaf and stamen stipules leads us to another interesting subject, viz., that of the cotyledons.

The rariations in the forms of these organs is very great. Some take the form and substance of leares, some become stores of nourishment for future use, such as we find in the corm and the tuber. What is their morphological position?

If we go back to the stipule and bud-scale we shall, I think, find that cotyledons may be considered more reasonably as either the one or the other.

It may be as well to recall to the reader's mind the identity of the leaf and stem by quoting what Dr. Masters ("Teratology," p. 356) has said in discussing so-called adrentitious leares in Miconia and Gesnera. "A much more natural explanation than that giren by Prof. Morren is that the development of adventitious 
leaves, instead of occurring in the same plane as the blade of the leaf, occur in different planes, like the leares of a branch." $\mathrm{He}$ adds, "thus showing the close relationship, if not the intrinsic identity, between the leaf-stalk and its continuation the midrib, with the branch and its sub-divisions." He also states that Casimir de Candolle propounded the notion that "the leaf is the equivalent of a branch, in which the upper portion of the rascular circle is abortive."*

In another place I have stated that, from observations made in India, I had come to the conclusion that the leaf was only a repetition, on a small scale, of the branch, very much as the budscale is a repetition, on a still smaller scale, of the leaf, and the hair, on a microscopical scale, a repetition of the bud-scale.

Also, in discussing the genesis of the axillary bud, I have endearoured to show that it is a branchlet of the leaf which corresponds to a cladophyl; that when the leaf decays, or before, this branchlet (axillary bud) takes the lead and continues the growth of the plant.

Now if we look upon the plumule of the seed as a bud, we immediately perceive that the cotyledon or cotyledons naturally take their place as either stipules or bud-scales, the plumule, in lengthening, corresponding to the petiole of the leaf.

Indeed, we have only to glance at a section of a grain of wheat, given in Fig. 66, to be conrinced that the corm-like part

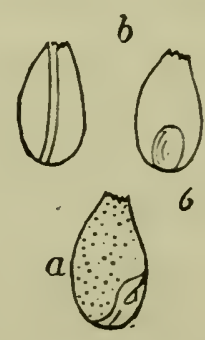

Fig. 66. Grains of Wheat, "Henslow's Bot. for Beginners": (a) cotyledon and embryo, $(b)$ back and front view of the same.

of the seed, containing the starch and gluten, is no other than a thickened bud-scale, which we have styled cotyledon, and that the embryo or bud occupies its axilla.

* "Théorie de la feuille" (Arch. des Se. Bibliotèque Universelle, 1868). 
Still more plain is the date-seed in germination, Fig. 67. We have here a bud-scale $(b)$ invaginating the stem, and haring the cotyledon $(a)$ at its apex; while $(c)$ is a second bud-scale inraginating the terminal bud.

Then the embryo of Ouvirandra fenestralis, Fig. 68, leares us in no doubt whaterer on this point. The thick part $(a)$ is the cotyledon, while the thin part $(b)$ is the plumule; that is, the plumule is in the axilla of the glume-like thickened cotyledon.

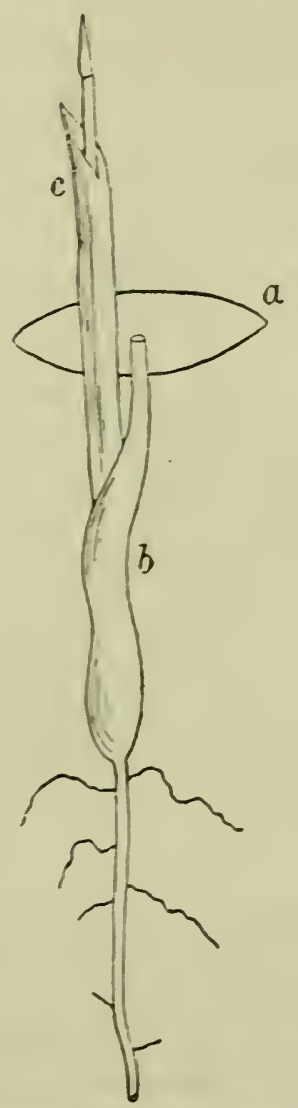

Fig. 67. Seed of Date, germinating (Sachs' "Phys. of Plants," Fig. 236).

In the stipules and bracts of the Begonias we seem to hare. repetitions of cotyledons, the leaf proper corresponding to a branch, while they function as bud-scales to that branch while young.

In Fig. 69 we have a good illustration of the leaf petiole contimuing as a stem. It is what Bruant calls the fertile leaf of Begonia Amelice. (a) is the scar left by the deciduous stipule; (b) is the leaf-blade, which is at the same time the bract or bud- 


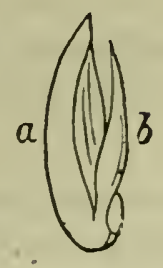

Fig. 68. Embryo of Oıvirandra fenestralis (Lindley's "Veg. Kingd.," p. 210).

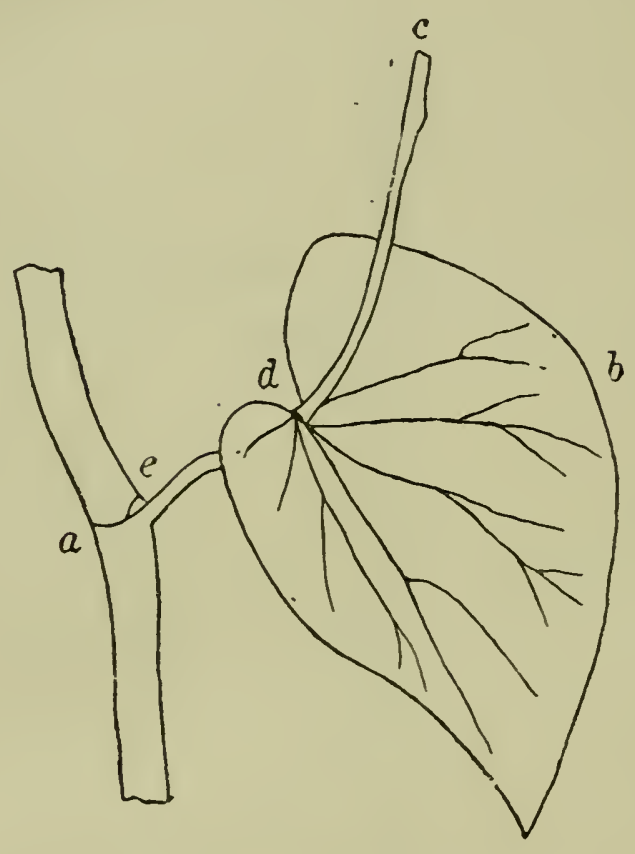

Fig. 69. Begonia Amelia (Bruant).

scale of the flower peduncle $(c)$, emerging from its axilla $(d)$, while in the axilla proper of the leaf petiole we hare the usual axillary bud $(e)$. It is also a good illustration of a bud-scale or bract becoming leaf-like, or a spathe, as in Calla, Anthurium, and others.

With regard to the cotyledons of the fir-tree, Prof. Henslow (p. 74, "Bot. for Beginners") says that each of the two cotyledons is divided into several segments.

Upon the supposition, howerer, that cotyledons are bud-scales, those of the fir would naturally fall into their proper morphological position as a repetition of the rerticillate or almost rerticillate 
disposition of the fir-leaves, bud-scales being only an imperfect development of leares.

In the germinating seed of Drosera, as shown magnified in Le Maout and Decaisne's "Syst. of Bot.," p. 406, the cotyledons occupy the morphological position of either bud-scales or stipules. We have here almost a copy of the Maratia leaf-bud, the Drosera imitating it even in the circinate vernation of the leaf. Fig. 70 is an outline of it.

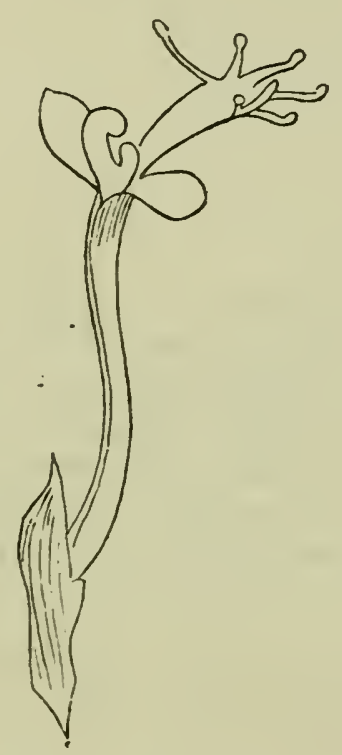

Fig. 70. Drosera, germinating seed (mag.). 
"But what is an explanation? Perhaps the best definition is that it is a description of the unknown, in terms of the known, for we can only know anything when we can trace likeness between it and other things with which we are familiar, and this erolres comparison. Comparison is not however possible till objects are known, with which the unknown thing can be compared. . . . . But making wrong comparisons is better than not making any."-Wm. Schooling, Westm. Rev., Feb. 1891. 


\section{XII.-STAMEN AND ANTHER.}

THE whorl or whorls of stamens or male organs of a flower-the Andracium, as some botanists prefer to call them-is now universally admitted to be the transformation of a leaf or leares. The basis for this admission is founded on such a large number of teratological facts that it has risen to the stage of a "moral conviction." If stamens can revert to leares it is logical to beliere them transformed leares or parts of leares. The transformed specimens collected by Dr. Masters in his "Vegetable Teratology," do not leare an opening for escape from this conclusion.

Now admitting, as we must, that the stamen is a leaf, the question arises, what part of the leaf is transformed into an anther.

Asa Gray ("Structural Botany") and others look upon the filament as homologous with the petiole and the midrib, and the two anther-cells as homologous with the two sides of the leafblade. At p. 255, he considers that "pollen is a special derelopment into peculiar cells of what would be parenchyma in a leaf, and that the line of dehiscence is the line of the leaf margin."

This riew is supported by what Thuret says of Porphyra laciniata.* "Les spores et les anthérides naissent de la transformation des cellules de la fronde." The transformation apparently consists in the segmentation of the regetative cells.

Sachs, in his "Text-book of Botany," p. 541, considers the filament and connective as the leaf, of which the anther lobes are appendages. Moreorer, on p. 490, he says that "these so-called 'sexual organs' are really spore-bearing organs, comparable to the spore-producing leares of the vascular cryptogams." Further, on p. 514, he says: "The pollen sacs of the coniferæ resemble the 
sporangia of the vascular cryptogams in the mode of their derelopment. A section through the pollen-sac of one of the Cupressinex, for example, shows that itresembles a sporangium of Lycopodium." And, at p. 515, he states that "Goebel draws attention to the fact that in the majority of the Cupressinex the pollen-sacs are protected by an outgrowth of the staminal leaf, which he considers to be analogous to the indusium of Ferns."

It was gratifying to meet with opinions such as these regarding the anther, for in studying cryptogamic plants I had come to the conclusion that in them we find the rudiments of many of the parts of higher plants.

On p. 541, Sachs truly says, regarding the nature of the stamen, "that it cannot be arrived at by a study of derelopment alone, but comparisons must be instituted," and eren in some cases the "phylogenetic method" must be followed.

I certainly agree with him. His conclusion is not only reasonable, but very important. However instructive microscopical and histological observations may be, we should not forget that in erolution, cells are as likely to abort and disappear, while others in a state of dormancy may come to the front and take the lead, just as whole parts of a plant sometimes do. Histology alone, therefore, dealing as it does with cell-derelopment, is insufficient to discover homologies. Moreover, it bewilders and confuses the mind with innumerable new names, without making the nature and homology of an organ much clearer, and without bringing us any closer to the solution of the main question. 'Chis, in my opinion, is- what relation the different parts of a plant, as we see them, bear to each other, and what relation the parts of the higher plants, which are so conspicunous, bear to those of the lower and lowest which are not so conspicuous? The solution of this question would enable us to mentally grasp plant evolution as a whole, and thus form some conception of the transition between the unicellular and the myriads of multicellular components of the regetable world. What we are all aiming at, I should say, is to understand, in some measure, how this vegetable creation we see around us has been brought about, by the process called evolution.

In Abies Pectinata (Sachs, Fig. 350) and in Asarum Canadense (Fig. 358) each stamen with its pair of dorsal anthers 
recalls nothing so readily as a contracted and modified fern-pinna, with its indusia, such as we see in Blechnum boreale, Fig. 71 .

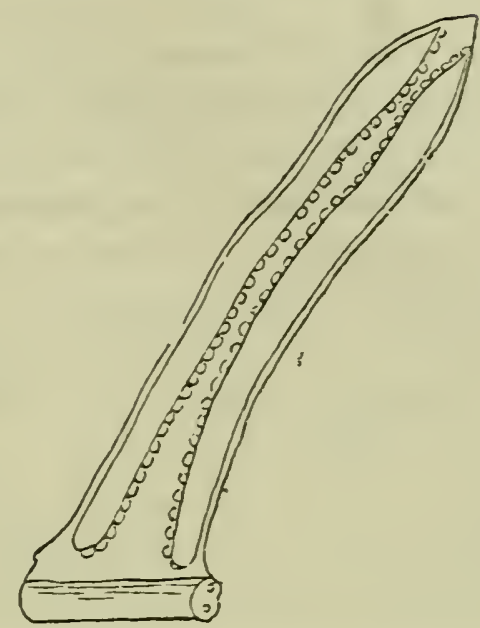

Fig. 71. Sori of Blechnum boreale ("Hooker's Brit. Ferns," pl. 40).

The anthers of the Scotch fir do so much more completely, as will be seen by Fig. 72. They are exactly like a contracted frond, with two dorsal sori, each sorus haring a double indusium. Then each contracted frond of this fir, for the purpose of protecting its pollen while unripe, is orerlapped by the one below it, so as to form an imbricate cone.

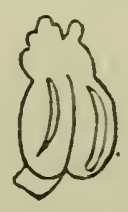

Fig. 72. Anther of Scotch Fir.

We have here pollen and spores as homologues, with the difference that the former are naked, and emerge directly out of the surface of the staminal blade, while the latter are enclosed in the gland-like tip of a hair, the sporangium.*

* The spore is nothing but a bud, like any other bud. After it germinates it produces a prothallus, or rudimentary flower, with sexual elements, as any other bud does. The former evolves the flower at once, the latter takes time to do so. 
Similarly, the anther of the Iris is dorsal or extrorse, that is, it dehisces on the back like the indusium of most ferns. In reality it consists of no other than a pair of sori on the contracted back of a staminal frond, filled with pollen grains-the homologues of spores.

The stamens of Zamia Muricata (Sachs, Fig. 344) resemble nothing more closely than the peltate indusia of Aspidium Lonchitis, Sw., and others, in which the peltate indusium had become thickened and adherent to an expansion of the placenta which bears the sporangia.* The pollen sacs of this Zamia bears a close resemblance to the sporangia of Ophioglossium and Botrychium. That they are differently grouped would signify little, for we see sporangia, which nobody denies are sporangia, differently grouped in different ferns.

We hare only to examine almost any male cone of conifers, including Salisburia, and of Cycads to find homology with the sori of ferns. They are situated dorsally, and of course modified in various ways.

In Porphyra laciniata, as Thuret has shown, we have the cells of the leaf becoming the mother cells of pollen. The cradle of pollen is not here specialized as in the anther, but is still generalized. Pollen, or its other name antherozoids, is produced in any regetative cell of the leaf. This shows us that there is no essential difference between regetative and reproductive cells. The separation exists in the higher plants as a useful sub-division of labour.

Moreorer, Thuret states that there is no fundamental difference in the process of erolution between male and female elements of this alga, for in abnormal cases the contents of the primitive cell change partly into female and partly into male elements. All the cells of the frond do not become fertile, for here and there are found regetative cells which have not undergone transformation. In other words, we might say that what we call regetatire cells are abortive reproductive cells.

The indusia of ferns and their sporangia are a further specialization of the reproductive cells. In Porphyra laciniata

* I call it placenta because I do not see that it is anything else. It is borne on a vein or axis. 
the two kinds of cells are mixed up in the frond; but in lower unicellular plants there is no such thing as separate regetative cells.

In the double indusium of Pteris Aquilina we have a suggestion which is worth noting. I shall lead up to what it strongly suggests presently.

First in Woodsia hyperborea, Br., we have the separate sori on the nodes of the reins, each sorus being surrounded by an involucre of hairs (Fig. 73). An almost parallel of this in

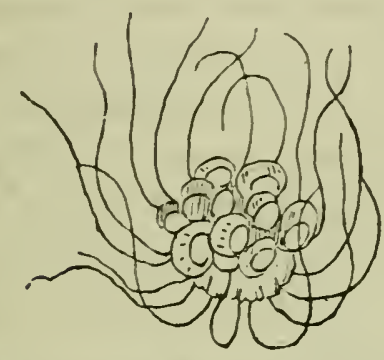

Fig. 73. Sorus of Woodsia hyperborea (Hook., "Br. Bot.," pl. 7).

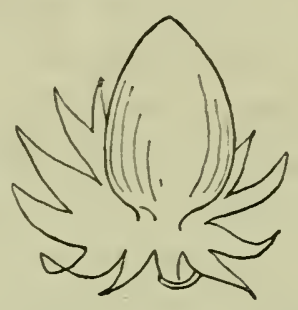

Fig. 74. Arillate orule of Myristica (Le Maout and Decaisne, p. 651).

phœnogams is to be found in the arillate ovule of Myristica, Fig. 74 .

Then in Woodsia Ilvensis, Br., we have these same separate sori-each still surrounded by an involucre of hairs-arranged in rows along the margin of the pinna, with the margin slightly turned over them.

Finally, in Pteris Aquilina (Fig. 75) we have the sori confluent all along the margin of the pinna, with the involucral

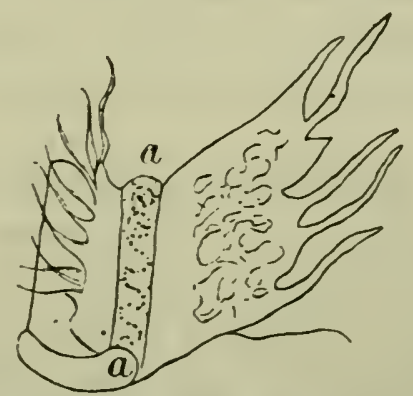

Fig. 75. Portion of marginal placenta of Pteris Aquilina (Hook., "Br. Bot.," pl. 38), ( a a) confluence of sori. 
hairs also confluent abore and below (or on both sides of the confluent sori) so as to form two foliaceous indusia, with the tips of the hairs only free. By this we see that it is possible to conceive every foliaceous indusium to have originated from a confluence or fusion of simple hairs.

The margin of the pinna of this Pteris aquilina is thickened into a placenta, out of which sporangia (or fertile hairs) have dereloped. If we now contract the pinna of this Pteris to its simple midrein, that is, abort the mesophyl, we shall have an organ which does not essentially differ from an anther, with its two loculi, like that of Magnolia,* except that the spores are contained in sacs, while the pollen grains are free. Spores and pollen grains are unicellular bodies, they germinate in a similar manner, and have been compared to each other by Berkeley.

Then in the fertile pinna of Blechnum boreale, Sw. (Fig. 71), we have a single indusium on each margin of the pinna, which arrangement, by contraction of the pinna, would give us the rudiment of an anther with only one cell, the two opposite indusia forming the two flaps of a one-celled anther.

Asa Gray ("Structural Botany," p. 255) gires a diagram to explain how pollen can be formed between the anterior and posterior layers of the leaf-blade. Of course many things are possible in nature, but as we have similar productions ready to our hands in more ancient and less differentiated forms of plants, I see no good reason why we should go out of our way to invent new and more difficult modes of origin of pollen.

The sporangia of ferns emerge from placentas situated on the veins of the frond. Veins, according to my mode of thinking, are homologous to branchlets, therefore sporongia are homologous to buds, either branch-buds, or leaf-buds, or hair-buds, or any bud the reader likes to think of. Whether we call them leaf-buds or branch-buds is of little moment, there being no essential difference between them.

In many ferns the sori are naked, like clusters of buds, or orules, without indusium, as in Polypodium. But in others they are corered by either a peltate indusium, as in Aspidium, or by a bract-like indusium, subtending the sorus, as in Nephrodium, Cystopteris, and others. In Asplenium filix foemina, Bernh., the

*Le Maout and Decaisne, "Syst. of Bot.," p. 193. 
attachment of the indusium is on the side. In Asplenium lanceolatum, Huds., and others, the attachment is also at the side, though elongated, as if it were a confluence of smaller side bracts. All the bract-like indusia emerge from the veins, as ordinary leares do from stems, and in Lygodium, each separate sporangium, or spore-case, has a separate subtending bract. Some indusia are more like wings of stems than bracts. All indusia appear producible by a confluence of hairs. The radiating hairs of Eleagnus might represent the origin of the peltate indusium or Aspidium.

Again, in Scolopendrium vulgare, Sm., we have two adjacent veins giving off two elongated indusia, like the wings of stems, the free edges of which face each other, and give cover to two rows of sporangia, the whole being indistinguishable from a onecelled elongated anther.

The fertile pinnæ of Cryptogramme crispa, Br., and Blechnum boreale, Sw., as already stated, also lead the mind in the same direction, viz., that the morphological origin of the anther, as we find it in phænogams, is probably to be found in the sori of ferns, with their single or double indusia (adjacent sori becoming confluent or fused).

In other words, the sorus appears to be a transition form between the reproductive leaf of Porphyra laciniata, and the anthers of phænogams. I consider the leaf of this alga as the rudiment of the specialized stamen of the higher plants. It is a simple frond, the vegetative cells of which produce pollen or ovules, or both.

Curionsly enough, the pollen of phænogams follows the quaternary division of the pollen of Algx. Thuret says of Cutleria multifida, p. 22: "Il est curieux de retrouver ici une exemple de cette division quaternaire, si fréquente dans les organes reproducteurs des cryptogames." He shows the same quaternary division in Porphyra laciniata. Is this resemblance between tetraspores and pollen grains accidental or has it a deeper meaning?

In the anther of Liriodendron and Asarum Canadense we appear to have a repetition, in a much modified form, of a double indusiate sorus, and in this case the anthers dehisce dorsally, like the two indusia of Pteris aquilina and others. 
The parenchyma of the leaf or frond-the mesophyl-appears to be of little consequence morphologically, that is, it easily aborts or disappears, without influencing the veins or branchlets of the leaf-stem, which appear to be of all importance, because it is these which carry the nourishing fluid in a complex plant. I prefer to look upon pollen grains, and the nucellus of orules, as homologous with spores, and these with buds, the spore-cases or sporangia acting as protecting covers to the spores.

Asa Gray, at p. 255, gives examples of deviations from the typical two-celled anther, as if anthers must necessarily have been inherited from some one typical form. What is called a typical form means a form that belongs to the majority of flowering plants. But that may only mean that in remote ancestral times there were plants with this collateral variation, riz., of a two-celled anther. The plant owning such an anther may have had some other advantage in the great battle of life, and may have been selected for generations, and survived to transmit many and many descendants with the same inherited character of a two-celled anther. It does not at all mean that there was some fixed law of anther evolution, of which the type was two-celled, any more than, supposing the survivors to have had a one-celled anther, we would be justified in calling this typical.

The variations in derelopment must hare been infinite, and the further back we go in time the more we find these rariations running into fewer streams, from which our variations of to-day have been derived, each generation inheriting a great deal from its ancestors, and erolving some deriation of its own. For instance, to borrow an example from the animal kingdom, just see how stubborn the character of seven rertebræ in the neck is. It runs through the whole of the mammal section, with the fewest exceptions. While, on the other hand, see how much variation is admissible in the organs which serve immediately to adapt the individual to its surroundings. Just see what difference there is between the nose of a gorilla and that of an elephant. Another instance-just consider how much rariation the fruit of the Citrus has undergone to suit itself to the tastes, fancies, and wants of man, while the leaf for which lie cares little has taken its chance,

- Beyond being the atrophied representative of the original reproductive cells. 
and has remained unselected. It has consequently altered rery little, excepting in size.

Who can tell how many of our present forms of plants, with all their details of character, have descended from distinct forms? We are always trying to refer the form of an organ to some one typical form, as if we beliered that there was any such prototype.

The anther of Gomphrena is one-celled, and may have descended from the two adjacent clusters of spore-cases, like those of Scolopendrium vulgare, Sm., in which the placentas of the sporangia, from contiguity, have become confluent, the indusia opening, like the edges of an anther in opposite directions. The anther of the Mallow may be explained, either in the same way, and by becoming a little twisted, or by descent from a plant which had a bract-like indusium, such as Asplenium filix fœmina, one flap of the anther corresponding to the indusium, the other flap corresponding to a contracted frondlet.*

If, howerer, these likenesses seem unsatisfactory to the reader, he has not far to search for an almost exact morphological equiralent of the mallow anther; in Lycopodium clavatum, Lin., we have an exact copy of the mallow anther, in the biralvular indusium, only it is sessile. It is, moreover, located in the axilla

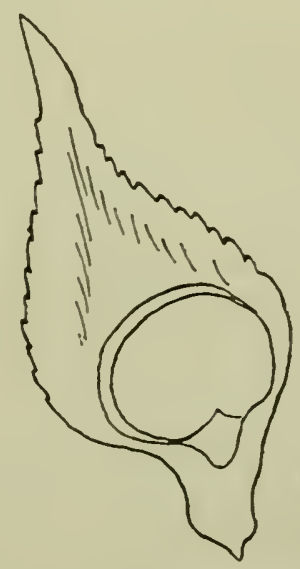

Fig. 76. Two-valved capsule of Lycopodium clavatum, including spores (Hooker's “ Br. Ferns,” pl. 49).

* It is enough to glance through "Hooker's Brit. Ferus" to discover numerous homologies. 
of a leaf, as the bracts or scales of the Lycopodium have been called by a sort of promotion from scales to bracts. Nothing can better illustrate the genesis of a one-celled anther than the sorus of this Lycopod. It is, moreover, located in the axilla of a bract (Fig. 76), just as stamens often are located in the axilla of a petal or bract, such as we see in Myrica, Fig. 77.

In the genus Salvia the one-celled anther is carried away from its fellow by a widely diverging fork of the stamen, much in the way that the two sori of Gymnogramme leptophylla, Desv., Fig. 78, are on distinct prongs of the venous fork.

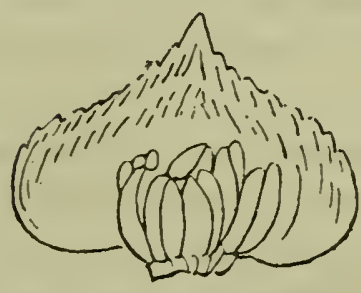

Fig. 77. Bract and stamens of Myrica, Gale. (Le Maout and Decaisne, p. 682).

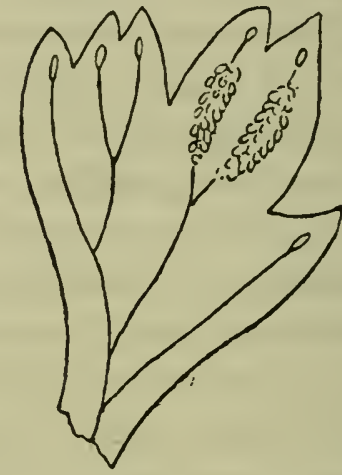

Fig. 78. Sori of Gymnogramme leptophylla, Desv.

(Hooker's “ Brit. Ferns," pl. 1).

We may perhaps think too much of the fact of sori appearing on the dorsal aspect of the fern leaf as a great difference between cryptogams and phænogams, which give off their pollen and ovules from the ventral aspect. But if we consider what the fern leaf really is-a stem with its branchlets united by mesophyl, which,'in other words, means only a fasciation of its branchlets, we shall think little of this difference.

Then in Acrostichum (including Olfersia) the sporangia are either on the upper surface (ventral) or on both surfaces. And in A. peltatum the fructification is exactly like that of Dorstenia, on a peltate expanded receptacle, fringed by pinnules. In Clfersia the sporangia cover both surfaces of the midrib (dorsal and ventral), while in T'richomanes the sporangia are situated all round the vein, which projects, beyond the pinna, denuded of mesopliyl, in the form of a bristle. 
Moreover, Dr. Masters ("Teratology") mentions several cases, in which sori are abnormally produced on the ventral aspect of fronds, such as in Scolopendrium vulgare, Polypodium anomalum, Asplenium, Trichomanes, and Cionidium Moorei.

It therefore would appear that the production of dorsal sori is a question more of inheritance, convenience, and protection than one of impossibility of ventral emergence.

Apart from all this, is there really such a thing as ventral and dorsal aspect of a leaf as something very different the one from the other, from a morphological point of view? They are simply the two sides of a branch, which have for untold ages been turned the one towards the light, and the other from it, thus acquiring by heredity different functions.

To show the utter insignificance of the position of the anther, from a morphological point of view, it is enough to mention one genus, that of Trillium. In some species of this same genus the anthers are introrse, in other's marginal, and in other's extrorse! It appears indifferent to this genus where its anthers are placed. To the species their position may be of importance. The right position might mean easy powdering of some insects' hairs with pollen for purposes of fertilization. The wrong position might mean the reverse. One might imagine the genus Trillium, telling its species, "Place your anthers where you like, and fight out your own battles. To me, their position is a matter of indifference, but to you it may mean either prosperity or extinction."

It is a feature of so little importance that even a little twisting, so common in many parts of plants, might change their dehiscence from dorsal to ventral or vice versâ.

Warming, in his paper on the ovule ("Ann. des sc. 'Nat. Tom.," 5 and 6, Bot., 1878), finds that there is no essential difference between the pollen cell and the nucellns cell of the ovule. They are both reproductive cells, and he compares the anther to a sporangium, which Goebel says is a sac producing spores endogenously.

Goebel ("Outlines of Classif.," p. 301) further says: "The structure, origin, and the formation of pollen grains, by division of the pollen mother cells into four parts, agrees in the minutest particulars with the details given in the ease of the sporangia of the vascular cryptogams . . . . . The important point 
Which results from these considerations is that the seed-beaning plant, with its pollen grains and embryo-sacs, is the equiralent of the spore-producing generation of heterosporous vascular cryptogams," that is, of those which have both male and female spores.

Both pollen cells and spore cells germinate in a similar manner. 'The ones are naked, the others corered. In the ovules of Gymnosperms and Angiosperms, something similar occurs. Those are naked, these are covered. 'That is, relatively covered by the curling up of the carpel margins, although in some the carpels remain open.

Dr. Masters ("Teratology," p. 192) records a case of the cone of Abies excelsa which normally produces only orules. Abnormally, however, it produces stamens in the lower scales and ovules in the mper, indicating that ovules and stamens are interchangeable.

He also records a case of Breckia diosmcefolia, Rudge, in the ovary of which stamens were evolved instead of ovules; and a case of a hyacinth, in the ovary of which the placenta produced both anthers and ovules, and cases of pollen within the ovule of Passifora, and all intermediate stages of transformation between the anther and the ovule (p. 185).

So that we appear to have here not only unity of anther and orule, but also unity of the sexes. 'The separation of the sexes appears to be only a matter of convenience and adrantage in the struggle for life, two differentiated individuals producing more variation in the progeny than bisexual undifferentiated individuals. It stands to reason that the more distinct the individuals are which bear the separate sexes, the greater will be the inclividual variation, and the larger number of variations will result from the recombination of the sexual elements.

In the hundreds of modifications of anthers, we get that of Menispermum Canadense, in which each pollen-sac is again divided into two locelli by the growth of a partition. Similar partitions or so-called false dissepiments are not infrequent in the ovary. The partition in the anther may be explained by the ingrowth of the margins of the double indusium, thus dividing each anther sac into two locelli, as a carpel would divide its cavity into two cells by the ingrowth and fusion of its margins. 
In anther's of Magnolia and Liriodendron, and of the Pines, give us, perhaps, some of the best examples of what I have been trying to impress the reader with, riz., the apparently strong homology between the anther sacs or locelli and the sori of ferns, and more especially so with those of P'teris aquilina.

Histology appears to tell us little about the homology of the anther. It tells us that out of a mass of parenchyma or common cells, certain cells become differentiated, that is, they grow differently, and take on different characters. These then give rise to mother cells, which change into tetrads. Then the protoplasm in the cells of a tetrad becomes corered with a new cell-wall, which is the cell-wall of the pollen grains.* The transformation of the mother cells into tetrads is shown in Fig. 79.

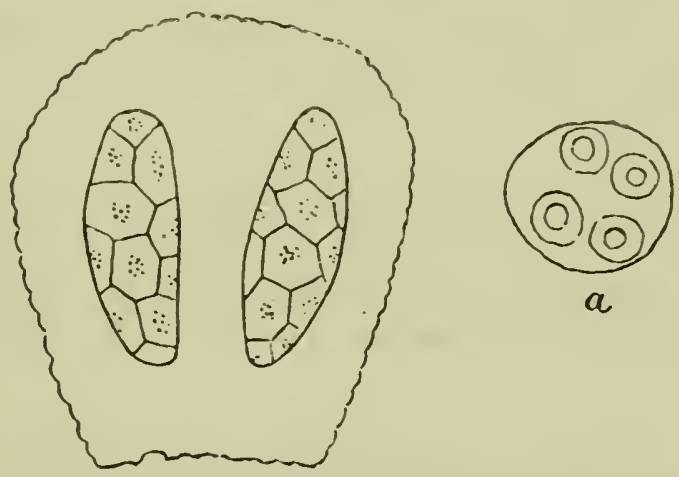

Fig. 79. Section of young auther of Melon, with two cells filled with mother cells (Le Maout and Decaisne, Fig. 702): (a) mother cell of the same, originally hexagonal, containing four pollen grains (tetrads).

Histology has no doubt shown us that these tetrads, under various names, are to be found wherever reproductive cells are to be found, from the frond of Porphyra, as Thuret has shown, to the anthers of melons, \&c.

We have, therefore, to compare other organs of other plants, after freeing our minds from the bias of words and books. The study of the emergence of the sori of ferns affords, perhaps, a good schooling for the study of the morphology of the inther. We must imagine the fern leaf as dirested of mesophyl, which is only a sort of glue with a special funetion, which fasciates the

* Goodale, "Phisiol. Bot.," p. 171. 
veins of the leaf or branchlets of the leaf-stem. We must further divest our mind of the terms ventral and dorsal. These aspects of the stem-leaf have reference only to its lighted or shaded aspect. The stem, when cylindrical and erect, has no ventral or dorsal aspect, unless we choose to call its southern and northern aspects by such names.

I do not say that the sori-arrangement of ferns is the only mould from which the anther's could have evolved, but I do think that the fructification of ferns and the anthers of phrenogams have had a common beginning. Apart from the origin of the anther, there is, perhaps, as interesting a study to be got out of the modifications it has undergone in phrnogams themselves, as in the study of the transformations of their leaves.

Now I propose to analyse the anther through an entirely different route, which, apparently, could not possibly lead to it.

On the petiole of the cherry, peach, apricot, \&c. there are two glinds. Sometimes they are at the base of the blade or on its margin, and sometimes lower down on the petiole. We find, probably, homologons glands on the petals of Berberis vulgaris, Fig. 80.

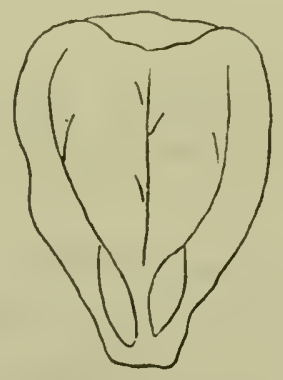

Fig. 80. Petal of Barberry, showing its two glands (mag.).

On the young leares of the cherry and others these glands are of a rerdish colour.

On each of the teeth of the young leaves of these and similar trees there is a gland, also of a reddish colour. On the teeth of the young mexpanded leaf of Viola odorata, Fig. 81, we have similar tooth glands, and the leaf is curled up like a carpel. 


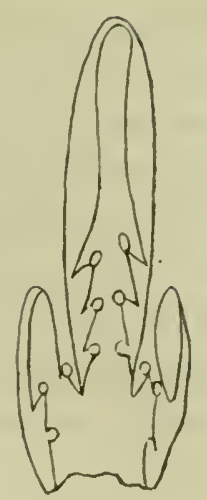

Fig. 81. Unexpanded leaf of Viola odorata (Payer, pl. 37).

These tooth-glands are evidently the homologues of ovules, such as we see in Sparmannia Africana, Fig. 82.
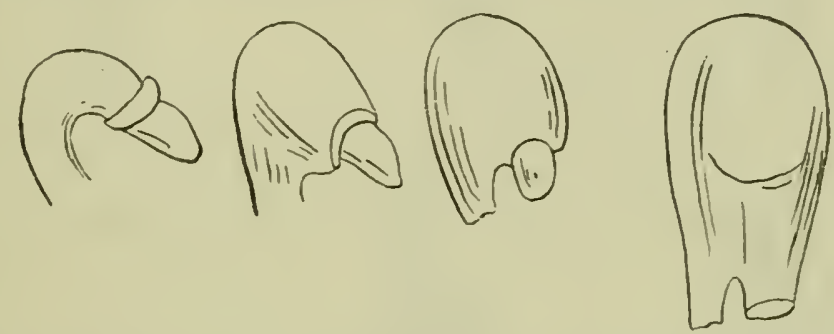

Fig. 82. Different degrees of development of the ovule of Sparmannia Africana (Payer, pl. 5).

I found that each of the teeth-glands* of the cherry secretes a drop of limpid liquid. I also found that the largish reddish glands on the petioles, which are a feature of this class of trees, secreted a similar liquid.

The glands on the petiole evidently stand for aborted side leaflets, which are a common feature in the Rosacere, that is, although the leaves of the cherry and others are simple, they descend from compound leaves, like those of the rose; and the large glands on the petioles are merely the remnants of aborted leaflets. $\dagger$ This remnant I consider to be the amalgamation of the teeth-glands of the aborted leaflets into one large gland. I

* The teeth-glands are well shown in the leaves of Passiflora vitifolia (Gurd. Chron., 23 Aug. 1890, p. 243).

$\dagger$ In like manner, the leaves of Colletia ahort into either stipels or glands. (Gard. Chron., 10 Jan. 1891, fig. 13). 
was convinced of this by finding, in some young specimens, that the leaf, in addition to the pair of large glands on the petiole, had two smaller similar glands on the margin of the base of the blade, only differing from the single teeth-glands in being larger. And their largeness, as compared with the size of the teeth-glands, convinced me that they were larger, owing to cohesion or fusion of several together. Therefore, it was reasonable to conclude that the still larger petiole-glands were due to the cohesion of all, or of a large number of the teeth-glands of the two suppressed leaflets.*
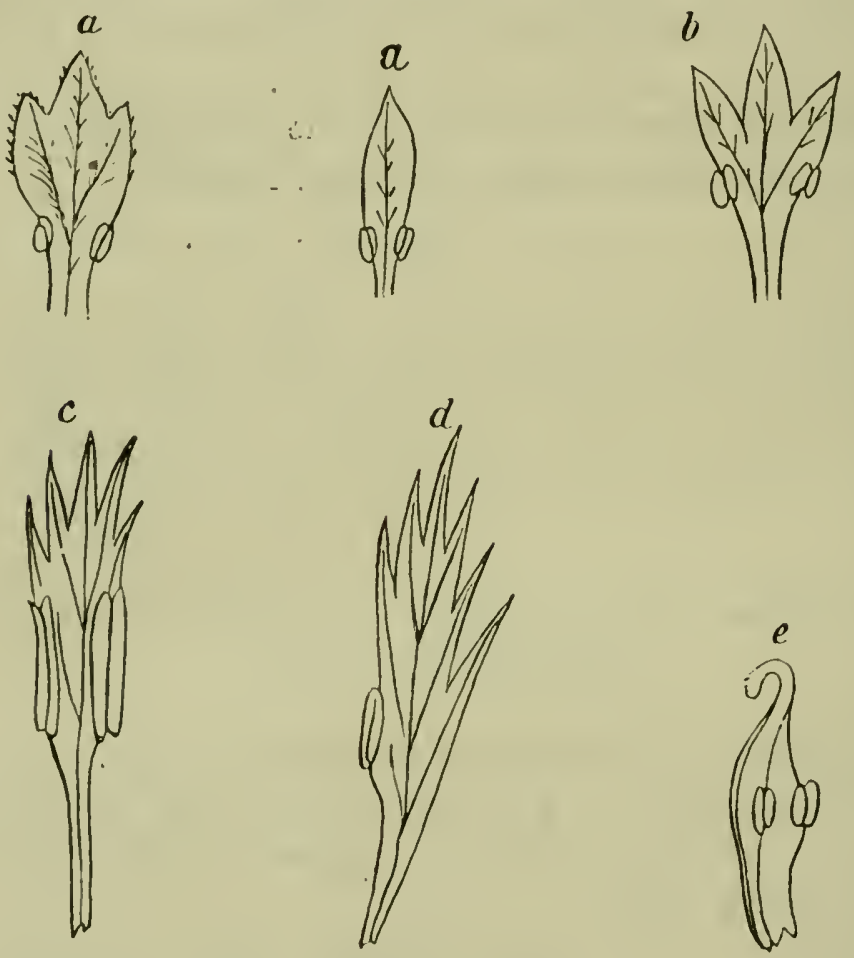

Fig. 83.

(a, a.) Green leaves of Fraxinus ormus, trilobed and simple, with antherlike bodies (Paul Brousse);

(li.) Foliaceons stamen of Alpine strawberry (Prof. Henslow, "Struct. of Flowers");

(c.) Stamen of green rose (Henslow);

(d.) Involucral bract of Nigella with anther (Masters);

(e.) Staminiferous carpel of Rannuculus anricomus (Henslow).

* This rather conflicts with Prof. Henslow's theory that glands or necteries are originated by the irritation of insects ("Floral Structures," p. 143). 
The sequence of all this appears to be sufficiently logical.

In one cherry tree I found that the glands are sometimes close to the base of the blade, sometimes on the middle of the petiole. Sometimes there are from one to four glands, and at other times they are absent, or are only to be found on the lower margin of - the blade, or higher up.

The teeth-glands in these and similar plants would appear to correspond to arrested terminal buds of the teeth, the latter being, as $I$ think, arresterl branches.*

In the transformation of a leaf into a stamen, it appeared to me not impossible that the two anther cells might correspond to, or be homologous with, the gland-like bodies in the cherry leaf and others, resulting from the amalgamation of the teeth-glands of the transformed leaf-blade, the blade itself being suppressed. Indeed, this notion wonld, I think, find support when we examine the reversion of stamen to leaf, such as is seen in Fig. 83 .

The teeth-glands can be seen to perfection in the young cherry leaf. If sereral leaves are examined, one becomes "morally convinced" that the larger glands on the petiole can only be the fusion of the teetin-glands of the two suppressed leaflets. $\dagger$

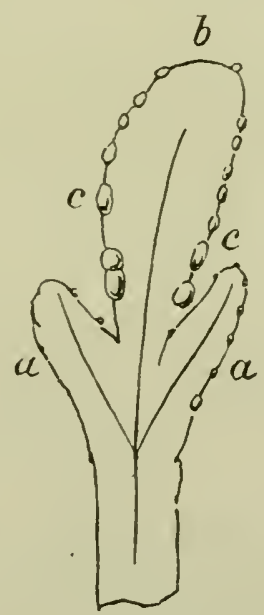

Fig. 84. Bud-scale of Cherry tree (mag.): ( $a$ a ) stipules, (b) undeveloped leaf-blarle, $(c, c)$ tooth-glands fused into larger glands.

* Vide Chapter on Stems and Cladophyls.

t Suppressed leaflets are also represented by glands on the midrib of the leaf of Erythrina Indica Purcelli and others. 
But in order to convince the reader that this is the right interpretation of the petiole glands of the cherry leaf, as also those of the peach, apricot, \&c., I shall place before him a very interesting series of drawings taken from mature.

Fig. 84 represents the bud-scale of a cherry tree, with two adnate stipules and an undeveloped blade. On the margin of the blade are glands. The lower one'on the left is a fusion of two, and wonld correspond to one of the petiole glands in Fig. 85. The other marginal glands are fusions of the tooth-glands shown in Fig. 86, the teeth not being developed.

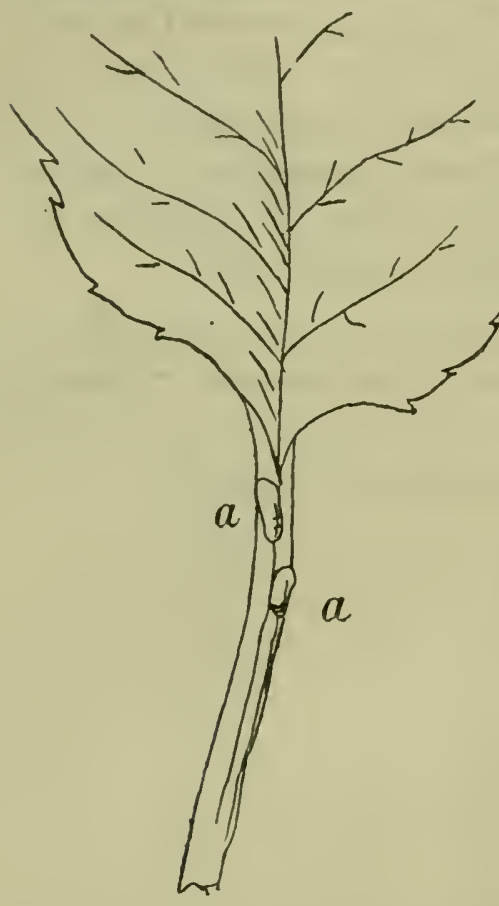

Fig. 85. Part of Cherry leaf: $(a, a)$ petiole glands.

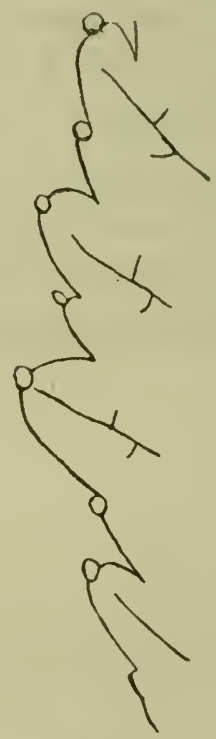

Fig. 86. Margin of Cherry leaf showing tooth-glands (mag.).*

Fig. 85 gives part of a cherry leaf, showing the two petiole glands, representative of suppressed leaflets.

Fig. 86 is the margin of a cherry leaf, enlarged to show clearly the teeth-glands.

Fig. 87 is part of an apricot leaf, showing the two glands ligher up, at the base of the leaf-blade. The glands of the cherry

* These tooth-glands appear to be the nucelli of Warming. See Disenssion on the Ovule. 
leaf, and also of the peach leaf, are often met with in this position.

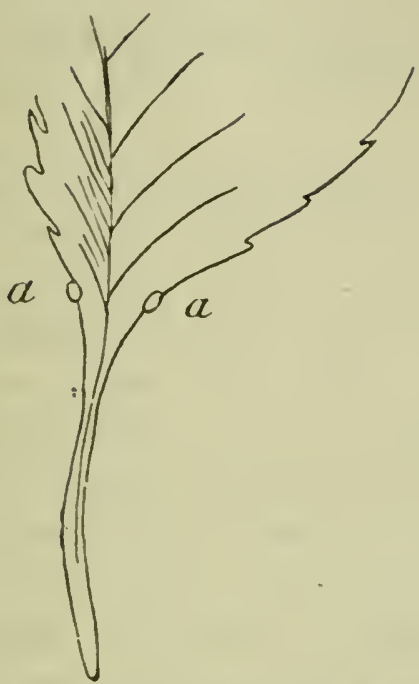

Fig. 87. Part of Apricot leaf : $(a, a)$ petiole glands.

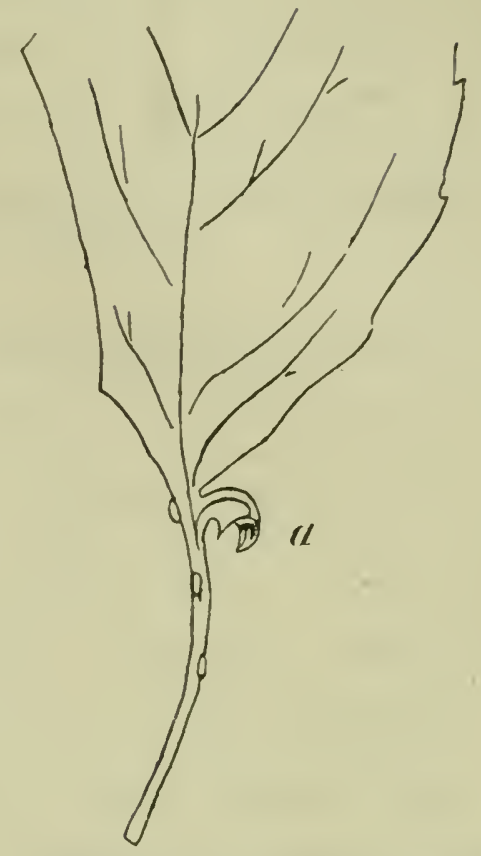

Fig. 88. Part of Apricot leaf, with one gland (a) reverted to leaflet.

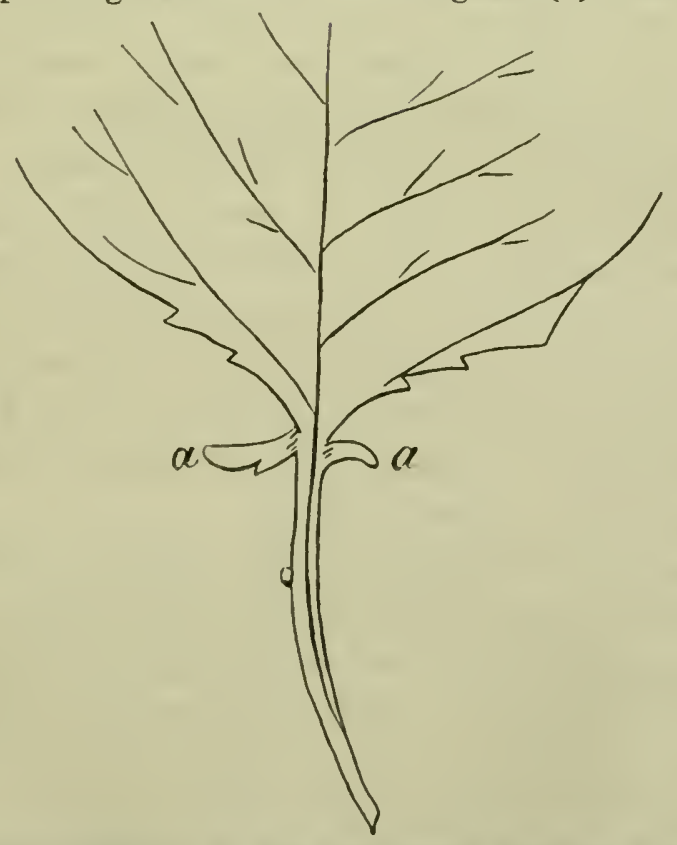

Fig. 89. Part of Apricot leaf, with two glands reverted to leaflets $(a, a)$.*

* For these six drawings I am indebted to Mr. James Kelway, jun. 
Fig. 88 is part of an apricot leaf. It shows one of the glands reverted to leaflet; and Fig. 89 shows both glands reverted to leaflets. In the two latter cases there were other glands on the petiole. This feature varies much in the different cultivated varieties. In some kinds of cherry the petiole glands are entirely suppressed; those of Fig. 85 are taken from a variety which had them large and prominent on the petiole. Sometimes they were opposite each other, and sometimes at different lerels, as shown in this figure.**

Now the two anther cells of the reverted stamens $(b, c$, and $d$ ) in Fig. 83 appear just to correspond to the glands on the petiole of the cherry leaf, and are rery probably homologons with them.

An orule, though potentially a complex borly, is initially only a simple cell, like a tooth-gland. The tooth-gland is only an arrested ovule, and the petiole gland only an amalgamation of arresterl orules. Potentially, then, these petiole glands may be either pollen sacs, or nests of orules. Whether they develop into this or that would depend on the course that circumstances give them. 'The rererted stamens, although antheroid in structure, occupy the position of amalgamated glands on the margins of leaves, and there wonld appear no goorl reason to consider these two borlies as other than the same thing. In case of the total suppression of one petiole gland, we would have the reverted stamen $(d)$, Fig. 83. This would not improbably correspond to the one-celled anther of mallow and Globe amaranth.

Teeth-glands are to he found on most leaf-like appendages in their young state, stipules, leares and leaflets, bud-scales, and also as terminations of hairs in the so-called glandular hairs.

Where stipules turn into glands, as in Impatiens (Fig. 43, G. Henslow's "Floral Structures"), their morphology may be similar to that of petiole glands, viz., a fusion of the teeth-glands, with suppression of the stipule-blarle.

The stamens of Polygalu vulgaris, shown in Fig. 90, are probably a fusion of the filaments; but their anthers being oneceller, they illustrate what I mean by the glands on the tips of leaf-teeth, corresponding to orules or pollen sacs. Now stamens are sometimes seen to revert to carpels, witl ovules on their

* In the Gurden of 26 th $\Lambda$ pril 1879, W. W. speculates on the function of these pretiole glands, but does not allude to their morphology. 


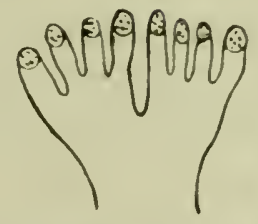

Fig. 90. Stamens of Polygala vulgaris, with one-eclled anthers (Le Maout and Decaisne).

margins. 'This is exactly what one would expect if the foregoing theory had any basis of truth. Fig. 91 shows a carpellized stamen

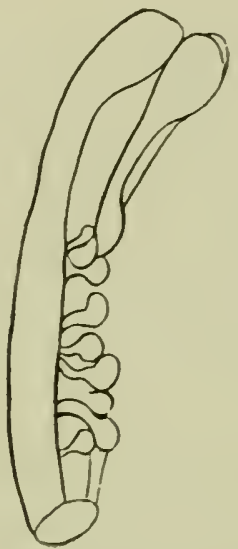

Fig. 91. Carpellized stamen of Cheiranthus, after P. Brousse ("F́tudes des Fruits"), pl. 8, fig. 3.

of Cheiranthus. If the cherry petiole gland be the fusion of the teeth-glands of a suppressed leaflet, and if it be homologous with an anther-cell,* then it would follow that sometimes the anthercell would declare its nature by reversion to a leaf structure, with the re-appearance of the teeth-glands as ornles. The above figure shows that this does eceur. Several cases of ovuliferous anthers are given in Dr. Masters' "Teratology." $\dagger$

We see that this route of analyzing the anther, that is, through the glands on the cherry-petiole, secms to lead to precisely the same conclusion as that of analyzing it through the sori of ferns. Then if this view of the anther be correct, we would have the glands on

* Curiously enough the anther cells of Adhatoda betonica are on different levels, as in cherry glands.

† In a case of Paonic moutan (very doulble) an imperfect earpel had orules on one margin and an anther on the other margin. 
the teeth of leaves as remuants of aborted sori, the originals of which might be such as we see on the tips of the teeth of Adiantum and others. Indeed, the teeth of leaves receive a separate vein or fibro-vascular bundle in the same way that the Adiantum sorus receives the termination of a vein.

The two anther cells, to my mind, cannot but be homologous with the two petiole glands or of others like them, the leaf-blade being suppressed. When the stamen reverts to a leaf, as in Fig. 83, the anther or anthers return to their position of glands, although, of course, they may remain polliniferons, owing to incomplete reversion.

Curiously enough, after conceiving all this, I accidentally came across an adumbration of what I have been trying to work ont. I have likened the anthers to the glands on the petiole of the cherryleaf, and this is what Asa Gray ("Structural Bot.") states in a note to page 254: "Sachs takes the filament with the connective to be the homologue of the whole leaf, and the anther cells as appendages*; others in likening the anthers to glands, adopt a similar view" !

According to my view, we would have the amalgamated glands of the cherry petiole teeth-glands, pollen grains, and ovules, cull homologues. Then I have shown that teeth are no other than abortive branches, so that the marginal buds of the Bryophyllum take their place as branchlets of the teeth, and become homologous with axillary buds. TVe have thus a whole string of homologiesaxillary and marginal buds, glands of the cherry petiole, of the peach and other leaves, marginal tooth-glands of leaves, pollen grains, and ovules, with their plumule or seed-bud. All these become homologous according to this view. This is exactly what I hinted at on pages 211 and 246 of the "Cultivated Oranges and Lemons of India and Ceylon."

I do not enter into the microscopical structure of all these parts, because I know that in the cell there is a nuclens and granules, within the nucleus another nucleus and granules, and so on. Not only is the anther cell, in its incipience, potential pollen grains, but the ovule cell is a potential volole tree, with its stem, roots, leaves, stamens, pistils, and again ovules. 'To each little step' in this evolution, histologists appear to have given a different name.

* What can appendages mean morphologically? 
What concerns me in these pages is a broarl comparison of parts of plants from whatever division of the regetable kingdom they may come, and I do so, because I accept the ereed that all vegetable structures, howerer complex, hare erolred from simple unicellular plants.

In this transformation of leaf to stamen, all manner of rariations occur. In the curling of leaves when young we probably get a hint of the origin of extrorse and introrse anthers. In the Polygonacex, the young leaves are curled extrorsely; while in the $V$ iola, they are curled introrsely.

In the rariations which stamens. undergo, we find that, not only are the stamens separated from the pistils into distinct unisexual flowers, but also into rlistinct trees. The anther is attached to the filament in rarious ways, and it opens to let out the pollen in one of many ways. In some plants it opens by a slit, in others by pores or valves. What I said regarding the dehiscence of the ripe ovary wonld apply to the dehiscence of the anther. In some stamens the anthers are turned inwards, in others ontwards. Some are on the top of the filament, some on the sides, and so forth.

For all these little differences botanists have invented distinct names, which may have some value in shortening descriptions, but which are certainly bewildering to beginners.

The one-celled anther, such as that of Gomphrena, Mallow, and others, is not difficult to conceive as having been erolred out of a leaf-blade with incurved margins, such as that of Viola and others. This incurving of the margins is repeated in the carpels of many plants.

Then, if the surface of this leaf be covered with globular hairs, such as are plainly visible on the young leares of Chenopodium petiolare, we shall have the reproductive hairs, which we call pollen in the stamen.

The two-celled anther seems at tirst more difficult to understand, as to its origin from a leaf-blade. If, howerer, we examine the two-cellerl anther of the Hornbeam, we soon become aware that this stamen may be made $u$ of two one-celled stamens joined together by fusion of their filaments. Further fusion would reduce them to the two-celled anthers we see everywhere.

Fusion, as I have shown elsewhere, has been one of the great. modifiers of organs, and we should not forget the possibility of 
two stamens becoming fused into one, either partially, as might be those of the Hornbeam, or completely, as might be those of Hepatica, Heartsease, and others.

In the "Nuoro Giornale Botanico" for April 1888, Tab. 15, Fig. 7, are shown two stamens of Ficus fused by their filaments, leaving the anthers separate, as in the Hornbeam.

In Tab. 14, Fig. 12, the same ocenr's in Verbascum.

In Vol. 18, Tab. 3, of the same journal, a number of teratologieal anthers are given from Lonicera, which support the notion of the anther originating in an incurving of the margins of the leaf or leaflet, as in the sori of Cryptogramme crispa and others. 'The whole fertile frond of this fern is like a series of anthers.

The possible origin of the two-celled anther out of the union of two one-celled anther's is also seen in the divergent anther cells of Penstemon pubescens, of several L.abiatce, of Monarda, Calamintha, of Salvia, \&c.***

It wonld seem easy for the approximation of such one-celled anthers, and subsequent connation, to give origin to those of Pyrola, Isopyrum, Liviodendron, Asarum, and others. $\dagger$

In Schizandra coccinea, the anthers are one-celled on the opposite margins of petaloid filaments. The contraction of such a filament would naturally approximate the one-celled anthers, and make a two-celled anther.

'The anther cells having become connate, to form a two-celled anther, may afterwards group themselves in various ways, by fusion of their filaments, as we see them in Candollea cuneiformis.

The circular anther of Cyclanthera is evidently a fusion of many anther's forming a ring, with one continuons circular dehiscence.

In the Cncurbitacer there is often a combination of two-celled and one-celled anthers, each twisted into the shape of an $S$ for want of space.

In all anthers, whether one-celled or two-celled, the pollen grains might be comparable to the globular hairs of the Chenopodium petiolare leaf, and to the ovules of Nymphrea, Butomm., and other's, in which the whole carpellary surface is ovuliferous.

* See Asa Gray's “ Struct. Bot,” pp. 255 and 256.

$\dagger$. See P. 252 of same author. 
In the evolution of pollen, however we may call its various stages by different names, we camnot lose sight of the main fact that every regetable cell is only a repetition, with madification, of the original protophyton, or unicellular body, which is the basis of all the aggregations we see, and for which a whole dictionary of terms has been invented.

I have already stated that pollen originates in the mother-cells, each of which contains four pollen-grains, and therefore these tetrads are comparable to the tetraspores of cryptogams. When, however, I throw my mind back to Dallinger's monarls, I find simple nucleated cells moving about, which eventually ripen into pollen-grains and ovules, or, what comes to the same thing, male and female cells, which, after conjugation to form a bigger cell, burst and let out a multitude of spores; therefore, the quaternary sub-rlivision of the mother-cells in these cases would alpear of little significance.

According to my interpretation then, the glands on the petiole of the chemry leaf have stored up in them potentially, either leafteeth, or ovules, or pollen. What governs the crolution of the one in preference of the other, from the same cellular basis, we do not know.

The histological methorl will not help us much, for we see that an anther in its young stage consists simply of uniform cells, some outer, some inner. It is only after some time that the development of mother-cells begins to make its appearance. In these eventually develop pollen-grains, in gromps of four.

The homology of the petiole glands can only be cleared by induction, hased on comparison, position, and teratological transformations.

If a part, which is normally an anther, sometimes derelops into a leaf, or leaflet, or petal, we have no choice but to believe that the anther has stored $u p$ in it potentially the teeth of a leaf.

If we find that the teeth of a cherry leaf sometimes amalgamate into a gland similar to those on the petiole, we logically infer that the glands have stored "1p in them potentially the teetlo of leaflets, and that they are aborted leaflets converted into what we call glands, in the same way that stipules are aborted leatlets. 
Similarly, if we find carpels changing into toothed leares, we have no choice but to conclude that the teeth are the homologues of orules.

None of these parts need be histologically identical, or have the same function. To consider them homologues it is enough that they should occupy the same position, and be sometimes convertible one into the other. 

"We are hardly in the habit of regarding seience as being quite the same kind of thing as ordinary knowledge; yet where can a definite distinction be found? Only, and that ronghly, in science being organized and measured knowlerge; and yet common knowledge in some spheres is far more accurate than science in others."- "Fairy Tales and Scienee," Westminster Revien, February 1891. 


\section{XII.-CARPELS, PLACENTAS, OVULES, BUDS, EMBRYOS, AND SPORES.}

\section{Axilcaly Bud and Ovule.}

WE see the axillary bul, either dormant or active, almost universally in phænogams. Is this organ a new creation in phænogams, or is it derived from forms which are lower down in the scale of organization? There is nothing corresponding to it in cryptogams.* What, therefore, can be its genesis in phænogams, and what its object?

As to the object, next to the seed, which is only progeny capable of variation or not, according to circumstances, the bud proper appears to be of the greatest importance in the struggle for existence.

By the axillary bud persisting on the permanent stem and being capable of renewing or resuscitating the plant next season, that same individnal can continue its existence, and be ready again to transmit quickly to its progeny any useful inherited feature. If the seed alone remained to transmit any good accumulated qualities, it is evident that it might perish from not finding suitable conditions for its derelopment. Moreover, the seed is an independent and often variable bud, $\uparrow$ and thus, even if it found a place and succeeded in germinating and developing, it might not inherit the useful qualities already accumulated by the parent. On the contrary, the axillary bud has a place already; it does not require to search for suitable food, because its parent

* Except perhaps in Asplenium decussatum and similar ferns, vide Fig. 159, "Goebel's Outl. of Classif."

$\dagger$ Variable when the orule has been pollinated, but otherwise probably not (that is parthogenetic).

A p. 1724. 
feeds it, and usually, and very generally, it is incapable of variation.

So here we have two important parts: (a) the seed-an organ of variation; it therefore possesses the power of adapting itself to new surroundings, with the disadvantage, however, of the chance of losing already acquired useful characters; and (b) the axillary bud-an organ of reproduction. It has the advantageous power of retaining and perpetuating any useful characters already obtained.

It is plain, therefore, that it must have been of great service to the species for the individual to retain a piece of itself which did not wither with the change of season, as the buds of many annuals do. It was also useful that the axillary bud should not vary to the extent that the seed might do, so that if the latter should produce any disadvantageous variation, which might endanger its life, there would always be the axillary bud to fall back upon, and to reproduce any good quality already obtained. Or, to put it in other words, we might look upon the seed as a feeler or scout, with powers of new variations, with the view of further progress; it may or it may not succeed. On the contrary, the bud is a conservative organism, which maintains any good feature already acquired.:

The horticulturist imitates this proceeding to a nicety. When he has obtained a desirable variety by seed, he keeps it up by cuttings or division, that is, he propagates it by bud, while at the same time he goes on sowing the seed in order to obtain new variations, sometimes worthless, sometimes useful. By underground stems or stolons the individual plant does a similar thing. It searches for new ground and nourishment, but it only reproduces the parent features.

I do not think that it admits of doubt that any advantages which the individual has already accumulated can only be safely retained by maintaining a piece in its embryonic condition-a dormant bud-and protect it through an inimical season with the object of rejuvenating the exact qualities of the parent with the returning favourable season. It is evident also that this can be done in the best way by this piece forming part of the permanent portion of the plant, that is, either the stem or the root. This, I take it, is the object of the axillary bud, or any other ordinary' bud, as interpreted from the struggle-for-existence point of view. 
The other point that remains to be worked out is : What can lave been the genesis of the axillary bud? In other words, How did it come there?

In the cryptogamic watel plants, from which all land plants must have evolved, we do not meet with any such organ as the axillary bud of phrnogams. It cannot be that the bud is better protected in the leaf axilla, for it is at the coldest season that the leaf falls off, and leaves the dormant bud unprotected and exposed to cold. The axillary bud is evidently intimately associated with the leaf in origin, but, at the same time, it does not wither and fall off with it.

To search for the genesis of this axillary bud, then, we must go back to a class of plants in which buds, as we mean them in flowering plants, do not exist at all. This would seem like a paradox ; it is not so, howerer.

In seaweeds we do not find any axillary buds. In these lower strata of regetable life the leaves are branches or divisions of the main stem, that is, they are all cladophyls or stem-leares. Fig. 92 shows a portion of a leaf of Sargassum decurrens (Fucacex).* In this seaweed, and many others, we seem to have a hint of how the axillary bud may have originated in land plants, which must be considered as descendants of seaweeds. Here we have the leaf, the flowering branch, the bract, and the flower-bud of phænogams perfectly sketcherl ont. From the leaf petiole, close to what we would call the axilla, a raceme is given off with alternate bracts. Again, from the petiole of each bract, near its axilla, a smaller raceme of receptacles is given off, the lower sub-division of which is modified into a resicle or float.

An evolutionist cannot desire a more perfect specimen in seaweeds of the ancestral form of similar combinations in phænogams. He has only to purge his mind of the old notions which allhere to mere distinctions of words, in order to see the plain relationship. In ferns, which may be considered as seaweeds, emerged from water into air, the buds are also on the leaf-stalk, as shown in Figs. 99 to 101.

Now let the evolutionist consider how easy it would have been for the petiolar raceme of this Surgassum to become wholly axillary by the mere and trifling shortening of the petiole. The 


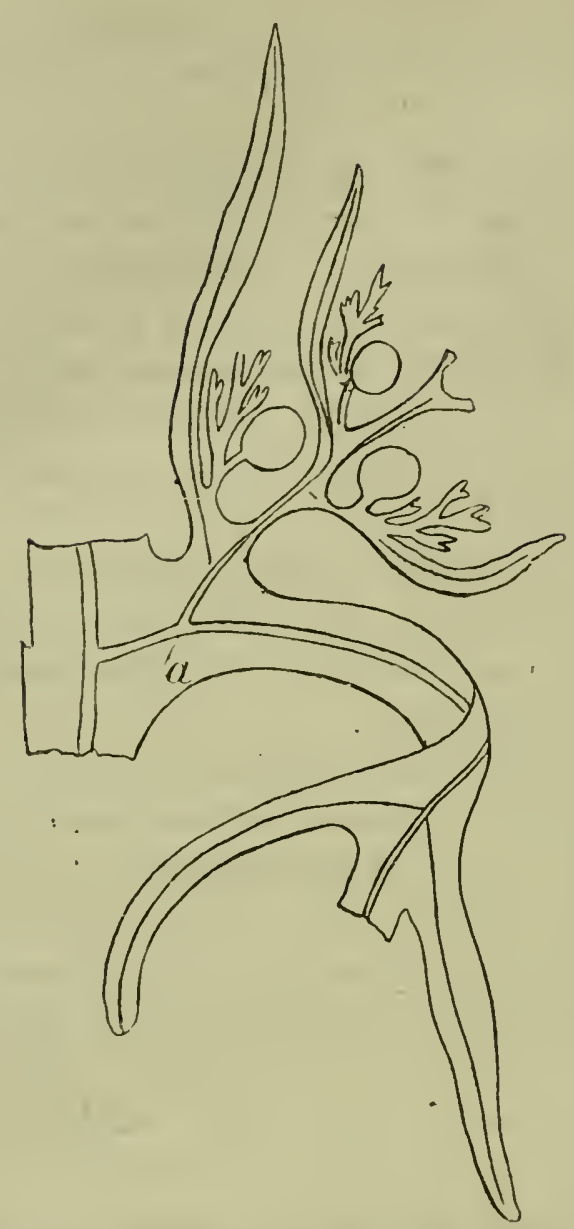

Fig. 92. A branch or leaf of Sargassum decurrens*: ( branch of petiole.

lengthening or shortening of the petiole is such a common experience of every grower of plants that I need not dwell on its possibility. Once become axillary, it was only a step for the petiolar branch to become adnate to the stem, and so lay the foundation, through innumerable variations and trials, for the axillary bud of our days.

In Sargassum bacciforme (Fig. 93) we already find the petiolar branch became axillary in the shape of a resicle or float. Finally, when the leaf-branch took to becoming deciduous after

* Pl. 145, vol. 2 and 3, "Harvey's Phyc. Austr." 'This sliows a branchlet with float and receptacle close to each axilla. 


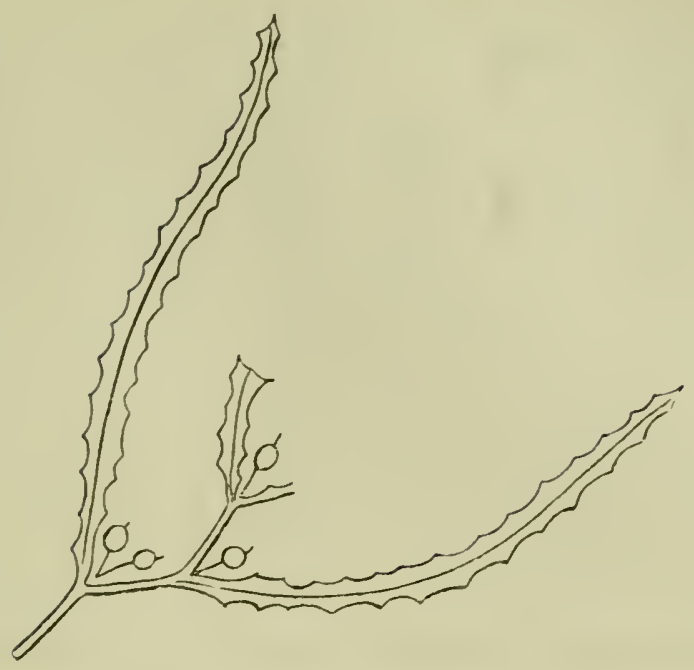

Fig. 33. Sargassum bacciforme, Ag.*

emergence into an air-life, and withering from seasonil changes, the adnate bud, now axillary and dormant, was left behind, as part of the stem.

In the "Srrstem of Botany" of Le Maont and Decaisne an illustration is given which clearly shows the relationship of the axillary bud and the petiole. The vascular bundle, which feeds the axillary bud, branclies off from the petiolar bundle, as shown in Fig. 94 (B). It confirms my idea of the axillary bud having originated in a branch of the petiole. By shortening of the latter it became axillary. Subsequently it allhered to the stem and beeame part of it, thus releasing itself from dependence on the leaf-branch, as a sub-division of which it had originated. 'This, in my opinion, is the genesis of the axillary bud in plrænogams.

In his "Introd. to Crypt. Bot.," Berkeley, at p. 32, in referring to the relation of phrnogams to cryptogams, says:"The foliaceous expansion is of little consequence. All such productions are mere off-sets' from the axis, $\dagger$ whether horizontal or vertical, which are often dispensed with altogether."

In a note, he continues, "Such expansions may or may not have rascular tissue. In the former case they would be mere

* Pl. 109, "Harv. Phyc. Brit."

$\dagger$ That is, branches or sub-divisions of the stem. 


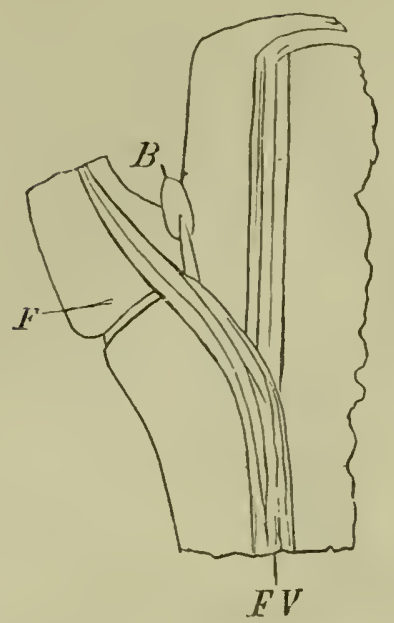

Fig. 94. Petiolar vessels. B. bud; F. leaf scar; F.V. fibro.-vasc. bundle.*

off-sets from the bark. It is obvious that the possible or actual formation of a bud in the axil of each leaf is favoured by the presence of vascular tissue."

At p. 33, he says, "Spiral vessels may be:few (in cryptogams), but there are phænogams of very different aspects and affinities, in which they are equally or more deficient."

I have endeavoured to show that the presence of the axillary bud is not due to vascular tissue in the vieinity of the axila. Whatever gave origin to the vascular tissue in the leaf ut all must have given origin to that of: the axillary bud also, as a branchlet or sub-division of the leaf, which eventually coalesced with the stem and remained as part of the stem, and is now designated axillary bud; while the rest of the leaf becamo: deciduous and was thrown off after decay.

The sporangia of Selaginella incegualifoliat are no other than the branchlets of the mordified leaves of the spike: They are. not connate, either with the stem or with the petiole.

In Isoetes lacustris + the sporangium (also a branchlet of the leaf) beeomes connate and embedded in the base of the leaf. While in phænogams the axillary bud (also a branchlet of the leaf) becomes connate with the stem, the leaf proper becoming deciduous.

* Fig. 696, Le Maout and Decaisne.

† “Goebel's Outlines of Classif.," 1). 292.

$\ddagger \quad " \quad, \quad$ " $\quad 295$. 
To recapitulate then, the frond of this Sargassum (Fig. 92) is essentially what one might call a bipinnate cladophyl, the leaf proper of phænogams being only a further modification of some such ancestral form. This cryptogam in its frond has a main midrib (the stem) and sub-divisional midribs (the leaves). It hats flower racemes, emerging from the petioles of the pinnæ close to their axillæ. Then each flower spikelet or spore receptacle is subtended by a bract-like frond. What more is neerled to prove their homology with similar organs in phænogams? And what more is needed than infinite reproduction, and consequent keen selection through ages of time, for these simpler vegetable forms to emerge out of water, and on dry land be transformed into the innumerable forms of stem, leaf, and flower which we see everywhere?

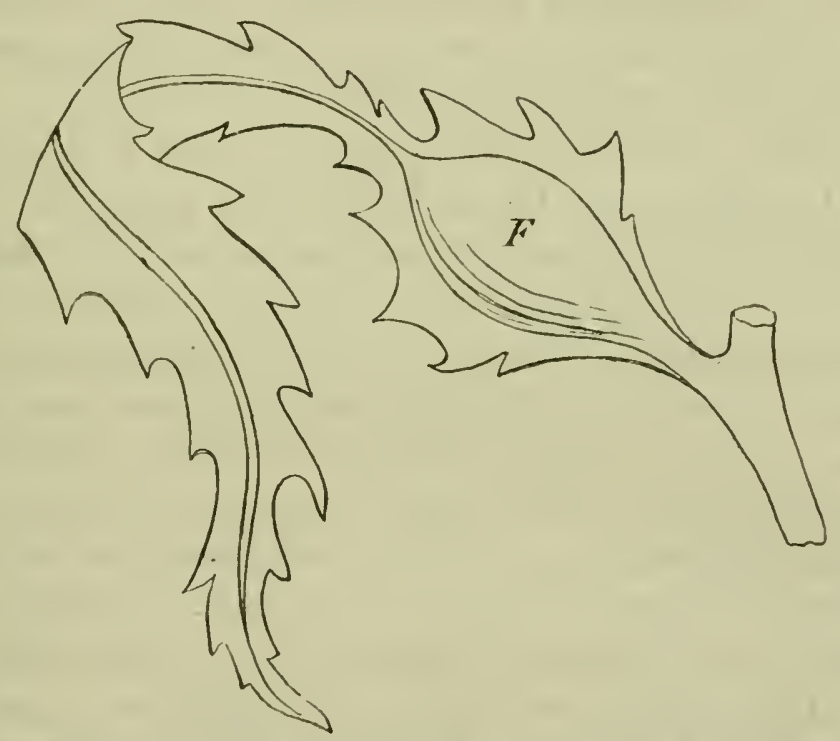

Fig. 95. Sargassum lacerifolium, Ag., showing float $\mathrm{F}$.

Moreover, Sargassum lacerifolium, Ag. (Fig. 95), besides a similar inflorescence with bracts, shows that the vesicle which acts as a float is only a bladdering of the petiole, as in Trapa natans and others.

I believe that among seaweerls we have many type forms of existing phænogams, from which, or from similar forms, it is not. unreasonable for an evolutionist to suppose that the latter may

* Pl. 208, "Harv. Phyc. Austr." 
be lineal descendants, making, of comse, dne allowance for the difference in structure and suitability to surroundings which ages of evolution have wronght between the so-called flowerless and the so-called flowering plants.

'The bud or undereloped leaf-branch of phanogams is enveloped in bud-scales, as a protection against the inimical conditions of season and weather. Of these I lave treated more fully in another chapter.

Asa Gray, in lis "Struetural Botany," says: "Buds are the germs of stems," and that the cotyledions and plumule of the embryo are, morphologically, "the first bud, on the summit of the initial stem." He did not see, however, or at all events he did not say so, that the seel-bud presents no difference whaterer from the stem bud, other than that it is often, but not always, as we now know, the amalgamation of the contents of a germ cell with those of a sperm cell, and that it is prepared to lead an independent and often variable life. Of this, however, more elsewhere.

'The axillary bud is usually single, but there is no law why' it should be always so. On the contrary, in many cases both of cryptogams and phanogams, multiple buds occur. In Gleditschic there are three buds under the base of the leaf. In the Tartarean Honeysuckle, the Citrus, and others, more than one occur. Even in Sargassum bacciferum (Fig. 93) two floats sometimes oceur in one axilla. It is true that in some cases the adventitious bud or buds may be branches of the main bud, and $O$. Penzig, in his "Studj sugli Agrumi," seems to have established that the spine in the axilla of the Citrus is a scale of the bud. Rumphius, however, in his "Herb. Amboyn," refers to a citrus spine which bore flowers.* But whether we consider the additional or adventive bud as a scale, or a leaf, or a branch is of little importance to an evolutionist, who considers them all homologous organs.

Multiple axillary buds are much like polyembry in seeds. Instead of their being one bud, there are other's in addition as sidebuds. These develop before the axis of the main bud is lengthened. Had their dormancy been further protracted, while the main bud developed, they would only appear as axillary buds of the branch.

* Vide "Oranges and Yemons of India and Ceylon," p. 317, Limo nipis. 


\section{The Ovula.}

M. Eng. Warming, in the "Annales des Sc. Nat.," tome v, vi., Bot., p. 177 (1878), gives 91 pages of cliscussion on the ovule. He closes his article by saying, "I should he happy if this memoil should enable us to armit in a general way the theory of Brongniart, the only admissible and true one. If I am to-day convineed of it, it is due to the ingenious botanist slave-Ladislao Celakorsky."

At the beginning of his article, Warming gives what Ad. Brougniart wrote in 1844. It is this: "Then there are two different origins for ovules-one in the great majority of phanerogams, in which the orules come from the elge of the carpophyls, and representing lobes or teeth of those carpopliyls; the other belonging to only a small number of families such as the Primulaceæ, Mirsinæe, 'Theophrastex, and probably the Santalacer, in which the ovules correspond to distinct leaves borne on the prolongation of the floral axis. The nucleus is a new production-a cellular nipple developed on the superior surface of this lobe (or tooth) of the leaf, and in the bottom of the cavity which it has former."

It so happens that each tooth of almost any leaf in its young stage has a nipple or gland, which, later on, atrophies and either falls off or hardens in a horny point.

In ordinary language, the nucleus means the "kernel" of the seed, and this Brongniart beliered to be a new production. Warming endorsed this view.

In Chapter IV., "De l'Orule," Warming comes to this conclusion :-

"Few organs have had more varied interpretations than the ovule. According to Schleiden, St. Hilaire, Braun, Strasburger, Wigand, Eichler, \&c. consider it a bud, on which every integument* would be an independent leaf, or a disc (Schacht, Endlicher, Unger); others, as an organ of leafy nature, in which the funicle only (Rossmann), or the funicle and the integuments, would be an orular leaflet, or the lobe of a leaf. 'Then opinions direrge.

* The integument might be regarded as the ragina of an undeveloped leaf, and the disc as a fusion of leaf or stamen nipules. 
Some cousider the nucellus (or body of the ovule) as a part or tooth of this leaf (Reissek); others think it a new creation. In the latter case it is sometimes regarded as a bud (Caspary, Rossmann, incline to -it); sometimes as a métablasteme; and latterly, as the homologue of a sporange (Brongniart, Cramer, Van Tieghem* and Celakorsky). I incline to the latter view,", says Warming, "and I understand that Eichler does so also. Some observers think the ovule admits of a different interpretation, according as it is on the extremity of the axis or on aleaf. With Celakovsky, I however, recognize that the morphological signification of an organ does not absolutely depend on its position."

In his final resumé, p. 251, Warming says: "The theory that the ovule is a bud is supported by the terminal position of a great number of ovules, which makes them appear as emerging directly from the axis. . . . . nevertheless (p. 254)," the theory of Brongniart is much more admissible.

First. Because carpels and placentas are phyllomes, and therefore it is difficult to admit that ovules are buds. (!) It is true that buds can grow on leaves, but to admit that orules were similar buds regularly borne on the carpellary leaf would require reasons of great weight. (!)

Second. Teratological specimens show us that the ovule is always transformed into a lobe of a leaf, on which the nucellus is a new creation, as an outgrowth. Sometimes there are two nucelli $\dagger$ on the same ovular leaflet.

Third. The development of the nucellus is so like that of the pollen-sac of Angiosperms that there is no doubting their homology, $\uparrow$ now the pollen-sac is homologous with the sporange, therefore, the nucellus is comparable to a macrosporange or ovule.

- . Finally, as pollen-sacs are borne on leares; as this is also true of the ovule; as the sporange of eryptogams, the common and original form of the reproductive organs of phænogams, are also borne on leaves, we must admit, in a general way, that the reproductive organs of all vascular plants are borne on leaves, and that morphologically they are métablastemes."

All this controversy about whether the ovule is a bud, or a lobe or tooth of a leaf, becomes obsolete the moment we recognize

* The nucellus is a sort of large hair which the leaflet embraces as in a cupule. (In the original this is a foot-note under the nane of Van Tieghem.)

$\dagger$ Vide glands on Cherry leaf (stamen and anther). 
the stem and the leat, us one rua the same thing. "Bower regards the whole leaf in vascular cryptogams; from apex to base, as an axis (or stem), the phyllopodium, which may be brauched or inbrancherl."”*

Looking at the whole question from an evolutionary point of view, there can remain no doubt that the axis or stem, and leaf, (caulome and phyllome) are one and the same thing. Land plants could not have evolved from any other than seaweeds. In these we find, as in Gigartina lanceolota (Fig. 16) and Fucus marginifer (Fig. 20) and others, that there is no differentiation of stem and leaf, and that the margin of the cladophyl, or leaf-stem, is often the budrling surface. In Fucus marginifer, if a lobe were separated, it would, like a seed, grow into a plant. When a stiffening midrib was evolver, there was still no differentiation of stem and leaf, as in Delesseria (Fig. 12). But the mirlrib also assumed the office of budding surface. When the wings or blades decayed, the midrib remained as the stem. Therefore, the marginal bud of the leaf, the midrib bud, and the stem bud are all one and the same thing.

It follows that the ovule is a special leaf-bud, erolved through natural selection, because it was a benefit to the species to vary. This variation was brought about by the mingling of the contents of the male bud (pollen) with that of the female bud (ovule). This mingling became of such importance that elaborate appliances were evolved by which insects were forced to take a rery extensive part in this process.

No one now doubts that the carpel which bears the ovules is any other than a form of leaf. $\dagger$ The elaborate paper of Warming just noticed is a controversy about words. The difficulty of recognizing that the bud and the ovule are one and the same thing arises not from the things themselves, but from the different names that were originally fixed on to them. It shows how cautious new investigators should be in handing down mnecessary terms to future generations. Often they only waste time and mental energy.

How it is possible to make the orule anything but a burl is to me inconceivable. If it aborts as a bud, it becomes a tooth or a

* Goebel's " Outlines of Classif.," note to p. 214.

† Vide Carpels of Sterculia, Fig. 103. 
hair, or it disappear's altogether. However microscopists may obscure the question of identity by a number of new names, the great fact remains that the ovule, through all its cellular transformations, erentually develops into a branch, like the axillary bud! The difference between the two is, as I said, that the ovule is subject to impregnation by pollen. Now, however, we know that even this is not necessary for the development of the ovule. In parthenogenetic seeds, which do not differ sensibly from other seeds, we get a repetition of the branch, and this does not differ in any appreciable way from that produced by the bud.

The notion of a difference between the two may have been originally engendered by a difference in position. 'Then a different name was given to each, and this has stuck to them, not because they are distinct, but because the bud and the seed happened to be borne on parts of the plant which were originally supposed to be fundamentally different.

The moment we discover that the axillary bud is a branchlet of the leaf-petiole, we must conclude that by contraction it can become a tooth like the stipel of a compound leaf, and that by so doing it occupies the exact homological position of a marginal ovule. So that not only in their anatomical position are the orule and the bud the same thing, but also in the result they give after development.

To sum up, what is the real difference between the seed and the bud apart from their minute anatomy?

The seed is producible on the margin,* on the mid-rib, $f$ or on the lamina of the leaf. $t$

The seed coats may be regarded as a fusion of bud-scales, open at their apex in the ovule, to admit of the pollen tube, or, as the vagina of an undeveloped leaf. The cotyledons may be regarded as large inner bud-scales, which expand after bursting throngh the seed coats. They are nursing bud-scales, which have a distinct function. The result is a branch with an independent life, and sulject or not to variation.

The bud is producible on the margin, or on the mid-rib (in seaweeds) of the leaf, or almost on any part of the plant, $\$$ but

* In the pea. $\quad \tau$ In ophrys apifera.

I In nymphxa.

$\S$ Elsewhere I have discussed the probability of orules on the lamina being the same as the globular hairs on the surfaee of the leaf of Chenopodinm petiolure. 
oftenel as a branchlet of the petiole, in its axilla, and adnate to the stem. It is protected by separate bud-sciles. It has no need of special bud-scules which act as cotyledons, because it is nursed by the parent stem. 'The result is a branch not subject to variation. Like the buds of polyps, it lives attached to its parent. This, howerer, is not always the case, because in the lily the axillary bud separates from the parent as the seed does.

Prof. Weismann ("On Hererlity," p. 225) cliscusses the causes of parthenogenesis. "The formation of polar hodies has been repeatedly connected with the sexuality of germ cells."

Minot and Balfour maintain that the polar body is the male part of the hermaplirodite egg-cell, and that an egg, which has lost its male part, camnot develop into an embryo until it has received a new male part in fertilization. On the other hand, an egg which does not expel its male part may develop without fertilization. $\dagger$ In a note, Prof. Weismann say's that "the formation of a polar body in parthenogenetic eggs has now been proved."

All this may modify our conception of the cause of parthenogenetic seeds, as distinguished from pollinated seeds, but it does not touch the fact of their being both branches, and, therefore, homologous witl the axillary bud, or any other bud.

Whether there be one or more polar borlies in the orule is of little importance. I take $m y$ stand upon the acceptance of the leaf being a stem, and upon the fact that both the bud and the orule erentually develop into branches or stems. Therefore, the orule on the margin of the carpophyl, as in Sterculia, is as much a bud as the marginal bud of the Bryophyllum leaf, or as much a bud as the axillary bud on the stem proper.

The facts of parthenogenesis leads us to believe that we have two kinds of carpellary buds, the ordinary or parthenogenetic bud, and the fertilizable bud. 'The former would produce the parent form, tale quale, as an axillary bud would do, while the latter being fertilized would rary.

If the parthenogenetic loul is so, owing to some morlification connected with polar borlies, as Weismann states, then it would follow, prima facie, that the axillary or other ordinary bud has some similar or parallel modification by which it ean derelop into

* Vide cotyledons in another place.

$\dagger$ That is, it will produce a branch pure and simple, as the hurd does. 
the parent form, without the need of fertilization. If it should be proved that the ordinary bud has no such thing as polar bodies, then it would follow that these in the parthenogenetic orule (or bud) are not likely to be of the importance ascribed to them.

If it can be shown that the plants resulting from parthenogenetic seeds and from axillary buds are two different things, then we are justified in looking upon their origin as different; or although their origin may be identical, something has interfered to cause the difference in their adult derelopment. But if the parthenogenetic seeds discovered by Dr. Cunningham in the Ficus produce the same plant as the axillary bud or any other bud of that same Ficus, then I think we are not justified in considering the seed and the bud as two different things, although the one is produced in a fig and the other in an axilla or on a root.

If the parthenogenetic seed be the same thing in origin as the fertilized seed, which no one seems to dispute, it would follow, under the supposition indicated in the foregoing paragraph, that the fertilized seed would also be equal to a bud.

Professor G. Henslow ("Floral Structures," p. 307, 1888), after discussing the phyllody of the floral whorls, says: "The conclusion, therefore, which seems deducible from the foregoing observations is that an ovule is simply an appendage* (not a bud) to the fibro-vascular cord of the margin of the carpel, and under monstrous conditions, can grow into foliaceous excrescences* to the carpellary leaf. It is not, therefore, axial in its characters. Since all that is required to start from is a fibro-vascular cord, this may be furnished by any cord, even the midrib; and such is the case in some monstrous states of Primula, in which rudiments of ovules are found on the midribs as well as on the margins of sepatrate carpels."

All this, I must confess, appears to me a play of words. Once admit that a leaf, branch, and stem are one and the same thing, as Bower does, at any rate in the vascular cryptogams, and "foliaceous excrescence to the carpellary leaf" can only mean branches. $\dagger$

* Appendage and excrescence appear to be mere words which can have 110 homology.

t The casc of Calebogyne ilicifolium can leave no donbt that bud and ovnle are one thing ("Limnean 'Trans.," vol. 18, 1. 509). 
A fibro-vascular cord is not at all necessary for evolving buck, for Delesseria dendroides (Fig. 14) and D. coriifolia (Fig. 12) evolve them out of a cellular cord, their midrib; and Fucus palmatus marginifer (Fig. 20) evolves them out of its cellular margin.

I have elsewhere hinted that the nerves, veins, and margin of a leaf are all sub-divisions of the stem, and, therefore, may have nodes, or budding points. Moreover, experiments made on certain cryptogams tend to show that not only vaseular and cellular cords have the power of budding, but every cell has it, as it should have, considering that the protophyta, of which it is made up, have all budding powers.

Vöchting is stated to have made the following experiment on a Liverwort.* $\mathrm{He}$ chopped it up rery finely, and spread the fragments on moist earth. After some time the whole surface budded into young liverworts, which would indicate that, under certain circunstances, all the cells, like spores, were reproductive organs, and capable of reproducing the parent plant. $\dagger$

The margin of the leaf, in phrnogams, is homologons with the margin of the fern frond, where sporanges are developed. In other parts of a fern frond sori develop on what we might call the nodes of the fern reins, or at the termination of a vein.

In the "Oranges and Lemons of India and Ceylon," p. 211, Morphology of the Citrus, I maintained that orules and ordinary buds were one and the same thing. It is gratifying now to find that Prof. E. Ray Lankester is of the same opinion. In his "Adrancement of Science," under the heading of Parthenogenesis, at p. 245, he says:- "Parallels of these methods of reproduction (fission and germination) in animals were readily recognised in plants, in the multiplication by seed, by cuttings or shoots, and by separate buds. A broad line was drawn between "buds and eggs," however egg-like the former might appear, in the assumption that eggs were special bodies of a peculiar structure, destined to be "fertilized" by the spermatoza of the male, after which process only conld they develop. These distinctions, some

* "'The Mystery of Birth," by Grant Allen, New Review for June 1891.

$\dagger$ This is exemplified by Beyonia phyllomaniaca. The surface of its stem, petiole, and leaf become covered with young plants, hudding ont of the rellular hairs. 
twenty years ago, were the more dirmly impressed in the minds of biologists by the recently-acquired knowledge of fertilization or impregnation. 'Then comes the demonstration, by Siebold, of the capacity for derelopment of true eggs, eren when not impregnated. 'The sharpness of the limit between buds and eggs was by this at once destroyed; and the closely-following researches of Leydig (antecedent to Siebold's work in some cases), Huxley, Lubbock, and Leuckart, on the structure of the supposed buds of aphis and allied insects, and of lower crustaceans, proved that these bodies were morphologically ova, originating in ovaries, and having the essential structure of fertilizable ova."

Prof. Huxley introducerl the name of pseudova for these egglike buds. But, in a note, Prof. Ray Laukester says :- "The falsity implied in the prefix seems to make a rather stronger distinction than is desirable between any of these bodies, for they are all truly ova, though ova of various special properties."

Prof. Lankester then goes on to say:- "Whilst, then, up to this period such a thing as parthenogenesis appeared to be a strange exception, the question has now shifted, and since the essential identity in reproductive power of cuttings, buds, psendora, and eggs is proved, the problem before naturalists is rather" Why are eggs ever fertilized?' in short, 'What is the use of the male sex at all ?' We have animals and plants multiplying by fission, breaking up into two or more parts, each of which becomes a new individual; we have them giving rise by growth to masses of cells, which become detached, or remain attached, and developing each into a new individual; and, finally, we have them elaborating single large cells, which become detached and develop each into a new individual. Why should it be that, in certain cases, these last require fusion before they develop? . . . Mr. Darwin has sllggesterl the most satisfactory theory of fertilization in assigning to it the object of fusing two life-experiences in the progeny, which thus gains tendencies and acquires impulses from a wider area than does an unfertilized orum, and is in so far strengthened."

Prof. Weismann has endorsed Darwin's supposition. He considers that the object of fertilization is the creation of variation, through the "fusion of two different life-experiences." Thus, through each cross, fertilization-germs are collected in one cell from wirler and wider areas, so that we grat inleritances not only of 
parents, but of grandparents, of great grandparents, and so on, ad infinitum.

We might look upon inheritunce as a struggle for mastery between the germs of the immediate parents and the chain of more distant parents at the hack of each, the progeny being the outcome of this struggle.

In an ovary containing thonsands of seed-buds, such as the poppy-head, we may possibly get a mixture of different inheritances, viz., parthenogenetic bud, inheriting the features of the mother only; buds containing a preponderance of the father's features; buds inheriting a blending of both parents' features; and buds containing various proportions of ancestral features.

With respect to ora, I find a curious statement in "Natural Inheritance," by Sir Douglas Galton, p. 15. In discussing the improbability of acquired habits becoming iuherited by the unborn child, he says:- " Moreorer, it must be recollected that the connexion between the unborn child and the mother is hardly more intimate than that between some parasites and the animals on which they live. Not a single nerve has been traced between them, not a drop of blood has been found to pass from the mother to the child."”*

Admitting that the fœus, when in the womb, is like a foreign body, how about the ovum, which was budded off by the mother's ovary? One would wish to know, moreorer, how the fœtus grours, if it takes nothing from the mother? Is it one of those nondescript bodies that can produce something out of nothing? But Galton goes on to say that the foetus "obtains its air and nourishment from the mother purely through soakage." And is this not enough, considering that with this soakage multitudes of minro-organisms may pass from one to the other?

I think all this strange reasoning comes from Weismann's having propounded the idea that protophyta and protozoa are influenced by surroundings, while these same protophyta and protozon are not influenced by surroundings when they are emberded in their soma. It would be strange if this were so, considering that electrical influence can pass through the whole

* There still appears to linger in the minds of biologists a sort of superstition that nerves and hlool are a sine quî non for the transmission of influences. 
length of a wire stretehed across the bottom of the Atlantic ! and this, too, without the aid of nerres. What is to prevent influences passing from the ontside of the borly to the sperm and germ cells, and what is to prevent the influence of the body being communicated to those cells? Have we not heard, over and over again, that the universal ether pervades everything, and that even one set of nerve cells can send a message to another set of nerve cells at a distance? And have we not also heard that the nerve-cell, which is the seat of all nerve energy, is itself only " minute bit of protoplasm enclosing a nuclens? Have we not also heard that carnivorons plants can transmit impressions and cause movements at a distance, withont there being any trace of so-called nerves? *

\section{'Tue Embryo.}

In comparing the terminal bud of Euonymus japonicus (Fig. 96) with the embryo of the wheat-seed (Fig. 97), as

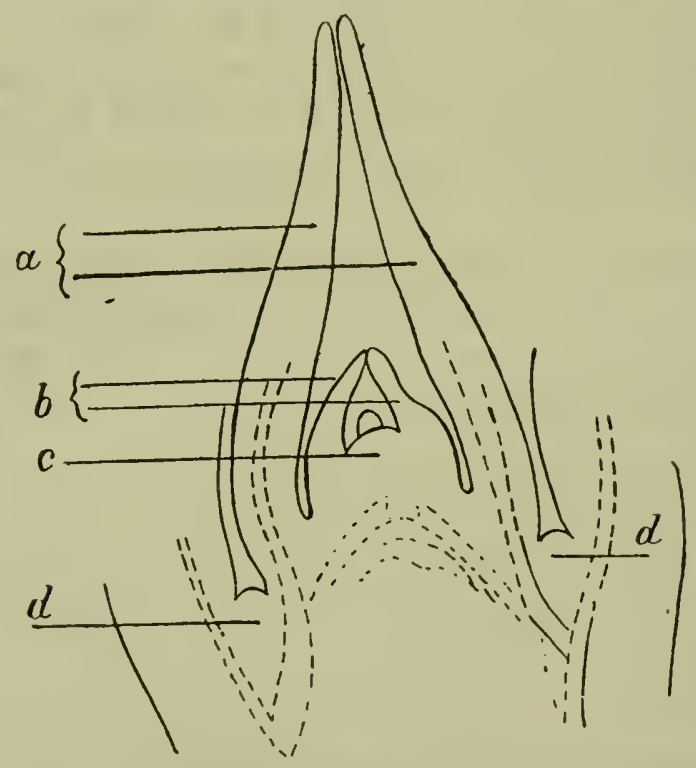

Fig. 96. Longl. sect. of terminal bud of Euonymus japonicus: (a) outer bud-scales, $(b)$ inner bud-scales, $(c)$ growing point, $(d, d)$ axillary buds.

* On one occasion I witnessed the migration of that curious caterpillar which travels in single file, with the head of one touching the tail of the other. While the column is in progress the removal of the last one causes the whole column to stop. It is evident that a telegraphic message is sent through a dozen caterpillars to the foremost leader, althongh there is no nervous communication right through the column. I think that biologists may sometimes forget that there is such an agent in nature as electricity, and that it may have a great deal to do with nodifications in living things. 


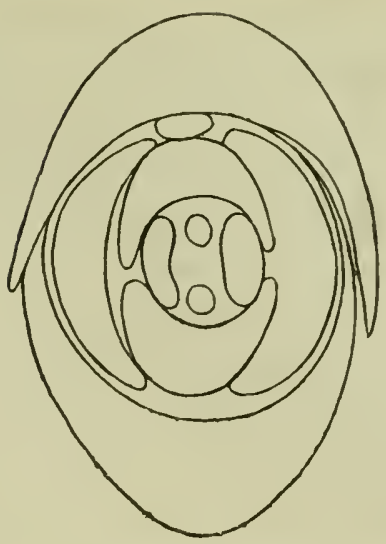

Cross section of the same (Strasburger and Hillhouse, Fig. 65).

given by Strasburger and Hillhouse (" Handbook of Pract. Bot."), I cannot say that I find such essential difference between them, even when examined microscopically, as to warrant their being considered as other than one and the same thing.

In the ordinary bud we find a number of bud-scales with the growing point in the midst of them. In this monocotyledonous embryo (Fig. 97) we find the same thing, $(a)$ is one bud-scale

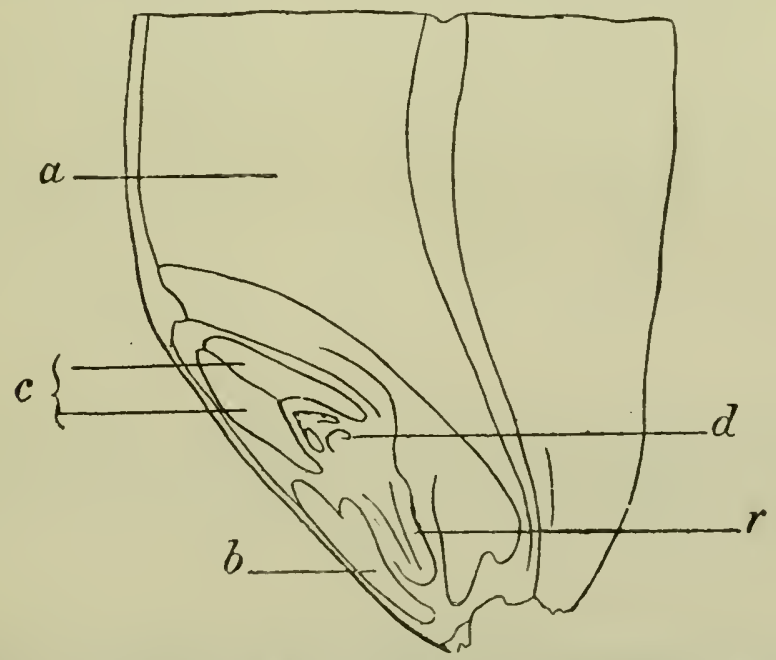

Fig. 97. Part of a grain of Wheat (Strasburger and Hillhouse, Fig. 112a), $(a, b)$ bud-scales, $(c)$ inner bud-scales, $(d)$ growing point, $(r)$ radicle.* altered into a storage-scale, $(b)$ is its atrophied opposite. What the authors call cotyledons appear to be two immer bucl-scales

* These are my interpretations, not the anthor's. Compare with similar parts of terminal bud of Euonymus joponicus: 
$(c)$, and within those again the growing point $(d)$; the radicle $(r)$ is nothing but a continuation of what is called the stem. But the latter character belongs to the axillary and marginal buds also, for we have the axillary buds of the lily and Asplenium decussatum (Fig. 42) and others giving off radicles. The marginal budls of Bryophyllum calycinum do the same.

If position alone were enough to warrant a distinction between the bud and the orule, then we ought logically to make a distinction also between the axillary and the root-bud.

Farther, if we turn to the orule of Hippuris vulgaris (Fig. 98), we shall find (that is, as I see it) that it appears to be
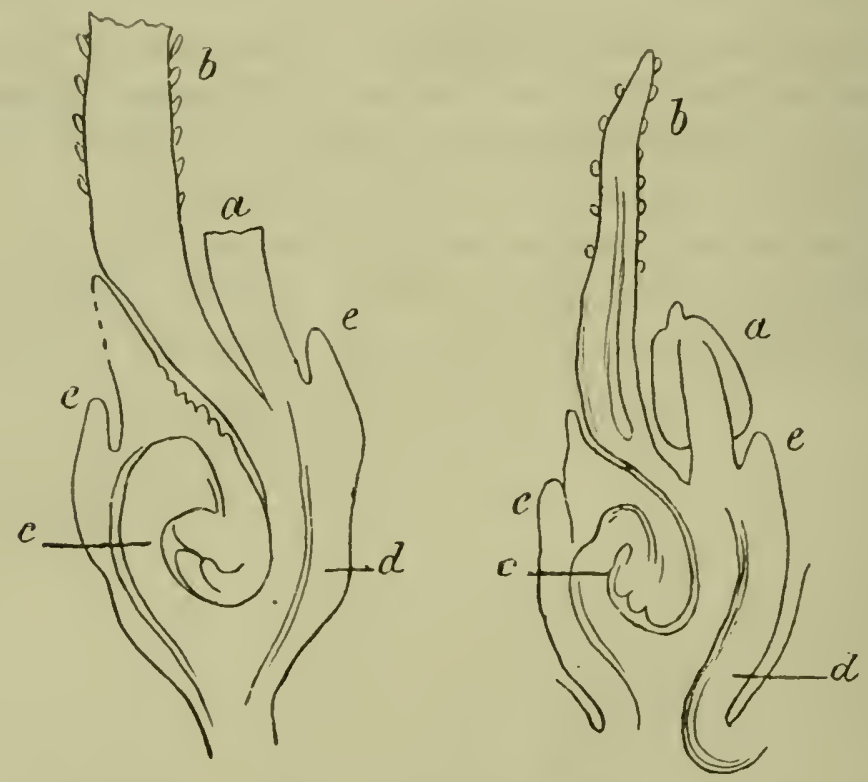

Fig. 98. Hermaphrodite Hower of Hippuris vulgaris: (a) stamen, (b) stigma, (c) anatropous ovule, $(e, e)$ bud-scales. The left-hand Fig. is an enlargement of the right-hand Fig. (Sachs" "Text-hook").

nothing more than a branch bud* emerging from the petiole (d), and having a circinate vermation, exactly like the frond bud emerging from the petiole of Aspidium,filix mas (Fig. 101), and of Pteris aquilina (Figs. 99 and 100).

* The axillary bud, as I have been trying to show, is also a branchlet of the leaf petiole, hecome adnate to the stem. 


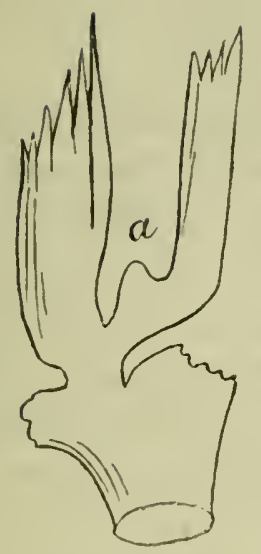

Fig. 99. Bud on the leaf-stalk of Pteris aquilina (after Goebel, Fig. 156).

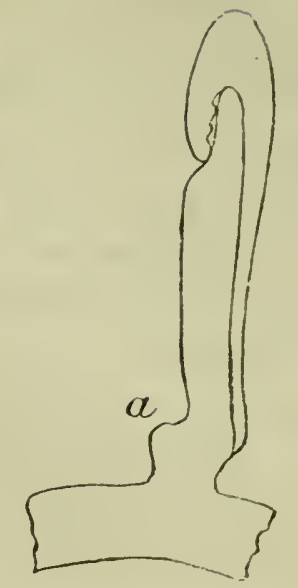

Fig. 100. Bud on leaf stalk of the same. $(a, a, a$.$) Buds on the petiole of fern-leaves.*$

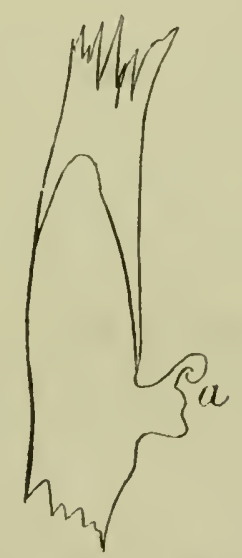

Fig. 101. Bud on the petiole of Aspidium filix mas (Goebel's "Outlines of Classif.," Fig. 158).

Vide also a more developed bud in $B, k$ of the same Fig. in Goebel's "Outlines."

It is clear to me that the anatropous ovule is only a branch bud, with a circinate veruation, the funicle representing the stem, which alleres to the bud-scales, represented by the integuments, while the nucleus is the terminal bud. In the case of Hippuris, the petiole $(d)$ is dichotomons, one branch deveioping

* These correspond to axillary buds in phænogams, and to $(a)$ in Sargassum, Fig. 92. 
into an anther and the other into a stigma, much is we see them in the Camna, while $(e, c)$, are bud-scales of the two leaves, or branches as we may choose to call them.

An ornle appears to be the terminal bud of the rein, or branchlet that feeds $i t, *$ in the same way that the burl at the apex of a braneh is the terminal bud of the stem; or the axillary bud is the terminal bud of a branch of the petiole.

The ornle of the Yew is surrounded by an aril, which appears to be only a fusion of bucl-scales, like the disk of a flower. What does it signify that the aril grows after the orule is fertilized? That may be only a matter of convenience, and a rariation connected with natural selection.

We see that, accorling to Penzig, the scale of the Citrus axillary-bud derelops into a spine long before the bud itself makes any attempt to develop, and often the spine is the only part of the axillary bud that does develop, the bud itself remaining abortive.

It is usual to consider the arillus of the Yew as a growth from the disk, which surrounds the orule. But what is this disk? It is probably an abortion of stamens, like that of the orange, the paony, the rhododendron, and others. Stamens are leares, and leaves are bracts. So we may call the arillus at once a whorl of fused bracts, serving a special purpose. If they are bracts, the reader might ask, why have they not grown simultaneously with the outer bracts? There may have been goorl reasons for this. It was necessary that the orule should be at first naked, to faeilitate fertilization; after this had happened, the aril began to develop, but it was important that the ovule should not be advertized till it matured, and therefore in the first stage, the aril was green, and indistinguishable from the leaves; in the second stage, it became of a bright rose, and sweet to attract the attention of birds, and invite them to eat it, and so help to disseminate the seed.

'The disk is nothing but a fusion of abortive stamens, or nipples of other phyllous organs. It is, therefore, no alsurdity to consider the arillus of the Yew as a fusion of bud-scales. We see similar fusions of bud-scales occurring elsewhere.

* Vrins and veinlets beingr only the ultimate sub-divisions of branches. 
We see for instance a fusion of bud-scales, after fertilization, in the juniper. Three fleshy scales have three ovules in their axillæ, after fertilization the scales fuse and form, the juniper berry (Prof. Henslow's " Bot. for Begin.," p. 75).

Every micropyle in fact is like this. The extremities of the bud-scales (called primine and secundine*) are separate. After fertilization they fuse and form the integuments. Of the micropyle only a trace remains in the hilum.

The integuments of the seed may perhaps be better understood by considering them homologous with the ragina of the leaf of grasses, and more especially that of sedges, and some orchids, such as Disa grandiflora. Imagine the axillary bud as a seed, and the vagina of the leaf (when the bud develops) withont its blade as the primine. The secundine then is only the ragina of the leaf above that again. If, in imagination, we get rid of the internode between the two, we shall have one ragina within another, or the secundine and primine, and the stem will be the terminal bud inside both, or the nucellus.

\section{Placenta.}

Now, with regard to placentation, I find the following forms recognised :-

(a.) On the margin of the carpel. This may be parietal, where two margins meet to form a suture, as in the garden pea (Fig. 102) and Sterculia (Fig. 103), supposing the carpels

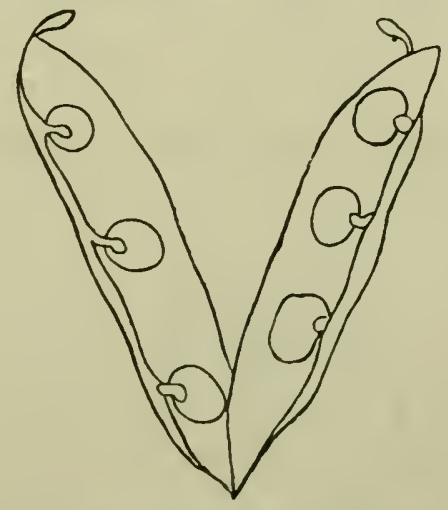

Fig. 102. Marginal placenta of l'a pod.

* Probaby both are fusions of bud-scales. 
to have curved inwards, and their margins to have met, instead of remaining open like leaves, with orules on their margins.

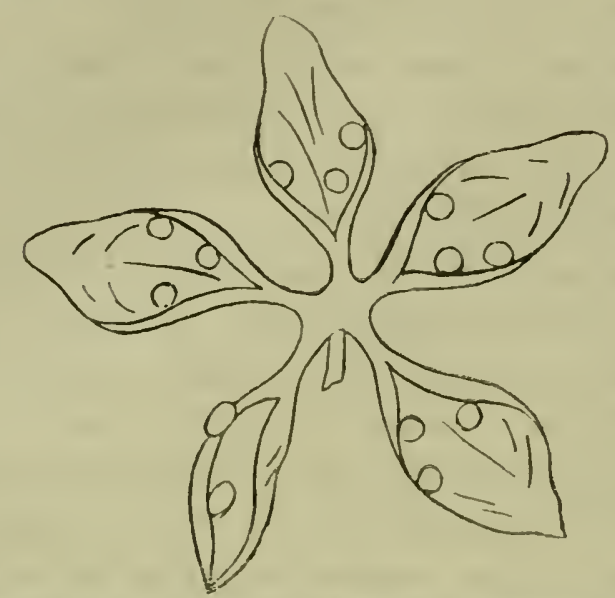

Fig. 103. Sterculia (Le Maout and Decaisue).

Then the margins of the carpels may so curre inwards as to meet in the centre of the ovary, and form what is called a central placenta, as in Hypericum (Fig. 104).

(b.) On the whole interior surface of the carpel (general placenta, as Paul Brousse calls it), as in Nymphrea (Fig. 105).
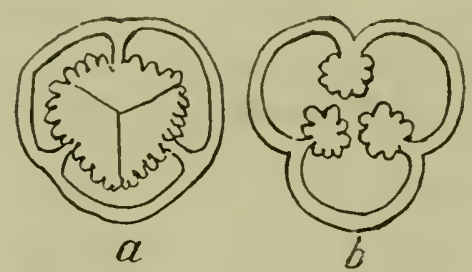

Fig. 104. Hypericum : ( $($ ) unripe, (b) ripe capsule.

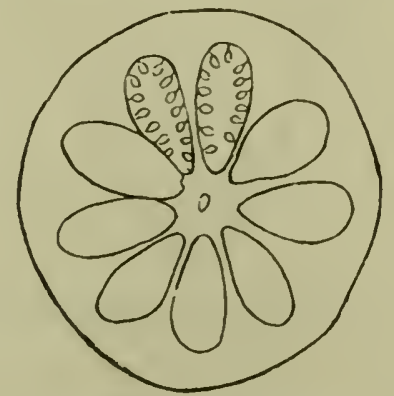

Fig. 105. Nymphrea. 
(c.) Free central placenta, that is, on a sort of axis, unconnected with the carpels, except at their base, as in Spergularia (Fig. 106).

This free central placenta has been much discussed. Some have considered it the termination of the branch axis; others as a modification of parietal placentation with orules produced only at

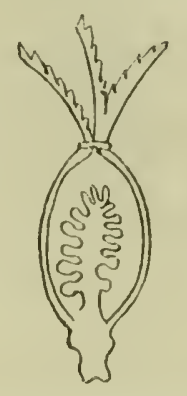

Fig. 106. Spergularia.

the bottom. But I think that in the staminal tube of the Malvacex, we have perhaps the homologue of the central free placenta.

I think there are two ways of looking at the origin of this tube :-

First. It may be formed by the fusion of the long filaments of the stamens, the anthers remaining free.

Second. The tube may be formed by fusion of the bodies of appendages like those of the petal of Parnassia Caroliniana (Fig. 107). These appear to be of the nature of branched

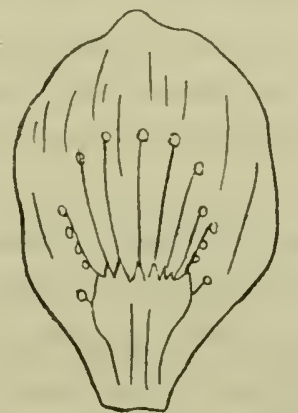

Fig. 107. Parnassia Caroliniana (Te Maout and Decaisne, Fig. 457).

glandular hairs, growing from the axille of the petals in the same way that a similar appendage grows from the axillæ of the anthers of Larrea Mexicana (Fig. 108). For we have no right to suppose 


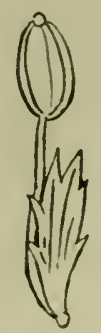

Fig. 108. Larrea Mexicana (Asa Gray, “Stru. Bot.," Fig. 379).

that because leaves have turned into petals and stamens, they are, therefore, nerer capable of giving forth buds of some sort from their axille. 'The appendages of Parnassia are probably groups of abortive stamens, * the anthers being represented by the glands at the tips of the hairs.

Now, if in the axilla of the carpels of Spergularia (Fig. 106) similar appendages merged, and fused into a column, they would prodnce the free central column of Primulacea. In such a case, the orules would he transformed glands. The column would be something like the staminal tube of the Malvacere.

Asa Gray ("Structural Botany," p. 267) would explain the central free placenta as a "parietal placentation with the margins of the carpels oruliferous only at the bottom, and the placenta there conspicuously developed, and completely united." 'This might be so, but it appears to me that the axilla of the carpels wonld be quite equal to dereloping buds of the nature of those of Parnassia, which by becoming united into a column would give rise to the free central placenta of Spergularia. In such a case the ovules of this column would correspond to the glands on the teeth of the leaflets, such as we see on the young stipules of the apricot tree and other plants, the blades being contracted and fused into a column.

If, however, we take a broader view of the origin of phænogams in an evolutionary sense, we have only to turn to Trichomanes radicans, Sw., to see, in the placentation of its sporanges, the rudiments of the free central placentat of phanogams (Fig. 109). There we shall see that the midrib of the cladophyl is continued as

* They might be called either axillary stamens or axillary ovules.

$\dagger$ According to Warming, the sporange was considered the homologue of the ovule hy Brongniart, Cramer, Van Tieghem, and Celakorsky. Ife and Gichler inclined to the same view. 


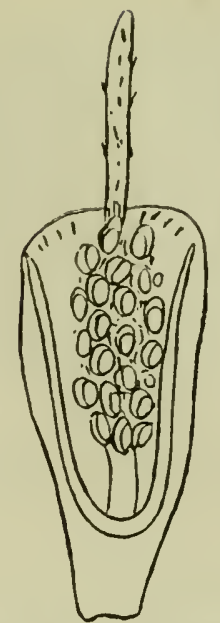

Fig. 109. Sorus of Trichomanes radicans (Hooker's "Brit. Ferns," pl. 42).

a placenta or sorus, its prolongation as a bristle having acquired for it the common name of Rooting Bristle fern, so that there is good reason for considering the free central placental as the termination of a branch axis, as some botanists have considered it.

In connexion with the idea of buds and ovules being the homologues of sporangial, in the "Gard. Chron." of 12 January 1884, p. 57, occur's an interesting (lrawing of Scolopendrium vulgare, var. cristatum (O'Kelly). It has a sagittate and cristate frond. It is studded on its upper surface with buds, on the line of sori, which normally would occupy the under surface. These bulbils are simply buds on the veins, the latter being nothing but branchlets of the midrib all fasciated into a frond. In this case, howe ver, instead of sporangia we have the reins breaking out into buds, the frondlets of each bud being probably converted sporangia.

(d.) There is yet another form of placentation which, perhaps, may not have receired sufficient attention from botanists. I mean the placenta on the midrib of the carpel, as in Ophrys apifera, Fig. 110. Possibly it may have been taken too much for granted that parietal placente are always marginal, but it is evident to me that such placenta may often be on the midrib, while the margins of the carpels may have fused and left no trace of suture, as I think has been the case in the peel carpels, or divisions of the citrus. 


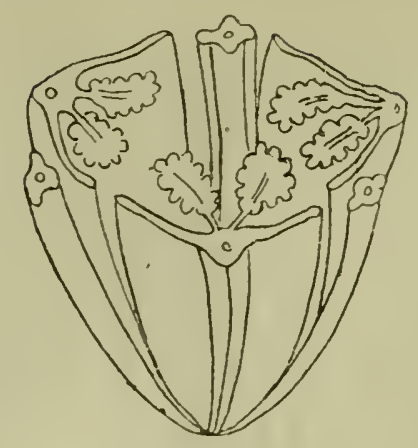

Fig. 110. Ovary of Opluris apifera (Lindley's “ V. K.," Fig. 119).

In my mind there is no doubt that the placentæ of Ophrys aprerc (Fig. 110) are on the midribs of the carpels, and form two rows of branches or compound hairs* along the midrib. This ovary really consists of six carpels, the three alternate ones being contracted into simple and barren midribs, probably owing originally to want of sustenance.

Prof. Henslow, in his "Floral Structures," mentions that in some monstrous states of Primula, rudiments of orules are found on the midribs.

The placentation of Tetrapoma barbarcefolia, Fig. 111, might be either on the margin or on the midrib of the carpels. The

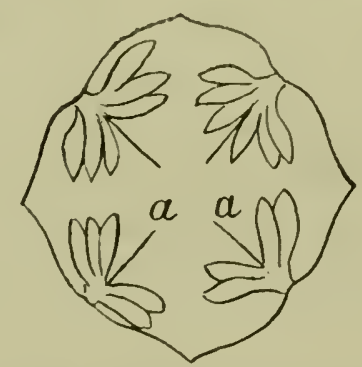

Fig. 111. Tetrapoma barbarafolia (Tue Maout and Decaisne, p. 223).

incomplete septa $(a, a)$ might be either a continuation of the fused margins or an outgrowth from the mirlrib.

Delesseria dendroides (Fig. 14) shows us that the midrib is equal not only to giving off hairs and glands, and ovules, but also suborlinate cladophyls or leaves.

* Vide "Glandular Hairs." 
As so many botanists have considered the ovule as the homologue of the sporange, the placenta of phonogams would be the homologne of the cellular cushion from which the sporangia emerge, , and the placentation of Osmunda regalis and others would be that of a midrib, the parenchymatous lamina having disappeared.

As to dehiscence or splitting of the ripe ovary to let out the seed, the two principal kinds are along the marginal suture, or along that of the midrib. It is possible that sometimes one may be mistaken for the other, for in the case of Ophrys apifera, if instead of splitting along the margins it split along the midrib between the two rows of ovular bunches, the dehiscence would appear marginal.

That splitting may occur in rarions directions is only too erident. Asa Gray, at p. 117 of his "Structural Botany", says, "The spine of Fouquier $a$ is a portion of the lower side of the petiole or midrib, indurated and persistent, the rest of the leaf separating by splitting when it has served its office." $\dagger$

Once admit that splitting of the capsule can take place along the midrib, that is, in a longitudinal direction, and you, at the same time, admit that splitting can take place in all directions diagonally and transversely, and in all ways, for if dehiscence can occur along the midrib, it can occur along its branches-the nerves and reinswhich may have any direction. Or, as in many cases, where the fruit is fleshy, it will not occur at all, and the seeds are let out either by birds or insects or animals eating the fleshy part, or by its decay. Of course, where the contained seed is only one, no dehiscence is needed, as in the samara and akene.

Therefore, dehiscence when it does occur, can do so along the margin, the midrib, or along any sub-division thereof. This would include the transverse dehiscence of the Portulaca, the valrular of Jeffersonia, the poppy, and others.

What I said of the ovaly would of course apply to the dehiscence of the anther, which presents some curious ways of letting out its pollen.

* Also the homologue of the receptacle from which the akenes of the strawberry emerge.

† Described in Plante Wrightiance, ii., 63. 
With reference to the origin of phænogams from cryptogams, I should like to point out that the ovary of the former appears to be a direct descendant, with much modification, from the conceptacle of seaweeds. It seems absurd to say so, but if the reader would compare the fruit of Lardizabala biternata, outlined in Fig. 112, he would see that it is nothing but a modification of the head of conceptacles of Cystoseirc barbata, Fig. 113, and that
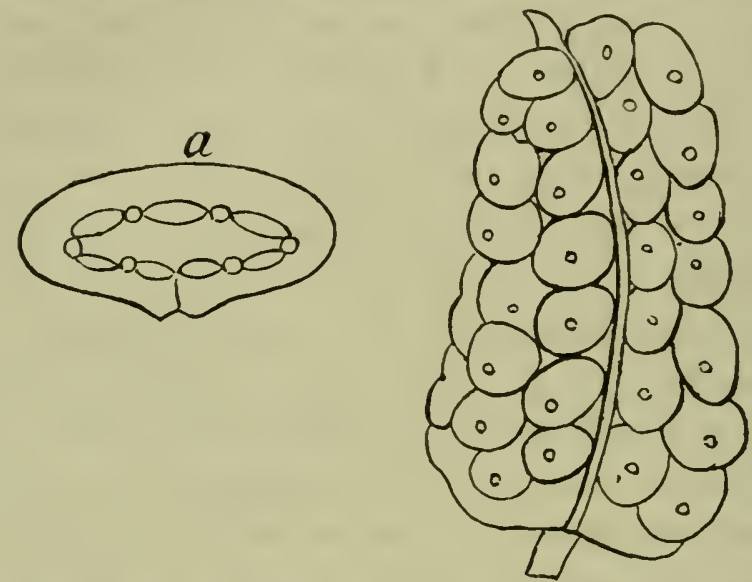

Fig. 112. Fruit of Lardizabala biternata (Le Maout and Decaisne, p. 206): (a) is a transverse section of one of the ovaries.

each ovary $(a)$ is nothing but a modification of the conceptacle. Lardizabala is a phænogam, and no botanist is likely to loubt that it is related to other phænogams with a totally different ovary, such as we find in the pea. Curiously enough, this interesting plant is polrgamous, like a polygamous Fucus.

I would ask in what does the ovary of Lardizabala (a) essentially differ from the conceptacle of Myriodesma shown in Fig. $129(a)$. 'The latter, besides ornles, contains anthers, that is, it is monccious, while the former contains ovules only, that is, it is diacious. We know, however, that some species of Fucus have monæcious conceptacles, while other's have them diæcions. So that eren this insignificant difference is swept away. The fruit head of Lardizabala may, without much stretcli of the imagination, be considered as resulting from the contraction of the Myriodesma frond, clustering the conceptacles round the midrib. This we alrearly see done in what are called the receptacles of Sargassum and other seaweeds. 'The receptacle in these is only a chustering of conceptacles or orule cavities on a contracterl frond, 
as seen in Fig. 113. If we call the fruit head of Lardizabala a receptacle and the ovary $(a)$ a conceptacle, we shall hare essentially the same thing.

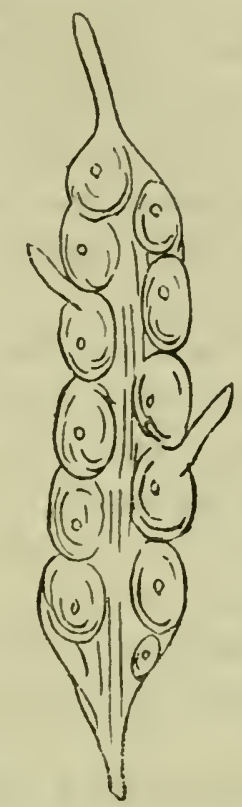

Fig. 113. Receptacle of Cystoseira barbata on which are clusterad the conceptacles ("Harv. Phrc. Brit.," pl. 360).

\section{Polyenibr.}

Penzig ("Studj sugli Agrumi") has counted as many as forty embryos in one Citrus seed, so that it was rather a raceme of embryos. It is well known that from one seed of Citrus several plantlets often germinate.

Now, how can we tell whether all these embryos have been pollinated? The chances are that many would remain as simple buds (parthenogenetic embryos). There is a possibility, at all events, that some might be pollinated and some not, and a certain number of both kinds might develop. This would explain why some seedlings repeat so frequently the type of this female parent, as buds do, while others vary, being a mixture of male and female elements. The stimulus of pollination in some might start other embryos into parthenogenetic growth.

In the Khasia Hills of Eastern Bengal, where the Suntăr $\breve{a}$ orange is largely grown solely from seed, there would appear to be a fine field for some interesting ohserrations in this direction. It 
might be ascertained what percentage of seedlings vary from the parental type.

Botanists, in cases where there are more embryos than one, call them adventitious, that is, according to so-called rule, they have no business to be there, they are accidental; but this word explains nothing, and, moreover, as in the Citrus, this adventitiousness is so frequent, we must look upon it as rather the rule than the exception. To the believer in the theory of erolution and descent, there must be some more logical way of accounting for them.

Now, by referring them back to a class of plants which is low in the scale of development, we may, perhaps, find a hint of what this polyembry really means. The sorus of ferns is a placenta, from which emerge numerous sporangia, each containing numerous spores or embryos. A partial reversion of the Citrus seed to this ancestral mode of seeding may, perhaps, not be an illogical way of accounting for these adventitious embryos. We call it reversion, but for all we know it may be a continuation of an ancestral mode, without interruption.

Under the heading of oil-glands I referred the origin of the dots on the Citrus leaf to the conceptacles of certain seaweeds. Seaweeds might not inappropriately be called water-ferns. Not impossibly, both in its oil-glands and in its polyembry, the Citrus may repeat remnants of characters which were of importance in its very distant progenitors.

Evolution demands some homology between the spore and the embryo of the ovule. In the Citrus seed as many as 40 embryos have been observed in one seed, so that it would appear this seed is often a nest of buds, emerging from a common placenta. This polyembry might be explained by a contraction of a bunch or raceme of embryos, included in one seed.

In the Citrus seed, at all events, the homology between ovule with many embryos and the sorus of ferns appear to me clear. The embryos of the seed being homologous with individual spores.

Systematic botany has so long impressed upon us that ferns are different beings from flowering plants that we cannot now readily divorce our minds from the idea that they are totally distinct. But in what does the rhizome of a fern differ from the rhizome of any flowering plants? 
In what does the stem of a Tree Fern differ from the stem of a Cycad and a palm? The cryptogam and phænogam differ no doubt, and more so, perhaps, than the horse differs from man; but, morphologically speaking, I cannot see that they are so distinct that it would be absurd to consider the spore and the Citrus embryo as morphologically one and the same thing. When there is only one embryo in a Citrus seed, it would appear to mean that all the spores or embryos but one have been suppressed.

The spore and the embryo are both unicellular, and the difference between them, at a certain stage, appears to be this: The former is fitted to live an independent life while it is still in its unicellular stage, while the latter has to derelop itself further under the nursing care of its parent, and become a bud with an incipient radicle and provided with a store of nourishment in its bud-scales (cotyledons), before it becomes fitted to lead an independent life.

We have become so accustomed to see beantifully formed and coloured flowers, that the form, colour, and splendour strike us as being of paramount importance, but every schoolboy now knows that the essential parts of a flower are the pollen and orules, that is, the male and female elements.*

When the fern spore germinates, it begins its life by producing a rudimentary flower, with male and female elements-the so-called prothallus. After the sexual union, the ovule of the fern develops into a bud-homologous with the bud of a seed-which grows into the plant, and after a certain further growth, the process of disseminating spores recommences.

In phænogams there are many stages before the flower containing the sexual elements appears. The ovule after fertilization grows into a special form of bud, which we call the seed. When, under farourable circumstances, it develops further, a number of leares and stem have to be formed before the sexual parts appear. These appear later or sooner, very often as the surroundings tend to luxuriance or to starration.

Then the difference between them is that the spore changes at once into the sexual parts, while the embryo has to go through a more elaborate process before it does so.

* The modern view of colours and forms of flowers of course is that they are connecterl with insect and bird life. 
"It is scarcely too much to assume that if cryptogamic plants were better known than they are, the knowledge would be available for unravelling the more complex phenomena of higher types, and even of the rery highest." -Review of H. Baillon's Medical Botaxy, Westminster Review, February 1891, p. 161. 


\section{XIV.-TRICHOMES, PRICKLES, GLANDULAR HAIRS, SPORANGIA, \&C.}

\section{Trichones.}

Asa Gray, in his work on "Structural Botany," p. 209, says, "Bristles and hairs in all their variety and modifications are properly outgrowths of the epidermis only, and therefore consist of extended cells, single or combined, unaccompanied by vascular or woody tissue. 'To them has been given the general name of trichomes, that is, structures of which hairs are the type."

In examining some Jonquils, I found that within the spathe, besides flowers, there were long hairs, representing spathels, or aborted spathes. These hairs were so fine that they were attracted by the ebonite mounting (evidently electrified) of my lens. Structurally they were hairs, and, therefore, might serve as types of trichomes, yet, morphologically, they were spathes or bracts !

At p. 210, Asa Gray says, "But in some bristles, such as those of Drosera, a subjacent stratum of tissue enters, including one or more ducts, or even some woody tissue. Prickles are of this class.* . . . . . Such outgrowths may even be formed in regular order, as the prickles on the calyx-tube of Agrimonia, and scales on the acorn-cup of oaks, and yet have no morphological importance." (!)†

..... "Structural difference between trichomes and outgrowths (Emergenzen of the Germans) is not absolute, and the morphological distinction must rest upon other ground than auatomical structure."

* "It may readily be demonstrated that the prickles of the Rose and Rubus arise not from epidermis only, but also from the subjacent tissue of the cortex" (Bower, "Praet. Bot.," p. 147).

f In my opinion the "regular order" has a great morphological significance. 
"If we do not govern words, words will govern us," said an eminent student of words.

The basis of distinction on account of anatomical structure, we see, breaks down at the threshold of the inquiry. What remains for us to investigate now may be indicated by the question-is there any morphological distinction between a trichome and other parts of a plant?

Primâ facie, common sense would refuse to make an essential distinction between a trichome and a branch when it is considered that the former can now be a trichome and then a branch. ${ }^{*}$ In the same way that it refuses to make an essential distinction between leaf, stamen, carpel, stipel, and gland when the first can be transformed into any of the others, or vice versâ.

It appears that botanists have made a distinction between hairs and other structures on the ground that they are outgrowths of the epidermis, as if the epidermis had fallen from the clouds, and had no connexion whatever with the development of the plant. The trichome has hitherto been looked upon as a sort of entity independent of all other cells, and not as an atrophied member of a colony.

Originally there was no such thing as epidermis, because it had no raison d'être. A differentiated cellular layer on the external surface of plants appeared only when they emerged from a water life. The epidermis, both in animals and plants, is evidently conditioned by the dryness of the atmosphere under certain circumstances. It thus protects the subjacent layers of cells from that very dryness which originated the epidermic layers, so that the functions of all the cells enclosed within the epidermic bag might be carried on without direct interference from atmospheric changes, or, at all events, with as little interference as possible.

Even in those phænogams which have some of their leaves submerged, as in Ranunculus and others, the differentiated layer known to histologists as epidermis is wanting in the submerged leaves.

I am aware that through the stomata the external air can find its way into the interior of the leaf tissue, but besides the passage

* The simple trichomes of Begonia phyllomaniaca of the stem, petiole, and blade turn into branches furnished with leaves! 
being controlled by two cells at the opening, the hygrometric state of the air within may be modified by the transpiration of the inner cells.

From all this it would appear that the distinction, which microscopists and histologists make between trichomes, as belonging to the epidermis, and other structures, is only one of words.

A little consideration will show that all the lower fungi, sporangia, antheridia, \&c., \&c., are indistinguishable from trichomes, except that they give forth reproductive cells, while the trichomes, or hairs proper, have this function aborted.

When land plants evolved out of water plants, the outer layer of the mass of cells we call epidermis became atrophied, and functioned as a protective covering to the softer tissues beneath, so that the latter might still carry on a quasi-water-life. Then outgrowths from this layer further protected the plant from cold, \&c. by adding a hairy covering like that of animals.

But all this did not suppress in the trichomes the potentiality of reversion to ancestral functions, whenever conditions became farourable. Microscopic fungi appear to be nothing but trichomes, with regetative and reproductive powers, though both are of a rudimentary character.

Curiously enough, one cannot look through the drawings of G. Thuret's "Etudes Phycologiques" (1878) without seeing, at a glance, that the most important organs of seaweeds - -antheridia and spores-corresponding to stamens and ovules in phænogams-have no other but the structure of trichomes. Their emergence too is from the superficial layer of cells of the frond, which would correspond with the epidermis in phænogams.*

Thuret calls the stems, which bear the antheridial and spores, hairs (poils), and rightly too, for no one could call them anything else. These hairs, nevertheless, branch into sexual organs!

The antheridia of Fucus serratus, pl. 11 of Thuret's work, are also nothing but sub-divisions of hairs. The hairs interspersed among the spores in pl. 12 are probably only atrophied antheridia, reducing the sexual organs, originally monœcious, into the diœcious form. 
When the spores of Cutleric germinate, they are in essence nothing but floating trichomes giving off trichomic rootlets.

Fig. 114 is a portion of the branched antheridium of Cutleria multifida, Grev. (Thuret, pl.9). If the capsules containing the

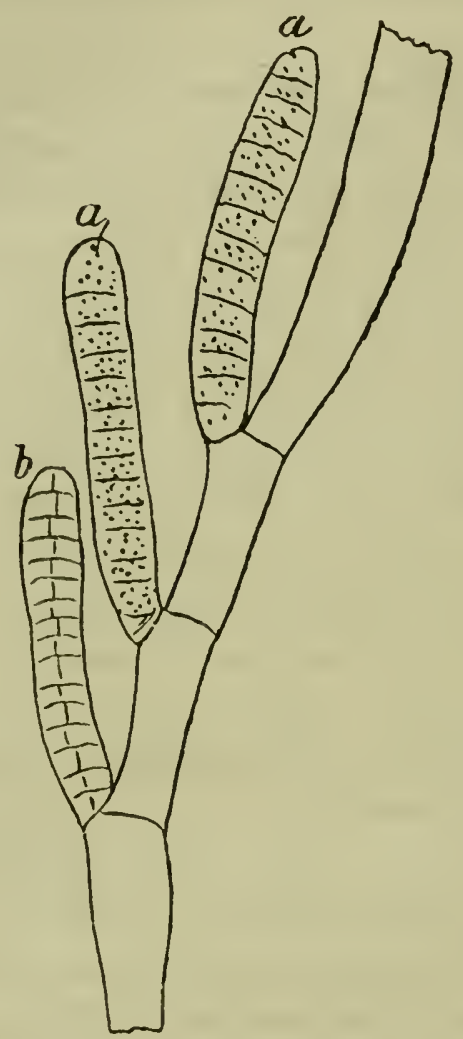

Fig. 114. Branched antheridium of Cullcric multifida: ( $($ ) capsules filled with antherozoids, (b) empty capsule (enlarged).

antherozoids aborted, the whole might be indistinguishable from a glandular hair. 'The capsules are sub-divided into chambers, by transverse and also longitudinal walls. The resulting cells contain antherozoids, which, morphologically, are nothing but pollen grains.

In the female conceptacle of Fucus serratus there are barren hairs, which I take to be atrophied male organs. In the male ennceptacle there are branching hairs which bear antheridia, 
containing spermatozoids, and also ordinary hairs, which may be considered as abortive male organs.**

Here it may be noted that Selaginella inequalifolia $\dagger$ has its most important organ-the sporangium-unfed by direct fibrovascular tissue. The latter branches off from the stem to the leaf, leaving the sporangium to one side, and only comnected with the rest by simple cellular tissue. It is a reproductive hair to all intents and purposes.

It should be here also noted that both the male and female sporangia of this Selaginellat are nothing but axillary buds and branchlets of the leaf, the ligule being only a bud-scale.

\section{GraNdurar Hairs.}

If we take up a branch of the moss-rose and examine it with a lens, we see what are called branched glandular hairs. They cover the bark, the petioles, the nerves, the veins, and leaf margins. What legitimate inference might one draw from this fact? At all erents, the inference that I drew was that all these parts, including the margins of the leaflets, were only sub-divisions of the stem, and that, in the leaflets, the parenchyma fasciated these sub-divisions for the purpose of facilitating circulation, aëration, and illumination of the plant blood.

I also came to the conclusion that glandular hairs are the remnants of the reproductive organs, which still exist on the stem of Cymopolia barbata (Fig. 124), a calcareous Alga.

In most roses, for instance, on the margins of their young leaves and bud-scales, we find glandular hairs, and also teeth surmounted with the same gland as that of glandular hairs. We then find these glands changing their character on the teeth of the fully formed leares. The tooth becomes tipped with a red conical point, not pin-headed, as in the glandular hairs. It is only now and again that you see a minor tooth tipped with a pin-head.

* Since writing the foregoing I find that F. O. Bower ("Practical Botany," p. 402), writing of oogonia of Fucus serratus, which oogonia I take to correspond to ovules, says, "each of these is seated on a unicellular pedicel, and may be regarded as a metamorphosed hair."

† Goebel's "Outlines of Classif.," p. 297.

† " ",$\quad$ p. 292. 
The prickles on the rose-stem are not usually tipped with a pin-head, nevertheless, they are mere exaggerations of the stalk of the glandular hair, for on the midrib of the young leaflets the prickles are now and again tipped with a gland. The prickles become changed into glandular hairs, * as shown in Fig. 115.

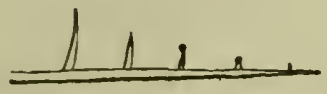

Fig. 115. Prickles changing into glandular hairs on the midrib of the Rose leaflet.

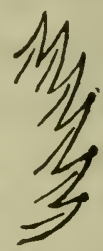

Fig. 116. Teeth of Rose leaf. The lower ones with glands, the upper with only points.

These appear to be only repetitions of the teeth of the rose leaf, as shown in Fig. 116. The point of the prickle and the point of the tooth are only atrophied and modified glands; the gland of one tooth either atrophies, or is modified into the point of another tooth.

According to this view, we may consider the tooth as a glandular hair, with a foliaceous stalk. But this we also find on the stem of the moss-rose. There we find branched glandular hairs, with their common stalk flattened and foliaceous. They do not differ in structure from teeth, and have vessels projecting into them, as teeth have. In the moss-rose we find many of the leafteeth tipped with globular glands; on the margins of the teeth are rows of glandular hairs, representing minor teeth. The sepals of the moss-rose are one mass of branched foliaceous prickles, each tipped with a gland, and the branches become re-branched, each branchlet being tipped with glands.

It is impossible to look at the margin of a moss-rose leaf, through a lens, and not be convinced that the main teeth of the bud-scales, stipules, and leaves are nothing but branched glandular hairs, and that the minor teeth are simple glandular hairs, like those on the stem and sepals. We would then be justified in

* This is plain in the ycllow Scotch rose and in the dog rose of the hedges. 
considering the glandular hairs of all other plants as homologous with teeth. The teeth of other varieties of roses also, especially those nearest the petiole, are often tipped with a gland, but in these the teeth are not branched, as in the moss-rose. The teeth of the sepals of the latter are no other than miniature branches with secondary hranched teeth on them, each limb or tooth, as I said, having a gland at its tip.

Not only the stem and midribs, but the nerves and veins of the moss-rose have glandular hairs, so that the under surface of the leaflets seems as if sprinkled with crimson pollen.

There is abundance of evidence to show that prickles are only modified glandular hairs, for in those roses which have large and small prickles on their stems, the small ones are all tipped with glands; otherwise they do not differ from the larger ones. As the stem lengthens and thickens, the base of the prickle lengthens and broadens.

If we turn to the hop-plant we find that the stem is riclged. On the ridges are minute hooked prickles. The ridges are not unlike those of the horse-tail, which are also minutely toothed. In the furrows between the ridges of the hop-plant are globular hairs, which, in other words, are glandular hairs without the stalk. The prickles are continued on the petioles, but on the nerves they are changed into ordinary hairs.

The base of the hop-prickle is small, and much resembles the lenticels on the Elm and Elder stems, $\uparrow$ so that perhaps it may be permissible to consider that, after all, lenticels may be a further atrophy of prickles, which existed in the ancestors of these trees, in spite of the lenticels having a stoma on their summits.

From all this it would appear that ordinary hairs, glandular hairs, teeth and teeth prickles, and also stem prickles, and branches are essentially one thing, and that they do not differ morphologically from spines, which may be either abortive branches, stipules, or petioles. Moreover, it would appear that the glands

* J. G. Baker ("Journal Royal Horticultural Society," October 1889, p. 208) says: "There is no hard and sharp line of demarcation between aculei, aciculi, and gland-tipped seta."

$\dagger$ Compare with prickles on the supporting roots of the Palm, Socratea exorrhiza (Royal Kew Gardens). 
on the hairs, and on the teeth, as well as the modified glands at the tips of prickles, correspond to abortive terminal buds.*

In endearouring to broaden the speculation, these glandular hairs may lead us to curious conclusions.

On the young leaves of the hedge bramble, along the reins on the upper surface, are found numerous minute white globular glands, withont a stalk, or with a very short one. They are exactly like pollen grains scattered orer the leaf. Here and there are a few pink ones, like the pin-headed glands of the stem and petiole. If the rearler, with his imagination, contracts the blade of the leaflet, so as to reduce it to an anther, he will have these white globular hairs crowded together, and corresponding to pollen.

I do not say that they are pollen in disguise, because they are like pollen, but because I consider these and glandular hairs as abortive reproductive organs, and, therefore, wonld be homologons with pollen grains.

The leares of the yellow jasmine have pollen-like glands on both sides. 'The lower surface of the leaves of the sweet pea, and the stem and tendrils, are covered with white glandular hairs, without stalks; they are simple minute globules, especially on the young parts. The upper surface of the leaves has them also, but they are not so numerous. In the garden pea they are not visible, even in the youngest leaves, but there are certain dots, which may be remnants of them. The broad bean has them, but they are more pronounced on the upper surface. The French bean has them, but they are very minute, as if on the road to suppression, like those of the garden pea.

Ordinary hairs may be only these pollen-like glands, with the stalk developed, and the gland atrophied.

Then "putting two and two together," it would appear probable that glandular hairs are only atrophied reproductive organs, corresponding to pollen and ovules. Or to put it in other words, as the strawberry receptacle is the rose receptacle turned inside out, so the glandular hair may be the seaweed conceptacle turned inside out and atrophied, owing to other and more modified reproductive organs being developed.

* Compare with fertile teeth of Phacelocarpus complanatus, pl. 252, "Harvey"s Phyc. Austral.," and of Aucanthococcus pusillus, pl. 266. 
Glandular hairs, whether stalked or stalkless, are to be found on many plants belonging to different orders. And when we consider that they are interchangeable with hairs and prickles, we may consider them as a universal feature in phanogams. If not found in one part they are found in another, so that they must have some deeper morphological significance than that of mere epidermal accidents.

In the calceolaria we find that, on the outer or lower surface of the sepals, the hairs are mostly ordinary hairs, while on the inner or upper surface they are glandular.

We see ordinary hairs on the petiole passing into glandular hairs on the sepals in other plants.

In the Dock, the hairs are half-way between ordinary and glandular hairs. They are club-shaped.

Various modifications of glandular hairs are met with. Some of the hairs of the nettle become stinging hairs. These appear to be only glandular hairs, with the apex prolonged into a fine tube. On the turnip leaf are glandular hairs, like those of the stinging nettle, only the glands at the base of the hair are smaller.

The reader may say these are very pretty speculations, but all or most of the organs you have been writing about are epidermal emergences. Quite so, but when needs be, ressels can be projected into epidermal structures, as we sce them in the foliaceous emergences of the stem of the moss rose, and in the tentacles of the Drosera. Moreover, in the sporangium of ferns, and in seaweeds, important reproductive operations are carried on without the aid of ressels.

Dasya sarcocaulon has branches, which Harvey* calls ramelli. They are nothing but branched hairs, made up of simple strings of cells. So are the branches of many other seaweerls.

It would appear that as plants progressed in evolution, and developed more complicated organs, suited to a more complicated life, they did not always free themselves of the old homologous organs, which may have become useless, but they often atrophied them, and turned them to other, and perhaps, in the changed cireumstances, more useful purposes. Some of the ancient persistent organs with altered function we now call hairs. In 
seaweeds, however, they are ramelli, or small branches. When atrophy occurs, once important organs may not only become epidermal, but often quite extinct.

I know that pollen grains are generated by fours in the interior of the anther nipple in mother cells, nevertheless, they eventually become superficial, and are shed exactly like the globular hairs on the leaves of Chenopodium petiolare and other Chenopodiums.

The reader should not forget that I start with the notion that every cell is a potential reproductive organ. He should also take note of the fact that G. O. Bower found glandular hairs in the intercellular spaces of Aspidium.* So that glandular hairs are not only produced on the exterior, as an outcome of the epidermis, but also in the interior of the parenchyma! This is not surprising, when we think that there is no good reason why external cells should be morphologically distinct from internal cells. The fact of their being outside of the internal ones, and thus forming a sort of covering to the inner ones, and the fact of their having been called epidermis, do not alter their nature morphologically. This remains identical with that of the ancestral monophyta, from which they descended, although their function may be changed.

Le Maout and Decaisne, "System of Botany," p. 139, say that "True glands differ from glandular hairs only in projecting slightly, or not at all, above the epidermis; they pass insensibly into each other, as in glandular roses."

In the Droseras we have these glandular hairs developed into large sensitive tentacles. And it is in these plants that we find light thrown on the real nature of glandular hairs, which are found in many plants, although in the moss-roses the different parts are crowded with them.

Prof. Henslow ("Structure of Flowers," p. 307) says :- "The tentacles of Drosera, as is well known, are not epidermal trichomes, but structures issuing from branches, arising from the fibrovascular cords of the leaf, and therefore strictly homologous with the 'funnels' on cabbage leaves." $\dagger$ In a note he adds:-_"The

* "Practical Botany," p. 293.

$\dagger$ May not these "funnels" be more appropriately homologized with the leaflets on the midrib of Delesseria coriifolia, Fig. 12. 
'pitchers' of nepenthes, perhaps, originate in much the same way, from the original water-gland at the apex of the leaf."

Strasburger and Hillhouse ("Practical Botany," p. 80) say, regarding the Drosera tentacles, "Not only the epidermis, but also the inner tissue of the leaf is continued into the tentacles," as is shown in Fig. 117. Just so. But we may argue that the fibro-

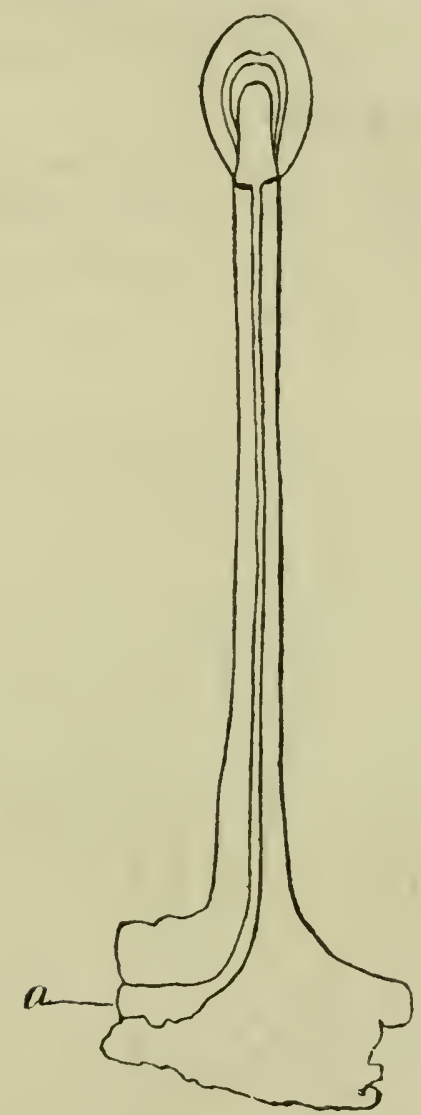

Fig. 117. Tentacle of Drosera rotundifolia (Strasburger and Hillhouse):

(a) inner tissues of the leaf.

vascular tissue has developed in the tentacles, not because they are different in nature from glandular hairs, but because these glandular hairs have dereloped tentacular power of movement and prehension, in addition to power of secretion. 'These tentacles are highly specialized glandular hairs, with power of movement responding to stimulus. Naturally, as this higher development proceeded, the fibro-vascular structures branched into thesc originally simply cellular structures. 
At p. $82 a$ of the same work a glamdular hair is given from the tooth of the stipule of Viola tricolor. "At the apex of each tooth there is a beautiful egg-shaped gland." ..... "It consists of two or more rows of elongated cells forming a core, upon which a single layer of cells is placed, arranged perpendicularly to the surface, and elongated in this direction." Fig. 118 shows that, in addition to the secreting epiclermal cells, there is a core of cells which is continuous with the inner structures of the stipule, although it is a glandular hair.

These superficial cells are a continuation of the epidermal cells. Morphologically, they are cells of the epidermis, like trichomes, although functionally they are secreting or excreting cells, the secretion consisting of slime and resin.

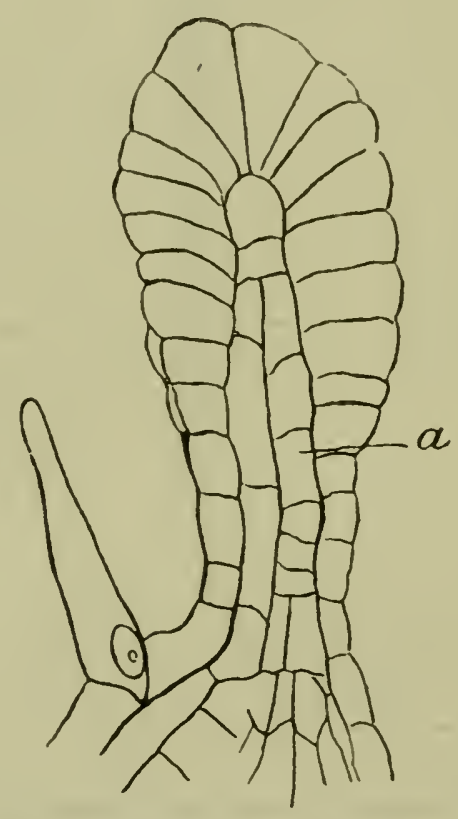

Fig. 118. Tooth-gland of stipule of Viola tricolor (Strasburger and Hillhouse, Fig. 36a): (a) inner structure of stipule.

Prof. Henslow lays stress on the fact that the fibro-rascular cord of the Drosera leaf branches into the tentacles, in order to prove that they are not trichomes. Let us, howerer, take another important organ-the sporangium of ferns, which is not considered as a trichome, Fig. 120. It is evidently a specialized trichome, as its stem is only cellular, and the inner tissues of the leaf do not hranch into it, as in the Drosera tentacle and stipule gland of 


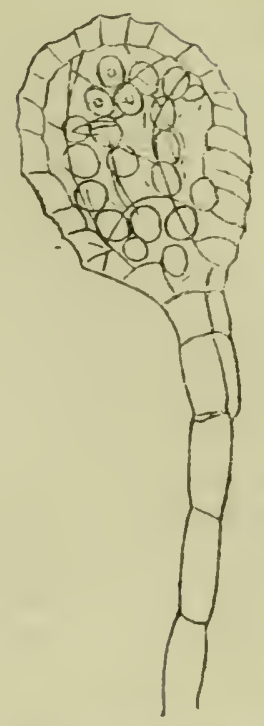

Fig. 120. Sporangium of Scolopendrium vulyare (Fig. 96, Strasb, and Hillh.).

Viola tricolor. 'The stem of the sporangimn consists of a thread of simple cells. There is no trace of vascular tiscue in it. Nerertheles:, at its summit there is a highly-specialized body capalule of producing cells, which reproduce the whole parent form! The head of the sporangimn does much more than the tentacle of the Drosera does, or ordinarily can do. The latter moves and secretes only; the former creates a new being. And all this without the aid of fibro-vaseular tissue, although the plant is called reascular cryptogam, and by simple inbibition of nomrithment from cell to cell. Anatomically, the sporangium may be called at trichome, but plysiologically it is undoubterlly a blanch.

All this shows us that the distinction we make between glandulan lair and tentacle appears incorrectly bitsed on the fact that the latter hats a core of fibro-raticulal tisine; for the sporangium has no tratce of it, and yet it is a much more highly organized borly. And, therefore, the clifference hetwern the tentacles of Drosera and epiclermal trichomes appear to mo to he only at distinction of words.

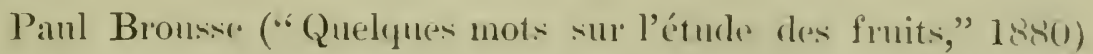
gives an interesting series of reversions of the glandular hair of Drosera intermedia, reproduced in Figs. 121 to 123. 


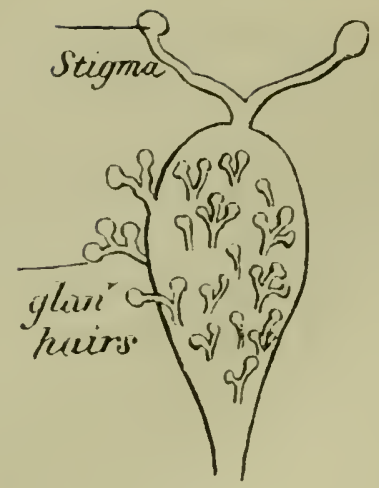

Fig. 121. Carpel of Drosercintermedia.

Instead of ovules the surfice was covered with glandular hairs.

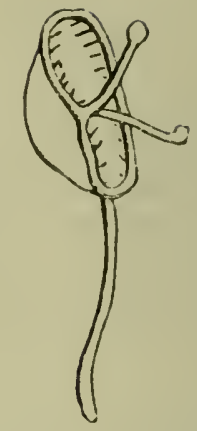

Fig. 122. Glandular hair of Droserc reverted to leaf having ordinary hairs on its edges, and two glandular huirs.

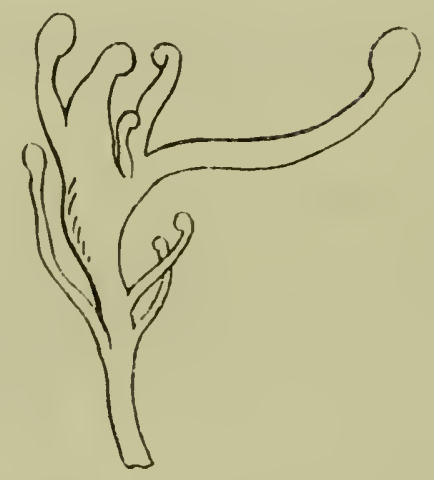

Fig. 123. Glandular hair of Drosera reverted to a branch with leaf-buds.

From these reversions it would appear that glandular hairs and ovules and branches are interchangeable, and so are glandular hairs interchangeable with ordinary simple hairs.

Why need we wonder that this should be so? Areording to Weismam, every vegetative cell was originally alvo at reproductive cell, the latter function having been retained in some, while it aborted in others. It will not follow, however, that, nnder certain circumstances, the regetative cell will not become potentially reproductive. It may be true that the tentacles of Drosera issue from branches arising from the fibro-vascular cords of the leaf. But the distinction given between these and trichomes may be owing to the undne stress we lay on fibro-vascular cords. Surely in cellular plants circulation of plant blood takes place 
without a specialized vaseular system; and in those we have stems and leaves and reproductive organs all the same. It does not appear to me that, because trichomes have no connexion with the fibro-vascular system, therefore they are not homologous with the tentacles of Drosera.

The reason why trichomes are not usially connected with the vascular system may well be that at its termination this system usially aborts, and leaves the epidermis and trichomes to be nonrished by imbibition of juice poured out by the terminal fibrils of the vascular branches, in the same way that the veinlets of the leaves terminate in the midst of a group of parenchyma cells, which are nourished by the fluid poured ont.

We see the epidermal hairs of Begonia phyllomaniaca turning into branches, and it is presumable that the need of specialized vascular branches gives rise to their development. Similarly, in Figs. 121-123, we see that the tentacles of Drosera intermedia can now be ovules, now glandular hairs, now branches, with suldivisional tentacles as leaves, and now simple leaves, with tentacles or orules on their margin, while other tentacles have ahorted into ordinary hairs. Can there be anything more like a branch, with verticillate sub-branches, than the hair of Alternantherc? *

We seem to be afraid of accepting the revelations of these reversions for what they really mean, because we are biassed by the notion which we have set up that disconnection with the fibro. rascular system also means disconnexion with the homological and morphological continuity of the whole plant. This break of rontinuity may be due, as I said, to abortion of the terminal vascular veinlets, because the cells in their ricinity can be nourisherl by cell-to-cell imbibition.

We seem to see striking examples of this homology at every turn. Examine for instance, the young pink leaf of Chenopodium petiolare. Its whole susface is elosely packed with minute globular cells, giving it a pollen-like surface. At the tips, where the leaves are turning green, these cells decay and are shed, and when the leaf turns wholly green, they have all disappeared. They are evidently what are called hairs, and possibly may be either protective or excretory. Examine then the placenta of Lobelia Tupa, and you will find the surface closely packed with similar, 
though egg-shaped, cells. They are functionally different from the cells of the Chenopodinum leaf, but essentially the same thing. By-and-bye they are fertilized, and begin to attract actively the vascular tissne, which their active function needs, and instead of decaying they grow into seed-buds. We might call those ovular trichomes, and these trichomic ovules. The Chenopodium cells may be regarded as atrophied orules, functioning as hairs, but possibly, under certain circumstances, like the glandular hairs of Drosera, they may revert to an orular function and bud out into branches reproducing the parent plant.

Again, to repeat what I have already stated elsewhere, Strasburger and Hillhouse, p. 254u, say that the conceptacles of Fucus vesiculosus are pear-shaped carities communicating with the exterior by an opening. The strnctures radially arranged in this cavity are sterile hairs, which remain unbranched, and others, much like these in structure, but copiously branched, bear male sexual organs, the antheridia. "The antheridia are unicellular branches of these hairs, of an elongated ellipsoidal form, and haring abundant contents" .... "Between the sterile and fertile hairs are the female sexual organs, the oogonia, "each containing eight eggs or oospheres."

Here we have simple sterile hairs, mixed up with branched fertile hairs, the nourishment and size of the carity probably not being enough to make all grow into fertile hairs, so that some, for these reasons, and also from heredity, remain atrophied, much as do many of the orules of orchids for want of fertilization and sustenance. Any organ, it appears, may be reducible, by atrophy, to a simple trichome or hair.

The hair when worked out to its algal origin is seen to be a reproductive organ. If we take, for instance, Cymopolia barbata, a calcareous alga (Fig. 124), we find that its stem is covered with reproductive hairs, a portion of which is giren in this figure. If these primitive reprodnctive organs became partially atrophied during the evolution of more complex organs, it is conceivalule that traces of them might remain on the bark of the strm and midribs, \&e., such as we find in the moss-rose, Ailanthus glandulose, and many where plants, in the form of glamdular hairs. Indeed, in this

* Which oogonia Bower regards as metamorphosed hairs. 
Cymopolia we alrealy have an adumbration of such atrophy in the sterile heads at $(a$.

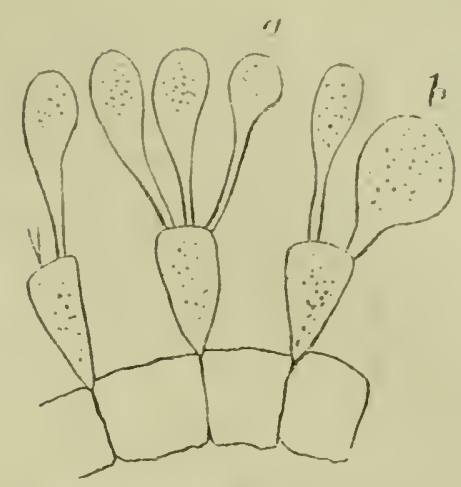

Fig. 124. Cymopolia barbata (Manual of Pueleon, Nicholson, and Lydekker, Fig. 1,360): (a) sterile processes, $(b)$ fertile processes containing spores.

Similar evidence of reproductive hairs atrophying into simple hairs may be obtained from Fucus serratus.

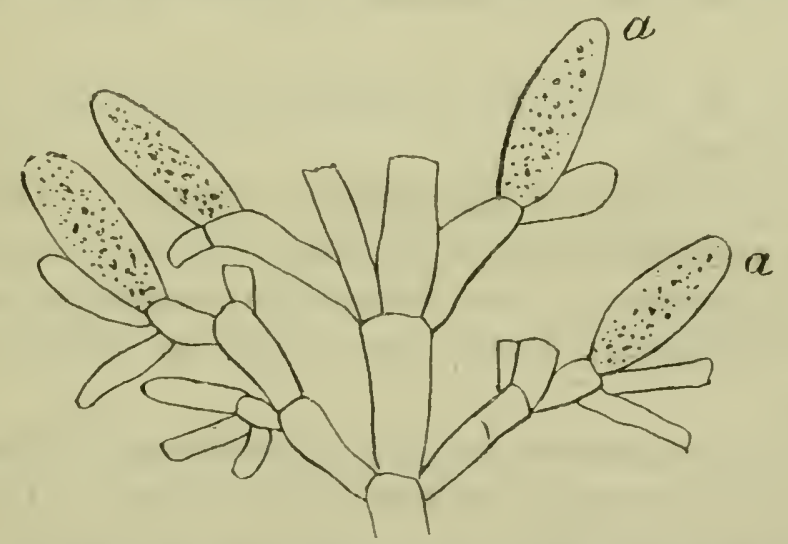

Fig. 125. Portion of a hair isolated from the male conceptaele of Fucus serratus with antheridia (a) (Thuret, "Ét. Phyc.," pl. 11). Enlarged.

Further, Goebel, "Outlines of Clansif., \&c.," p. 216, gives a figure of the Sporangia of Aspidium Filix-mas. Some of the Sporangia have a stalked gland. 'This is evidently an abortiv. sporangium, althongh it passes as a glandular hair. It in intoresting to note that in this fignre the sporangia, and the indusimm itself, are outgrowths of the layer of epidermis, which covers the 


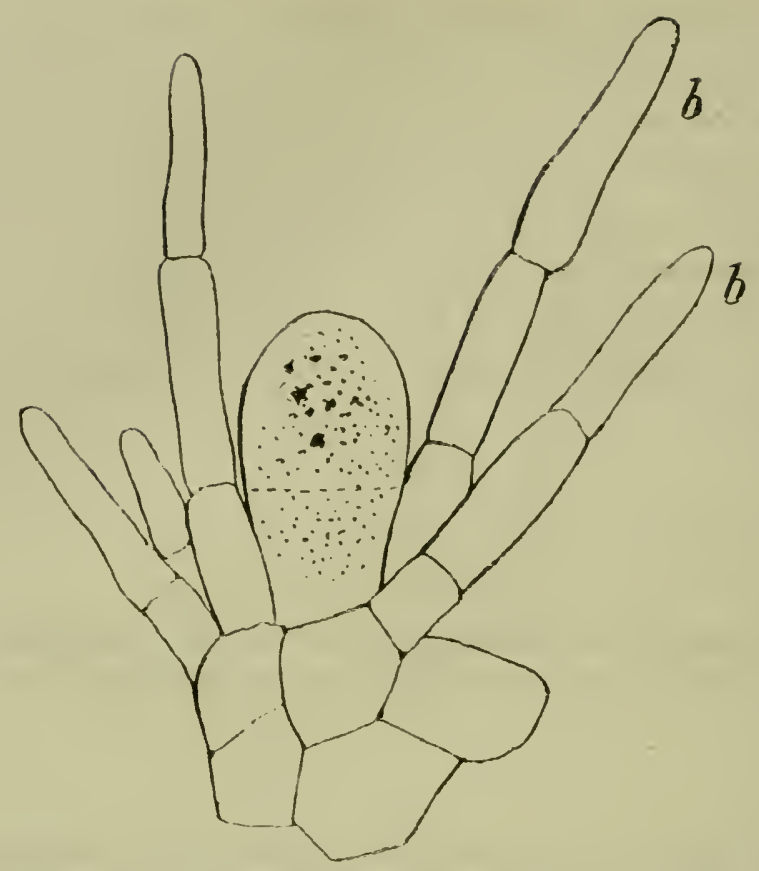

Fir. 125a. Young sporange isolated from female conceptacle of the same

Fucus, with barren hairs: (b) probably atrophied antheridia. Enlarged.

placenta of the sorus. They wonld therefore come under the definition of hairs.

The sorus-like tufts of alga have no indusium. 'This appears to be a covering originating in the needs of ferns, connected with atmospheric changes. It may be made up of radiating hairs fused into an umbrella-shaped body, much like the radiated hairs of Eleagnus.

Hairs may be remuants not only of reproduetive organs proper, but they may be atrophied teeth or lobes of leaves; they may be atrophied leaves, or bracts; in short, any part which is interchangeable with a branch, such as an ovule or other homologous part.

The development of hairs into bud-scales and leaves would be analagous to the development of the down of young birds into their adult feathers.

The involncral hairs of the sorus of Woodsia hyperborea would stand for bracts (pl. 7, "Hooker's Brit. Ferns"). So would those of the alga Helminthora divaricata which surround the cystocarp (Thuret, pl. 32). 


\section{PRICKLES OR SIPIE: :}

'These are described by anthor's as hardened hairs, while spines are said to be different-aborted branches, harlened stipules, petioles, \&c. I think the prickles on the margins of leares, nch as those of Agace, Bromelia, and many other's, are nothing but hardened teeth, and these I have shown are nothing but lobes or abortive branches. It will be sufficient to refer to the annexerl Fig. 126 to

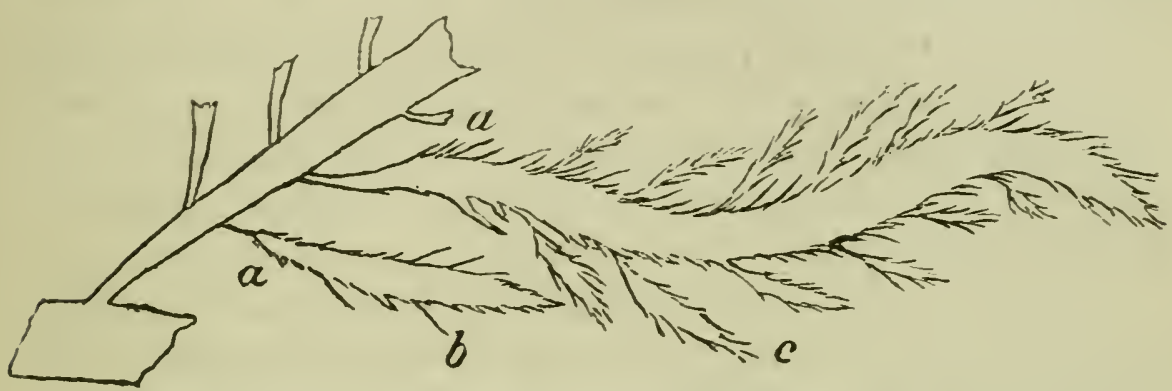

Fig. 126. Desmarestia ligulatu, Lamour ("Harvey's Phyc. Brit.," 11. 115): (il) teeth, (b) the same partially developed into branches, (c) well developed branches with marginal teeth.

satisfy the realer that prickles on the margins of leaves are interchangeable with lobes or branches. I shall quote the author's works regarding this alga, "All the pinnules are margined with minute spines like teeth, which in roung individuals produce tufts of delicate branching jointed fibres."

Ptilota plumosa, Ag. (pl. 80, op. cit.), also shows rery well the change of teeth into branches.

Reference may be made also to Figs. 115 and 116 already giren in discussing the teeth of leaves.

In Desmarestic, all stagen of development. am be seen from prickles (the author calls then minute spines) to branches. In face of these facts, it appenrs to me that the distinction betwern prickles and spines has no longer any raison àtre.

\section{RecdPTI:ATIOS.}

At one end of the evolutionary ladkler we almit that stl cells are both procreative aud regetative, as Weismann does. Ar the other end of the ladder a differentiation for econonical purposes take: 
place, one function being aborted and the other retained. It, therefore, seems unreasonable that we should not also andmit that the differentiated cell is still polentially what it was before, although it may not be actually so.

With this view it can be readily seen how all parts of a plant under certain circumstances can be interchanged, through albortion or reversion. Eren in a simple hair cell, disparagingly called a trichome, we find an astonishing potentiality, a bud-like (apacity of reproducing the whole plant.

The bias of former teaching disinelines us to admit as true what we see, and so we are erer trying to explain it away. We try to persulde ourselves that what we see is not what we see, but something else, and all this on the hasis of some one's authority, who, although a specialist, may as likely err as anyborly else.

It appears to me that in many cases different names have been invented for parts of plants under the antiquated supposition that all these parts lad a distinct genesis. The difference of name then engendererl in men's minds a notion of a radical difference in the things themselves. That notion has stuck to them, and will long stick. I do not think we have yet taken in the profound upsetting of old notions, which the theory of evolution has brought about.

One might now ask, what is the upshot of all this wearisome discussion about hairs?

The upshot is that the notion that the hair or trichome is an outgrowth simply of the epidermis, and is of no morphological significance, is no longer tenable:

(a.) Because hairs are found on plants which have no epidermis. In the lower plants, similar structures, anatomically indistinguishable from those of the higher plants, stand for branches.

(b.) Becanse simple hairs, and à fortiori branched and glandular hairs, by comparison with similar organs in the lower plants and hy teratological specimens, can be shown to be aborted reproductive organs or buds, and, therefore, re-convertible into hianches, leaves, leaflets, \&c.

(c) Becanse if a hair is, muler ecrtain circumstanres, conrertible into a branch, there is no part of the plant which may not be represented in an atrophied state by a hair. 
To take all this in one requires to take a much broader view of evolution than is usually found in books treating of plants, and to consider that seaweeds which have important reproductive organs of no more complex structure than the hairs of higher plants have been the organisms from which all land plants have evolved. In this erolution many of the formerly essentially important organs have not always been thrown off and become extinct. In many cases they have persisted, their function becoming altered to suit the conditions and surroundings of the innumerable developments we see ererywhere. As these organisms progressed in development more complex reproductire and regetative organs were pari passu dereloped, and, therefore, the old reproductive organs were either totally suppressed or atrophied as mere incumbrances, or altered into useful subsidiary organs.

I shall conclurle this long and not rery clear discussion by a teratological phenomenon I recently observed in Osmunda Regalis, var. capitata, exhibited by MIr. E. J. Lowe at the meeting of the Royal Horticultural Society of 8th September 1891.

At my request Mr. Lowe kindly gare me the apical portion of a frond which had become fertile. On careful examination I foumd that it gave off sporangiferous hairs with a thick stalk singly from the reins of the pinnx, as we see hairs giren off from the nerves of leaves. The teeth of the pinnules here and there were also sporangiferons, which, to my mind, prores that teeth of leaves, hairs, and sporangia are one thing, and that probally what we call glandular hairs are no other than abortive sporangiferous hairs. From this it wonld appear that sori in other ferns, whether sheltered by an indusium or not, are mere tufts of sporangiferous or fertile hairs, and that nne-celled stamens and ovules correspond to sporangiferous hairs.

In the Prothallimm of ferns the archegonia and antheridia appear to correspond to teeth of leaves in phænogams. (Vide pp. 201 and 207 of Goebel's "Outlines of Classification," \&c.)

When we aceept Erolution we must be prepared for a Revolution in thought, not only in all that concerns the so-called lifeless kingdom, but also, and more especially, in all that regards the kingdoms we are plensed to call living-the botanical and zoological kingdoms. 
"The history of the progress of knowledge is but an account of the passage of the inconceivable into the conceivable."-Charles Darwin. 
XV.OIL GLANDS, CONCEPTACLES, AND FIGS.

\section{Oil Glands and Conceptacles.}

Le Maout and Decaisne, in their "System of Botany," p. 140 (1873), evidently had considered oil glands as ordinary glands, for they say, "Sometimes the glands are sunk in the thickness of the bark, but they are always near the epidermis; such are the glands called vcsicular of the leaves of St. John's Wort, and Myrtle, and of the bark of the Orange, which contain a volatile oil."

According to Strasburger and Hillhouse (1889) the oil glands of Ruta, Graveolens, and Dictamuns Fraxinella are first cellular, then the cells break down, and are converted into essential oil, the breaking down commencing at the centre, as shown in Fig. $127(a)$ and $128(b)$. At p. 164 they say, "The oil gland
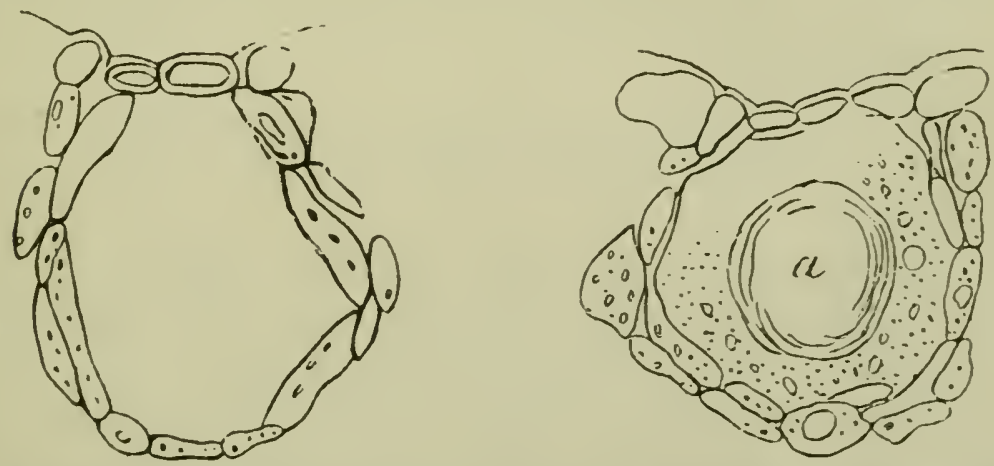

Fig. 127. Oil glands, or cavities of Ruta Graveolens (Strasburger and Hillhouse): (a) drop of oil.

is lysegenous in origin, that is, it arises from the breaking down of cells, instead of from their separation. This breaking down commences at the centre of the mass of gland cells." 

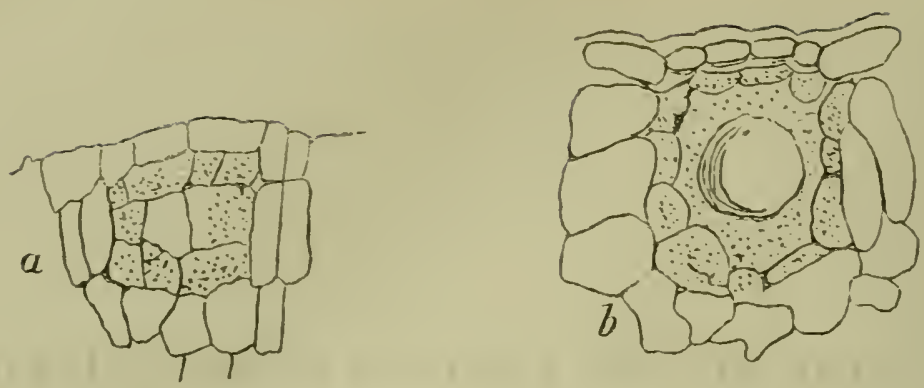

Fig. 128. Oil cavities of Dictamuns Fruxinclla (Sachs' "Physiology of Plants: (a) early stage, showing breaking down of central cells only, (b) cavity with a drop of oil.

Sachs says, at p. 183,* "The oil glands of the Orange and others originate, so far as investigation extends, from a single mother cell, which, as it slowly derelops, undergoes many divisions in all directions, so that a multicellular mass of tissue of roundish form arises, $\dagger$ the cells of which subsequently become remarkable as containing rery granular, apparently dead, protoplasm. Later on, the thin cell walls dissolve, the process commencing in the micldle of the spheroidal group, and proceeding outwards. There arises a roundish cavity, filled partly with watery sap, partly. with drops of ethereal oil or balsam $\ddagger$ the products of solution of the mass of cells. The layers of tissue surrounding this carity fit closely on all sides, without intercellular spaces, and thus form a kind of wall to the receptacle for the secretion." This is well seen in the leares of Citrus.

Why Sachs calls it a secretion is not very clear. If the oil comes by a breaking down of cells, it is more likely to be a degeneration.

O. Penzig, in his "Studj sugli Agrumi" (1887), p. 53, says, "The contents of the single cells which form the oil gland are at first protoplasm with a high refraction, afterwards they are of essential oil, which fills the whole of the cell. By degrees the walls of the central cells are ruptured, and the essential oil fills the centre of the gland. Then the remains of the destroyed cells line the walls of the carity thus formed, so that in the adult gland

* "Text Book of Botany."

$\dagger$ Such as is seen in the derelopment of the anther, for instance.

\$ Such as shown in Figs. 127 and 128 . 
can be distingnished the internal cavity filled with oil, a layer of cell-remains, and outside all the altererl cells of the mesophyl." And at p. 52, he say', "the glands of the leaf occupy half or two thirds of its thickness, and a layer of cells, on the external side, occupies the would-be mouth of the gland."

In "Cultivated Oranges and Lemons of India," p. 206, I rentured upon a suggestion in connection with the oil glands of the Citrus. I said, "How conld the oil cells of the Citrus first have come into existence? Were they oil cells from the beginning of time, or were they trausformations of something else? Tuking into consideration that these oil cells now exist all orer the bark; that the axillæ or angles of the leaf-crenations contain each an essential oil cell; that the leaf-buds of Bryophyllum-calycinum are produced in similar positions, and that in homologons points of the pulp carpels of the Citrus seed-buds are developed, the suspieion might be raised in one's mind that, after all, these oil cells-so constant in all parts of the Citrus-may not impossibly be connecterl with spore sacs or similar organs in some ancestral cryptogamic form."

At the risk of being tedions I have quoted the passage in full, as I think it of some importance. I shall now proceed to show that my suspicion of the true nature of oil glands is not without foundation. I then thought that not improbalbly they were remuants of ancestral organs of reproduction, degraded or atrophied, and turned to other uses in the struggle for life, when more specialized organs of reproduction were being erolred.

'The great struggle for cxistence, we should remember, is not only a struggle between individual and individual, between species and species, race and race, but also between parts or organs of the same individual, so that some parts are degraded or atrophied, while others increase in size and importance of function. Such phenomena in the regetable kingdom are rery frequent. Tre see leaves degraded into tendrils, branches into spines, leaflets into glands or stipels, important organs in one plant degraded into insignificant parts in another, becoming dreciduous after a bricf existener, or beconing wholly extinct. We eren sece esintial orean. in one plant transformed into simple hairs in another, and so on.

Surh is reolntion-at ressedess flow of life, with rhange. Degradation and extinction are going on in one direction, while 
an unfolding of dormant vigour, and complexity, awakening new forms, are going on in another direction -the whole with a wonderful elasticity of parts, ever suiting itself to new surroundings. Nerertheless, the force of heredity is often so strong, that it is ever restraining the tendency to change. It thus often prevents a degraded organ from becoming wholly extinct. Howerer useless it may have become on the old lines, new uses are often found for it on other lines as a helper in the great struggrle.

'To show that there is foundation for considering the oil glands of the Citrus of eryptoganic origin, we shall have to dive down to the lower strata of the vegetable kingdom. There we shall find the genus Fucus, in which Lindley ("V.K.," p. 22a), quoting from Thuret, says, "The fructification is contained in little spherical (arities sitnated beneath the epiderm, and called conceptacles. Completely closed at first (note this) the conceptacles open eventually at the surface of the frond by a little pore or mouth through which the reproductive bodies escape.* Their exit is
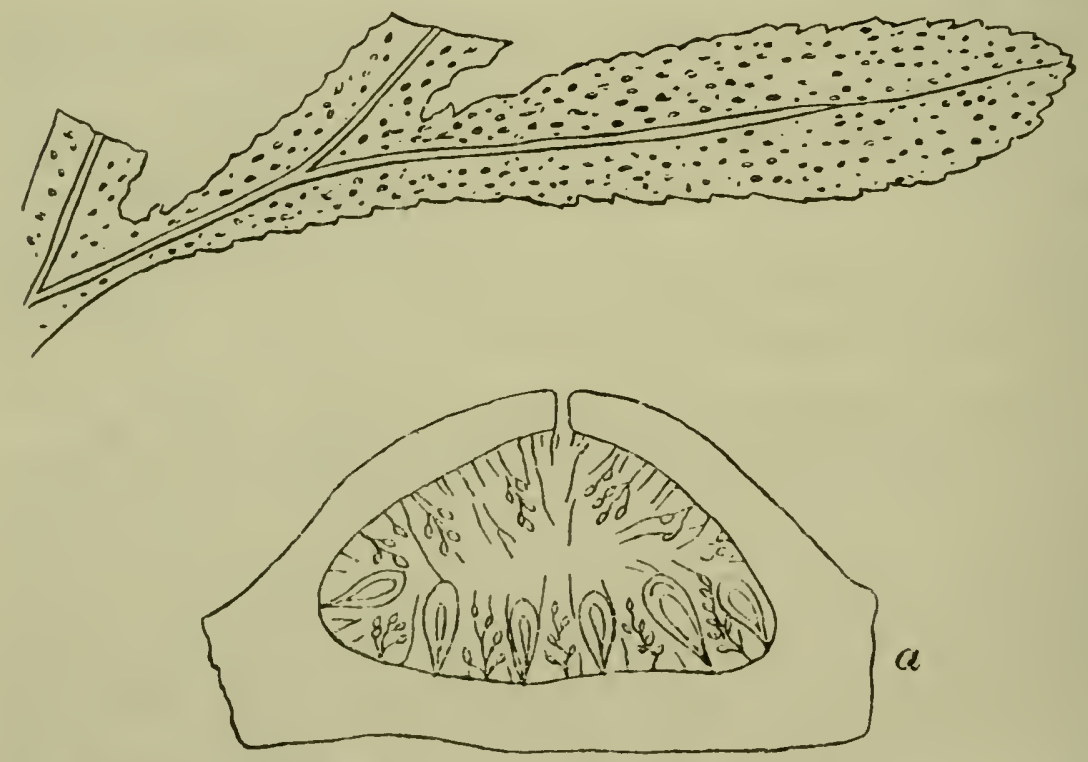

Fig. 129. Frond of Myriodesma latifolia ("Harv. Phyc. Austr.," pl. 24) dotted with fertile conceptacles: ( $a$ ) enlarger conceptacle, showing spores and antherides.

* In my opinion these conceptacles do not differ morphologically from the soc $i$ of ferns. The latter are on the surface, the former are embedded in the substance of the frond. Some seaweeds have their conceptacles on the surface, like sori. 
assisted by the hairs which line the conceptacles, and which all converge towards their mouth. 'These hairs are jointed and branched, it is they which support the antherides, and it is at their base that the spores are fixed. In certain species spores and antherids are found in the same conceptacle. In others, on the contrary, these two organs are produced in different (onceptacles, and on different individuals."

In the genus Fucus, and in other Alga, we find some interesting dots disseminated over the frond. In Myriodesma latifolia these are the only organs of fructification called by Phycologists conceptacles. 'They consist, as seen in Fig. 129 (a), of spores and antheridia, that is, male and female elements.

In Fucus vesiculosus, however, and other species of Fucus, we find that the active conceptacles are concentrated in specialized heads or receptacley, an they are called. The receptacles or groups of conceptacles correspond to rulimentary spikes of rudimentary flowers. While (note this) the diffused dots on the remaining portion of the Fucus fronds are no longer active organs of fructification, but have become atrophied. They are remnants of ancestral active organs in some alga, from which this form of Fucus descended.

In Myriodesma latifolia we have an alga which has not yet specialized a head of conceptacles, but has them disseminated all over the frond.

In the Fucus the atrophicd conceptacles are there because heredity was too strong for them to be entirely effaced.* We are not told what use the Fucus makes of them in their atrophied state, but we may perhaps get a hint of the conneetion between Fucus conceptacles and oil-glands by taking a look at another alga, Vaucheria sessilis, Fig. 129a, in which Strasburger and Hillhonse tell us the dots on the frond are oil drops: It would appear that in this alga the dots $(a, a)$ or conceptacles (as I take them) had degenerated into oil-glandst or oil-cells owing to specialized organs of fructification having developed $(b, b)$, and which $S$. and $H$. have called antheridium and oogonium, corresponding to stamens and carpels in phrnogams. The authors call these dots oil drops, but it may, perhilps, be presumed, as in other cases, that these

* Like the splint bones of the horse.

$\dagger$ The term gland in this case is misleading, as it is not an active secreting organ, but a breaking down of dead cells. 


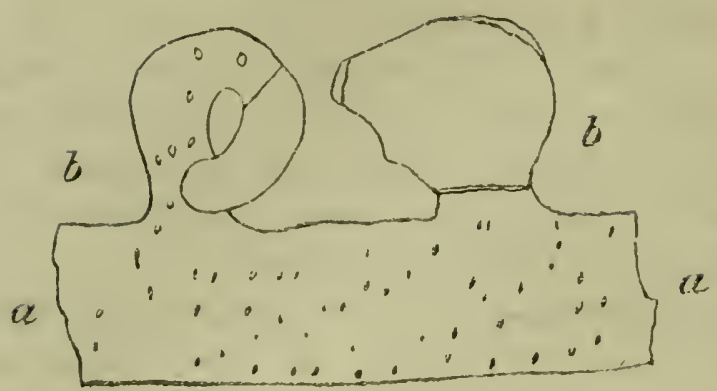

Fig. 129a. Vancheria sessilis ("Pract. Bot.," Strasb. and Hilih., Fig. 88) : $(a, a)$ are the oil drops, $(b, b)$ antheridium and oogoninm.

drops of oil are produced by the breaking down of eells, as in thr drops of oil which appear in the Citrus oil-gland.

This, then, to recapitulate, is my view of the oil-glinds on the leaves and other parts of the Citrus. They are probably remnants of Fucus or other seaweed conceptacles. Although the fertile conceptacles of this alga are gathered into a head at the end of the branch, nevertheless, the whole frond still remains dotted over with what appear to be atrophied conceptacles, inherited from some previous form like that of Myriodesma, in which the conceptacles had not yet been specialized into a reproductive heal at the tip of a branch, but were generalized orer the frond, that is, every part of the frond bore reproductive organs. These atrophierl conceptacles of the Fucus wonld rery probably correspond, as I said, to what are ealled oil-glinds in the Citrus, the latter being the same persistent structures turned to other uses.

We cannot suppose that in the Citrus the oil-glands are of vital importance to the plant, for thousands of other plants have them not, so that it is reasonable to suppose them inherited remnants of some orgams that were originally of vital importance to some ancestor. In the Citrus, orgaus of fructification are no longer needed on the fronds proper, because a much more sprecialized organ, in connection with insects and birds, has been developed in the flower and fruit proper. 'These remnants of aneient reproductive apparatus are, uneretheless, still inherited to point ont to us, as it were, the homologieal history of the different parts of the higher plants through a long succession of forms 
descending to very ancient cryptogams, representatives of which are still extant. The essential oil in the Citrus and others, by its diffusion through the air, advertises a suitable plant to a suitable insect, and also may warn off destructive insects.

One might multiply evidence to almost any extent to strengthen the notion that the oil-glands on the Citrus leaf are no other than remnants of conceptacles or reproductive organs such as we find in seaweeds.

For instance, Harrey, in describing the foliage of S'argassum vulgare, , says, leares "serrated, strongly ribbed, copiously glandular." He also calls these leaf dots "muciferous pores or glands." He does not, it is true, mention that these glands of the Sargassum leaf are in any way connected, in origin, with conceptacles, but any one looking at the frond of this Sargassum, and then at that of Himanthalia Lorea, $\uparrow$ dotted with conceptacles, and also at that of Myriodesma latifolia, Fig. 129 of these Notes, cannot help being convinced that the muciferous spores or glands of Sargassum are the same thing as the conceptacles of Himanthalia and Myriodesma. The glands of Sargassum are not needed as conceptacles, because other special reproductive organs called receptacles (and crowded with conceptacles) are developed in that plant.

From atrophy it is an easy step to total obliteration, for in Sargassum bacciferum $\ddagger$ Harvey says: leaves "destitute of muciferous pores, or glands."

Here, then, are two closely allied plants included in the same genus (Sargassum), the one is dotted with glands, the other destitute of them. What wonder is it that we should find so many plants destitute of glands on their leares? They have not only grown out of the stage of reproductive organs on their ordinary leaves, but they have lost all trace of them as needless incumbrances. The Citrus, the myrtle, and several others are the ones which continue to retain traces of them, because their remnants have been turned to other useful purposes in the economy of the plant.

*P1. 343, "Phyc. Brit."

$\dagger$ Pl. 78

$\ddagger$ Pl. 109

,

$\triangle$ p. 1724. 
Gustare Thuret ("Etudes Phycologiques," 1878, plates XI., XV., XVI.,) gires figures of three species of Fucus ; serratus L., vesciculosus L., and platycarpus, Thur. The whole frond of all three is corered on both sides with conceptacles or spore-sacs. But it is only towards the points of the fronds that these conceptacles are fertile. In the remaining portion of the froud they are abortive, indicating most probably that in antecedent forms the whole frond was corered with fertile conceptacles. The sections

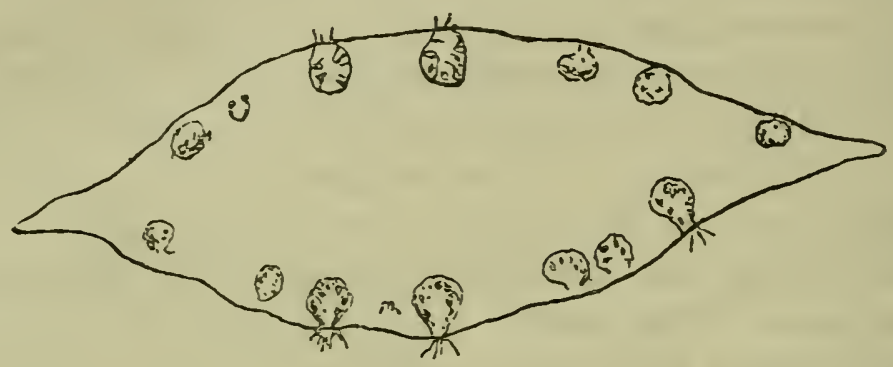

Fig. 130. Cross section of the frond of Fucus platycarpus, showing the conceptacles opening on both sides of the frond (Thuret, "Études Phycolog," pl. 17).

given by Thuret of the fertile parts (Fig. 130) show the spore sacs on both sides of the frond, some mature and open, and others progressing towards maturity and closed.

Now Penzig in his "Studj sugli Agrumi," p. 52, has shown that the oil-glands of the Citrus are on both sides of the leaf. He further shows that the oil-gland is a sac filled with cellules. At a certain stage, as already stated, the central cellules dissolre, and turn into essential oil, while the outer ones remain as a lining to the sac. The mouth of this sac or oil-cell is closed by a layer of epidermic cells, which in the orange peel with a little pressure bursts, and the oil squirts out.

I confess I do not see anything preposterous in considering the essential oil-glands of the Citrus as possible degenerations of conceptacles in some fucus-like remote ancestor.

Judging from the Fucus of to-day, I should say the fertile conceptacles of its ancestor were scattered all over the frond on both sides. But certain portions of the frond, in subsequent generations, having been specialized as conceptacle bearers, the remainder of the frond retained traces of them as atrophied remnants. 
What wonder is it then, considering that all our land plants must have descended from seaweeds, that the Citrus and several other land plants should hare inherited on their fronds remnants of those very conceptacles which in the modern Fucus are found also abortive, except in the specialized parts? The Citrus, long, long ago, grew out of the habit of erolring germ and sperm cells out of its leaves proper. It now evolves them out of modified leares-the stamens and carpels,-but it has not got entirely rid of the remnants, on its leares, of its former reproductive organs. Howerer we may refuse to see any close connection between an orange-tree and a Fucus, nevertheless, from an erolutionary point of view, we cannot deny them relationship.

The cellules of the oil-glands might, without much stretch of the imagination, be looked upon as spores, degenerated into the fatty matter of the essential oil, in the same way perhaps that ora of animals are said to degenerate into fatty matter when no longer needed as ora. They then are turned to a different use, and serve a totally different end in the struggle for life.

We now feel more than convinced that the splint bones in the horse's foot are remnants of two other digits in a three-toed ancestor, yet it will probably be considered a preposterous attempt to try and descend to the conceptacles of a Fucus-like plant for the explanation of these remnants in the Citrus frond!

Some might say that it is too ridiculous to tell us that the delightful orange has had a Fucus for a remote ancestor. But it seems just as ridiculous, or as wonderful, that man (made in the image of God) should have come from a one-celled orule, and in his derelopment hare passed through the images of a fish, a lizard, a dog or other mammal, and have finally bloomed into a philosopher.

More curious and suggestive still is the surface of a Nillipora, a form of low animals not very distant from the calcareous seaweerls. They have their surface covered with pores, not only large and small, like the oil-glands of the Citrus leaf, but disposed exactly like them. Fig. 131 (A and B) shows the surface of Millipora and Fig. 132 (C and D) that of the Citrus leaf.

This is what Prof. Nicholson says of the Millipora alcicomis, "Its calcareous skeleton is usually in the form of a foliaceous or laminar expansion, or is simply branched." In this calcareous 
structure are tubes, " in two series, differing slightly in size, and they open on the surface by apertures correspondingly different in dimensions, of which the larger ones are called the 'gastropores' (a), and the smaller 'dactylopores' (b), Fig. 131. 'The gastropores and dactylopores may be irregularly distributed, or the dactylopores (the smaller ones) may be arranged in more or less definite systems round the gastropores." In the tubes are lodged zoöids. Their reproductive process is imperfectly known.
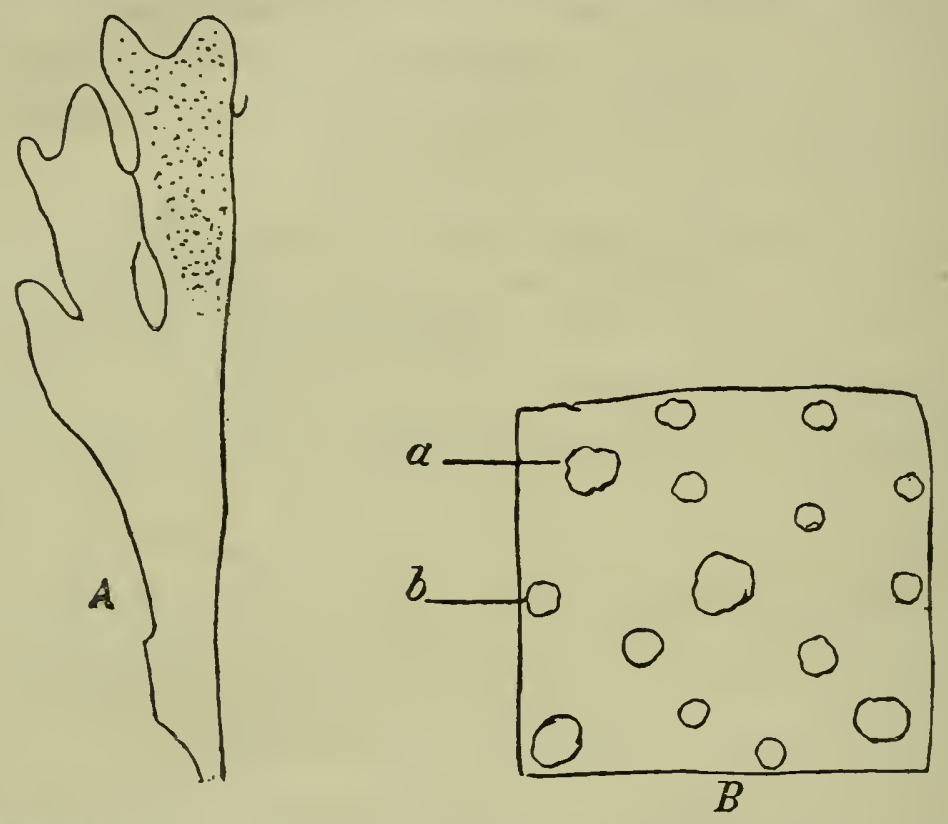

Fig. 131. Millipora alcicornis ("Manual of Palæontology," Nicholson and Lydekker, pl. 108): ( $A$ ) natural size, $(B)$ part of surface enlarged.
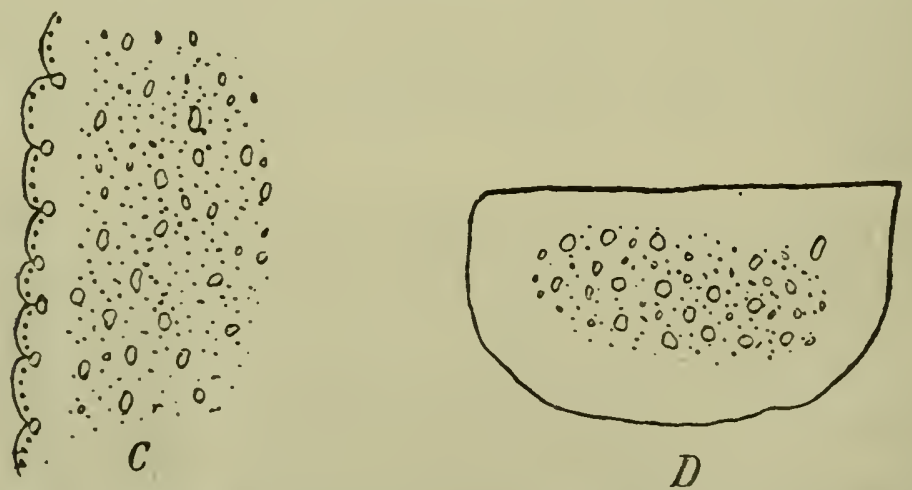

Fig. 132. (C) portion of Lemon leaf, showing large oil-cells surrounded by smaller ones: $(D)$ is a longitudinal section of Lemon peel, showing the same disposition of oil-cells ("Cultiv. Oranges and Lemons of India," pl. 181a and pl. 188e). 
I do not mean to say that the oil-glands of the Citrus and the pores of the millipora are exactly the same thing, any more than I would mean by saying that the hand of a man is the same thing as the forefoot of a lizard. What I do mean is that, taking into consideration the evolution of the higher animals and plants from the lower, and the branching off of both from the primitive unicellular bodies, together with the force of heredity, there would be sufficient ground for looking upon the surface of the Citrus leaf, with its large and small dots, as having some distant relationship with the surface of the millipora, with its similarly disposed and similarly sized dots. The one suited to a life in the bottom of the sea, the other suited to an air life, with totally different surroundings and functions.

I have pointed to the millipora in order to explain in some way the different sizes, and the disposition of the oil-glands in the Citrus leaf, but it is with the conceptacles of the Fucus, Sargassum, and other seaweed fronds that I would claim for them a homology.

The minute anatomy of the Fucus conceptacles of course differs from that of the oil-glands, but as I consider the latter as "persistent structures with altered function," this need not surprise us. It only requires a thorough belief in evolution, with inheritance of certain parts, together with a certain power of imagination and freedom from dogma, to bring the two on the same lerel of a common origin. The conceptacle no longer being needed as a reproductive organ is modified into an essential oilgland to serve another purpose in a surrounding of insects.

This same hypothesis, viz., of descent from a Fucus-like plant, may account for the oil-glands on the Citrus bark. For originally the stem was a cladophyl, like that of Delesseria (Fig. 12). The blades of the petiole and leaflet are the survivals of a winged stem, and the midrib is a dwarfed representative of a branch of that ancient Fucus-like ancestor, the oil-glands on both sides of the Citrus leaf being the modified descendants of the barren conceptacles of the Fucus frond.

All this may, however, seem to the reader a pack of absurdities. If so, all I can say is-I cannot help that. I do not lay any claim to being the inventor of the theory of Erolution. I am only humbly trying to apply its principles in explaining the presence and disposition of the Citrus oil-cells, placed all orer its surface with the same regularity of the pores in the millipora. 
The application of the objective method of rerification is here, as in many other cases, out of the question. We see the moon as a disk with a plane surface. No one has ever seen the back part of the moon. Yet who now doubts that the back part is generally spherical? This inference in time becomes as strong a conviction as if it were bronght about by ocular rerification, simply because it can be nothing else. Perhaps the community of descent between these oil-glands and the seaweed conceptacles may in time acquire the cumulative power of a strong moral conviction.

Of course, if we continue to make such an essential distinction between animals and plants as was maintained in past ages, the assumption that there can be any relationship between the pores of the millipora and the Citrus oil-glands will appear ridiculous. We are, howerer, by degrees discorering that this distinction can no longer be strictly maintained. We see that the male and female elements of the lower plants, and of the higher animals, are essentially the same thing. We, nevertheless, continue to comfort our prejudices by calling the male elements of the latter spermatozoa and those of the former spermatozoids, all the time feeling certain that it is a "distinction without a difference" !

I have made this little digression because some might think I am not justified in comparing the surface of an orange with that of a millipore. In order, howerer, that the reader may not fancy I have giren myself up to romancing in making a distant comparison between plants and corals, I shall quote a passage from "A Naturalist in North Celebes," by S. J. Hickson. At p. 150, he says, "The prevailing colors on the coral reefs are a deep greenish brown and a bright green. The latter occurs most frequently on the young actirely growing branches. Some of these colours dissolved in alcohol have been submitted to spectrum analysis by competent authorities, and in many cases the report is that they camot be distinguished from, or are very closely allied to, chlorophyl. If in the future it can be proved, as I beliere it will be proved, that a very large majority of the corals on the coral reefs do possess a colouring matter allied to chlorophyl, which performs a physiological function very similar to that of plants, we shall have an explanation of some of the anomalies of life upon the reefs."

The anomalies are that on the coral reefs "animal life is far in excess of regetable life." This the author would explain by the 
corals functioning as substitutes of plants. He does not suggest whether these coral plants furnish both food and oxygen to the animals, not improbably they may do both. The carbonate of lime, held in solution by excess of carbonic acid, they withdraw and fix as their solid shell, and the remaining carbonic acid they may somehow decompose to furnish free oxygen for the respiration of animals. It is comforting to find that one is not alone in attempting to discuss what might at first sight appear wild aburdities.

'The reader has to run his mind back not to the millipora-that is a side-light-but to the Fucus, and think of the Citrus leaf and the Fucus frond as cladophyls, having a common ancestry.

Considering the myriads of modifications through which the leaf has passed, from the Alga frond to the leaf of the highest flowering plants, and the countless forms of leaf now in existence, it is not to be wondered at that comparatively few plants retain traces of the ancestral conceptacles. It is only by putting these remnants to a useful purpose, in connection with insects, that probably they still continue to exist, in an abortive form in the Citrus, the Myrtle, the Eucalyptus, and other plants.

It would, indeed, be a revolution in botanical thought if some one, some day, were to make it more clear to us that the charming orange tree of to-day was a Fucus in the beginning of time, when regetation on this earth had not yet emerged from the sea!

There are other plants besides those with oil-glands which gire indication of having remnants of what I think are ancient conceptacles. Many of the Crassulaceæ hare little ring-dots on either the upper side only or on both sides of the thick leaf. In some these dots are indentations, which to my mind would indicate that originally they were little reproductive carities. I hare not seen the origin of these Crassula dots noticerl anywhere.

Crassula aborescens (Wild.) has them rery plainly. Where the leaf is thin these dots can be seen, by transparency, as little clear circles.

Figs.

The fruit we call fig is considered by botanists as a receptacle similar to those of the Compositx; that is, the expanded end of a branch studded with sessile florets. The fig, howerer, is a closed 
receptacle studded with minute florets, having between them bracteoles or hairs. 'The floral expansion of Dorstenia, which is considered as an open fig, would give support to this idea. But now, how did the fig and its homologue the composite head originate?

I consider the fig as only an enlarged and bulged-out conceptacle. There is nothing in the fig which would militate against our considering it a highly developed conceptacle of a sea-weed, except perhaps the antiquated notion that there is an essential difference between phænogams and cryptogams. In the conceptacle we have spores and antheridia and barren hairs. In the fig we have female florets and male florets, and hairs or scales.

We know that even a hair can be transformed into a branch, as in Begonia phyllomaniara and Drosera. A fortiori we ought to admit that a spore and an antheridium, which are already the beginnings of flowers, can more readily be transformed into the male and female florets of a fig, which, after all, are admitted to be only shortened branches. Moreover, we must confess that the florets of the fig are a mere apology for flowers, and only called so by botanical courtesy.

The facts appear to show that as the cryptogam is a rudimentary form of the phænogam, so the spore and antheridium of the conceptacle are the rudimentary forms of pistils and stamens. As to the whole fig, it does not require a great stretch of the imagination to consider it a further development of the conceptacle.*

After all, what is the real difference between the seaweed spore and the fig achene, between the antheridium and the fig anther? The spore has to fight its way in water, and, therefore, does not require elaborate extra coverings for protection. It begins as an ovule in the primitive state of a simple cell, and remains so. The achene has to fight its way in the atmosphere, a medium of a continually changing temperature and hygrometric state, and therefore needs extra coverings. So that from simple ovule or spore it has acquired by selection what we call seed coats (in all probability modified bud-scales), and partially develops plumule and radicle before it is weaned, and before it leaves the leading strings of its mother.

This is what Dr. G. King (Sp. of Ficus, Indo-Malay and Chin.) says with regard to figs :- "Flowers, mostly unisexual, sessile, or

*Vide Fig. 129 (a). 
pedicelled; in some species, separated from each other by scales or bracteoles, and in others by hairs analogous to the paleæ of the receptacle of Compositæ. In others no appendages are apparent. Fire kinds of flowers are found, viz., male, pseudo-hermaphrodite, neuter, fertile female, and gall flowers." With the latter we have nothing to do here, as they occur only in connection with insects. A perusal of Dr. King's interesting work produces in the evolutionist a "moral conviction" that the receptacle of the fig is only a further development of the conceptacle of the seaweed; that the male and female florets are only a further derelopment of the spores and antheridia contained in the conceptacle; that in both the hairs are probably only atrophied male or female organs. Moreover, we find that both conceptacle and $f g$ are found to contain ( $a$ ) male and female florets, $(b)$ unisexual florets on the same plant, and $(c)$ unisexual florets on different plants.

To the erolutionist no better example of homology can be found than between the receptacle of the fig and the conceptacle of the seaweed. But to the botanist who has not accepted erolution from its foundation-the cell-to its mnth. power of transformation, the whole story may appear a laughable vision !

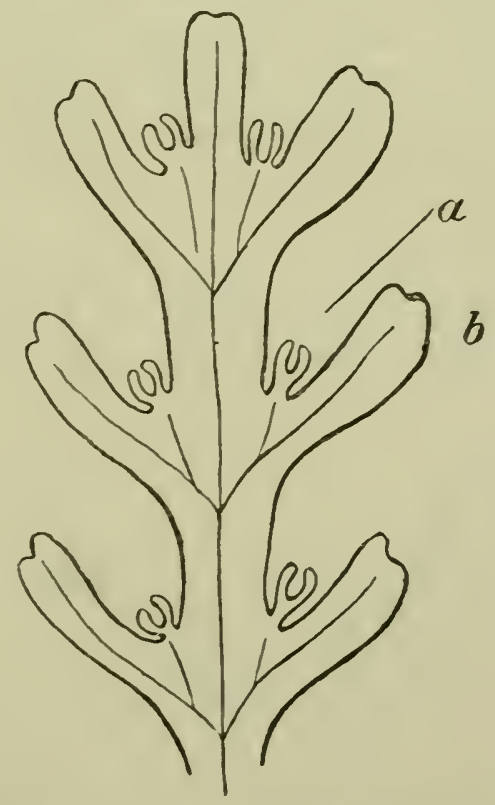

Eig. 133. Ideal seaweed-the rudiment of a fig tree (a seaweed not unlike this is given in Esper's "Icones fucorum," Tab. 3) : (a) conceptacle or rudimentary fig as an axillary bud, (b) cladophyl. 
Further, the fig receptacle, through Dorstenia, is admittedly only the rudimentary receptacle of the immense family of the Compositæ, and these through the Lobelias, Labiatæ, and others, come in contact with many other phænogams.

Let the reader endearour to dismiss from his mind the bias of the word phrnogam and of the terms reticulated leaf, and let him make allowance for difference of medium, and he may see in the accompanying diagram (Fig. 133) an ideal original seaweed out of which the genus Ficus could have sprung, riz., a winged and branched petiole (cladophyl) with bulged-out conceptacles in the axillæ-adumbrations of the future figs !

The reader would have a choice of either bisexual or unisexual conceptacles, as in the fig, for both types exist in cryptogams.

Thuret ("Etudes Phycol.") says of Fucus serratus, that antheridia and spores are nerer found either in the same conceptacle or on the same plant, so that separation of the sexes on different flowers and on different plants comes to us in phænogams from a long distance in time, and from the lowest plants. In unisexual conceptacles, howerer, there are barren hairs, which might well be atrophied sexual organs, because in Fucus platycarpus the two sexes are found in the same conceptacle, and, presumably, when one sex is suppressed, it leares behind it hairs as its atrophied representatives, the antheridia being nothing higher than compound sexual hairs.

There is among these lower organisms a form of conceptacle which is still more fig-like than that of the Fucus. I refor to the conceptacle of Corallina, shown in Fig. 134. It has also fig-like

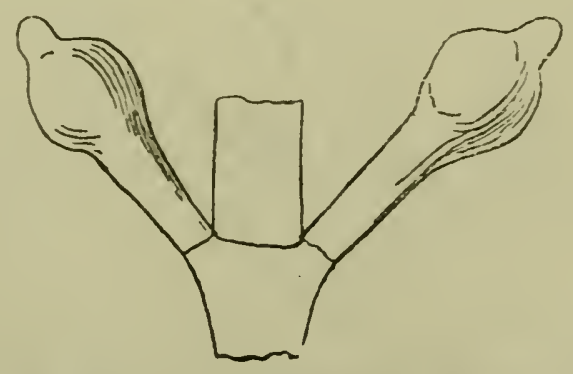

Fig. 134. Male conceptacles of Corallina Mediterranea, Aresch. (Thuret, pl. 49). 
female conceptacles. No one can glance at the enlarged section of this conceptacle as shown in Thuret's work, and not see in it a fig.

If it may be difficult to convince the reader that the oil-glands of the Citrus are atrophied remnants of seaweed conceptacles, it ought not to be so difficult to convince him that the fig is a modified conceptacle, such as that shown in Fig. 129 (a) of Myriodesma, especially if he take the trouble to examine and cogitate over the impressions left by the study of Thuret's "Etudes Phycologiques," Harrey's " Phycologia Brittanica," and "Ph. Australica," the works of Esper, Stackhouse, Berkeley, and others.

At all events, if he considers the Cycad a modified fern he ought not to find it difficult to see a fig in a conceptacle, and that there may be something in all I have said. 
"Science is the Gospel of to-day; the inspired volume not to be questioned by the profane, but dealt out with an air of infallibility to the awe-stricken multitude by its high priests." ...... "If those who speak for her had the courage and the modesty to confess more generally the limited extent of their knowledge, and the unlimited extent of their ignorance, we might have the good without the evil." . . . . "We do not know,"- "we have yet to learn."- "Scientific Ignorance," Saturday Review, 22nd August 1891. 


\section{XVI._SPURS.}

ARE the spurs or hollow cones we find on the petals of certain plants brought about by the agency of insects, or by natura selection?

There is reason to suppose that both insects and natural selection may influence the increase of a spur, but that it can be formed all of a sudden, independently of those agencies, does not, I think, admit of a doubt.

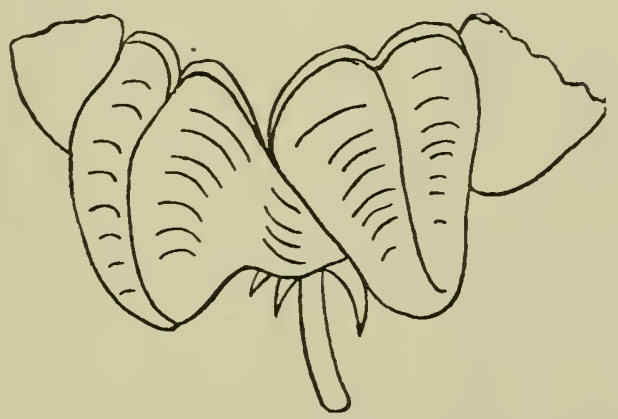

Fig, 135. Saccate petals of Blumenbachia coronata.

Blumenbachia coronata, Fig. 135, has saccate petals. One can easily conceive that these sacs once formed, especially if their interior secretes some liquid, might readily be increased by the probings of insects, and therefore also through natural selection.

The saccate petal of Calochortus pulchellus, once formed, might also, by the same agency, be easily lengthened into a long spur, like those of Aquilegia. What is difficult to account for, supposing that spurs do so commence, is a whole whorl becoming saccate or spurred at the same time.

Fig. 136 shows the saccate glume of Briza minor, which also might easily be conceived as forming the beginning of a spur. 


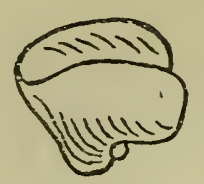

Fig. 136. Saccate glume of Briza minor, Syme's “ Brit. Bot.," p. 132.

On the 10th February 1891, however, Dr. Masters gave me some abnormal leaves of Yucca flaccida. All of them had two abnormal lobes on their margins, as shown in Fig. 137.
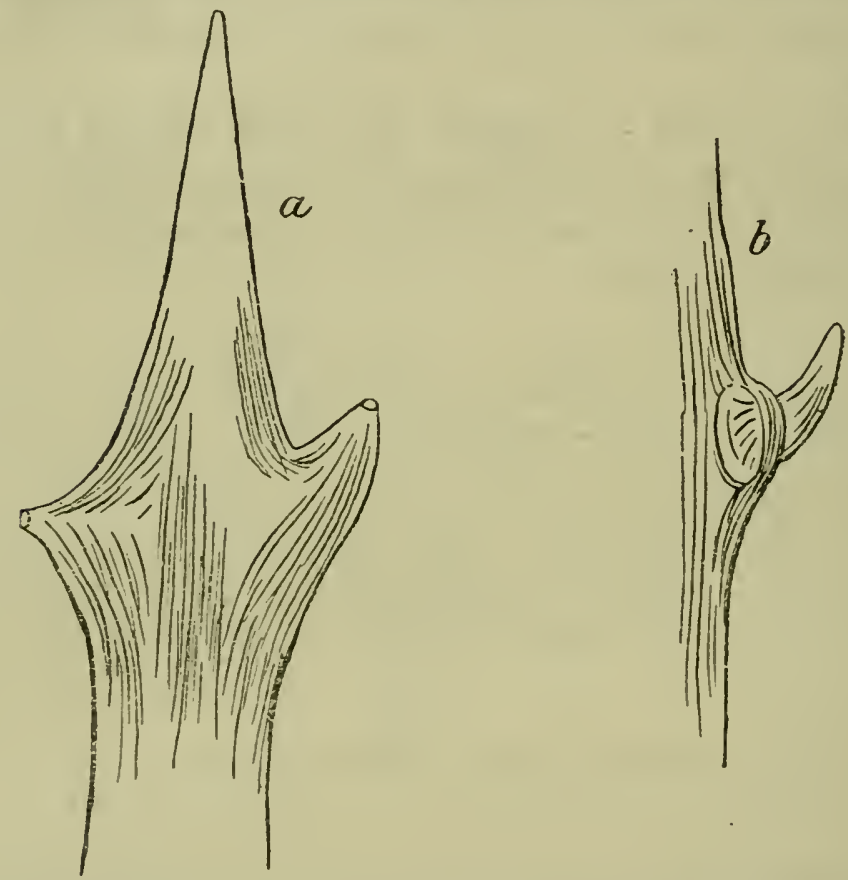

Fig. 137. Abnormal leaves of Yucca flaccida: (a) with lobes on margins, (b) with spurs.

(a) In some the lobe had turned into a hollow horn or spur as in (b). There was no indication of either the lobes or the spurs having been caused by insects. 'The ones and the others were, so to speak, spontaneous productions, probably repenting the teeth of other plants, such as the Agave.

In May 1891, among the interesting collection of plants owned by Wm. Hanbury at "La Mortola," on the Riviera, I saw a Sempervivum, with rather thin leaves, having a tendency to similar lobular projections on the margins of its leaves. 
Recently I examined the flower of a parrot-tulip. It had spurs on its petals, one of which is shown in Fig. $138(a)$.
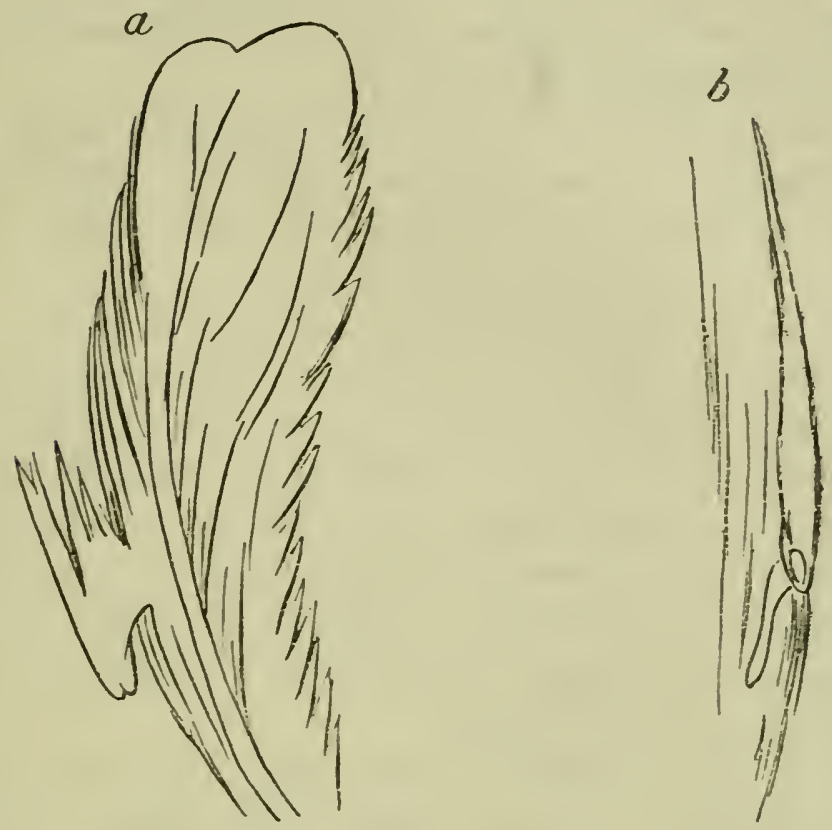

Fig. 138. Petal and leaf of Parrot-tulip: (a) with spur on body of petal, (b) with spur on margin of leaf.

In one petal the spur projected inwards, in another, outwards. Two of the petals had two spurs each, one projecting inwards and one outwards, the two remaining petals had no spurs. Some of the spurs were like pouches, others were very finely pointed.

This shows how easily a spur can be formed all of a suclden, without the accumulation of slow steps, and without the help, either of insects or natural selection.

Nerertheless, it is hardly conceivable that the spur of Angracum sesquipedale could have come of that length, without the help of insects.

It is very curious that the tendency to form spurs on the petals in the parrot-tulip is also to be found in its leares. Fig. 138 (b) shows a spur on the margin of one of the leares, about half an inch long, with a very narrow tube. It is evidently of the same nature as that shown in Yucca faccida, fig. $137(b)$. 
One would like to ask, how is it that spurs so often contain nectar ? One would have to ask another question also, viz., Are insects always in search of nectar, and nothing else? Is it not possible that in hot sunny days they are in search of water, whether sweetened with sugar or not?

In India, in the hot dry weather, I have seen flocks of little yellow butterflies on the edge of a pool of water apparently sucking in moisture. I have seen wasps on the outside of watercasks apparently doing the same thing.

Now, there is transpiration from all the soft parts of plants, which evaporates, and we never see it. Within the spurs it is possible for it to condense, and remain there in minute drops. Insects in search of water or nectar would soon find out these little buckets containing liquid. One can then understand that the frequent visits of insects, tickling the inside of a spontaneously formed spur, if it happened to condense the transpired vapour, might increase the supply, and with it, a tendency to cellular multiplication, and hypertrophy.

There does not appear, however, any reason to doubt that spurs do sometimes come out ready made, without any apparent previous inheritance.

In the Ranunculaceæ we can trace the successive steps from a pouch to a spur. For instance, in Aconitum Napellus, we have one sepal pouched; in $A$. Lycoctonum, that pouch becomes a pouched spur; and in Delphinizum peregrinum and Staphysagria, the latter becomes a conical and tubular spur. The two modified petals, which in $A$. Napellus were wholly nestling within the hood or pouch, in the Delphinium only a part of the petals becomes long spurred, and fits closely in the spur of the calyx.

Then in Helleborus fatidus all the petals become tubular; that is, the whole petal becomes a spur; while in Aquilegia all the petals are long spurred.*

At the meeting of the Royal Horticultural Society of the 9th June 1891 I saw a double Aquilegia. Some of the stamens of the central tassel had become petaloid, and were standing out separately from the other spurred petals. These petaloid stamens had anthers on the edges of their little spurs.

* See H. Baillon's “ Histoire des_Plantes.” 
Now the normal stamens of Aquilegia show no signs of spurs. 'The curious part of this reversion was that in becoming petaloid, the stamens did not revert to plain petals, but to small spurred petals. IVas the anther of the Aquilegia then a modification of a spurred petal or leaf, or of an ordinary shaped leaf ?

Again, in the Eclinburgh Botanic Garden, I saw the Aconitum Septentrionale. Normally, like other Aconitums, it has a sepalous hood, enclosing two spurred necturies on long stalks, which are modifications of petals. In addition, this Aconitum within the hood had two or three seta, which were evidently abortions of the remaining petals.

In some teratological forms, on this same plant, I found (a) that one of these sptae was transformed into a spurred nectary like the other two, but it was not located within the hoorl. This same specimen had a second sepal which was saccate with a commencing spur ; (b) had the normal two nectaries, but only one of them was inside the lood, and the remaining three seta were also somewhat spurred but much shorter, and the two side sepals were decidedly spurred; (c) had the upper sepal spurred, like that of Delphinium (not hooded). One of the lower and one of the side sepals were also prominently spurred. In addition, one petal was spurred and enclosed in the upper sepal; two other petals were also spurred, and were located outside the rpper sepal. A fourth petal was in the state of seta, with a tendency to become spurred; $(d)$ this specinen had two spurred petals (nectaries) within the hood, and no setce vhatever. 'The thres petals, which in some har been represented by seta, in this wre entirely suppressed.

Now in the Delphinium the normal form has a long spurred sepal, which encloses the spurry part only of two of the petals, two other petals are suall, and the fifth is entirely suppressed. The remaining four sepals are slightly saccate near their tips.

On the other hand, in the Aquilegia, all the segments of one whorl are normally spurred, and in some dlouble forms both whorls are spurred.

So that in these three allied genera, Aquilegia, Aconitum, and Delphinium, the variation of the flower consists only in variations of the spurring; with or without suppression of parts. 'There can

* The comparison of Delphinium and Aconitum is well shown in Asa Gray's “Struct. Bot.,” p. 188.

4 r. 1724 , 
be little doubt that spurs are readily inherited when once formed, more especially if insect agency keeps up that tendency. The teratological specimens referred to show that, in reverting to complete petals, the setre became spurred, which would indicate that they also were suppressed spurs, and that probably the Aconitum descended from some such form as that of the Aquilegia.

'To the evolutionist, however, the interesting part of spurs is that they can oceur all of a sudden, without being inherited. It stands to reason that if, from whatever canse, the cells of the margin multiply less rapidly than the cells of the middle part, the organ must become saccate, whether it be a leaf, a sepal, or a petal, and, if this tendency be inherited, it is conceivable enough that a saceate form may, by usefulness and further selection throngh insect agency, be turned into spurs of various lengths and forms. It is coneeivable that the spur of Angracum sesquipedale may have been lengthened by its bottom having been pushed further and further by probings of moths.

It may, perhaps, seem childish to speculate on matters which some might think the trivialities of plants. But who would have thought that the apparently childish fact that a bit of rubbed amber attracts minute objects would have eventually bloomed into the new science of electricity? In an evolutionary sense there is nothing trivial.

Dr. Charles Chapman, in his "Pre-organic Evolution," says : "Not a point of space, nor an atom of matter, nor a moment of time, nor the veriest shadow of a change exists, has existed, or will exist, but that erolution can be affirmed in connection with it." 
"Moreorer, as a number of isolated facts soon become uninteresting, the habit of comparison leads to generalization. On the other hand, as the traveller stays but a short time in each place, his descriptions must generally consist of mere sketches, instead of detailed observations. Hence arises, as I have found to my cost, a constant tendency to fill up the wide gaps of knowledge by inaccurate and superficial hypotheses."-Chas. Darwin, Nat.'s Vor. Rouxd the World (new edit., p. 537). 


\section{XVII.-GENESIS OF FIBRO-VASCULAR SYSTEM.}

We know that the lower plants, from which the ligher have evolved, have no such thing as a rascular system. How, then, has this come about? It surely has not evolred as a ready-made variation.

The character of vascular tissue is that it is made up of spiral cells.

Berkeley, in his "Introd. to Crypt. Bot.", p. 72, says: "The total absence of vascular tissue is one of the most general characteristics of Alga; but, as in Phænogams, the parenchymatous cells sometimes contain spiral threads, so also there are undloubted instances of spiral threads in Alga."

Here we have a statement of a great observer, which leads us to form some conception of how the rascular tissue may hare commenced and laid the foundation of what we call rascular plants.

Berkeley has shown that spiral threads or cells-the elements of the vascular tissue-can be found isolated, in an erratic state, in the cellular tissue both of alga and phrnogams.

Now bacteriologists have discovered spiral microbes, that is, cells or strings of cells which grow into a spiral. These can infiltrate themselves into the minutest tissue, or, at all events, their spores can do so. What wonder would it be, then, if the spiral ressels of plants owed their development to spiral microbes, which gained admission into purely cellular plants as parasites, and occupied their intercellular spaces, thus becoming part and parcel of the cladophyl tissues? It is conceivable that, in time, this parasite would develop sufficiently, so as to become an important item in the struggle for life of cellular plants.

. Of course such a hypothesis of the genesis of the rasculan system would demand that this microscopic parasite should not be harmful to the cellular plant. Quite so. There are numerous 
examples of microbes, which, far from being harmful to their foster-parents, are exceedingly useful, and help them in the struggle for existence. Indeed, parasites, even in our own bodies, perform a good bit of our physiological work, and probably we would die of starvation without them !

Such may have been the spiral microbe, which, once upon a time, may have become parasitic on what we now call the cellular plant, and entered into co-operative association with it. The development of this microbe we now call the vascular system of plants. The spirality of this microbe would lave given rise to a tube, through which the sap could better circulate than in the simple intercellular spaces, liable to be encroached upon and compressed by the growing and multiplying parenchymatous cells.

The parasite which rots timber finds no difficulty in ramifying itself between the cells of the solid wood.* Much less difficulty would this conjectural spiral microbe find in growing and ramifying itself through the sappy interspaces of the cells of plants.

Fantastic as this hypothesis of the genesis of the vascular system in cellular plants may at first sight appear, it is borrowerl from facts relating to microbes and the inycelia of fungi, the operations of which, at first sight, may also have appeared as fantastic.

After all, the whole of life seems nothing but the multiplication and development of microbes-some feeding on others and destroying them, some feeding on others and helping them to live and flourish.

It appears established that more kinds than one can live peacefully together, and help each other within the precincts of the same family, thus forming one structure out of two or more originally distinct and separate structures.

In such a case the order of evolution would be-first, a differentiation in monophyta, or one-celled bodies, with the result of a struggle, and a natural selection, even in living things so simple as these. This has, I think, been clearly proved by Dr. Dallinger in his experiments on monads.

* I believe this is now explained by the parasitic rootlets exuding a ferment, which dissolves and softens the wood through which they pass. 
Then we woukl have one monophyton becoming parasitic on another monophyton.* If both happened to find benefit from the association, their union, as a factor in further selection, would be secured, and henceforwarl they would have to settle among themselves what space and part of the composite body each should more beneficially occupy, and what the function of each would be in this compound and heterogeneous body. 'There' are many lomances in nature, and this, not impossibly, may be one of them !

'This hypothesis no doubt is based on slender evidence, but all hypotheses commence by being crucle, as every iclea must necessarily pass through its crucle stage, whether it be published in all its crudity, or whether it be kept " in petto," till it is matured.

We must conceive a transition from the cellular to the vascular stage of plant life, and on principles of erolution there appears to me only two hypotheses possible to accomnt for the transition of the one to the other. One is that alrearly given; the other is this :

Dr. Dallinger has shown that even among monads there is variation, and consequent natural selection. Indeed, this rariation appears to be a universal law of matter, whether animate or inanimate. But just now we have only to deal with living things, in their rery simplest forms.

This being so, it would follow that the same unicellular bodies, after aggregation into multicellular groups, would be liable to variation, and it is conceivable that some would so vary as to become spiral, and take their place in the builling up of the vascular system of the eolony. The supposition is that the cells wonld continue to vary after grouping into colonies, and that in time the alfferent variations would occupy the places most beneficial to the life of the colony as a whole. Naturally, those colonies whose individual cell-rariations could not understand each other, so to speak, would die awa in the course of competition with other colonies, for want of that exquisite

* When I say parasitic, I mean that the germ of one monad found entrance into another, and associaterl itself with it. 
co-operation which is needed for the health, vigour, and progress of each colony of composite cells.

In other words-the two possible hypotheses are-

(a.) Variation introrluced from without as a parasite; and

(b.) Variation occurring within, after nniform cells had been grouped into colonies.

But Berkeley says that in "Phænogams, parenchymatous cells sometimes contain spiral threars," and although in the generality of Algre they are not discoverable, yet "there are undoubted instances of spiral threads in Algæ."

Now this looks rery much as if these erratic spiral threads got into the parenchymatous cells of phænogams, and among the cells of Algr, as parasites, that is, they found their way into them from without. Add to this that bacteriologists recognize the existence in complex borlies of spiral microbes, as erratic parasites, introdnced from without, and the reader will see that it does not require great stretch of the imagination to conceive that the genesis of the vascular system in the evolution of plants may have been brought about by the introduction of spiral microbes into the colonies of wholly cellular plants. This is the more conceirable because Alga, the origins of all vascular plants, have no hardened epidermis, and their cells are often cmbedded in a gelatinous matrix, through which a parasite, especially of a screw form, could easily work its way. Indeed, we know that even spermatozoa are able to work their way through the gelatinous envelope of the orum in order to reach their distination.

When one hears lectures on microbes, one begins to ask himself the question - is there any living thing that is not either a unicrobe pure and simple, or in the pliysiology or pathology of which some microbe does not play a part? From what we hear and read, microbes would appeas" to have "a finger in every pie of life."

Many diseases are now said to be the growth of and the poisonous action of microbes.

Putrefaction and the production of ptomaines are said to be the work of microbes.

The production of indigo, the disappearance of sugar in beetroot juice, the production of alcohol and vinegar, of curds and cheese, the nitrogenous substances of leguminous plants, the digestion of cellulose in the stomach and intestines of herbivora, 
and who knows how many other things, are the work of microbes!

The great process of evolution, from the simplest to the most complex living thing, appears to be an incessint battle of microbes-some inimical, and destroying whole colonies of other microbes; and some friendly, co-operating and helping, as allies and associates, in this incessant battle of life.

In "Nature" of 6th August 1891 the following occurs, in comnexion with the struggle for existence between microbes and the component cells of an organism.

"These atmospheric conditions (electrical and other changes) need not be antagonistic to the potato, they may even in themselves be advantageous to it; but if they help the microbe more than the plant, the microbe will gain the vietory, and the plant be destroyed."

I have not myelf seen any erratic spiral microbes in either algae or phænogums, but Berkeley, Klein, and others have seen them, and, therefore, taking their statements as true, I rlo not see that the idea is preposterous-that the genesis of vascularity in cryptogams may have been clue to the introrluction of a spilal parasitic microbe in the interspaces of the parenchymatous cells of algae, and that in course of time it became an associate of them and a helper in the battle of life, rleveloping itself as alga emergerl into the air into what we now call the vascular system of phrenogams, with all its modifications.

All this of conrse is a speculation, foumded on what are supposed to be microbic facts. 
"There are those who are echoes, and there are those who are roices 'There are some writers who represent faithfully, and express strongly, the dominant tendencies, opinions, habits, characteristics of their age. ..... There are others who either start new ways of thinking, for which the public around them are still unprepared, or who throw themselves in opposition to the dominant tendencies of their times. . . . . . It is not surprising that the first class are by far the most popular."-_ Carlyle's Message to his Agc," by IV. E. H. Lecky, Contemporary Review, Oct. 1891. 


\section{XVIII.THE DISK, THE CITRUS, THE RUTA, AND 'THE PAENIA MOU'TAN.}

\section{The Disk.}

WHAT is the morphological position of what we call in general terms the disk?

Asa Gray defines the disk as a "part of the receptacle, or" a development of it, enlarged under or around the pistil." 'Then, according to its exact position, various names are given to it. "Not rarely," he sars, "it divides into lobes, as in Vitis, in Periwinkle, and most Apocynaceous plants, and in Cruciferæ. These are termed glands of the disli, and, indeed, are commonly glandular or nectariferous. It is not possible by any direct demonstration to distinguish between such productions of the receptacle, which are classed as belonging to the axis, and suppressed or undeveloped phyllous organs, such as stamens, which glands of the disk may sometimes represent."

This is true, and the reason of it is not far to seek, for there is no inorphological difference between the axis and its sub-divisions, commencing from the bud-scales and ending in the carpels and ovules.

Considering that the flower is a shortened branch, the receptacle becomes no other than the central part of that braneh, or what corresponds to the stem; and every part around it, including the disk, must be of a phyllous nature, that is, a subdivision of the stem, taking this as the main midrib of the whole plant.

The whole flower is a cladophyl or branch, and all its parts correspond to lobes or teeth of that cladophyl.

* This term is unfortunately also used for the central florets of a compusite flower. 
The lobes of the Vitis disk heing alternate with the stamens, it is quite clear that they are suppresscd stamens. In the rhododendron I have counted ten projections on the disk, and it became quite clear to me that, corresponding with the ten stamens, they also were suppressed male organs.

Yet Prof. Henslow ("Floral Structure"), p. 4, says, in writing of disks, honey glands, \&c., "but as these, when they oecur on the floral receptacle, are merely cellular protuberances, and form no part of the floral whorls proper-not being foliar in their origin - they may be omitted, especially as their position is by no means constantly the same in all flowers." In a note he somewhat morlifies the foregoing statement thus: "I do not here allude to certain glandular structures, which may be the homologues of arrested organs."

The disk in my opinion is to stamens, and other floral divisionns, what the stipule is to a leaflet, riz., an abortion of a part which in allied flowers was dereloped. The disk is simply a return to the ceillular nipple (or amalgamation of nipples) from which all foliar organs originated.

It is no wonder, therefore, that the disk is cellular in structure, as Prof. Henslow describes it.

When a number of nipples fuse round an axis, they naturally take the form of a disk. Similar fusicns may, howerer, occur in the abortive teeth of a leaflet, but then, not being disposed round an axis, we do not call them disks, but glands. I refer to the fusion of teeth-glands on the petiole of the cherry leaf (Fig. 85). In both cases the nipples are abortions of reproductive organs. The disk is an abortion of stamens, and the petiole-gland is an abortion of a leaflet, the only parts that remain being the teeth-glands, amalgamater into a petiole-gland.

Any whorl of a flower can become a disk which possesses great elasticity, that is, it can contract into a whorl of nipples or teeth, and under other circumstances, it can expand into a cup, or split up into foliaceous organs.

For instance, in Narcissus deficiens, * we have the crown reluced to teeth (sxpe dentibus sex minutis coronæ loco). Then 
in Hermione* the crown is searecly recognizable, and is like that of the cowslip, and "Forget-me-not" (coronâ obsoletâ luteâ).

In the throat of the Hippeastrum again there is a fringe which probably serves to shut ont small insects from the nectar, which is secreted further down. This is evidently the homologue of the throat teeth of $N$. deficiens, which in $N$. Poeticus have fused and become a shallow fringed cup. In the Jonquil this cup' has a level margin, but in other Narcissi and in the Daffoclil it has become a prominent part of the flower, with its margin dividrel into six lobes. Then in many of the double forms of Daffodil this same crown or cup is split up again into petals. This crown appears to be nothing but a disk, situated outside the stamens; while in the Ruta and Orauge, the disk is situated inside the stamens. In Rhus Cotimus (Sumach) the stamens are inserted on the disk. 'They are similarly inserted in Sanginsorba officinalis.

The petaloid scales which emerge from the lisk of Brexic spinosa are of the same nature as the throat-fringes of Hippeastrum, and so are the so-called nectaries of Parnassia palustris, which are glandular fringes emerging from a disk at the base of the petals.

In the Citrus and Rute the disk has a wary margin, as shown in Figs. 139 and 150, each crenation possibly representing a suppressed stamen or group of stamens. If in these two the orary were engulfed so as to become inferior, the disk would remain as a cup, similar to the crown of the Narcissus, but inside the stamens.

In the Paonic Moutan this same cup is within the stamens proper, and envelops the whole orary, excepting the stigmatic surfaces of the carpels. It often has teeth on its margin, and on one occasion I found an anther on one of the teeth, which would clearly indicate its origin. It is a fasciation of stamen filaments, and its beautiful purple colour matches that of the filaments proper exactly.

If we take the development of the stamens proper of the Citrus according to J. B. Payer, we find that at first only five nipples appear, alternating with the petals; then on each side of these original stamens (not as an inner whorl) another nipple apprars as if it were the tooth or lobe of a leaf, making fiftecn stancirs, with the original five now more developed.

On the sides of these again other nipples appear, so ats to make twenty-five, each group forming a fire-toothal leuf, each tooth 
terminating in an anther bud, not unlike the glandular terminations of the nectaries of Parnassia. Further on, the filaments of the stamens of Citrus become nore or less connate and grouped as we see them in the mature flower, the form of the stamenwhorl being a broken cup, which, if it were dwarfed and the anthers suppressed, would form a second disk outside the disk proper, as it was while the young anthers were in the stage of nipples.

\section{The Citrus, the Ruta, and the Peonia Moutan.}

What is the morphological position of the orange-peel?

As far as I am able to see there are three possible hypotheses of the origin of the peel :-

(A.) That it is the outer lamina of the enclosed carpels, just as one might say the upper and lower surface of a leaf, the lower or dorsal surface corresponding to the outer surface of the peel, while the pulp surface corresponds to the upper or nentral surface of the leaf. This riew I find is accepted by several botanists. Let us, how-
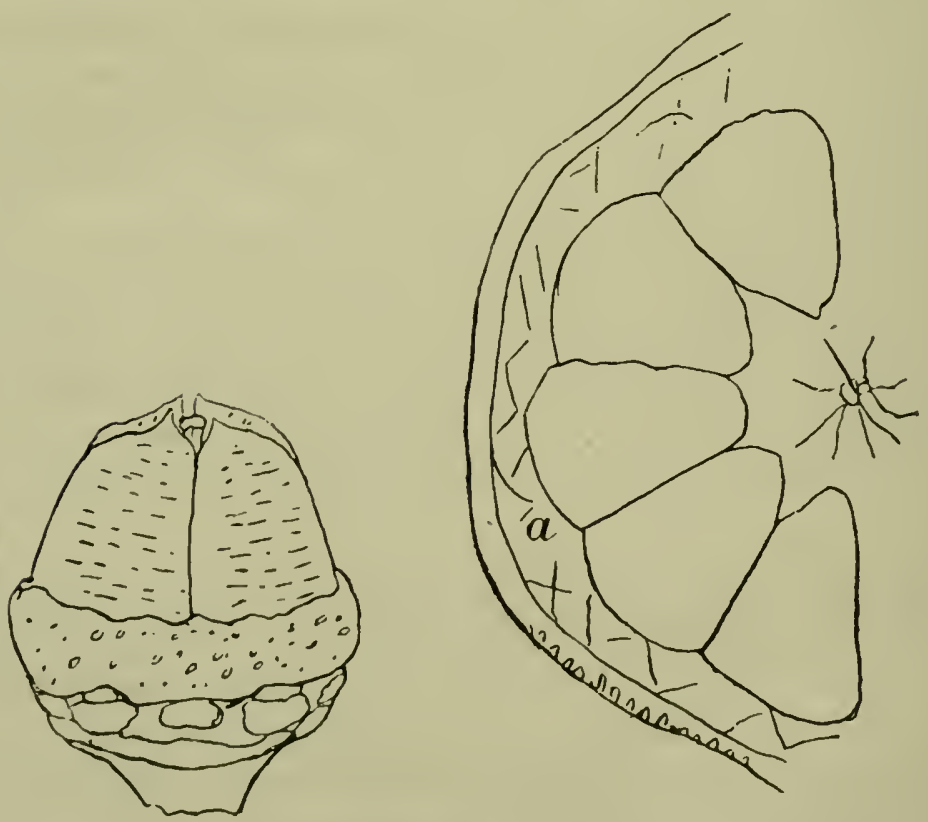

Fig. 139. Ovary and disk of Ruta Fig. 140. Portion of "Laroo" orange, graveolens (Payer's “'Traité d'orgauogénie de la Fleur,", pl. 15).

showing considerable spaee ( $(t)$ between the peel and the pulp ("Or. and Lem, of India, \&c.," pl. 126), 
ever, examine what objections can be brought forward to this view of the peel.

(a.) If the peel were the outer surface of the carpels, it seems reasonable to suppose that the margins of the onter surface would curl inwards with the inner surface to form the closed pods of the pulp ball. This they do not do, while in the Ruta grareolens (Fig. 139), in which the carpels are fiee at all ages, the outer surface curls inwards simultaneonsly with the inner surface, so as to form the closed pod. Payer says: "The carpels are free at all ages, while the styles, first free, are afterwaris soldered together."

(li.) Althongh, in the Portngal orange, the lemon, the citron, the Pumelo, and others, the peel is so closely adherent to the pulp as to require a knife to separate it, thus supporting view $(a)$, in the 'Tangerine orange the peel is very loosely atherent to the pulp, and in the Larno and Suntaru oranges of India there is actually a space of a third of an inch between the peel and the pulp carpels, so that the pulp ball can be rattled within the peel (Fig. 140).

(c.) In a teratological specimen which Dr. Masters exhibited at the scientific meeting of the Royal Horticultural Society, the orange presented the following characters :The peel, as nsual, enclosed a ball of pulp-carpels; but within these, again, there was a second whorl of carpels, without peel, and closely allherent to the outer whorl of carpels. Curionsly enough, in the centre of the inner whorl there were two longitudinal strips of peel of an orange colour. What is more curious is that the glandular surfaces of these two strips were turned inwards, that is, towards the centre, and not outwards, like those of the onter enveloping peel.

Now, supposing that the peel be the outer surface of the pulp carpels, where is the peel of the inner whorl of carpels in this specimen? They had none! While in the centre of the whole there were two strips of peel, as if they did not belong to any carpels, and were attached to the incurved margins of the inner whorl, with the glandular surface twisted tovards the centre, as if they were independent phyllous members. I do not see how this 
teratological specimen can in the least support hypothesis (A). The diagrams shown in Figs. 141 and 142 will perhaps better explain the composition of the specimen given me by Dr. Masters.

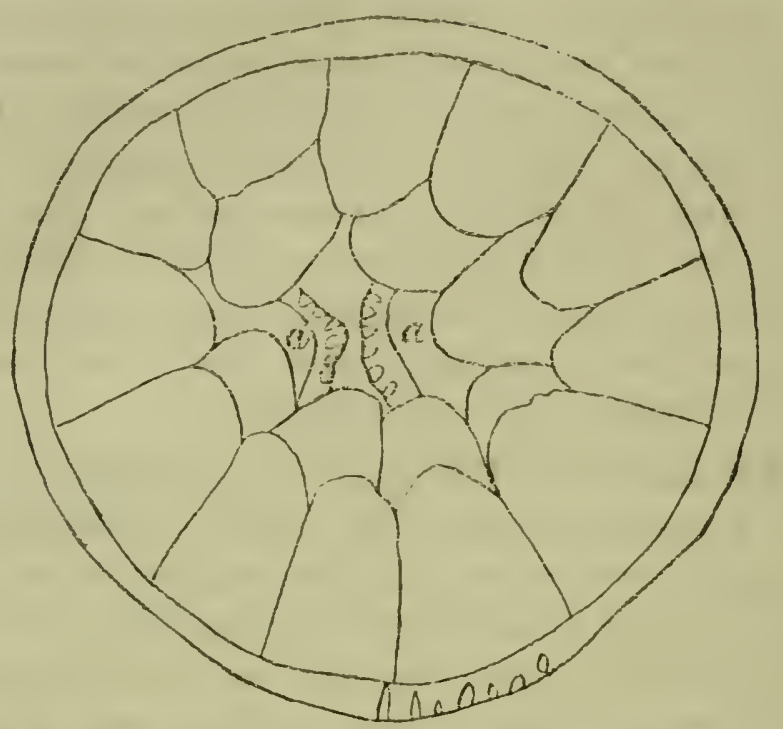

Fig. 141. Cross section showing isolated peel strips at a a.

We have a somewhat similar arrangement, though more complicated, in the fruit of the Bergamottier à fleur double, shown in Risso's 'Tab. 56. This is what Risso says of it: "Mais le centre lui-même etait particulièrement occupé par une longue bandle

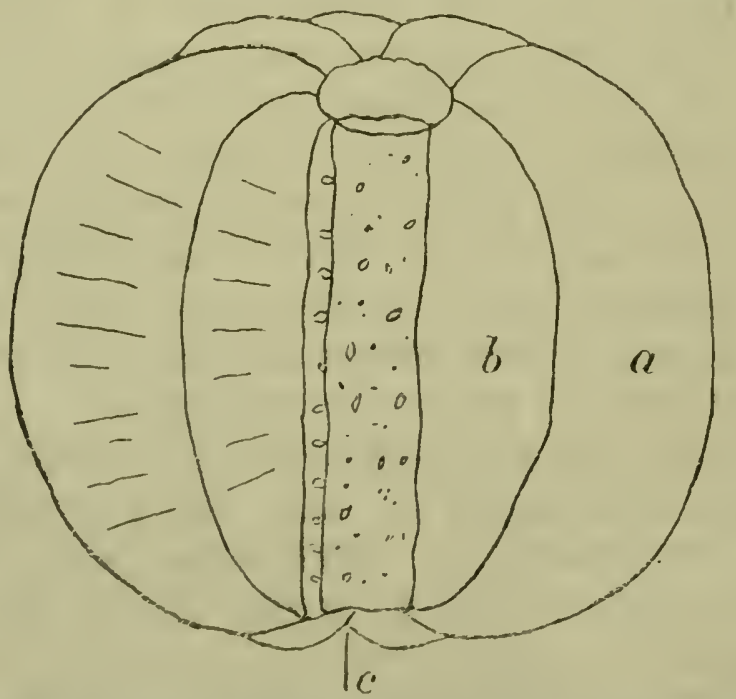

Fig. 142. Half the olange showing one of the isolated strips of pee :

$(a)$, outer whorl of carpels, (b) inner whorl, $(c)$ central strip of peel. 
tortuense, janne, formée par la reneontré de demx écorces opposées, et qui semblait avoir été destinées ì circon-crire nne cavité, mais qu'une cause quelconque arait détruite par la pression." In this case the ojl-glands of the central pe+s ane shown in the sime direction as those of the outro peel, whereas in that of Dr. Masters the two strips of central peel wele twisted, and the oil-glanck were in the opposite direction to that of the outer peel.

In both cases, however, the central pert has no corresponding pulp-carpels, so that if we accept hypothesis (A), these inner prets woukl be the outer sides of enrpels left -tranded by the desertion and suppression of their inner siles:

Both these specincens clearly indicate to ne that the peel, like the pulp, is mate np of rlistinct plyyllous organs.

Dr. Matsters gare me another specimen, which is of common occurrence, viz, an orange complete within an orange. This, I consider, is a completo dombling of the fruit, much as we see the doubling of a dafforlil, viz, the sepals and petals repeaterl. In this orange the peel and carpels were repeated alternately with their own colours, just as the sepals and petals of certain dafforlils, in doubling, are repeated with their oun colours.

(d.) In the teratological specinen (fingered citron) shown in pl. 139 of "Cultivated Or'unges and Lemons of India and Cerlon," and in Figs. 143 and 14t of these Notes, there were two whorls of what seem to be a

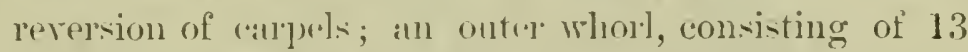
distinct fingers, anul an inmer whorl, consisting of seren distinct fingers, shown in Fig. a of that plite. Both these whorls han thr chatacter of perl, and were not opposerl to atch other, as if they were the inner and onter lamina of on" carpel, as shown in section, Fig. 14 . Doreorer, there was nothing in this fingered reftron which conlet be taken for julle.

(e.) I hare seen many specimens of ritrons which hat the surface divilecl into rohering serments, as if they descenclerl foum distinct phyllons momber's, such as are shown in pls. $145,147,150$, and many others, of "Oranges and Tamoms of Thulia." Woll, the pulp

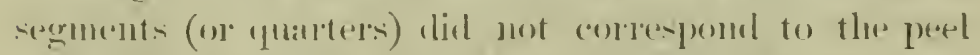
segments, hut were like the segments of Fig. 144, as if the two were independent whorls. It might be said A p. 1724. 


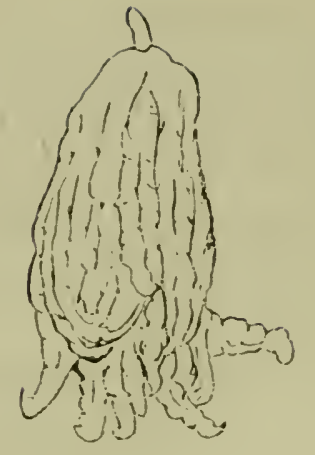

Fig. 143. Fingrered Citron much reduced ("Or. and Lem, of India," 11. 139, Fir. a).

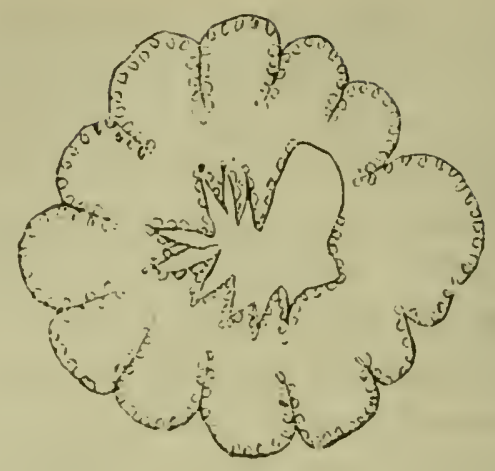

Fig. 144. Section of Fingerer Citron, almost natmral size ("Or. and Tem. of India," pl. 139, Fig. $c$ ).

1hat the parts of a finit ane subject to displacement. Exactly; but if the nuter surface of a carpel is subject to displacement with regard to its imner surface, it can hardly be maintained that the two surfaces belong to one carpel. Hypothesis (A) would tlien be no longer tenable.

It might, however, be said that the peel is, in many raricties of Citrus, so closely adherent to the pulpcarpels that they cannot be considered as two distinct things. 'This argument, it will be secn, is two-erlged. In the Citrus the pulp-carpels are easily scparable one from the other, and so anybody can see that they are all distinct parts; but in the Egle marmelos they are as closely bound together by intervening parenchyma as the pulp-carpels of many Citrus are bound to their peel. Therefore, this same argument might be used to show that the pulp-carpels of the Egle marmelos are not distinct things !

(f.) Then we have the pvidence produced by two Citrus ovaries fusing into one fruit, such as those shown in pls. 223 and 224 of "Or. and Lem. of Indlia." If the peel be a part of the pulp-carpels, and not a separate envelope, why does it in such cases hehave exactly like the fused corollas of the hyacinth when they enclose two ovaries? By the fusion of the two corallas a common envelope is made for the two ovaries. The 
peel of these fused lemons does exactly the sime thing. Therefore, it is reasonable to consider it honnologons with the corollat, that is, of a plyyllous nature.

Now the facts I had before me in Indlia suggested a different hypothesis regarding the nature of the ('itrus peer. This is it, viz. :-

(в.) That the peel is a whorl of abortive carpels, or plyylous menbers, iudependent of the pulp, which forms :n inner whorl of fertile carpels, the peel sergurents, cohering tirst at their base, like a ganmosepalous (ally, and then curving inwards, like the fingers of a rlosed fist, as shown in Fig. 145. These then cohlere thronghont, so as to form a continuons envelope; finally, through human selection, the smooth orange peel wi see in the fruits of the shops was obtained.

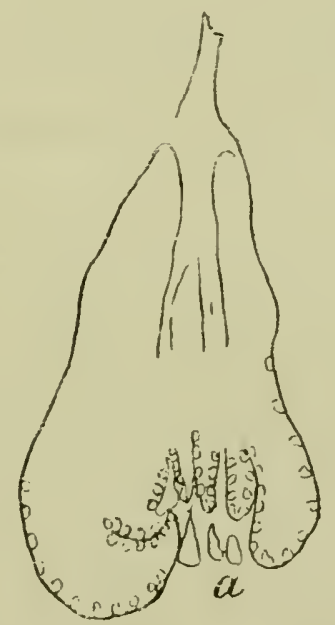

Fig. 145. Section of Fingered (itron elosing at ( $(1)$, but not cohering ("Or. and Lem. of India," pl. 140, Fig̣. $e$ ).

This hypothesis would be supported by the fingered citron alrearly alluded to (Fig. 143) ; by the great space between the peel and the pulp ball of the mature fruit of the Laroo and Suntara oranges; by the want of oppositeness between the segments of the pulp and peel of many eitrons, and of the two whorls of the fingered citron; by the complete absence of pulp, in Fig. 143, and in Risso's fingered lemon.* This absence of pulp would point 
rather to a suppressed whorl than to the suppressed imer surfaces of the carpels.

But Dr. Master's teratological orange would appear to support lyypothesis (в) still more strongly. The inner pulp-carpels had no peel at all, and the centre was occupied by two independent strips of peel with their glandular surfaces reversed, as if they had been twisted abortive carpels.

'There is, however, seemingly an ohjection to this hypothesis. M. Ph. Van Tieghem, in delineating the structure of the Citrus pistil, does not show any separate rascular bundles for the peel. He ignores it, and so does he the disk, as firr as vascular bundles are concerned. This would appear to militate against my hypothesis (B) of the peel being a separate whorl.

All Van Tieghem shows is that below each pulp-carpel there is a vascular bundle, which splits into three strands, one becoming. dorsal and two marginal, which feed the ornles. Then side branches from these three bundles are giren off, which, inosculating, feed not only this carpel but its enreloping parenchyma.

"To recapitulate," he says at p. 55, "all the forms of pistil we have examined up to the present, and which belong to a very large number of natural families, offer us the most complete identity of structure, if we leare out the parenchyma and some accessory modifications in the vascular system. Whether there be one carpel $(\log e)$, as in the Legmminosa; three, as in the Liliacex, . . . . or ten in the Citrus, " the rascular system always maintains the same essential disposition; always the axis is axtinguisher in producing a variable number of appendicular independent systems, the marginal bundles of whieh nomish the orules."

"The differences in form which the pistit presents depend only on the different and quite original mamer in which the parenclyyma linds togetlere the visenlar systems of the appentages, $\dagger$ now forming round each a distinct slieath, now

* Why Y.T. fixes on ten carpels, as the normal number in the Citrus, is not clears.

$\dot{T} \mathrm{~V}$. 'T. seems to use the word appendages for phyllons suld-disisions of the flower (the earpels); while $\lambda$ sal (ilaty alpears to see the term for those parts which he does not cuu-ider of a phyllons nature. 
enveloping all in a common sheath, in the lomogeneity of which valious degrees nury be distinguished."

From this it would appear that Van 'Tieghem consirlers the pulp-carpels as the carpels, and that the parenchyma, whether it envelops the whole carpel ball as in the Citrus, or each earpel separately, as in the Egle marmelos, as a something extraneous to the carpels. 'Therefore, it would follow, as a logical conclusion, that the covering of the parenchyna-the peel-must go with it, and camnot, in Van 'Tieghen's view, be considered as the outer surface of the pulp-carpels.

Indeed, it wonld require only a little consideration to see that the dorsal rascular bundle corresponds to the midrib of the pulp) earpel, and to the dorsal bundle of the pea-pod. If we took the whorl carpels, which form the funit of the Aconite, and surromeled it hy a cellular jelly, we would have what Vau Tieghem would lead us to muderstand he means by the fruit of a Citrus, the jelly corresponding to the parencliyma and exterual peel.

From all this rather wearisome risenssion it would appear that although, primâ facie, Van Tieghem's study of the vascular bundles of the Citrus pistil militates against my hypothesis, on closer consideration it appear's to support the idlea that the pulpcarpels form a whorl, independent of the enveloping peel.

I would here remind the reader that my hypothesis is that the peel is an atrophied whorl of carpels, which does not attract towards its vascular ramifications, such as carpels with marginal fertilized orules would do. It is possible, moreorer, that too much stress may be laid on the supposerl significance of fibro-vascular bundles, to identify an important from an unimportant organ. If we throw our mind back to the genesis of things, we shall find that Harrey dercribes seaweeds, which are futhoms long, with branches and sub-branches, and yot thre is not a trace of fibrovascular bundles in their whole composition! All the biologracal work is done by cell-to-cell imbibition, or by interecellular circulation. It is only when we come to land plants, where resistance, support, and circulating apparatus to pump up liquids linom thes soil to arery pant of a tree, some lumeleress of fret high, that a complicated fibro-vasonlar system hecomes necessury. But in atrophied parts it is obvious there is no necel of rascularity. 'They are wholly cellulat. 
It would be interesting if some morphologist in India were to investigate the distribution of the vascular bundles of the fingered citrons in the young state of the fruit; some new light might be thrown on this question. I had not the opportunity of studying them microscopically.*

In enrleavouring recently to work out the grenesis of the orangepeel another interpretation lias suggested itself, viz. :-

(r.) 'That it is a continuation of the bark, moditied as orangepeel.

I shall try to explain this view by menns of diagrams.

In the ordinary linanch the bark gives off leares, and goes beyond each leat or whorl of leaves. In linct, the leaves themselves may he considered as thin double liyers of bark, stiffened amd smported by the fihro-rascular network, which inserts itself bet ueen the two hark layers. These bark folds are for the purpose of multiplying the surface, and the stiffening is for the purpose of better illumination and aëration.

O. Penzig (Studj singli Agrumi, p. 52) tells us that the oil-colls of the upper surface are distiuct from those of the lower surfuce. showing that the leaf consists of two layers of bark. In fact, the leaf-nipple, in growing, pushes the bark hefore it, and ends ly becoming enclosed in it, above and helow, while the fibro-rascular system of the leaf is developerl between the two layers.

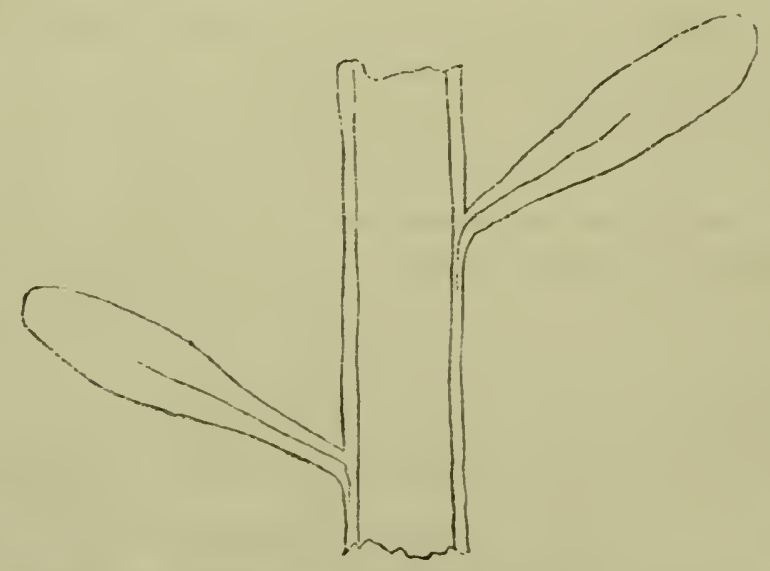

Fig. 146. Diagram showing the hark over the leaf.

* Mr. Hanbury errows the fingered citron at "La Mortola," on the Riviera. Perhaps somebody may he indueed to investigate this matter there. 
The bark, in going beyond each leaf or whorl of leares, envelops the whole stem, as shown in diagran, Fig. 146.

In the apple, pear, hanana, prickly pear, melon, and hundreds of others, in which the ovary is inferior, the fruit envalope is the lark, and in the banama and prickly peal it can be peeled off as readily as one can peel the bark off any green sten. The leares in the case of an inferior ovary, or what correspond to leavessepals, petals, stamens-are given off from the ridge surrounding the apex of the fruit, as shown in cliagran, Fig. 147.

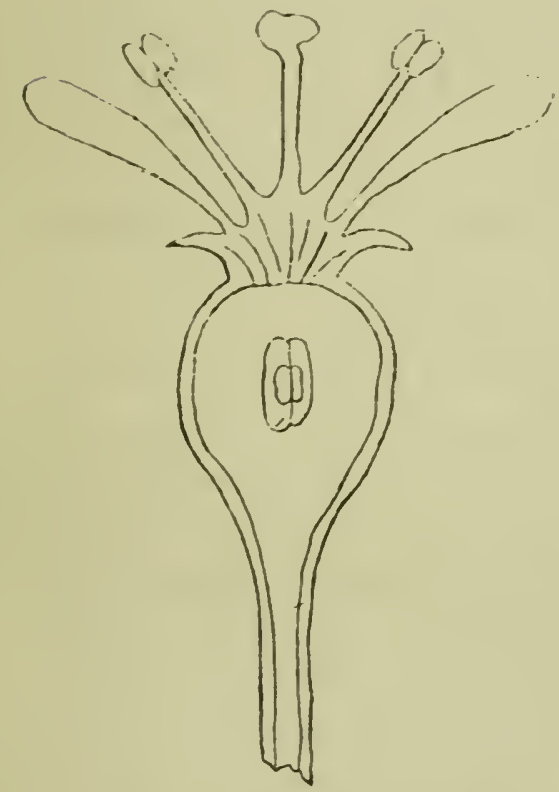

Fig. 147. Diagram showing the P'ear enveloperl in bark below the flomal leaves.

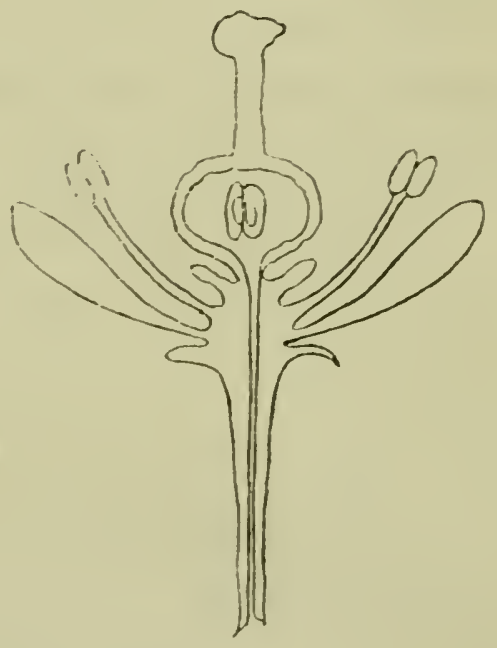

Fig. 148. Diagram showing the olange ovary fillshed beyond the floral leaves and covered with lark.

Now, in the olange it is possible that the peed is also a rontinuation of the bark, with this difference, viz, that the ovary, unlike that of the pe:ur, is pushed up beynud the floral louves, the bark following it, as it wonld follow the stem heyond ordinary leaves, the lisk proper lewing only a fold of the lark moler the ovary, representing a slppresed plyllous whorl. as shown in diagran, Figr. 148. 
In the apple, pear, and others, the bark ends in the floral leares. In the orange the bark goes beyond them, and ends by surrounding the ovary, so that it becomes superior.

This hypothesis would accomt both for the closeness of the peel in certain Citrus, and for its looseness in others, but seemingly would not account for the dissociation of the segments in the fingered citron. But upon further consideration we find that the ordinary leaves, although expansions of the bark, are dissociated from the stem-bark, and, therefore, the fingers of this teratological Citrus may be considered as isolated portions of the bark, such ats leaves might be.

It will be readily seen that this hypothesis (c) brings us round to hypothesis (B), riz., that the orange-peel is a whorl of a phyllous nature, and distinet from the enclosed pulp-carpels!

The solution of this puzzling question seems, then, to rest on another question, viz., whether the bark on the sten receives special fibro-vascular bundles for its nourishment, or is sustained by side branches of the main ressels of the stem.

According to Sichs' "Phys of Plants," Figs. 129 and 165, the bark does not receive special rascular bundles. It is cellular in structure, and is in communication with the pith, throngh the medullary rays. It is only penetrated by the valscular bundles, which go into each leaf. This is the reason, I imagine, why Van 'Tieghem, in his transverse sections, shows only the bundles which go to nourish the pulp-carpels. The peel has no spocial bundles deroted to it. It is nourished by imbibition from the sidc branches of the carpel vessels. It and the parenchyma within it correspond to the bark of the stem.

Indeed, if we examine elosely the atecompanying Fig. 149, from Payer's "Traité d'organogénie," we shall sce that the pulpocarpels (b) are distinct from the surrounding cellular tissue $(d)$, which afterwatrds closes over them and is continued in the style of the pistil. The base $(c)$ of this carpellary cup in the mature flower hecomes the disk proper (c), shown in Fig. 150, while an inner disk-whorl becomes connate with the carpels (b), and grows with them als a covering bark (the orange peel). We see how readily this disk tends to sub-divide itself into projections, both in the Citrus and the Rute, so that the sogments of the fingered citron are not very diflicult to (xpllain. 


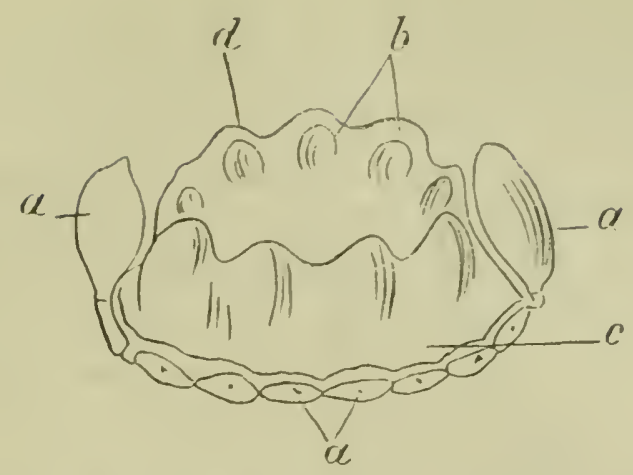

Fig. 149. Citrus carpels in young stage (Payer, pl. 25): (a) stamens, (b) carpels, $(c)$ outer margin of disk, which in the ripe flower becomes the disk proper, $(d)$ peel bark, which the carpels are carrying with them.

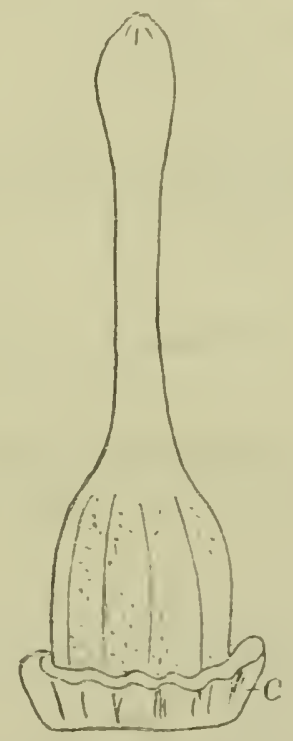

Fig. 150. Pistil of Citrus with the disk proper (c) (Payer, pl. 25).

Supposing now that these figures were developed into active leatres, they would receive fibro-rascular bundles as other leaves do, hut as they continue to function simply as bark, they can dispense with them and remain wholly cellular.

We spe sinilar phenomen in the atrophy of other parts, such as the toothlets on the tooth of a Primula leaf, Fig. 151. If this tooth were to become further atrophied, the subordinate teeth would wholly disappear, and the whole main tooth would be 


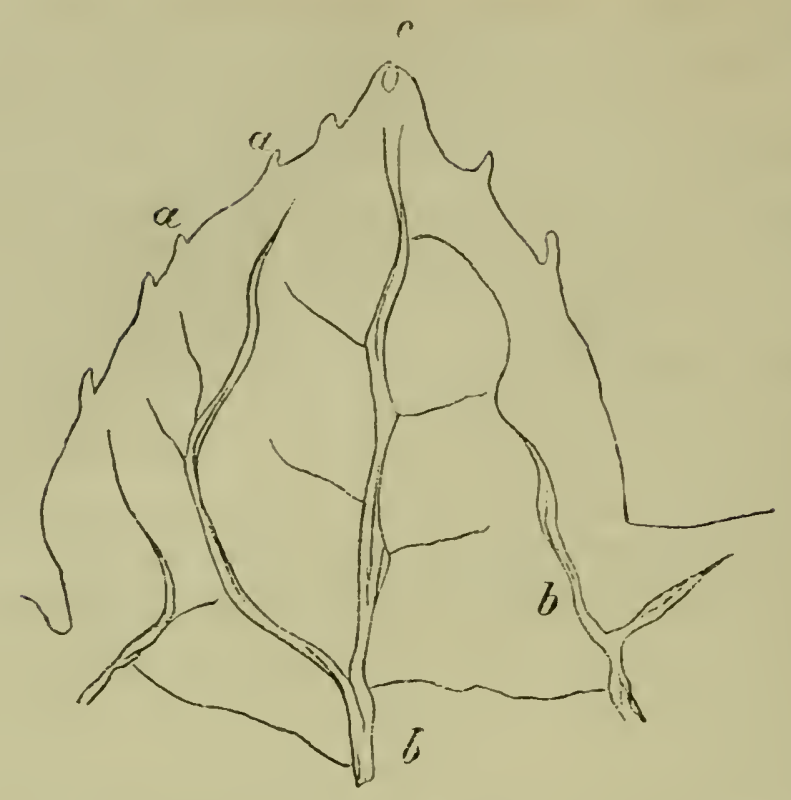

Fig. 151. Tooth of leaf of Primula smensis, with subordinate atrophied teeth $(a, a),(b, b)$ rascular bundles, $(c)$ water-pore (De Bary, "Comp. Anatom").

reduced to the size and functionless condition of $(a, a)$, without ressels.

It goes without saying that fibro-vascular bundles are subject to depauperation, atrophy, and total suppression, like every other structure.

You might say, but even when a leaf, in which they are highly developed, depauperates to a bract, some evirlence of their formel existence will remain. That is so, if depanperation and atrophy have not procecterl far enough. It would be absurd to fancy that, when a bract has been further depauperated into a stipel, or a hair, as in the case of the hair-like bracts, ol" "spatellas," which separate the individual flowers of Trecissus polyanthus, any trace of the original fibro-rascular bundles still remains. The bract, now reduced to a liair, is nothing lout the simplest of cellular structures, not differing in the least from any cellular structure we find in seaweeds.

Therefore, the alsenee of special fibro-vascular bundles in the orange peel, which botanists might put forward as a reason for not consirlering it of a phyllous nature, may only mean that the 
segments, of which the peal is nudoubtedly made up, nerer. reached the stage of leaves; or else that, having done so, they returnerl to the depauperated state, similar to that of simply cellular structures.

The absence of any trace of special fibro-vascular tissue in the peel, it is evident to me, cannot he accepted as an argument that the segments of the peel, as seen in the digitate form, are not of an independent phyllous nature.

Bracts and sepals, leatlets and whole leaves are often so depauperated as to loose all trace of fibro-rascular tissue, yet they are of a phyllows nature, which in reality means that they are sub-divisions of a stem, or of a cladophyl.

It is quite sufficient to look over the drawings of the Rutaces, given in Baillon's "Hist. des Plantes," to feel convincerl that the olange peel is not the outside of the pulp-carpels, as some botanists luelieve.

In the Rutacese, to which the Citrus belongs, I think we find ummistakable evidenee that the carpels proper are gradually encroached upon by the atrophied stamens fused into what we call the risk.

Ruta graveolens, as will be seen in Fig. 139, has a low "peel," encircling the base only of the carpels.

Erythrochiton braziliense has a still higher "peel," which rises above the ovary in the shape of a fire-lobed tube. 'This is what Prof. H. Baillon says of it: "The stamens appear as if they were inserted high up on the corrola, because their filaments, while doubling the tube of the corolla, only free themselves at it: grorge..... The high conical disk hicles all the lower' portion of the orary ..... Sterility of a certain number of stamens is the rulet in the majority of the species of this grenus."

Spiranthera odoratissima has its "peel" divided into segments, each segment covering a carpel half way up, with allhesion on the margins of the segments, so that it forms a fluted cup, like the young peel of the Citrus, Fig. 149.

* I eall its disk peel, so as to make the homolngy more apparent.

$f$ The reader should unte this, becanse I maintain that the orange peel is marle up of enlarged sterile stamens, fused together like the sheath of l. montan. 
Galipea macrophylla has a "peel" which corers more than hirlf the ovary, and is as closely applied to it as the peel of a Valencia orange. It has, moreorer, a staminal tube sumomuted by two fertile and five sterile stamens, the latter looking nucommonly like the sterile stamens or (ligits of the monstrosity we call digitate Citrus (vide Fig. 159), though of course the latter are very much larger.

Ticorea jusminiflore has a disk like that of Ruta and a staminal tube, consisting of seven stamens, two of which are fertile, and fire with broad foliaceous filaments sumounted by birren anther.:*

Ravenia Rosea and Coleonema album have regular disks, or what I would call incipient " peels."

Medicosma Cunninghami has a staminal tube, from which the orange peel might easily have been boln, while within it there is a disk, which is made up of separate bilobed segments, and undoultedly represents a whorl of sterile and atrophied stamens.

'Then Peltostigma ptelcoides, below its ovary, lus a disk, or staminal cushion, from which an indefinite number of stamens emerge, like that of the Prony. 'This cushion being in more than one whorl would indicate that the disk proper in other genera is only a part of the staminal cushion.

We come now to the Citrus, which has a tenclency, by the fusion of its stamen-filaments in to groups, to form a staminal tube, within this is the disk proper, which we must now look npon as a part of the staminal cushion, and abore the disk is the peel proper, entirely enclosing the carpels proper, and fusing with the carpel styles.

'The digitate Citruses undoubtedly slow us that the orange peel is made up of distinct segments, like the sterile stameus of Grilipea Macrophylla, thongh much langer.

In the "Gardeners' Chronicle" of 29 March 1890, p. 399, there is a notice of the "Cultivated Oranges and Lumons of India and C'ylon." It is stated that in the opinion of the elder De Candolle, "Organogénic Végétale," p. 41, the peel or rind is an enlargenent of the disk. Of coun'se it is. But what is the disk, hut a fusion of

* These barren anthers are noteworthy, because they are like the glands on the teeth of the young Cherry leaf (Fig. 86). 
stumen-nipples or buds? And, therefore, the enlargement of this can be nothing but the continuation of abortive stamens or carpels, which, when dissociated, produce the fingered lemon hlown in Fig. 159.

On p. 381, the "Gindeners' C'hronicle" says, "Dr. Bonaria holds' the opinion that the peel which corers the arpels consists in reality of a row of modified or abortive carpels, but this is a view which, as at present arlviserl, we cumnot shalle."

Yet curiously enough, on p. 397, Fig. 60, of the same Jommal, a drawing is given of a teratological specimen, which proves that my interpretation of the origin of the peel is the correct one.

For what more sutisfactory support to my interpretation can there be than this interesting specimen? Is it not clear that the peel is made my of a fusion of phrylons organs, which, in this (ase, are depauperized to simple scaly bracts?

I reproduce the drawing in outline, as it is the most intere-ting teratological specimen I have yet spen. Fig. 152 hardly need:

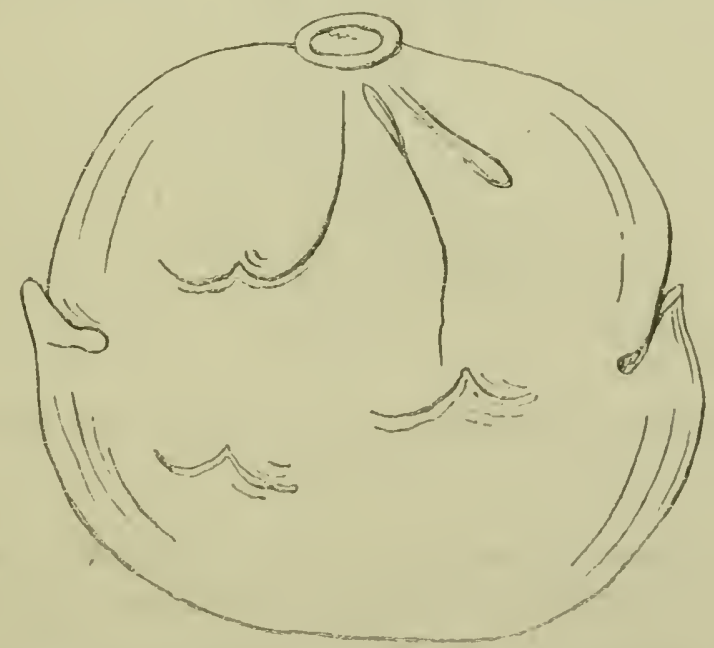

Fin. 152. Malformed orange, from "Garteners' Chronicle," 29 Mareh 1890, p. 6011.

any explanation. 'The orange peel it represents evidently was formed of more than one whorl of hacts. 'The pulp of this oranger,

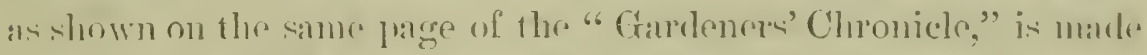

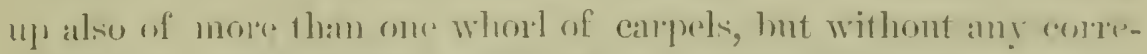
spondence with the peed catpels, howing that the two and totally distinct. In short, these is as little corresponrlence in this oranger 
between the pulp-carpels and the peel bracts as there is between the carpels and the petaloid stamens in the rery donble Pronies. The one set of whorls increase independently of the other set.

Now in the Pronia Moutan we have something rery similar, in my opinion, to the orange peel. With the exception of the stigmatic surfaces, all the carpels are euveloped in a purple sheatl, the margin of which is often surmounted by a set of teeth. On one occasion, as I said, I found an anther on one of these teeth. The genesis of this sheath became therefore clear. It is a fasciation of a whorl of stamen-filaments. Its beautiful purple colour, moreover, coincides exactly with the colour of the stamenfilaments proper.

Fig. 153 shows the sheath enclosing the carpels. It will be seen that the sheath occupies the exact position of

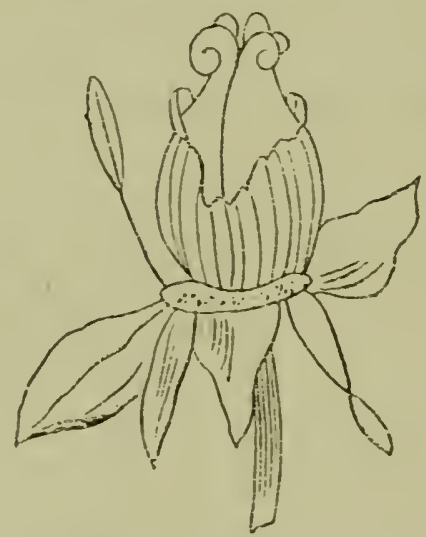

Fig, 153. Sheath of $P$. Montan, in part removerl (Le Manut and Dec, Fig. 443).

the disk in Ruta graveolens, and is probably homologons with it, and therefore the disk of the Ruta is probably the remnant of a suppressed whorl of stamens, or other phyllous appendages. One leaflet, in aborting, often becomes a stipel, a number of teeth in ahorting often hecome a substantial gland, or fusion of teeth-glauds, as in the cherry leaf, and the contignity of a number of similar ghands disposed in a whorl might easily canse them to fuse into a disk. Such a disk might easily come about by the abortion of the sheath of the $P$. Montan. Indeed, in the $\dot{P}$. Albiflora, and other's, we have the disk, or rudiments of the disk, and not the sheath. In the Parmia officinalis, the lisk is 
only rudimentary, as shown in Fig. 154, and is not unlike the undeveloperl disk, or "would-be" sheath, of the Rutu grareolens (Fig. 139).

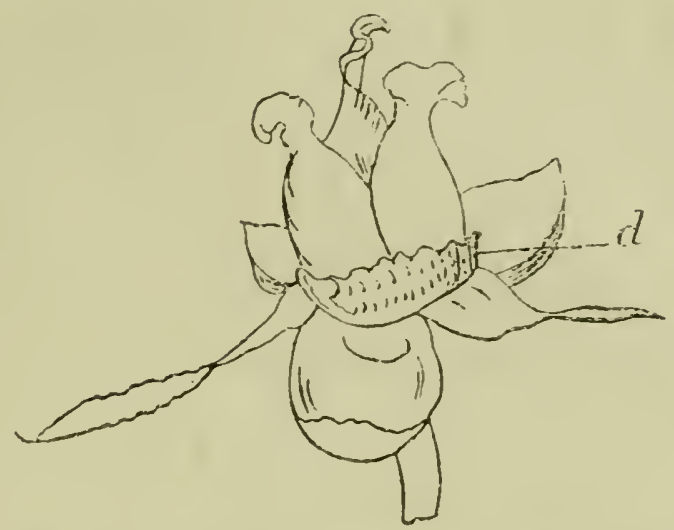

Fig. 154. Disk (d) of Pronia officinalis (re Maout and Decaisne).

It is from this disk that a large number of petals in the donble varieties are born. In the most double then the carpels also turn into petals.

It might be said that the disk of the Citrus is distinct from the peel. True. But this is only in the mature flower. In the young flower, as the reader will see by referring to Fig. 149, the disk is really what afterwards becomes the peel $(d)$, while $(c)$, which is only the base of the peel, afterwards swells out into the disk proper (Fig. 150, c). Therefore, the disk of the Citrus, and of the Ruta, the peel of the orange, and the sheath of the $P$. Moutun appear to be one and the same thing, that is, all homologous. In other words, they are all expansions of the bark, just as leaves are. It may not be difficult now to see why in teratological specimens of the Citrus the peel divides into fingers, as the bark might do into leaves.

If the reader will refer to the sheath of the $P$. Montan (Fig. 153), he will see that it does not differ from the sheath of the accompanying Tangerine orange. The one partially enclosed the carpels proper, while the other entirely does so ; the style, with its stigma, in the orange ordinarily becoming deciduous, after fertilization, at the point (a) in Fig. 156.

I have had the opportunity of examining a large number of flowers of Proonia. Woutan, both of the single and donble varieties. 


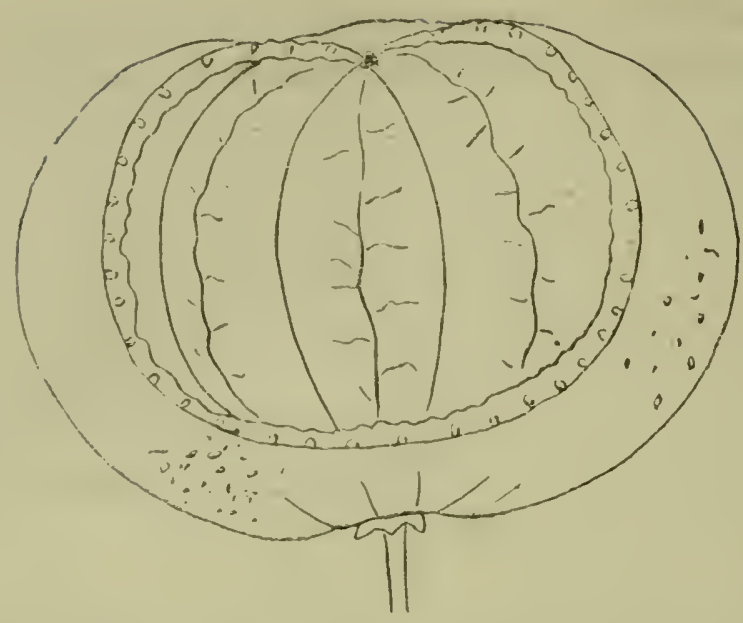

Fig. 155. Sheath of Tangerine Orange partially removed.

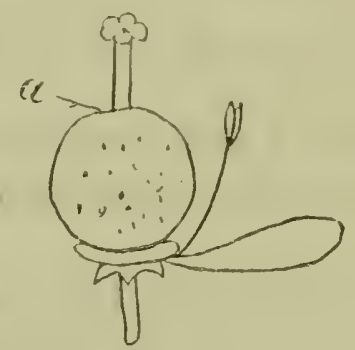

Fig. 156. Orary of Orange after fertilization, the style and stigma dropping off at $(a)$.

For this opportunity I am indebted to my frjends Messrs. Ielway and Sion of Langport.

'The following is a résumé of my obscrrations.

In the single $P$. Moutan the sheatl completely envelops the carpels, with the exception of the stygmatic surfaces. In some cases it encroaches also on the stygmatic surfaces. It is purple both on its onter and inner surfinces. 'This corresponds with the colonr of the stamen-filaments.

In a semi-double: Japanese variety, named "Mrs. IVilliam Tielway," the petals are pulre white, and the sleath is also white, while the stamen-filaments are also white.

In the single varieties the surface of the sheath is ristinctly furrower longitudinally, as if it were male up of an agghtutination of tilaments, the tips remaining fress romml the stigmas of the carpels. 
In semi-double varieties, the sheath clivides into a fringe, made up of long and short segments, as shown in Fig. 157.

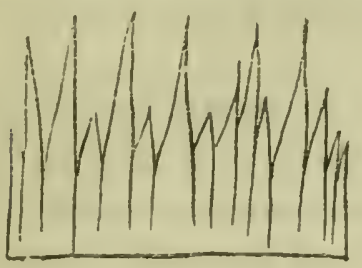

Fig. 157. Sheath of a semi-rlonble P. Momitu, spreas ont.

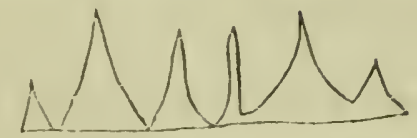

Fig. 158. Remmants of the sheath of a double P. Montan, spread out.

In still more donble varieties the sheath is further dwarfect into a whorl of teeth of a deep purple colom surrounding the earpels, as shown in Fig. 158.

In other cases only a segment of the sheath is seen here and thase, as a hig purple tooth.

Then in the most double specimens no trace of the purple segments conld be found. In their place surromoling the carpels was a ling of small pale petals, within these in one specimen I found seven short stamens, two of which were petaloid. The shath was either not developed or it was ronverted into petals and stamens.

In one case among the normal stamens I found several short filaments withont anthers. These were indistingnishable from the points which make up the fringe of the sheath margin.

In rery dontle specimens the order of disposition is the following :-

Rows of broal and romnderl petals;

Row's of stamens:

Rows of narrow fringed petals;

Rows of stamens again ;

Dwalfed sheaf, split up into small segments;

And in the centre the carpels.

On the whole the carpel sheath of the P. Moutan is very persistent, and is not realily got rid of by donhling, althongh it is much dwarfed in the very double ones, and in many cases reduced to simple purple teetli, scattered round the base of the carpel tuft of prtals (petalovid (arpels).

From a great number of observations I made, I came to the conclusion that the sheath of the P. Moutan is a fasciation of 4 p. 1724 . 
barren stamens, similar to the barren stamens of Trolius Europceus, only in this they are not fasciated and are exterior to the stamens, while in the $P$. Moutan they are fasciated and interior to the fertile stamens.

The single Pronia Peregrina has no sheath, but in its stead, surrounding the base of the carpels, there is a ring of bilober nipples, sometimes of a purplish colour, sometimes white. These evidently occupy the position of the sheath in the $\boldsymbol{P}$. Moutun, and may be considered as either the rudiments or an abortion of the sheath.

I consiler the panony sheath to be the homologne of the staminal tube of the Malvacere, with this difference, that, in the parony, the anthers have aborted and the tube is much shorter.

Now, is there any further evidence to prove that the Citrus disk is a whorl of suppressed stamens, and the orange peel of a similar nature? I think there is.

Risso and Poitean, in their "Hist. Nat. des Orangers," Tab. I., give some teratological specimens which just answer this question. 'Two of them are given in Fig. 158. The anthors say:
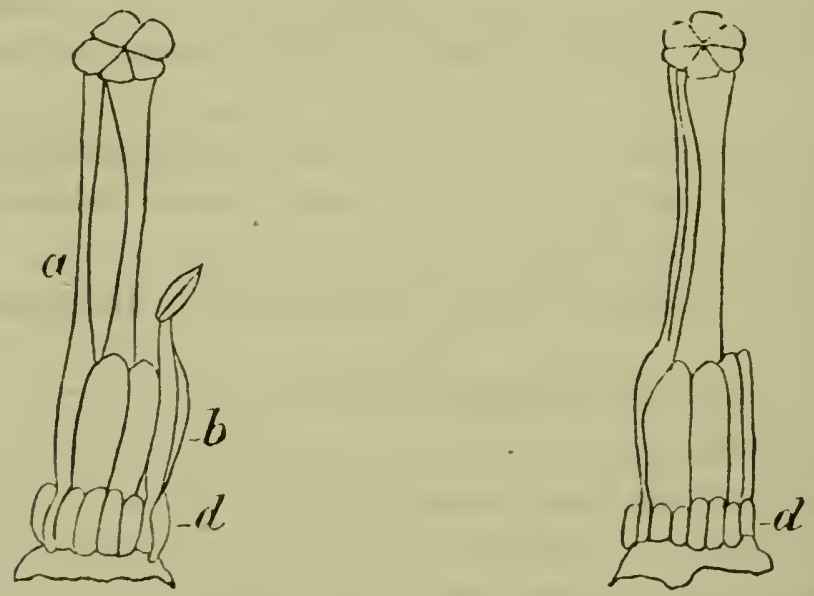

Fig. 158. Two ovaries with adherent stamens (Risso and Poiteau, Figs. 16 and 18, T'ab. I.)

"La Fig. 16 représente d'un côté un filet d'étamine $(a)$ adhérent ¿̀ l'ovaire, et un stigmate, ct de l'autre côté, une étamine $(b)$ très courte, dont le filet fort épaissi adhère longitudinalment à l'ovaire. La partie de l'étamine soudée à l'ovaire perd peu-à-peu sa coulenr blanche, pour prendre celle de l'ovaire, à mésure qu'elle s'identifie arec cet organe, et se nourrit de ses sucs," 
Then, at p. 31, they say" "Nous venons de voir des étamines placées dans le plan du nectaire; ${ }^{*}$ la Fig. 19 nous en montre placées dans l'interieur mème de ce plan."

This means that the stamens of the Citrus may be inserted outside the disk, on it, or inside it. Normally, however, they are ontside it. Nevertheless, this abnormal condition leaves the imprersion that the disk of the Citrus is only a suppressed whorl of strmens. Incleed, in cases where a stamen adheres to the peerl, ats is shown in Fig. $158(b)$, such a stamen replaces one of the lobes of the disk. Risso and Poiteau say : "Quand une étumine adhère à l'ovaire, son point d'insertion est dans le plan même du nectaire, ct elle $y$ cause une interruption." I do not think that this leaves us in much doubt about the allhering stamens being part and parcel of the disk, and that the latter is normally only a silpuressed whorl of stanens.

But what about the orange peel to which the stamens sometimes adhere?

What I have already quoted from Risso and Poitenu shows that the filament of the adhering stamen by degrees loses its white colour, and takes on that of the orange peel, and becomes identified with its structure, which means that the filament and the peel are one thing. Indred, in the London shops and on the street harrows, anong the heaps of oranges, one may frequently pick out a specimen which has a longitudinal rrised strip on the peel, running from base to apex, and indistinguishable from the peel. Presumably, the genesis of this raised strip is the filcment of a stamen emerging from the disk and adhering to the ovary, and eventually becoming identified with the peel.

Risso and Poitean show all the disks on Tab. I., divided into segments. The segments, which mark the peel of many varieties of Citrus, appear to be no other than a repetition of the lobes of the disk (as shown in Fig. $158(d)$ ), which, in turn, are transformable into stamens, therefore they and the peel proper may he reasonably considered as homologous with the sheath of the Proonia Moutan, which I an satisfied is the fasciation of the filaments of aborted stamens.

The accompanying Fig. 159 shows a lemon devoid of pulp, with all its peel segments dissociated. The reader may call them 
either modified stamens or modified carpels or sub-livisions of the bark, such as we see in the leares of Cotyledon and other r'rasulacere, and in those of Mesembryunthemnem.

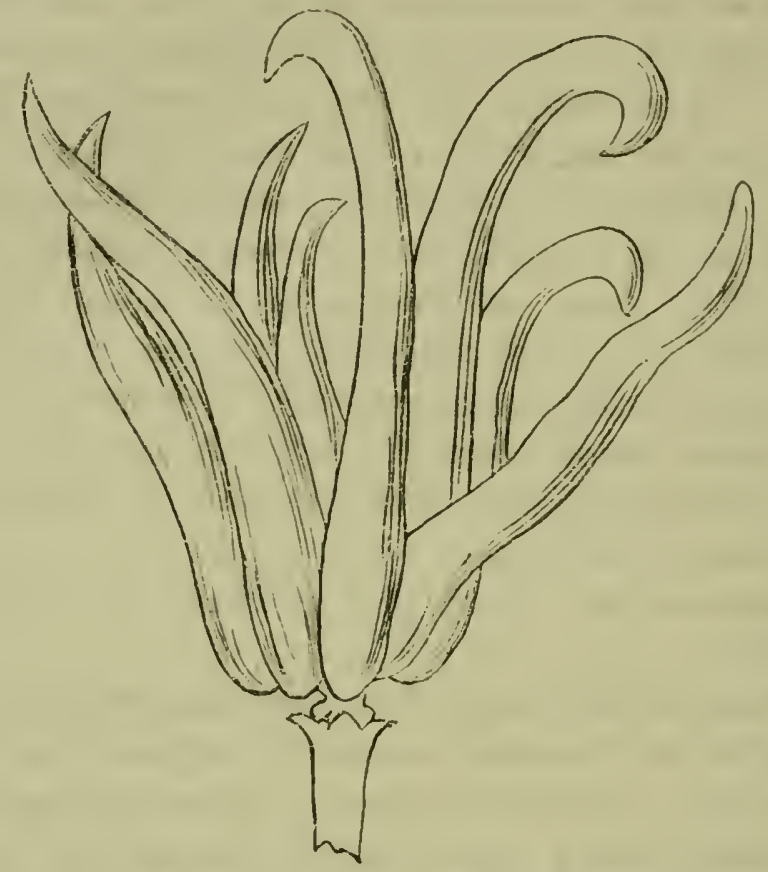

Fig. 159. Fingered Lemon (Penzig, "Studj sugli $\Lambda$ grumi," Fig. 6, pl. 9).

One would hardly credit the fleshy leaves of the latter and of Crassula with capability of conversion into stamens; nevertheless, if they are leaves there ean be no question that these lumpy organs are liomolngous with stamens. Not only these are so, but also the leares of such plants as Aloes and Agave! What possible difficulty then can there be in considering the segments of Penrig's Fingered Lemon, Fig. 159, as reverted stamens or (arperis.

Wre thus see that the segments of the peel ram be reither entirely dissociated, as we see them in this fingered lemon, or they "an become so comnate as to fuse into an envelope completely cuclosing the ovary and losing all trace of having heen made up of separate segments, as we see them in the smooth and uniform perel in the oranges of the Tondon stopls.

As to the nil-glands of the preet and the juice resicles of the pulp, there can lee no mistaking Penziges description of their internal structure. Though they may differ in form they are 
identical in general structure. 'They both consist of an outer' layer of cells with inner layers which, loy rlegrees, break up and are replaced by grlolules of essential oil which occupies the centre of the gland or juice vesicle, as seen in Fig. 127 ( $\iota$ ).

This is what Penzig says, 1. 53: "The oil-glands commence by gromps of cells which increase in number. As the gland enlarges, the central cells become completely broken up, and the central space becomes filled with essential oil ; so that the fully formed gland has a central cavity filled with oil, an inner wall formed of the broken-11) cells, and an onter cell wall enveloping the whole."

At 1. 92 he says: 'The juice resicles (energenz) connuence as nipples covered with epielermic cells containing groups of other cells. The fully formed ones consist of epidermis which cunclose: large cells, the outer ones of which contain small drops of wil suspended in their juice. At maturity, howerer (p. 94), in those varieties with abundant juice, the central cells get broken up and the juice fills the central cavity of the pulp resicles.

This might appear not quite like the structure of the oil-glands. But in describing the juice vesicles of the Egle sepiaria D.C. (Citrus trifoliata, Lin.), p. 145, Penzig does not leave us in doubt that their structure corresponds almost perfectly with those of Citrus; their essential oil at maturity gathers in large drops in the middle of the juice resicles, destroying their central cells, as in the oil-rrlands. In addition to oil they contain sugar, citric acid, se.

So that, barring form and addition of acid-sweet juict, the structure of the oil-glands of the leaves and peel of the C'itrus is essentially identical witly that of the juice resicles or hairs of the pulp.

Therefore, what I said in "Cultiv. Or. and Lem. of India," Ec., vi\%, that in the Citrus pulp the oil-glands of the peel are replaced by the juice vesicles or juice-hairs, as some botanists call them, is supported by Peuzig's analysis of their structure.

Then both the oil-glands of the peel and the juice resicles of the pulp have the same structure as the grandular hairs or dermal warts of Dictamuns fraxinella, shown in Fig. 160.

In another part I have endearnured to show that the hairs on the bark and leaves, and especially glaudular hairs, conld only have hat their genesis in reproductice hairs, such as we see in the 
stem hairs of Cymopolia barbata, Fig. 124. I have also endearoured to whow that the oil-glands of the peel are the modified homologues of the conceptacles of Fucus, and others. These conceptacles are filled with reproductive hairs, some of which may be atrophied, others filled with spermatozoids.

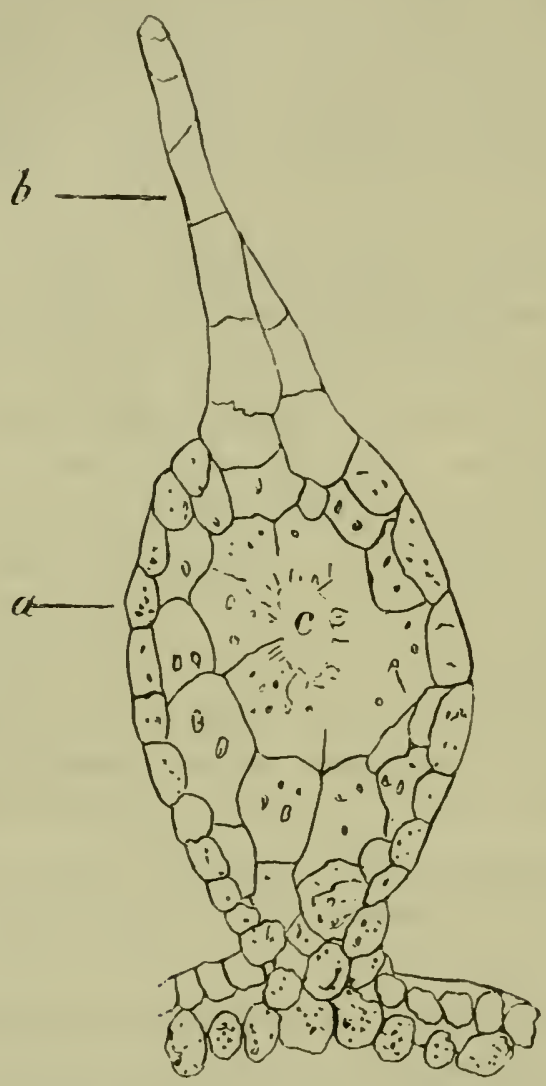

Fig. 160. Oil containiug dernal wart of inflorescence of 7 . fiaxinella ítach's "Phys. of Plts.," Fig. 184, after Rauter): (a).epidermal cells produced into a point, $(b) ;(c)$ breaking up of inuer cells containing oil.

According to my riew, then, we would liave reproductive hairs, glandular hairs, oil-glands of orange-peel, and juice vesicles of its pulp, all very probalbly homologous organs. 'To carry the homology a little further, not impossibly, the juice resicles (or juice hairs) of the pulp-carpels may be the remnants of male, reproductice hairs (antheridia) turned to other purposes, while the ovules on the margins of the carpels may be comparable to molified spores, which are fertilized in a roundabont way by the 
anther pollen instead of being fertilizer rivectly, as in the fucus, by the spermatozoids contained in the male hairs.

In fine, I may here say that I have endeavoured to leave no opening for the reader, if he has had the patience to read through this discussion, to say that I have not taken sufficient pains to identify and homologize this "blessed" orange peed ! 
"Carlyle was one of the first men in England to recognize the importance of German literature...... His translation of 'Wilhelm Meister' was published in 1824, and his noble essay on Goethe in 1532.... The editor, for whom he wrote it, reported that all the opinions he could gather about this essay were 'eminently unfavourable.' De Quincey, who of all English crities was believed to know Germany best, and Jeffrey, who exereised the greatest influence on English literary opinion, combined to depreciate or ridicule Goethe. But there is now no educated man who disputes that Carlyle in this matter was essentially right, and that his critics were wholly wrong."-"Carlyle's Message to his Age," by W. E. H. Lecky, Contemp. Rev., Oct. 1891.- Such is the value of authority. 


\section{XIX.-GENERAL CONCLUSIONS.}

ALL human reasoning is a prucess of putting two and two together. Logic and mathematics are nothing more. Accurate observation and acenrate experiment with the help of logic and mathematics have brought hmunan knowledge to what it is now.

From all that has heen sail in the foregoing notes on plants it follows:-

First.-'That there is no such thing as an essential difference letween the stem, the branch, and the leaf. 'They are all sulbdivisions of the same srstem. The different names used are more or less eonvenient ways of expressing which snb-division is meant. In seaweeds the stem and midrib are one thing. Prof. F. O. Bower has recogniserl this in ferns, but this recognition nust be extended to the highent plants of whaterev kind or form, withont exception.

Second.- That the axillary bud, universal in phanogams, is erpual to a branchlet of the leaf-petiole, which has become connate with the principal miclrib of the. plaut, that is, with its stem, or sub-division of it-the branch.

Third.-'That the nersen and reins of leaves are only smaller and smaller sub-divisions of the stem.

Fourth.-That the teeth of leaves alle the nltimate and atrophied sub-divisions of the leaf, and correspond exictly to the teeth of seaweeds, and have been derived from them. In seaweeds the teeth represent branches, and, therefore, in the leaves of phrnogams, although they may be atrophied, they necessarily 
represent the same thing, that is, branches of leases. When atrophy has been carried further, so as to produce extinction of the teeth, we have what is called an entire leaf, that is a leaf without teeth.

It necessarily follows that the angles between the teeth, where these do exist, represent axilla of leaves, each having a suppressed axillary but. In Bryophyllum and some ferns, however, the teeth axillae redevelop their buds. It is significant that in many leares a vein goes, not only to the tooth, but to its axilla, indicating therely that both the tooth and its axilla were originally important organs, but now atrophierl.

Fifth.-That the petiole was originally the midrib of the whole leaf, with a blade on each side of it ; that a portion of the midrih got rid of the blades or wings, and becane a naked petiole. Most naked petioles have still the remnants of the two wings in a pair of ridges, on the upper side of the petiole.

Sixth.- That stipules may be regarded either as-

(a.) Bud-scales of the leaf, and, therefore, of its sub-division, the axillary bud; or

(b.) As portions of the petiole wings left attached to the stem when the petiole became naked.

In Nigella damascena it is impossible to say whether these appendages are stipules or sub-divisions of the leaf.

Seventh. - That the cladophyl camnot he reganded as a feature of certain plants only, but as a miversal feature, from seaweeds, which are nothing but cladophyls, "ㄱ to the highest plants, however modified their stem and leat may be. The higher plants have been derived from seaweerls, and what we eall stem and leaves in those are only midrib and wings in these, that is cladophyls, or stemleaves. From this it follows that the midrils of a pimnate leaf is only a contracted cladophyl, and its pinna homologous with the lobes of Lenormandia maryinata.*

It follows also that stipels and stipe.llar glands cormpond to tecth or atrophied pinna. Phylloractus graudis gives us a goorl 
illustration of a clatophyl. It has a central midril, and alteruate side nerven (really what are callod branches), ending in the indentations or axilla of the margins, ont of which branches arise just as they do in the Bryophyllum leaf.

Eighth.-That there is no essential difference between the stem and the root. The one may be regarded as a continuation of the other, or both as two branches emerging from the same point. It is impossille to regard them as different when both the one and the other give off buds and roots. Both are suckels of material from the ontside, and each helps the other in its growth. It follows that the sub-divisions of the uain root correspond to the sub-divisions of the main stem, which are the leaves and branches. 'The media in which they grow, and heredity, determine the character which these two forms will take on. 'The leares of Nigella damascena are only distinguishable from roots by their being green.

Ninth. - That the tendrils of Vitis, Cucurbita, and others oceupy the position of aërial roots rather than other organs, that is, they are roots of attachment rather than roots of alysorption. This is well exemplified in thc aërial roots of orchids, and more expecially in those of the Vanilla planifolia, the aërial roots of which act as tendrils to the slender stem. Some tendrils might perhays be consillered as branches, such as those of Passiflora, which are often axillary, but the tendril at a node almits of diplacement, and it is often inpossible to say whether it is atipule, a leaf, a branch, or a root. As, lowever, in thesc Notes I have regarded roots, leaves, and branches as homologons, it makes little difference whether a tendril be regarded as the one or the other. What I think we should fix in on mind is that in seaweeds there are roots of attachment only, and roots of attachment and alsorplytion; and this same organ with a differentiated function appears to have been inherited hy phænogans, which produce in similar situations roots with the function of tendrils.

Tenth.- That tho stamen is a louf or clarlophy, the tilament corresponding to a petiole. and the anther to a blade. The pollen :bppears to alluit of varions interpretations:-

(a.) It may lo considred as the male element derived from the blarle of a sameerl, such as that of Cutleria 
multifida and Porphyra laciniata, with the female element surpressed, and segregated in the carpel;

(b.) It way be regarded as a form of globular reproductive hairs similar to the ordinary and barren leat hairs of Chenopodium petiolare;

(c.) It may be regarded as a moditication of sporangia, of which there are so many variations, both in seaweeds and ferms, ${ }^{*}$ and that the anther itself is a modified sortls.

What is significant is this, one of the lowest Algae, Sarcina, the vegetative cells of the frond of Cutleria, the various modifications of tetraspores in seaweeds, and the mother-cells of the anthers of phanogams, all have al quaternary division, as if they were all one and the same thing, derivable from the lowest organisms, passing into the fronds of seawcerts, and by specialization blooming as the pollen of the highest plants. The male and female elements, which in Cutleria occupy the same regetatire cell, appear by degrees to have separated into distinct organs, so as eventually to have become monœcious and diøcious orgaus. It is readily conceivable that by contraction and suppression of its female element, the frond of Cutleria or Porphyra would be equal to evolving the anther of phanogams. $\dagger$

Eleventh. - That the carpel is the homologue of the anther. Its ovules or female cells are the same female elements of Porphyra and other seaweeds, separated into a specialized frond. 'They are borne either' on the margin, on the miclrib, or on the whole surface of the carpel. The carpel, as we have seen, is nothing but a modifierl cladophyl, like that of any seaweer, such as Gigartina, Lenormandia, or any other. When the orules are marginal they correspond to the lohes or pinne of Fucus marginifer and Lenomandia, when they are on the midrib they correspond to the leaflets of Delesseria, and when they are on the gencral surface they correspond to the scattered reproductive cells

* The sporangium contains male and female elements, for the spore develops, in the prothallium, male and female organs. If in the sporangium the fumale element is suppressed, what is left will correspond to pollen.

$t$ There is, I think, another view of the grenesis of the anther, which will require time to work out. 
of the frond of Porphyra. There is no escaping the conclusion that ovules are burs, for they reproduce a branch in rlue course, and in cases of parthenogenetic ornles, a branch identical with that derived from axillary buds. The axillary bud being a branchlet of the leaf becomes, ipso facto, a tooth, and as surbh, is one and the same thing with the ormle, which is a tooth of thr arpel. There is no escaping the conclusion that ovules correspond to the glands on the tips of the teeth of leaves, for if we once recognise the identity of carpel and leaf, the marginal ovule and the tooth-gland fall into identical positions, and can be no other than homologons parts. It will thus be seen that the gland on the leaf-tooth falls also into its proper place as the terminal bud of an atrophied branch. These leaf-teeth, originally cladophlyyl lobes, are sulvject to total suppression. In the Agares they arr very prominent as horny or woody teeth, and the terminal hud of the leaf is a formidable spine, but in $A$. pruinosa, ${ }^{*}$ the serrations are minute, and in $A$. attemata and Ellemeetiana, the fleshy leares are destitute of teeth, and the terminal spine, which would rorrespond to a terminal lond, is changed into a seta.

Truelfth.-That the contraction of a leaf-blade may canse the fusion of all the teeth-glands, and so give origin to the amalgamated glands on the petioles of the cherry, the plum, the peach, the patsion flower, the Erythrina, and other's. These amalgamated teeth-glands of course would lie the homolognes of amalgamaterl ovules, and as such wonld be the homolognes of anthers and of sporangia.

Thirteenth.-That, if the seerl is a burl, it must follow that the cotylerlons are only bud-senles, or stipules, used for purposes of storing nutriment, this bud being destined to lead an indepentndent life. They correspond in function to the albumen of the egge, and to the function of leares. The albumen proper belongs to erery seerl, which is alsorbed either during the ripening of the serel or during germination. The axillary bud naturally does not require this storage, becanse it derives its mutriment from 
the parental stem.* If the seed-bud or plumule is a brauch and homologous with any other branch, it will necessarily follow that it is also homologous with the stem of a grass, a serlge, a horsetail, an orchil, \&e. Then very probably the primine and secundine of the seer will find their homologues in the leat-sheath of the horsetail, or the vagina of the serlge and orchirl laaf, the blade of the latter being suppressed. Imagine the seed to remain attached to its parent and growing into a branch, and you have the two integimments falling into their proper places as two of the leaf-sheaths of the horstail, with the internode suppressed.

Fourteenth.-The hairs of plants are the most interesting part, from an evolutionary point of view. I look upon them as atrophied reproductive organs of various forms. They have been given varions names by botanists, and have been considered as unimportant epidermic emergences. Nevertheless, there is no part of the plant which cannot be and is not sometimes reduced to the level of an epidermic hair, without any vascular tissue. The root, the stem, the leaf, the pinne, the stipules, the axillary bud, the sepal, the petal, the stamen, the carpel, the ovule, all can be atrophied into hairs. The terminations of the branches of Rhus cotinus, or its racemes, are nothing but a conversion of peduncles into hairy endings, with the flowers suppressed. Now and again, at the apex of a hairy peduncle, there is a floret. The atrophied branches of this Rhus correspond to hairy rootlets. The glandular branched coverings of the stem and sepals of the moss-rose, and the teeth of its leaves, are only branched hairs, dereloping foliaceous stems. There can be little doubt that they correspond morphologically to the variously shaped branches which are to he found on the external surface of seaweeds. In the higher plants these hairs are remnants of important reproductive organs, derived directly from the lower plants, and therefore must be homologous with them. In the animal kinglom their analogues would be the splint bones of the horse, which are remnants of once useful digits.

Fiftenth.-The fig is obvionsly a further drvelopment of a conceptacle of a Fucus or other seaweed. And there is every

* When the stem decays, or when the buds drop off, they also become temporary stores of nutriment. 
prason to believe that the oil-glands of the bank, leaves, and peel of the Citius, and similar glauds in other plants, are mere remmants of seaweed conceptacles, that is persistent features nurned to other uses.

Sixteenth.-It does not serm ditfienlt, firally, to build up the Hrower and the flower head from the simplest forms of male and female organs. I can only here give an outline of the process of erolution of thr higher forms from the lower elements. In the C'haracea we haw the male and female elements close to rach other-the rudiments of stamen and ovule. In fertain ferns and in Lrcoporls the sporangium is axillary. It is not rlfficult to conceive that fusion of two or more sporangia of this kind would evolve a monacious heal of male florets, with all the bracts arrangerl round them, as rudiments of involucres, or sepals and petals. It is further not difficult to conceive that reproductive male and female organs in close contignity, such as those of the Characer, called "glolule and nucule," might form the foundation of the stamen and achene in a hermaphrodite flower, say, of a Vreleriana for instance, with the hairs round the "globule and nucule" dereloped into sepals and petals, and so by fusion after firsion develop the eapitulum of a composite plant. It is not difficult to imagine that a one-achened and a one-stumened flower, wy fusion with a similar one, might produce a two, three, four, five-stamened and five-achened flower; and that two fire-stamened flowers might again create one of ten, and so on. If, in addition, in iusgination, you hring into play other factors of modificationatrophy, transposition, and suppression-which undoubterlly have played a great part in modifying the external features of plants, there is no regetable form known to us, even, perhaps, the nondescript Melwoitschia, which may not be conceived to have evolved out of some other pre-existing and allied form. This, however, is too extensive a subject to form part of a general conclusion of the foregoing Notes, and its elahoration must be left for some future periorl.

Summary of General Conclusion.-The reader might well ask-Then is there any part of a plant which is not homologous

* I do not mean of courșe the Valeriana of our dass, but an ancestral Faleriana, 
with erery other part? A litthe reflection will answer this question with al decilerl no, there is not: How ran there be, when all complex and many-celled plante lave evolved from one-celled ancestor's-the monophyfra? How can there he, when land plants, which we have divided into stem, leaves, teeth, sepals, petals, stamen-, carpels, roots, \&e., hare descenderl from stawerest-, having their stem, leaf, stamen, and carpel all in one organ, the frond? Development only means at further and further separation of important organs on distinet and spectialized parts, although originally all :mmalgamaterl in one frond; and then each part again moilified in myrials of ways, accorling to spontaneons atomice rariation, held in clece by heredity, and acrording to surromnlings. Underlying the whole of the inyriuls of rariol forms of the regetable kingilon there is a unity which can be tracerl to the unicellular bodies of which all living borlies are composed.

By utilizing the libraries, herbarims, and gardens of all sorts, and by ntilizing the explorations of passed hotanists and modern microsenpists, and the labours of classifiers and systemitists, and, not least, by utilizing the result of experiments of horticulturists, there would appear now to be room for a "Philosophy of Plants," on a hasis somewhat different from that given in text-books. The new philosophy must be built up by the method of Erolution. If the writer of such a plilosoply give little consideration to seatweerls-the ancestors of all land plants-lie will miss the genewis of many parts of the phanogams of our time, and he will not he making the future stuly of Botany as easy and as fascinating as it might be matle. $\mathrm{Br}$ that omission, the writer of snch a plitosophy would make it al difficult, if not a repulsire sturly, and a study largely made up of woords!

"Without hrpothesis man iliscover's nothing," and without theories and philowenthes he comprehende nothing! 
.

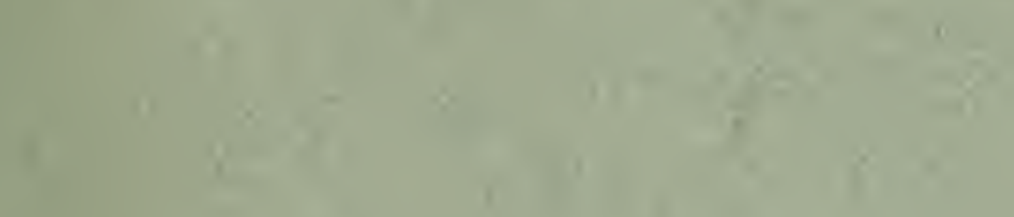

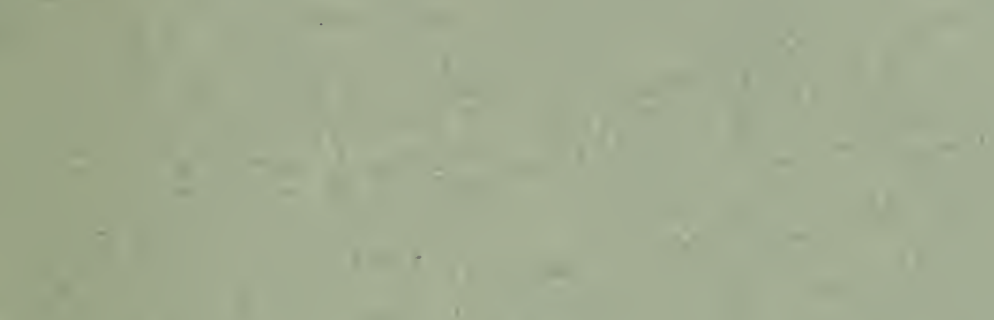

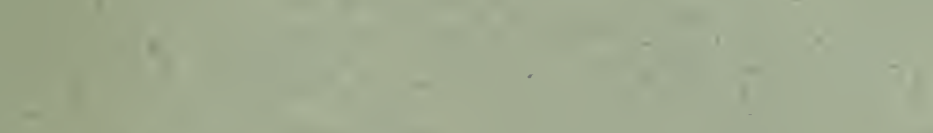

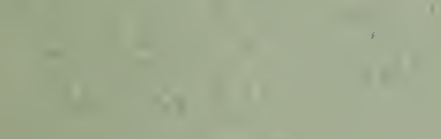

$y=-1$

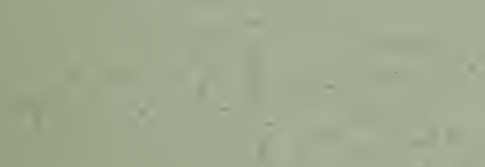

13

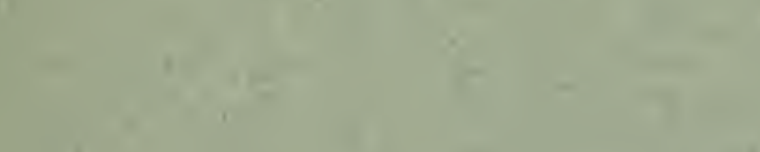

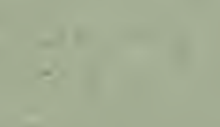

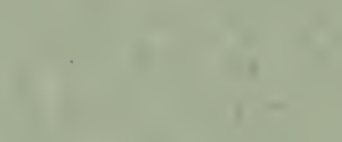

1)

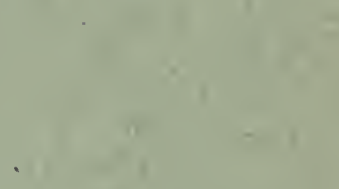

.

$\sqrt{1}$

$x+2=$

that 







\section{QK46.8569 \\ gen \\ Bonavia, Emanuel/Philosophical notes on}

||||||||||||||||||||||||||||||||||||||||||||||||||||| 


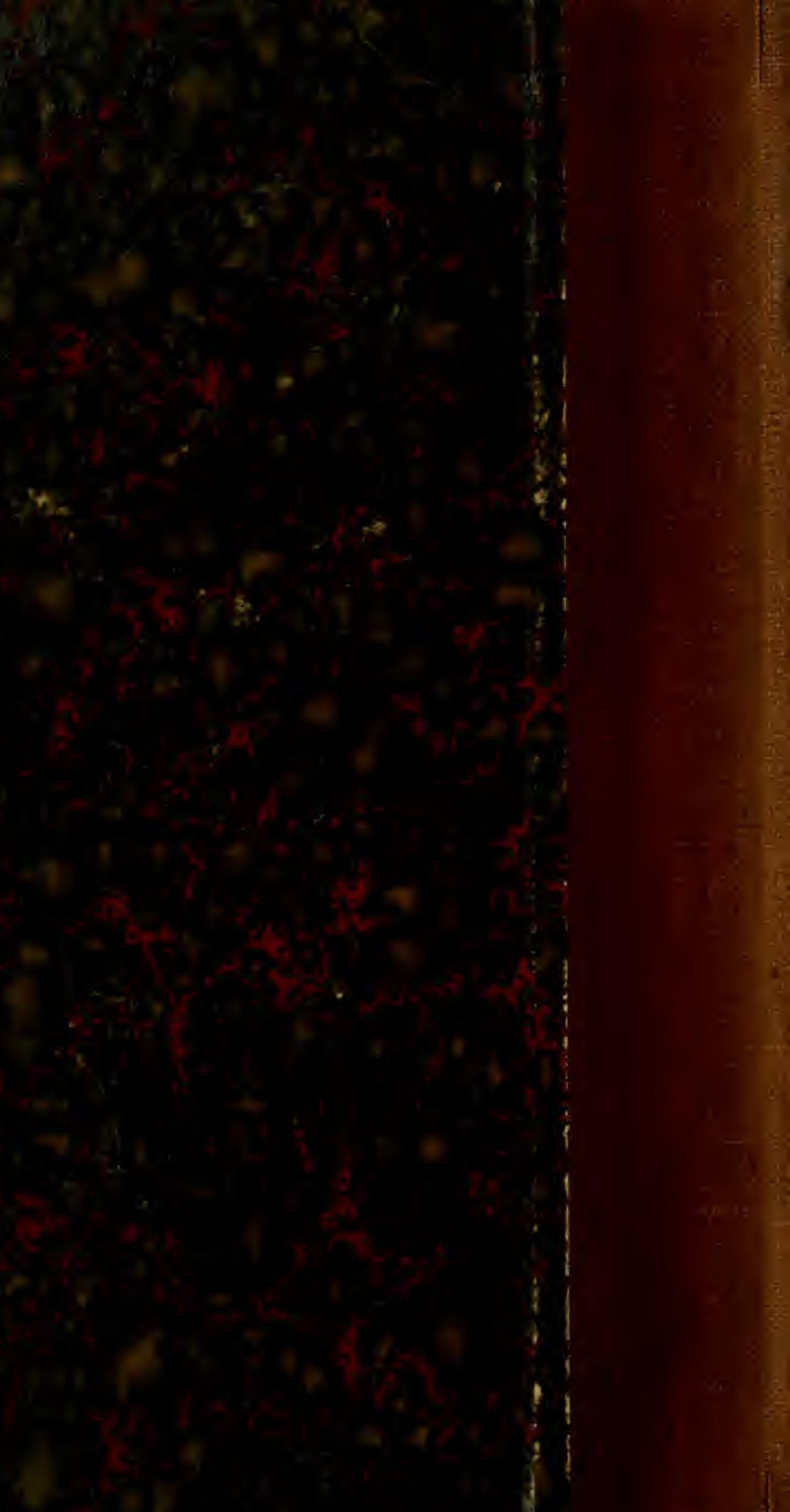

